Universidad deValladolid

\author{
PROGRAMA DE DOCTORADO EN \\ INVESTIGACIÓN TRANSDISCIPLINAR EN \\ EDUCACIÓN
}

\title{
TESIS DOCTORAL: \\ LA EDUCACIÓN PATRIMONIAL \\ INMATERIAL: ANÁLISIS DEL CURRÍCULO \\ Y EVALUACIÓN DE PROGRAMAS
}

\author{
Presentada por \\ Marta Martínez Rodríguez \\ Para optar al grado de
}

Doctora Internacional por la Universidad de Valladolid

Dirigida por:

Dra. Olaia Fontal Merillas

Dr. Alex Ibáñez Etxeberria

Dr. Cosme J. Gómez Carrasco

Valladolid, junio de 2019 



\section{Agradecimientos}

Aún recuerdo el inicio de esta aventura, cuando tenía que decidir entre la docencia en el colegio o adentrarme en el mundo de la universidad y la investigación. Como maestra de formación, y por vocación, fue una decisión difícil de tomar, pero que siempre he sentido acertada. En esta etapa han sido muchas las personas que me han acompañado y, que de algún modo u otro, han hecho posible la elaboración de esta tesis doctoral. Por ello, quiero agradecer en primer lugar:

A mi directora, la Dra. Fontal por confiar en mí, por ser guía pero sobre todo por enseñarme a volar. Gracias por contagiarme el entusiasmo por la investigación y por hacerme creer que se puede llegar a cualquier lugar con el esfuerzo del trabajo. Gracias por tu generosidad, por tu empatía y por todas las enseñanzas que acrisolaré siempre en mí.

A mis directores, el Dr. Ibáñez por confiar y valorar mi trabajo, por tu preocupación en mi desarrollo como investigadora, por tus correciones, por ser la mirada amiga en todos los congresos y tener siempre palabras de cariño; y el Dr. Gómez por querer formar parte de este trabajo, por tus aportaciones, por ser un ejemplo de investigador con el que espero seguir compartiendo. A Pilar Rivero y Miriam Escudero, por la oportunidad de realizar una estancia de investigación bajo su tutela, y a todos los profesores que han dejado una huella en mí.

A mis compañeras de risas, fatigas y sobre todo cafés durante estos cuatro años. Sofía, Silvia e Inma, gracias por haber hecho que este camino sea mucho más fácil, por formar un equipo, por compartir, por ayudar y celebrar cada logro. También gracias a Jesús, Carmen, Pablo, Azucena, Barbero, Jon, Luis Carlos por cada gesto de cariño.

A mis amigos, los de siempre y los nuevos fichajes. A Eva, Ana, Paula, Carolina, David, Lali... y en especial a Mónica y Ninostka por su amistad en las duras y en las maduras. Gracias también a los que ya no están y han estado porque me han hecho creer.

A mi familia, a mis abuelos que me han enseñado el valor de la humildad y siempre se han enorgullecido de mí. A mi madre por su amor incondicional. Y en especial a mi padre, que fue el primero en creer en el vuelo del condor, aun cuando éste no sabía que tenía alas. Gracias por ser y estar en esto, y en todo, por confiar, por ser mi apoyo.

A todos ellos, gracias. 



\section{Resumen}

El patrimonio cultural, y en especial el inmaterial, cobra especial relevancia como nexo de unión entre el pasado y el presente, y generador de sentidos de identidad y pertenencia social y cultural. Estas potencialidades del patrimonio se desarrollan gracias a la educación patrimonial, que permite generar vínculos de pertenencia e identidad entre las personas y los bienes patrimoniales. Por ello, dentro del sistema educativo, el diseño y los contenidos curriculares relacionados con el patrimonio cultural inmaterial (PCI) constituyen un factor clave para la conservación sostenible del mismo, ya que solo lo que se conoce y valora, puede protegerse y preservarse. Al mismo tiempo, es necesario conocer y evaluar el gran número de programas educativos sobre PCI originados en los últimos años, con la intención de generar estándares de calidad para futuros diseños educativos.

El marco teórico se conforma por un análisis bibliométrico a través del software VOSviewer de las publicaciones indexadas en la Web of Science, la revisión de tesis doctorales, textos institucionales y proyectos en el ámbito nacional e internacional. De todo ello, inferimos que el PCI se presenta como una línea de investigación muy activa en los últimos años dentro de la disciplina de la educación patrimonial, tanto a nivel académico, como en el desarrollo de programas educativos, que necesitan ser evaluados a través de instrumentos de evaluación objetivos y calibrados.

El marco epistemológico se conforma por compendio de publicaciones, que equivalen a tres estudios cuyo objetivo común ha sido conocer el estado de la educación patrimonial en torno al PCI en el ámbito nacional; a través de la revisión del currículo, de los planes de estudios de los futuros maestros, y la evaluación de programas educativos mediante la aplicación del método secuencial para el análisis y evaluación de programas de educación patrimonial del Observatorio de Educación Patrimonial en España (SAEPEP-OEPE).

Cada uno de los estudios se centra en diferentes fases que contribuyen a alcanzar el objetivo general. El primero de ellos analiza el currículo educativo con la intención de conocer la presencia, el enfoque y la metodología de trabajo del patrimonio, y analiza los planes de estudios de los futuros maestros en torno al tratamiento de la educación patrimonial. El segundo de ellos analiza los enfoques y categorías de una muestra de $n=42$ programas de PCI, que han sido inventariados dentro de la base del OEPE. Todo ello con la finalidad de determinar estándares de calidad. El tercero de ellos realiza un análisis estadístico-descriptivo y relacional de un total de n=202 acciones educativas generadas en torno al PCI en el ámbito nacional, que nos permite conocer sus enfoques y categorías (Tipología de programa, ámbito educativo, tipo de público, 
adaptación y diseño educativo). Además se analizan la correlación existente entre las variables: Tipo de proyecto * Tipo de público y el ámbito del programa * Diseño educativo.

La evaluación de los programas se realiza a través del Método (SAEPEP-OEPE), que se configura como una secuencia de análisis con un enfoque mixto, formada por 8 fases de trabajo estructuradas en tres secuencias: Secuencia de registro, exploratoria y explicativa, que permite analizar el diseño didáctico de los programas para conocer los estándares susceptibles de mejora y los que mayor nivel de adecuación, con la finalidad de extraer claves de actuación futura.

Finalmente, las principales conclusiones alcanzadas son: (a) el currículo de Educación Primaria (RD 126, 2014) aborda el patrimonio de una manera holística y utiliza la secuencia procedimental de sensibilización, conocer-comprender-respetar-valorar, para cuidar-disfrutartransmitir como enfoque metodológico del proceso de enseñanza-aprendizaje; (b) La aproximación actitudinal hacia el patrimonio debe ser superado hacia un enfoque relacional, vinculante y experiencial entre el bien cultural y el alumno; (c) Existen diferencias autonómicas en el grado de sensibilización hacia el PCI en función de los Reales Decretos; (e) Existe una escasa presencia de asignaturas específicas en torno al patrimonio en los grados de maestro de educación primaria; (f) Un alto número de programas sobre PCI no explicitan o profundizan en el diseño educativo ni presentan evaluación; (g) Destaca negativamente la ausencia de programas adaptados a diversos colectivos; (h) El uso de las TIC también es escaso en los programas sobre PCI a pesar de las ventajas que presenta su utilización.

Además, se presenta un decálogo de estándares de calidad para el diseño de la estructura didáctica de futuros programas educativos enfocados en el PCI. Todo ello cierra el ciclo de la investigación planteada, pero abre nuevos interrogantes, que dan origen a líneas de investigación que se encaminan hacia la análisis correlacionales entre el contexto nacional y otros países del ámbito europeo o internacional.

Palabras clave: educación patrimonial, currículo, formación del profesorado, programas educativos, evaluación, patrimonio cultural inmaterial. 


\begin{abstract}
Cultural heritage -and more particularly intangible cultural heritage- becomes specially relevant when it serves as a connecting link between the past and the present and generates feelings of social and cultural identity and belonging. Such potentialities are developed by means of heritage education, which creates bonds between people and heritage assets. This is why, within the framework of the educational system, curricular designs and contents related to intangible cultural heritage (ICH) play a key role in the latter's sustainable conservation, since only that which is known and valued becomes an object of protection and conservation. At the same time, we need to know and evaluate the large number of ICH-related cultural programmes that have been launched in recent years so as to build quality standards for future educational designs.
\end{abstract}

The present dissertation's theoretical framework was shaped by a bibliometric analysis supported by the VOSviewer software and performed on publications indexed in the Web of Science, as well as the review of doctoral dissertations, institutional texts and both national and international projects. All of which points at the fact that ICH has emerged as a highly active line of research over the last few years within the discipline of heritage education, both at an academic level and as regards the development of educational programmes that need to be assessed by means of objective and properly calibrated evaluation instruments.

The epistemological framework of this investigation, on the other hand, results from a compendium of publications equivalent to three studies whose common goal was to assess the nationwide state of heritage by means of a review of the curriculum and the course of study of prospective teachers, together with the appraisal of educational programmes by implementing the sequential method for the analysis and evaluation of heritage education programmes designed by Spain's Observatory of Heritage Education (SAEHEP-SHEO).

Each of the three studies focuses on a different phase and all together they further the accomplishment of the general goal of our research. The first one analyses the educational curriculum in order to ascertain its coverage of heritage-related contents -as well as the approaches and working methodologies employed-, and further probes into the courses of study followed by prospective Primary Education teachers as regards heritage education. The second study analyses the approaches and categories in a sample of $n=42 \mathrm{ICH}$ programmes that were inventoried as part of the SHEO database, the ultimate goal being to establish quality standards for programme evaluation. The third item in the compendium of publications performs a descriptive statistical and relational analysis of a total of $n=202$ educational actions generated around ICH in the national territory so as to learn about their approaches and categories 
(program typology, educational scope, type of target audiences, level of adaptation and educational design). Moreover, the study analysed the correlation between the following variables: Project type *Type of end users and programme scope * Educational design.

The evaluation of programmes was conducted by using the SAEHEP-SHEO method, which involves a sequential analysis and a mixed approach including 8 working phases arranged into three sequences: recording sequence, exploratory sequence and explanatory sequence. In this way, we were able to scrutinise the programmes' didactic designs so as to detect such standards as may be improved upon and those others that exhibit the greatest adequacy —all with a view to extracting keys for future action.

Finally, the main conclusions reached are: (a) the Primary Education curriculum (RD 126, 2014) addresses heritage in a holistic way and relies on the awareness-raising procedural sequence knowing-understanding-respecting-valuing in order to care for-enjoy-transmit; (b) the attitudinal approach to heritage must be overcome in favour of a relational, binding and experiential approach that ties together the student and the cultural asset ; (c) there are differences across Spain's regions concerning the degree of sensitisation towards the $\mathrm{ICH}$, as is evidenced by a study of their educational laws; (e) there is a scanty presence of specific subjects on heritage in the Primary Education Teaching degrees; (f) a large number of programmes related to ICH do not make explicit or present in any depth their own educational design and moreover lack evaluation procedures; $(\mathrm{g})$ a negative impact is caused by the absence of programmes adapted to several groups; (h) the use of ICTs is likewise scarce despite their obvious advantages.

Additionally, this dissertation submits a proposal for a decalogue of quality standards to be implemented in the design of the didactic structure of future programmes focused on ICH. The above conclusions close the research cycle that we set out to complete while at the same time posing new questions that in turn open up avenues of research focused on correlation analyses comparing the national context and the situation in other countries both in Europe and elsewhere.

Key Word: Heritage education, curriculum, teacher education, educational programmes, evaluation, intangible cultural heritage. 


\section{Índice de Contenido}

CAPITULO I....................................................................................................................... 17

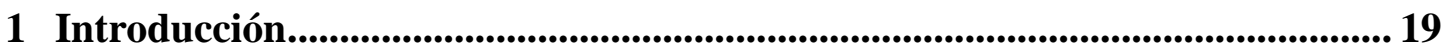

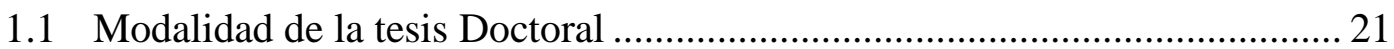

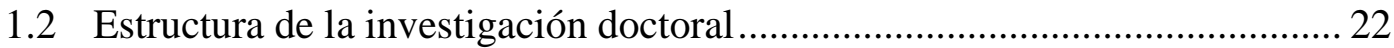

1.2.1 Planteamiento del problema e hipótesis de partida ....................................... 24

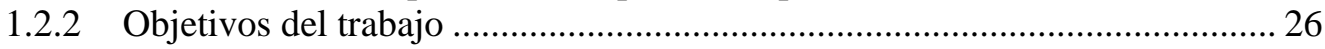

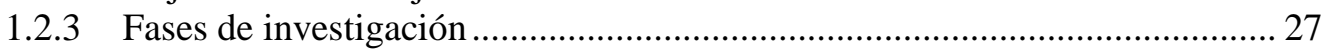

1.2.4 Justificación de la elección y relevancia de la temática .................................2 28

1 Introduction .................................................................................................... 31

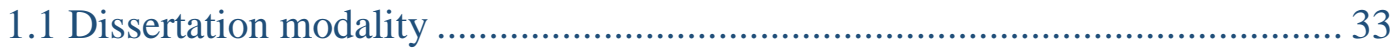

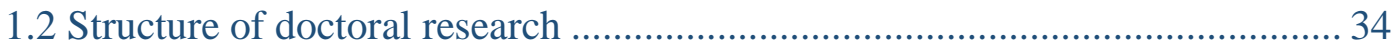

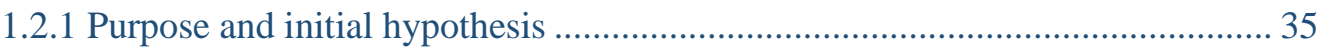

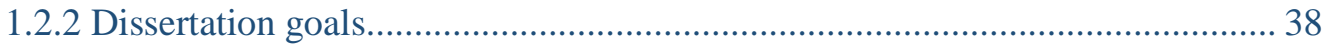

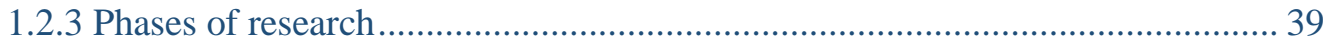

1.2.4 Justification of Research topic and relevance of the topic................................. 40

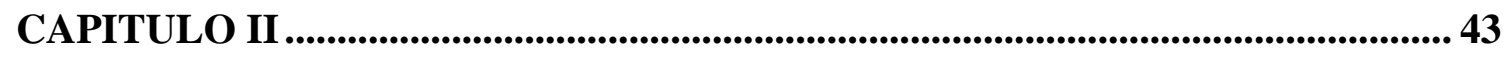

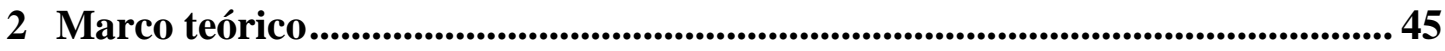

2.1 La dimensión inmaterial del patrimonio desde una perspectiva internacional: Evolución del concepto

2.2 Del folclorismo a la salvaguarda del PCI: La educación como conclusión

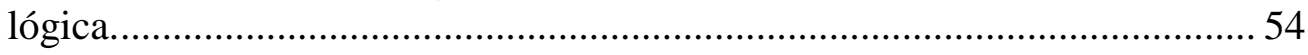

2.3 El Plan Nacional y la ley 10/2015 para la Salvaguarda del PCI .................... 64

2.4 El binomio patrimonio y educación en los textos institucionales y

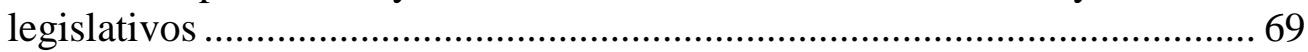

2.4.1 La Educación Patrimonial en los textos internacionales de UNESCO ............ 69

2.4.2 La Educación Patrimonial en los textos de la Unión Europea.......................... 75

2.4.3 La Educación Patrimonial en los textos del Consejo de Europa ...................... 78

2.4.4 La Educación Patrimonial en los textos nacionales y en la ley de Educación.....

2.4.5 El Plan Nacional de Educación y Patrimonio................................................... 103

2.5 Trayectoria y prospectiva de la educación patrimonial............................... 107

2.5.1 Focos de investigación que consolidan la disciplina .................................... 111

2.5.2 Mapas de conocimiento en torno a la producción científica en Educación

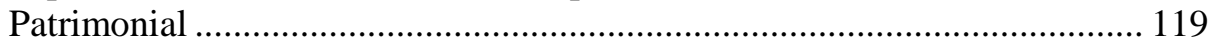

2.5.3 Tesis doctorales sobre Educación Patrimonial, evaluación de programas y

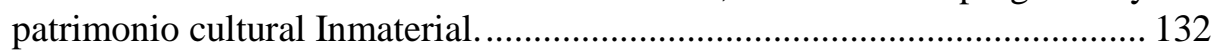

2.5.4 La investigación en Educación Patrimonial dentro de la educación formal con especial atención al PCI.

CAPITULO III

3 Trayectoria y prospectiva del OEPE: su método e instrumento de análisis. 145

3.1 Enfoque y paradigma del Método. 
3.2 Descripción del método SAEPEP-OEPE....................................................152

3.2.1 Conceptualización y diseño del instrumento EBEBE-OEPE. ........................... 155

3.2.2 El proceso de validación: La escala Q-Edutage.............................................. 158

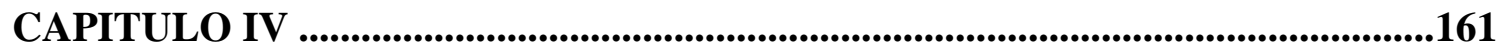

4 Presentación y contexto del compendio de publicaciones ...............................163

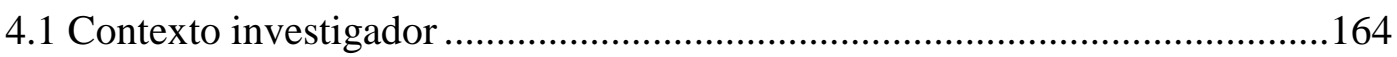

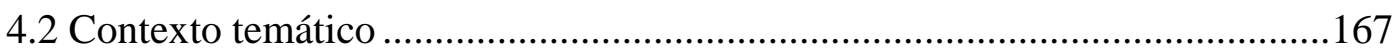

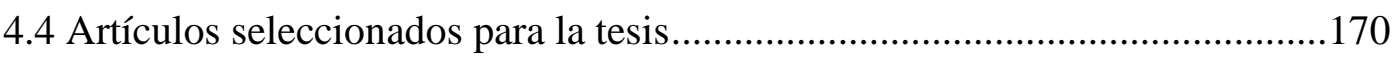

4.4.1 El patrimonio como contenido en la etapa de Primaria: del currículum a la formación de maestros.................................................................................. 170

4.4.3 An Analysis of Educational Designs in Intangible Cultural Heritage Programmes: the Case of Spain...................................................................... 188

4.4.2 Evaluación de programas educativos sobre Patrimonio Cultural Inmaterial . 204

CAPITULO V .227

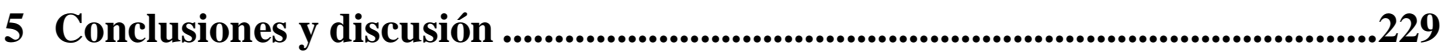

5.1. La educación y el patrimonio para enfrentar los desafíos del S.XXI. ...........229

5.2 Aportaciones más relevantes.....................................................................2231

5.2.1 La educación patrimonial en el currículo y en la formación de maestros...... 231

5.2.2 Enfoques y categorías de los programas educativos sobre PCI ..................... 237

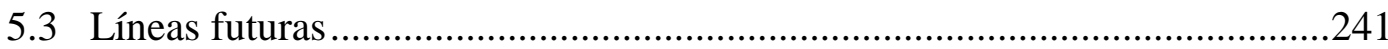

5.4 Limitaciones de la investigación............................................................242

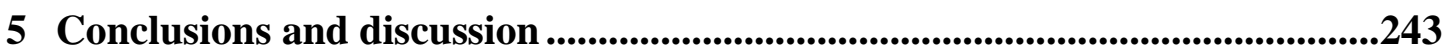

5.1 Education and heritage: Facing the challenges of the 21st century ...............243

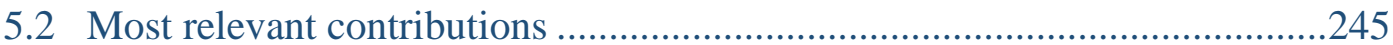

5.2.1 Heritage education in the curriculum and in teacher education....................... 245

5.2.2 Approaches and categories in educational programmes related to ICH .......... 251

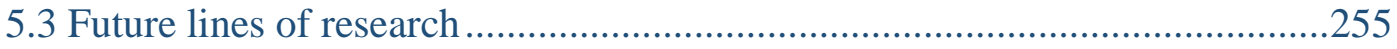

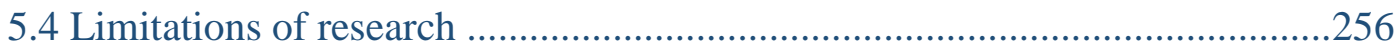

CAPITULO VI ...............................................................................................................................257

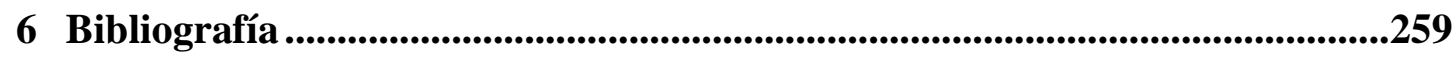




\section{Índice de tablas}

Tabla 1 Comparativa de términos pertenecientes al folclore y al Patrimonio Cultural Inmaterial.

Tabla 2 Recomendaciones del Comité de Ministros a los Estados miembros sobre la Estrategia del patrimonio cultural europeo para el siglo XXI en relación al componente el educativo y de conocimiento.

Tabla 3 Relación de las recomendaciones del componente educativo y de conocimiento $(\mathrm{K})$ con cada uno de los desafíos relativos a los tres componentes (DS, DCE, DD) de la Estrategia XXI.

Tabla 4 Distribución de competencias según Real Decreto 126/2014 y organización de las áreas

Tabla 5. Oferta de asignaturas específicas y de libre configuración por comunidades... 97

Tabla 6 Relación de Proyectos I+D+i concedidos en materia de educación y patrimonio entre 2014-2018

Tabla 7 Relación de tesis doctorales seleccionadas como resultado de la búsqueda en Teseo.

Tabla 8 Relación de tesis doctorales seleccionadas como resultado de la búsqueda en Teseo

Tabla 9 Instrumento de evaluación basada en estándares básicos EBEB-OEPE. 156

Tabla 10 Codificación de las variables de la escala Q-Edutage en función de los estándares de calidad. (Fontal et al, 2019) 160

Tabla 11 Proceso de trabajo durante el desarrollo de la tesis doctoral 167 


\section{List of Tables}

Table 1. Comparative terms of belonging to folklore and the Intangible Cultural Heritage. .61

Table 2. Recommmendations of the Committee of Ministers to member States on the European Cultural Heritage Strategy for the 21st century with regard to the knowledge and education component. 85

Table 3. List of recommendations for the knowledge and education component (K) including each of the challenges related to the three components (DS, DCE,

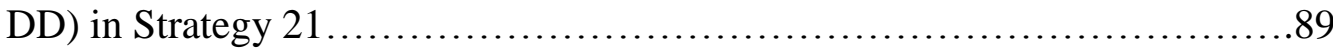

Table 4. Assignment of educational jurisdictions according to Real Decreto 126/2014

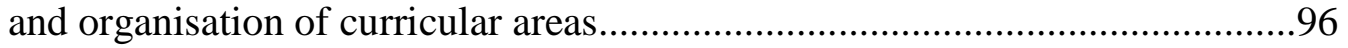

Table 5. List of specific and freely determined subjects by autonomous communities...97

Table 6. List of R\&D\&I Projects granted funding in the field of heritage education

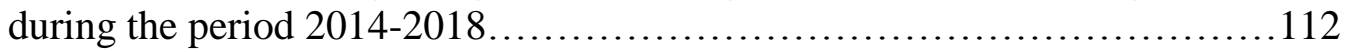

Table 7. List of doctoral dissertations following a Teseo database search..............132

Table 8. List of doctoral dissertations on ICH following a Teseo database search......136

Table 9. Basic standards-based evaluation instrument (BSBE-SHEO)......................156

Table 10. Variable coding in the Q-Edutage scale on the basis of quality standards. (Fontal et al, 2019) ....................................................................................160

Table 11. Work process involved in the completion of this doctoral dissertation........167 


\section{Índice de figuras}

Figura 1. Línea del tiempo sobre la evolución del PCI en la normativa internacional.... 51

Figura 2. Dinamismo inserto en la conceptualización del Patrimonio Cultural. 53

Figura 3. La modernización como peligro para el folclore y la globalización para el PCI.

Figura 4. Características del PCI. Unidades didácticas (2014). Fuente: IPCE................ 65

Figura 5. Ámbitos del PCI. Unidades didácticas (2014). Fuente: IPCE.......................... 66

Figura 6. Riesgos del PCI. Unidades didácticas (2014). Fuente: IPCE............................67 67

Figura 7. Captura del portal web Cultural heritage at the Council of Europe. Ejemplos de buenas prácticas en relación a las recomendaciones sobre el componente educativo y de conocimiento.

Figura 8. Frecuencias de los términos nacionales, autonómicos y promedio de las autonomías

Figura 9. Frecuencias de los términos nacionales, autonómicos y promedios de las autonomías en educación primaria.

Figura 10. Frecuencias de los términos nacionales, autonómicos y promedios de las autonomías en la ESO.

Figura 11. Comparación niveles educativos nacional, autonómicos y promedio

Figura 12. Tipologías patrimoniales que se trabajan en los contenidos curriculares de EP en las distintas comunidades.

Figura 13. Red de co-ocurrencias en base a la unidad de análisis key words en network visualization.

Figura 14. Red de co-ocurencias en base a la unidad de análisis keywords en overlay visualization.

Figura 15. Red de co-autoria en network visualization VOSviewer.

Figura 16. Red de citación de autor en network visualization VOSviewer.

Figura 17. Evolución cronológica de la producción científica por anualidades.

Figura 18. Tipología de documento de la producción científica del campo.

Figura 19. Red de citación de fuentes en overlay visualization VOSviewer.

Figura 20. Red de organizaciones en overlay visualization VOSviewer.

Figura 21. Relación de países en base a la producción científica en el campo.

Figura 22. Red de países en network visualization VOSviewer

Figura 23. Proceso evolutivo de las tesis doctorales sobre la muestra de la tabla 7...... 135

Figura 24. Infografía sobre la trayectoria del OEPE, proyectos $\mathrm{I}+\mathrm{D}+\mathrm{i}$ y fases de trabajo.

Figura 25. Método SAEPEP-OEPE. Procedimiento secuencial para la evaluación de programas. 


\section{List of figures}

Figure 1. Timeline on the evolution of the PCI in international regulations.............51

Figure 2. Intrinsic dynamism in the conceptualization of Cultural Heritage...................53

Figure 3. The great threat of folklorism and intangible cultural heritage........................59

Figure 4. Features of ICH. Didactic units (2014). Source: IPCE ...................................65

Figure 5. Areas of ICH. Didactic units (2014). Source: IPCE.......................................66

Figure 6. Risks of ICH. Didactic units (2014). Source: IPCE.........................................67

Figure 7. Screenshot of web portal Cultural heritage at the Council of Europe. Examples of good practices following the recommendations on the knowledge and

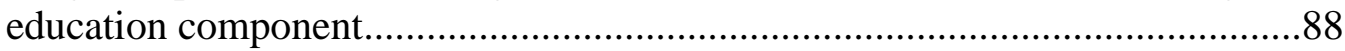

Figure 8. Frequencies of national and regional terms and average values for the Autonomous Communities

Figure 9. Frequencies of national and regional terms and average values for the Autonomous Communities in Primary Education. 100

Figure 10. Frequencies of national and regional terms and average values for the Autonomous Communities in Compulsory Secondary Education..............100

Figure 11. Comparison of national and regional educational levels and average values.

Figure 12. Heritage typologies covered by PE curricular contents in the several Autonomous Communities

Figure 13. Co-occurrence network for unit of analysis "keywords" in network visualization.

Figure 14. Co-occurrence network for unit of analysis "keywords" in overlay

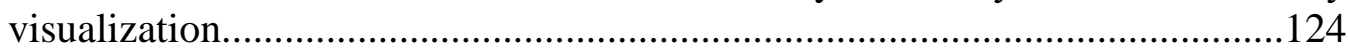

Figure 15. Co-authorship network in network visualization on VOSviewer................125

Figure 16. Author citation network in network visualization on VOSviewer.................126

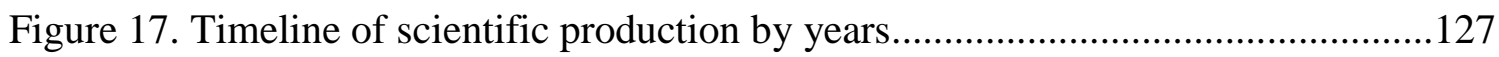

Figure 18. Document typology in the discipline's scientific production............... 127

Figure 19. Source citation network in overlay visualization on VOSviewer.................128

Figure 20. Network of organisations in overlay visualization on VOSviewer............. 130

Figure 21. List of countries by scientific production in the discipline..........................131

Figure 22. Network of countries in network visualization on VOSviewer....................131

Figure 23. Evolution process of doctoral dissertations on the sample in Table 6....... 135

Figure 24. Infographic showing SHEO's track record, R\&D\&I projects and work phases........................................................... 150

Figure 25. SAEHEP-SHEO method. Sequential procedure for programme evaluation............................................................ 
Cada hormiga, como la mayoría de los investigadores, no tiene idea de la forma del hormiguero que se está construyendo. La combinación de un gran número de hormigas y de investigadores consiguen resultados espectaculares, aun cuando cada hormiga o investigador no puede imaginar hacia dónde se dirige su trabajo.

Lewis Thomas (1974) 



\section{CAPITULO I}

\section{Introducción}

L'Orfeo. Overtura (Claudio Monteverdi, 1607)

$[1$

L'Orfeo Overture.mp3

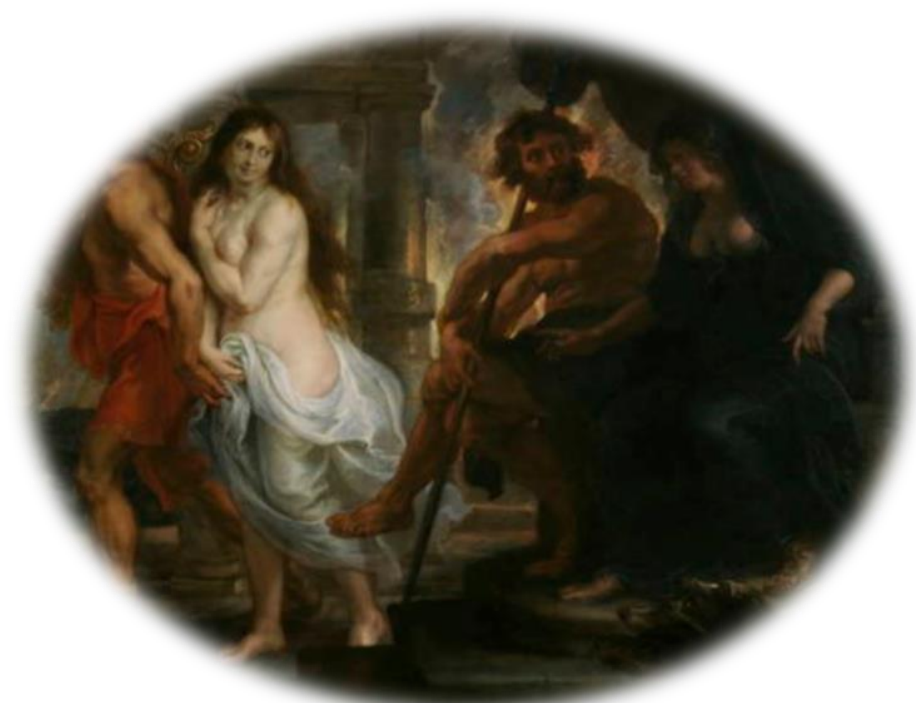

Orfeo y Eurídice. (Pedro Pablo Rubens, 1636-1638) 



\section{Introducción}

La presente tesis doctoral se enmarca en el programa de "Doctorado en Investigación Transdisciplinar en Educación" de la Universidad de Valladolid, y refleja un proceso de formación predoctoral financiado por la Universidad de Valladolid. Este contrato se vincula al proyecto de investigación EDU2012-37212 "Educación Patrimonial en España: consolidación, evaluación de programas e internacionalización del Observatorio de Educación Patrimonial en España (OEPE)”, liderado por la Dra. Fontal Merillas, que ve su continuidad con el proyecto EDU2015-65716-C2-1-R "Evaluación de los aprendizajes en programas de educación patrimonial centrados en los procesos de sensibilización, valorización y socialización del patrimonio cultural”.

Por consiguiente, esta tesis doctoral surge de la vinculación con el OEPE, de mi interés e inquietudes profesionales como maestra de educación primaria y de mi formación académica, que combina la diplomatura de Educación Musical y el Grado en Educación Primaria, ambas por la Universidad de Valladolid, así como estudios de conservatorio. Esta amalgama se acrisola en el interés hacia la educación y el patrimonio en su vertiente más inmaterial. Esta formación inicial se completa con la realización del "Máster en Investigación en Psicología y Ciencias de la Educación” de la Universidad de León, que despertó el interés en la investigación, y supuso la base de los conocimientos metodológicos y analísticos necesarios para el desarrollo del presente trabajo. A lo largo del periodo doctoral se ha estado realizando paralelamente el grado en "Historia y Ciencias de la Música" en el Universidad de Valladolid, que busca completar la formación académica de partida.

Este documento recoge los aprendizajes, las competencias y las destrezas adquiridas durante la trayectoria de formación dentro del grupo de investigación del OEPE, que es pionero en el análisis evaluativo del estado de la educación patrimonial ${ }^{1}$ a nivel nacional y tiene una trayectoria de 10 años de trabajo. Enmarcar la tesis dentro del segundo y tercer proyecto de $\mathrm{I}+\mathrm{D}+\mathrm{i}$ que dan vida al observatorio, ha supuesto dotarla de un empaque nacional, que de otro modo no hubiera sido posible. Del Observatorio se obtiene la base del universo muestral y el método secuencial de análisis y evaluación de

\footnotetext{
${ }^{1}$ El término Educación Patrimonial, referido a disciplina científica y materia de estudio curricular, se escribirá con minúsculas atendiendo a la recomendación de la Nueva Gramática de la lengua española que escribe los nombres de las disciplinas con minúscula o en versalitas. Esta norma verá sus excepciones en citas, nombres de proyectos, títulos de artículos o tesis doctorales.
} 
programas de educación patrimonial (SAEPEP-OEPE), que cuenta en la actualidad con instrumentos validados para la evaluación de la calidad de los programas educativos, escala Q-Edutage (Fontal, García-Ceballos, Arias y Arias, 2019). En la actualidad el observatorio cuenta con $1954^{2}$ programas sobre patrimonio cultural inventariados en la base de datos ${ }^{3}$.

Ambos proyectos han permitido colaborar de forma activa en diversas tareas que han enriquecido la experiencia formativa (i.e. organización y participación en encuentros científicos en el ámbito nacional e internacional, colaboración en la realización de informes con instituciones encargadas de la gestión del patrimonio cultural como el IPCE (Fontal y Martínez, 2016a) o la Subdirección general de patrimonio, tareas de inventario y análisis en los proyectos $\mathrm{I}+\mathrm{D}+\mathrm{i}$ o colaboración en publicaciones del ámbito).

Asimismo, se han realizado 2 estancias de investigación y 3 movilidades Erasmus + , que han favorecido el intercambio científico, el crecimiento personal y el perfeccionamiento de idiomas enmarcados en el desarrollo de la tesis doctoral:

1. Estancia de Investigación en la Universidad de Zaragoza, Facultad de Educación. Tutora: Pilar Rivero Gracia. (Febrero 2016 - abril 2016).

2. Estancia de Investigación en la Universidad de La Habana (La Habana, Cuba), Facultad de Educación/Colegio Universitario San Gerónimo. Tutora: Dr. Miriam Escudero. (Marzo 2017 - mayo 2017).

3. Movilidad en el marco del programa Erasmus+.

- Formación. Universidad de Oporto, Facultad de Letras. Tutora: Alice Semedo. (22/01/2018-26/01/2018).

- Perfeccionamiento de Idiomas. Londres. (29/01/2018 al 09/02/2018).

- Perfeccionamiento de Idiomas. Liverpool. (22/01/2019 - 02/02/2019).

\footnotetext{
${ }^{2}$ Fecha de toma de datos: 10-2-2019.

${ }^{3}$ La base de datos es una base interna del OEPE (solo accesible para los investigadores) donde se encuentra el inventario de programas localizados por el equipo de trabajo.

Los programas se clasifican en 17 tipologías diferentes en base a su naturaleza educativa y 18 categorías en base a su naturaleza patrimonial.
} 
La realización de la segunda estancia de investigación ha permitido presentar la tesis doctoral dentro de la mención "Doctor internacional", respondiendo a las estrategias de internacionalización y movilidad propias del ámbito de la $\mathrm{I}+\mathrm{D}+\mathrm{i}$ para la que capacita este proceso.

\subsection{Modalidad de la tesis Doctoral}

Esta tesis ha sido elaborada a través de la modalidad establecida en el artículo 4.1. de la normativa vigente sobre presentación y defensa de la tesis doctoral en la Universidad de Valladolid -Tesis por compendio de publicaciones- aprobada por la comisión Académica del Programa de doctorado en sesión de 19 de diciembre de 2016 dentro de la opción A:

Tres artículos de revistas incluidas en los listados de Journal Citation Reports (Social Sciences Edition)», «Journal Citation Reports (Science Edition)»o «Arts and Humanities Citation Index» de la «Web of Science»o en los listados de Scopus - Scimago Journal Rank- (SJR).

Los artículos incluidos en este documento final han sido publicados en revistas de impacto, cuya conexión temática es la educación patrimonial en torno al patrimonio cultural inmaterial. En todas ellas tratamos de averiguar cómo se trabaja con, desde y hacia el patrimonio inmaterial dentro de los tres ámbitos de la educación (formal, no formal e informal), aunque con especial atención a la educación formal. Para ello, las publicaciones siguen una trayectoria conjunta que busca conocer la presencia, el tratamiento y el enfoque metodológico del patrimonio en la normativa educativa que regula tanto el currículo de educación primaria a nivel autonómico y nacional, como los planes de estudios de los futuros maestros de educación primaria en las universidades públicas propias y adscritas, y privadas de la geografía española. Además de inventariar y evaluar el diseño didáctica de acciones y programas educativos en materia de patrimonio cultural inmaterial que se desarrollan en los ámbitos relativos a la educación formal y no formal.

Los artículos seleccionados que se incluyen en este documento, están ordenados en función de las fases de investigación planteadas inicialmente y no de la publicación cronológica: 
1. Fontal, O., Ibáñez-Etxeberria, A., Martínez, M. y Rivero, P. (2017). El patrimonio como contenido en la etapa de Primaria: del currículum a la formación de maestros. Revista Electrónica Interuniversitaria de Formación del Profesorado, 20(2), 79-95. doi: http://dx.doi.org/10.6018/reifop.20.1.286321

2. Fontal, O., y Martínez, M. (2018). Analysis of educational designs in intangible cultural heritage programmes: the case of Spain. Internacional Journal of Intangible Heritage, 13, 189-202.

3. Fontal, O., y Martínez M. (2017). Evaluación de programas educativos sobre Patrimonio Cultural Inmaterial. Estudios Pedagógicos, 43(4), 69-89. doi: http://dx.doi.org/10.4067/S0718-07052017000400004

Este orden se corresponde con la coherencia temática de los elementos analizados, en primer lugar análisis de la normativa educativa y posteriormente de los programas educativos.

\subsection{Estructura de la investigación doctoral}

La tesis doctoral parte de la necesidad de revisión y evaluación de las acciones educativas en materia de patrimonio cultural inmaterial, y de las normativas educativas que regular los modos en que se debe trabaja el patrimonio en las aulas, siendo esta la línea de continuidad que subyace a las publicaciones seleccionadas. La tesis doctoral se sustenta sobre una estructura de trabajo que parte de una revisión teórica sistemática e individualizada que respalda cada uno de los estudios. Reflejamos aquí las hipótesis, los objetivos y la justificación y relevancia de la temática seleccionada.

El trabajo se presenta en un documento estructurado en cinco partes. En el capítulo 1 "Introducción" se presenta una visión general sobre la investigación que se ha desarrollado. Para ello, en esta introducción se recoge un esquema general de la investigación, el propósito y las hipótesis de partida, los objetivos a alcanzar debidamente justificados, las fases propuestas para su consecución y relevancia de la temática planteada.

En el capítulo 2 “Fundamentación Teórica” se presenta la revisión teórica del campo de estudio, a través del análisis bibliométrico de la producción científica dentro de la 
disciplina, que nos permite generar mapas de conocimiento (redes), para conocer a través de la lectura de los nodos las principales líneas de investigación, los autores y países más relevantes en la producción científica, así como los organismos, fuentes, coautorías y la situación de la línea de trabajo en la literatura vigente. Este apartado también ofrece un análisis de la evolución conceptual del término patrimonio cultural, con especial atención a su dimensión inmaterial a través de los textos de organismos oficiales encargados de su gestión y salvaguarda - legislación, planes, convenciones, órdenes, etc. Por último se analizan los proyectos de $\mathrm{I}+\mathrm{D}+\mathrm{i}$ a nivel nacional e internacional, así como las tesis doctorales más afines desarrolladas hasta el momento.

Una tercera parte de la tesis, correspondiente al capítulo 3 "El OEPE y su método de evaluación de programas", recoge la trayectoria y prospectiva del OEPE como organismo marco de la tesis doctoral, así como el método e instrumentos de trabajo que dan unidad a las publicaciones del compendio. Se aborda su diseño y reciente validación.

El capítulo 4 “Presentación y contexto del compendio de publicaciones" se corresponde a la parte fundamental que configura el cuerpo de esta tesis por compendio de publicaciones. En esta sección se describe la conexión temática entre las publicaciones y la progresión metodológica. Se presenta el contexto investigador, y se pone en relación con otras publicaciones, informes y trabajos de investigación realizados por la autora que permiten enmarcar todo el trabajo realizado. Este tercer capítulo nos permite visualizar las conexiones y la línea de continuidad entre los artículos, así como la aportación individual de cada uno de ellos para la consecución del objetivo de investigación general de la tesis doctoral.

En el último apartado, capítulo 5 “Conclusiones y discusión”, se acrisolan y discuten los resultados obtenidos tanto en la revisión de bibliométrica sobre el campo de estudio, como las principales conclusiones que se alcanzan en los artículos que componen la tesis. En último lugar se presentan limitaciones del estudio y líneas de investigación futuras.

Finalmente, en el último apartado dedicado a la "Bibliografía" se recogen las referencias a todos los trabajos citados a lo largo del presente documento. 


\subsubsection{Planteamiento del problema e hipótesis de partida}

La educación patrimonial constituye un factor clave para la conservación sostenible del patrimonio, ya que solo se protege y conserva lo que se conoce y se valora (Fontal y Juanola, 2015). Además, la educación patrimonial constituye una herramienta de enseñanza-aprendizaje fundamental para el desarrollo integral de la persona (Apaydin, 2018). Por ello, es importante conocer las carencias y obstáculos que existen a la hora de llevarlo a la práctica.

A continuación, se presentan las cuestiones a los que tratamos de dar respuesta y que dirigen nuestra investigación. Partimos de una problemática general que se desglosa en varias cuestiones específicas. El orden de aparición se corresponde con la secuencia de investigación inicialmente planteada, que también responde al orden cronológico de los artículos.

Cuestión general:

¿Qué enfoque presenta el currículo y los planes de estudios de los futuros maestros de educación primaria respecto al patrimonio y cuál son los enfoques, categorías y calidad de los programas educativos que abordan el patrimonio cultural inmaterial (PCI en adelante)?

Cuestiones específicas

1-¿Qué concepto del patrimonio se transmite en el currículo de Educación Primaria? ¿Se relaciona esta con la construcción de la identidad?

2-¿Qué enfoque metodológico se plantea para trabajar el patrimonio en el currículo de Educación Primaria?

3-¿Existen diferencias a nivel autonómico en el tratamiento que hacen los reales decretos del patrimonio cultural y del PCI?

4-¿Qué competencias adquieren los futuros docentes de Educación Primaria a lo largo de su formación universitaria para trabajar la educación patrimonial en las aulas?

5-¿En qué medida correlaciona la presencia del patrimonio en el currículo y en el número de asignaturas obligatorias/básicas y optativas correspondientes a los planes de estudio del grado de Maestro? 
6-¿Cuáles son los enfoques y categorías que presentan los programas educativos sobre PCI?

7- ¿Qué tipología de PCI desarrollan los programas? ¿Cuál es su ámbito educativo? ¿Cuál es la tipología de programa? ¿A qué tipo de público se dirigen? ¿Presentan adaptación a personas con diversidad funcional o NEE? ¿Presentan un diseño educativo sólido?

8- ¿Existe algún tipo de correlación entre las categorías analizadas en los programas educativos sobre PCI?

9- ¿Existen sistemas e instrumentos de evaluación objetivos y validados para medir la calidad de los diseños educativos en la disciplina de educación patrimonial?

10- ¿Existen estándares de calidad relacionados con el diseño educativo, que ayude a mejorar la calidad de futuros programas educativos en torno al patrimonio?

En relación a los problemas de investigación planteados, las hipótesis de partida son:

H1. El concepto del patrimonio que se transmite en el currículo de Educación Primaria, presenta un enfoque holístico y se relaciona con la construcción de la identidad.

H2. La descentralización educativa provoca diferencias en el tratamiento que hacen los reales decretos del patrimonio cultural y del PCI.

H3. Los futuros docentes de Educación Primaria no adquieren la suficiente capacitación en su formación universitaria para trabajar la educación patrimonial en las aulas

H4. Existe un desfase entre la presencia del patrimonio en el currículo y el número de asignaturas obligatorias/básicas y optativas correspondientes a los planes de estudio del grado de Maestro.

H5. Las instituciones que diseñan los programas de educación patrimonial, en su mayoría, no establecen sistemas de evaluación de sus prácticas.

H6. La evaluación -tanto interna como externa- en materia de educación patrimonial no aparece reflejada en el diseño educativo de los programas. 
H7. No existen sistemas e instrumentos de evaluación objetivos y validados para medir la calidad de los diseños educativos en la disciplina de educación patrimonial.

H8. No existen estándares de calidad relacionados con el diseño educativo, que ayude a mejorar la calidad de futuros programas educativos en torno al patrimonio.

\subsubsection{Objetivos del trabajo}

Presentamos de forma sintética los objetivos planteados, con la intención de establecer la finalidad que perseguimos, distinguimos entre un objetivo principal y una serie de objetivos específicos derivados del mismo.

Objetivo general:

OG1: Conocer las categorías y calidad de los programas educativos sobre Patrimonio Cultural Inmaterial, así como el enfoque que recibe el patrimonio en el marco legislativo de la Educación Primaria y los planes de estudios de los maestros.

Objetivos específicos:

OE1: Conocer, analizar y diagnosticar el estado de la cuestión de la Educación Patrimonial poniendo el foco de atención sobre el PCI.

OE2: Analizar y valorar el concepto sobre el patrimonio que transmite el currículo de Educación Primaria.

OE3: Conocer y describir el enfoque metodológico que se plantea para trabajar el patrimonio en el currículo de Educación Primaria.

OE4: Analizar y valorar el tratamiento que hacen los Reales Decretos del patrimonio cultural y del patrimonio cultural inmaterial en las diferentes comunidades autónomas.

OE5: Analizar y describir las asignaturas que abordan el patrimonio en la formación universitaria de los futuros docentes de educación primaria en base a los planes de estudios de las universidades públicas propias, públicas adscritas y privadas a nivel nacional. 
OE6: Buscar correlaciones entre la presencia del patrimonio en el currículo y en el número de asignaturas obligatorias/básicas y optativas correspondientes a los planes de estudio del grado de Maestro.

OE7: Describir la escala Q-Edutage como instrumentos validado para medir la calidad de los diseños educativos en la disciplina de educación patrimonial.

OEs: Analizar enfoques y categorías (Tipología de PCI, Ámbito educativo, Tipología de programa, Público, Adaptación a personas con diversidad funcional o NEE) en los programas de educación sobre el PCI.

OE9: Analizar y valorar si los programas educativos sobre PCI presentan un diseño educativo sólido.

OE 10: Acotar y definir estándares de calidad para el diseño de futuros programas de educación patrimonial.

\subsubsection{Fases de investigación}

Con la intención de dar respuesta a los objetivos planteados articulamos la investigación en diferentes fases de actuación:

F1: Búsquedas y análisis bibliométrico de publicaciones sobre PC y PCI, que nos permitan elaborar estudios sobre el estado de la cuestión y desarrollar el marco teórico de esta tesis doctoral. Las búsquedas se han realizado en las bases de datos de la Web of Science, y la visualización de las conexiones entre temáticas y autores se han generado a través del programa VosViewer.

F2: Revisión y análisis del tratamiento del patrimonio en la legislación educativa a nivel nacional y autonómico de educación primaria, así como en los planes de estudios de los futuros maestros a nivel nacional. Realizar análisis estadísticos correlacionales entre ambos parámetros. Finalmente revisión y análisis de la presencia de la educación en los textos de las instituciones internacionales encargadas de la gestión y tutela del patrimonio.

F3: Localización, inventario y evaluación a través del Método OEPE de amplias muestras de programas educativos en materia de patrimonio cultural inmaterial en base a su estructura didáctica, para conocer sus enfoques, categorías, correlaciones así como detectar ausencias y presencias en la educación patrimonial. 
F4: Desarrollo de orientaciones y estándares de calidad para el diseño educativo de futuros programas sobre patrimonio cultural inmaterial. Limitaciones, líneas futuras de actuación y difusión e internacionalización de la investigación.

La principal contribución al campo es una línea de la educación patrimonial enfocada en el Patrimonio cultural Inmaterial, desde un enfoque evaluativo. Por un lado, evaluación de la legislación educativa vigente y de los planes de estudios universitarios de los futuros maestros sobre patrimonio, y por otro lado una evaluación de programas educativos sobre PCI a través de estándares de calidad que nos permite identificar los aspectos susceptibles de mejora y desarrollar decálogos de actuación que remitirán en la mejora de la práctica futura.

\subsubsection{Justificación de la elección y relevancia de la temática}

El patrimonio cobra especial relevancia, como nexo de unión entre el pasado y el presente, y generador de sentidos de identidad y pertenencia social y cultural (Apaydin, 2018). Estas potencialidades del patrimonio se desarrollan gracias a la educación patrimonial, que permite generar vínculos de pertenencia e identidad entre las personas y los elementos patrimoniales (Fontal, 2013; Fontal y Marín, 2018), fomenta la alfabetización cultural (Texeira, 2006), y promueve el respeto y la apreciación a la diversidad guiándonos hacia una sociedad más justa e inclusiva (Buckley y Graves, 2016). Además, la educación patrimonial constituye un factor clave para la conservación sostenible del patrimonio, ya que necesitamos conocer y generar vínculos con los bienes patrimoniales, que generen inercias de protección y conserva (Fontal y Juanola, 2015).

Tras poner de manifiesto el valor que presenta la educación patrimonial como instrumento de gestión y herramienta de enseñanza-aprendizaje para el desarrollo integral de la persona (Casanova, Arias y Egea, 2018; Islamoglu, 2018; Mun, 2018), es importante conocer las carencias y obstáculos que existen a la hora de poner en práctica esa formación patrimonial. En primer lugar, necesitamos conocer cuál es el la presencia y el enfoque que recibe el patrimonio dentro del marco de la legislación educativa, con la finalidad de descubrir si el currículo aborda de un modo adecuado la enseñanza del patrimonio, en qué áreas de conocimiento y a través de que metodologías de trabajo preferenciales. Al mismo tiempo, necesitamos analizar si los futuros maestros de educación primaria están recibiendo la formación suficiente y adquiriendo las 
competencias necesarias que le permitan trabajar estrategias de enseñanza-aprendizaje en torno al patrimonio, ya que ellos serán los encargados de trasladarlo a las aulas y de cumplir la legislación educativa.

Por otro lado, la labor investigadora como miembro del OEPE, nos ha permitido realizar análisis sobre el total de programas inventariados en la base de datos con lo que detectamos que existe un alto porcentaje de programas educativos focalizados en el PCI que necesitan ser analizados y evaluados. El análisis de los programas previamente inventariados en la base de datos del OEPE, responde a la intención de conocer el estado de la cuestión en torno a la educación del PCI a nivel nacional, que nos permita establecer indicadores de calidad para futuros diseños.

Esta proliferación de programas educativos sobre PCI se debe en gran medida a las normativas desarrolladas en pro de su gestión, salvaguarda y reconocimiento, tanto a nivel internacional como en la Declaración de Estambul sobre Patrimonio Inmaterial (UNESCO, 2002) y la Convención para la Salvaguarda del Patrimonio Cultural Inmaterial (UNESCO, 2003), como a nivel nacional con el Plan Nacional para la Salvaguarda del Patrimonio Cultural Inmaterial (Domingo y Timón, 2011) y la Ley 10/2015 para la Salvaguarda del Patrimonio Cultural Inmaterial. Todo ello se traslada a la sociedad que comienza a entender el patrimonio cultural con un enfoque más global y conformado por una naturaleza material, inmaterial y espiritual (Carrera, 2009). Por ello, queremos conocer y describir lo que es o debe ser el PCI, los valores adscritos, las formas de reconocimiento, los ámbitos en los que se desarrolla, así como los peligros en torno a su salvaguarda, donde la educación se convierte en un factor clave (Ahmad, 2006; Ahmet, 2018).

Los análisis realizados en el OEPE desde su inicio (Fontal, Marín y Pérez, 2013; Fontal y Gómez-Redondo, 2016; Fontal y Marín, 2016; Fontal y Martínez, 2016a, 2017, 2018; Marín et al., 2017) muestran que los diseños educativos de las propuestas no son suficientemente descritos en lo referido al diseño, la implementación y los resultados. Además, existe una ausencia explícita de sistemas de evaluación, lo cual dificulta la mejora de la práctica educativa. La necesidad de evaluar las acciones educativas en torno al patrimonio, ya es enunciada en el Plan Nacional de Educación y Patrimonio (Domingo, Fontal y Ballesteros, 2013). Esta necesidad de evaluación, presenta como una 
de sus líneas principales la evaluación de programas que permite el progreso de la práctica educativa y garantiza la calidad de los diseños didácticos (Pérez, 2000).

Al mismo tiempo, existía una ausencia de instrumentos validados dentro de la disciplina, que evaluaran las prácticas educativas y nos pudieran proporcionar información objetiva sobre la calidad de las prácticas, la adecuación a los niveles de implementación o la capacidad de logro y/o alcance de las propuestas (Soriano, 2014). En este sentido el observatorio dentro de su método secuencial de análisis y evaluación de programas de educación patrimonial (SAEPEP-OEPE) ha desarrollado y validado la escala Q-Edutage con la intención de suplir esta ausencia (Fontal et al., 2019).

La producción científica de la disciplina ha tenido un crecimiento notorio en cuanto al número y la calidad de los artículos de investigación. Al mismo tiempo a nivel nacional se ha producido un incremento en el desarrollo de tesis doctorales defendidas y proyectos de $\mathrm{I}+\mathrm{D}+\mathrm{i}$ concedidos en convocatorias nacionales (Fontal e Ibáñez-Etxeberria, 2017). Es importante conocer la evolución que se está produciendo en torno a la disciplina de una manera sistemática, por ello, en el marco teórico realizamos análisis de contenido y estadísticos-descriptivos basándonos en estos tres indicadores de calidad de alto impacto (Publicaciones científicas, tesis doctorales y proyectos de $\mathrm{I}+\mathrm{D}+\mathrm{i}$ tanto nacionales como internacionales). Al mismo tiempo, creemos necesario esclarecer el debate conceptual generado en torno al patrimonio cultural en las últimas décadas, dentro del ámbito político-administrativo y académico. Debemos asentar las bases teóricas y conceptuales, sobre la cual construir pilares que nos permitan abordar de una manera sólida, el concepto del patrimonio cultural desde la disciplina de la educación. 


\section{Introduction}

The present doctoral dissertation has been written within the framework of the University of Valladolid's $\mathrm{PhD}$ programme "Doctoral Degree in Transdisciplinary Research in Education" and results from a formative process funded by the University of Valladolid through a pre-doctoral fellowship. The latter was tied to research project EDU2012-37212 "Heritage Education in Spain: Consolidation, Programme Evaluation and Internationalisation" run by Spain's Observatory of Heritage Education, in turn led by Dr. Fontal Merillas. This project had its continuation in another one (EDU201565716-C2-1-R) on the "Evaluation of Learning Outcomes in Heritage Education Programmes Focusing on Cultural Heritage Awareness-Raising, Valorisation and Socialisation".

This doctoral research, therefore, stems from my involvement with SHEO, my professional interests and concerns as a Primary Education teacher and my academic background, which combines a diploma in Music Education and a degree in Primary Education, both from the University of Valladolid, as well as musical training at the conservatory. Such a background consolidated into my interest in education and heritage, particularly in connection with the latter's most intangible forms. My initial academic training was further enriched by my pursuance of a Master's Programme on "Research in Psychology and Educational Sciences" at the University of León -a course of study that inspired my interest in research and provided the methodological and analytical groundings needed to complete this dissertation. While engaged in my doctoral training, I also pursued a degree in "Music History and Science" at the University of Valladolid in order to enrich my original academic background.

The present document brings together learning outcomes, skills and competences acquired during my academic and research training as a member of the SHEO's research group, whose pioneer work in the evaluative analysis of heritage education in Spain has been implemented over a span of 10 years. The fact that I was able to embed my doctoral research in the Observatory's second and third R\&D\&I projects endows this dissertation with a national scope that it would not have attained otherwise. The Observatory provided the basis for the study's sample universe and the method for the sequential analysis and evaluation of heritage education programmes (SAEHEP-SHEO) which currently includes a number of instruments that have been validated for 
educational programme quality evaluation like the Q-Edutage Scale (Fontal, GarcíaCeballos, Arias \& Arias, 2019). To date, the Observatory has inventoried no fewer than $1,954^{4}$ programmes in its database.

Both projects made it possible for me to actively collaborate in several assignments that enhanced my formative experience (i.e. organising and taking part in scientific gatherings both at national and international level; producing reports in partnership with institutions responsible for managing cultural heritage like Spain's Institute for Cultural Heritage (IPCE) (Fontal \& Martínez, 2016) or the country's Subdirectorate General for Heritage; carrying out inventory and analysis tasks for the Observatory's R\&D\&I projects; or collaborating in publications related to SHEO's field of study).

Additionally, I carried out 2 research stays and 3 Erasmus + mobility actions that promoted scientific exchanges, personal growth and the improvement of my foreign language skills - all in the framework of my doctoral research:

1. Research stay at Universidad de Zaragoza, Facultad de Educación (Zaragoza, Spain). Tutor: Pilar Rivero Gracia. (February 2016 - April 2016).

2. Research stay at Universidad de La Habana (Havana, Cuba), Colegio Universitario San Gerónimo. Tutor: Dr. Miriam Escudero. (March 2017 - May 2017).

3. Erasmus+ mobility actions.

- Training. Universidade do Porto, Faculdade de Letras. Tutor: Alice Semedo. (22/01/2018-26/01/2018).

- Improving foreign language skills. London. (29/01/2018- 09/02/2018).

- Improving foreign language skills. Liverpool. (22/01/2019 - 02/02/2019).

In fact, the completion of the second research stay mentioned above made it possible to submit the present doctoral dissertation as eligible for an "International Mention" in compliance with current R\&D\&I internationalisation and mobility guidelines.

${ }^{4}$ Data retrieved on 10-2-2019. 


\subsection{Dissertation modality}

The present doctoral dissertation has been completed in accordance with the modality set out in article 4.1. of the University of Valladolid's current regulations regarding the submission and defense of $\mathrm{PhD}$ dissertations (dissertation resulting from a compendium of publications, i.e. following the so-called manuscript style): a modality approved by the Programme's Academic Committee on 19 December, 2016. More particularly, it meets the requirements laid down under choice $\mathrm{A}$ :

Three articles published in journals included in the listings of Journal Citation Reports (Social Sciences Edition), Journal Citation Reports (Science Edition) or the Web of Science's Arts and Humanities Citation Index; or, alternatively, in those of Scopus - Scimago Journal Rank- (SJR).

The articles included in this final document have been published in impact journals, their common thread being heritage education, particularly as regards intangible cultural heritage. All of them conduct an inquiry into the way in which intangible heritage is dealt with in all three educational settings (formal, non-formal and informal), even though special emphasis is laid on formal education. All publications pursue common lines of research aimed at establishing the presence and coverage of heritage - as well as the methodological approaches involved - in such educational regulations as define both the Primary Education curriculum at regional and national levels and the course of study followed by prospective Primary Education teachers at public, affiliated and private universities in the whole of the Spanish territory. Additionally, they contribute an inventory of educational actions and programmes in the matter of intangible cultural heritage that are being developed in formal and non-formal educational settings and furthermore evaluate their didactic designs.

The selected articles included in this document have ordered according to the initial research phases and not the chronological publication.

1. Fontal, O., Ibáñez-Etxeberria, A., Martínez, M. y Rivero, P. (2017). El patrimonio como contenido en la etapa de Primaria: del currículum a la formación de maestros. Revista Electrónica Interuniversitaria de Formación del Profesorado, 20(2), 79-95. doi: http://dx.doi.org/10.6018/reifop.20.1.286321 
2. Fontal, O., y Martínez, M. (2018). Analysis of educational designs in intangible cultural heritage programmes: the case of Spain. Internacional Journal of Intangible Heritage, 13, 189-202.

3. Fontal, O., y Martínez M. (2017). Evaluación de programas educativos sobre Patrimonio Cultural Inmaterial. Estudios Pedagógicos, 43(4), 69-89. doi: http://dx.doi.org/10.4067/S0718-07052017000400004

This order matches the thematic consistency of the whole set, in the sense that the analysis of educational regulations is followed by that of the educational programmes themselves.

\subsection{Structure of doctoral research}

The present dissertation results from the need to review and evaluate educational actions in the field of intangible cultural heritage and such regulations as govern the way in which heritage must be dealt with in the classrooms. This indeed provides the continuity that underlies the publications here compiled. Our research relies on a structure whose starting point is a systematic theoretical review according to the individual requirements of each of the studies making up the compilation. Once the structure is described, we will present the hypotheses and goals of our research, as well as the justification and relevance of the study topic.

This manuscript-style dissertation is divided into five sections. Chapter 1 “Introduction" provides a general overview of our research. To this purpose, it lays down a schematic outline of the latter, formulates the initial purposes and hypotheses, the goals to be attained as well as their proper justification, the several stages implemented in order to fulfil such goals and the relevance of the research topic.

Chapter 2 "Theoretical framework" includes the theoretical review of our field of study and involves a bibliometric analysis of the scientific output in the discipline. Such an analysis, in turn, makes it possible to generate knowledge maps (networks) whose nodes define the main lines of research, the most relevant authors and countries in terms of scientific production and the main organisations, sources and co-authorships operating in this knowledge domain, thus producing a picture of the present-day situation of this line of research in the current literature. This section additionally 
provides an analysis of the conceptual evolution of the term "Cultural Heritage", with a special focus on its intangible dimension, through a review of the texts issued by the official organisations entrusted with its management and preservation - legislation, plans, conventions, regulations, etc. Finally, both national and international R\&D\&I projects, as well as doctoral dissertations produced to date in this area of knowledge are likewise surveyed in this chapter.

The dissertation's third section corresponds to chapter 3 "SHEO and its method for programme evaluation". It discusses the trajectory and future prospects of SHEO - the institution that constitutes the framework for this doctoral research and the methodology and working tools that provide continuity and consistency for the publications that make up this manuscript-style dissertation. The Observatory's original design and recent validation are addressed in this chapter.

Chapter 4 "Presentation and context of the compendium of publications" constitutes the fundamental part within the main body of this manuscript-style dissertation. This section includes a description of the thematic links across the several publications making up the compendium and the underlying methodological progression. This section lays down the dissertation's research context and its connections with other publications, reports and research items produced by the author in order to contextualise the whole of her research trajectory. Chapter 3, therefore, showcases links and continuity lines across the compiled manuscripts, as well as each of the item's individual contribution to the achievement of the overall research goal of the dissertation itself.

In the last section, chapter 5 "Conclusions and discussion", the results from the bibliometric review of the research topic and the main conclusions obtained by the several articles making up the compendium are consolidated and discussed. Finally, the study's limitations are presented together with a number of future lines of research.

Last of all, the section dedicated to the dissertation's "Bibliography" includes the comprehensive list of references cited.

\subsubsection{Purpose and initial hypothesis}

Heritage education constitutes a key factor in the sustainable conservation of heritage itself, since only that which is known and valued becomes an object of protection and 
conservation (Fontal \& Juanola, 2015). Furthermore, heritage education is a key teaching-learning tool in the comprehensive development of individuals (Apaydin, 2018). This is why it is important to learn about the obstacles and shortcomings that exist when it comes to implementing heritage education actions.

Next follows a presentation of the main issues that we try to address and indeed guide our inquiry. We start from a general consideration of the problem, which is then broken down into several specific issues. The order in which such issues are introduced matches de research sequence initially laid down, in turn corresponding to the publishing timeline of the articles compiled.

\section{General problem:}

What is the approach implemented in the curriculum and in the course of study followed by prospective Primary Education teachers with regard to heritage? What are the perspectives, categories and quality levels of educational programmes that address intangible cultural heritage?

Specific issues

1- Which conception of heritage is being conveyed by the Primary Education curriculum? Is such a conception related to the construction of identity?

2- What methodological approach is being used to implement heritage-related contents in the Primary Education curriculum?

3-Are there differences between the Spanish regions in the way they enforce the national legislation on cultural heritage and intangible cultural heritage?

4- What competencies are being acquired by prospective Primary Education teachers during their undergraduate training in order to work on heritage education in the classroom?

5- To what extent is there a correlation between the coverage of heritage contents in the curriculum and the number of core/compulsory and elective courses in the course of study leading to a Teaching degree?

6- What are the approaches and categories used in educational programmes on intangible cultural heritage? 
7- What ICH typology is being developed by such programmes? What is their educational scope? What programme types are available? Who are their target users? Are these programmes adapted to persons with differing abilities or SENs? Do they exhibit a sound educational design?

8- Is there any kind of correlation between the categories under examination in educational programmes on intangible cultural heritage?

9- Are there objective and validated evaluation instruments in order to measure the quality of educational designs in heritage education?

10- Are there educational design quality standards in order to enhance the quality of heritage-related educational programmes in the future?

As regards the above-listed research problems and issues, the initial hypotheses are as follows:

H1. The conception of heritage that is being conveyed by the Primary Education curriculum exhibits a holistic approach and is related to the construction of identity.

H2. The decentralisation of education encourages differences in the way legislation (royal decrees) addresses cultural heritage and intangible cultural heritage.

H3. Prospective Primary Education teachers do not receive a sufficient level of undergraduate training for them to implement heritage education contents in the classroom.

H4. There is a mismatch between the curricular coverage of heritage-related contents and the number of core/compulsory and elective subjects in the courses of study leading to a Teaching degree.

H5. The majority of institutions designing heritage education programmes do not implement evaluation systems for their internships.

H6. Evaluation procedures - both internal and external - in the area of heritage education are not reflected in the programmes' educational design.

H7. There are no objective and validated evaluation tools to measure the quality of educational designs in the discipline of heritage education. 
H8. There are no educational design quality standards in order to improve the quality of heritage-related educational programmes in the future.

\subsubsection{Dissertation goals}

Next follows a schematic presentation of the goals set for the present dissertation. In order establish our main aims, we draw a distinction between a general goal and a series of specific ones that stem from the latter.

General goal:

GG1: To establish the categories and the quality of educational programmes dealing with intangible cultural heritage, as well as to define the approach to heritage evinced by the current legislative framework regarding Primary Education and the Teacher Education curriculum.

Specific goals:

SG1: To learn about, analyse and diagnose the state of the question regarding heritage education, with a special focus on $\mathrm{ICH}$.

SG2: To analyse and appraise the conception of heritage transmitted by the Primary Education curriculum.

SG3: To get to know and describe the methodological approach used to deal with heritage-related contents in the Primary Education curriculum.

SG4: To analyse and appraise the way in which regional legislation deals with cultural heritage and intangible cultural heritage in each of the Spanish regions (autonomous communities).

SG5: To analyse and describe the specific heritage-related courses that are part of the college training of prospective Primary Education teachers as reflected in the courses of study of public, publicly affiliated and private universities in the whole of Spain.

SG6: To trace correlations between the curriculum coverage of heritage contents and the number of core/compulsory and elective subjects in the courses of study leading to a Teaching degree. 
SG7: To describe the Q-Edutage scale as a validated instrument aimed at measuring the quality of educational designs in the discipline of heritage education.

SG8: To analyse approaches and categories (ICH typology, Educational scope, Programme typology, Target users, Adaptation to users with differing abilities or SENs) in educational programmes on ICH.

SG9: To analyse and appraise whether or not $\mathrm{ICH}$ programmes exhibit a sound educational design.

SG10: To define and narrow down the list of quality standards applicable to the design of future heritage education programmes.

\subsubsection{Phases of research}

In order to meet the above-mentioned goals, our research will complete the following phases:

PH1: Conducting VosViewer-powered bibliometric searches and analyses of publications on $\mathrm{CH}$ and $\mathrm{ICH}$ in order to sustain studies on the state of the question for each of the manuscripts making up the compendium as well as to develop the theoretical framework of this doctoral dissertation.

F2: Performing the review and analysis of the coverage of heritage-related contents in the current legislation, both national and regional, on Primary Education, as well as the presence of such contents in the courses of study of prospective teachers in Spain. Additionally, statistical analyses correlating both parameters will be performed in this phase. Finally, reviewing and analysing the coverage of educational issues in texts published by international institutions entrusted with managing and safeguarding heritage.

F3: Using the SHEO method in order to trace, list and evaluate broad samples of educational programmes related to intangible cultural heritage on the basis of their didactic structure. The ultimate goal of this research phase is to determine their approaches, categories and correlations, as well as to detect gaps and presences in the field of heritage education. 
F4: Developing guidelines and quality standards for the educational design of future programmes on intangible cultural heritage. Contemplating limitations, future lines of action and plans for the dissemination and internationalisation of research outcomes.

The dissertation's main contribution to the discipline is the constitution of a whole line of heritage education targeted at intangible cultural heritage from an evaluative perspective. This will involve, on the one hand, the evaluation, in terms of heritagerelated contents, of the current educational legislation and the courses of study leading to a Teaching degree; and, on the other, the assessment of ICH educational programmes by implementing quality standards that make it possible to identify aspects capable of improvement and to develop decalogues of measures in order to enhance future practices.

\subsubsection{Justification of Research topic and relevance of the topic}

Heritage is particularly relevant, as a link between the past and the present and generating meanings of identity and social and cultural belonging (Apaydin, 2018). These heritage potentials are developed due to heritage education, which allows to generate links of belonging and identity between people and heritage assets (Fontal, 2013; Fontal \& Marín, 2018), promotes cultural literacy (Texeira, 2006), and promotes respect and appreciation of diversity guiding us towards a more just and inclusive society (Buckley \& Graves, 2016). In addition, heritage education is a key factor for the sustainable conservation of heritage, as we need to know and generate links with heritage assets, which generate inertias of protection and conservation (Fontal \& Juanola, 2015).

After highlighting the value of heritage education as a management and teachinglearning tool for the integral development of the person (Casanova, Arias \& Egea, 2018; Islamoglu, 2018; Mun, 2018), it is important to know the deficiencies and obstacles that exist when putting into practice this patrimonial formation. In the first place, we need to know what the presence and approach to heritage is within the framework of educational legislation, in order to discover if the curriculum adequately addresses the teaching of heritage, in which areas of knowledge through which preferential work methodologies. At the same time, we need to analyze if future primary education teachers are receiving 
sufficient training and acquiring the necessary skills that allow them to work teachinglearning strategies around heritage, since they will be responsible for moving it to the classroom and comply with educational legislation.

On the other hand, the research work as a member of the SHEO, has allowed us to analyze the total number of programs inventoried in the database, with which we detected that there is a high percentage of educational programs focused on the PCI that need to be analyzed and evaluated. The analysis of the programs previously inventoried in the database of the SHEO, responds to the intention of knowing the state of the question regarding the education of the $\mathrm{ICH}$ at the national level, which allows us to establish quality indicators for future designs.

This proliferation of educational programs on $\mathrm{ICH}$ is largely due to the regulations developed for its management, safeguarding and recognition, both at the international level and in the Istanbul Declaration on Intangible Heritage (UNESCO, 2002) and the Convention for the Safeguarding of the Cultural Intangible Heritage (UNESCO, 2003), as well as at the national level with the National Plan for the Safeguarding of the Intangible Cultural Heritage (Domingo \& Timón, 2011) and Law 10/2015 for the Safeguarding of the Intangible Cultural Heritage. All this is transferred to the society that begins to understand the cultural heritage with a more global approach and conformed by a material, immaterial and spiritual nature (Carrera, 2009). For this reason, we want to know and describe what the $\mathrm{ICH}$ is or should be, the associated values, the forms of recognition, the areas in which it is developed, as well as the dangers surrounding its safeguard, where education becomes a key factor (Ahmad, 2006; Ahmet, 2018).

The analyzes carried out in the SHEO since its inception (Fontal, Marín \& Pérez, 2013; Fontal \& Gómez-Redondo, 2016; Fontal \& Marín, 2016; Fontal \& Martínez, 2016a 2017, 2018; Marín et al., 2017) show that the educational designs of the proposals are not sufficiently described in terms of design, implementation and results. In addition, there is an explicit absence of evaluation systems, which hinders the improvement of educational practice. The need to evaluate educational actions around heritage is already enunciated in the National Education and Heritage Plan (Domingo, Fontal \& Ballesteros, 2013). This need for evaluation, presents as one of its main lines the evaluation of 
programs that allows the progress of the educational practice and guarantees the quality of the didactic designs (Pérez, 2000).

At the same time, there was an absence of validated instruments within the discipline, which evaluated educational practices and could provide us with objective information about the quality of the practices, the adequacy to the levels of implementation or the capacity of achievement and / or scope of the proposals (Soriano, 2014). In this sense, the observatory within its sequential method of analysis and evaluation of heritage education programs (SAEHEP-OEPE) has developed and validated the Q-Edutage scale with the intention of supplying this absence (Fontal et al., 2019).

The scientific production of the discipline has had a remarkable growth in the number and quality of research articles. At the same time, at the national level there has been an increase in the development of defended $\mathrm{PhD}$ thesis and $\mathrm{R} \& \mathrm{D} \& \mathrm{I}$ projects granted in national calls (Fontal \& Ibáñez-Etxeberria, 2017). It is important to know the evolution that is taking place around the discipline in a systematic way, therefore, in the theoretical framework we perform content analysis and descriptive statistics based on these three indicators of high impact quality (scientific publications, $\mathrm{PhD}$ thesis and national and international $R \& D \& I$ projects). At the same time, we believe it is necessary to clarify the conceptual debate generated around cultural heritage in recent decades, within the political-administrative and academic sphere. We must establish the theoretical and conceptual bases on which to build pillars that allow us to address in a solid way, the concept of cultural heritage from the discipline of education. 


\section{CAPITULO II Marco Teórico}

Erlköni. Lied op. 1 (Franz Schubert, 1815)

$[\square]$

Franz Schubert - Erlkönig (Sheet music and lyrics).mp3

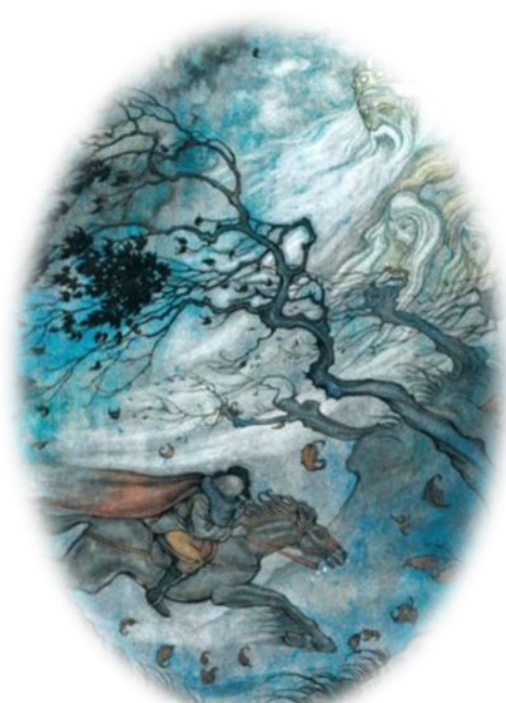

Erlkönig. (Lou van Strien, 1935) 



\section{Marco teórico}

\subsection{La dimensión inmaterial del patrimonio desde una perspectiva internacional: Evolución del concepto}

A lo largo de la historia los valores atribuidos a los bienes culturales han ido cambiando con motivo del dinamismo inserto en la conceptualización del Patrimonio Cultural, como construcción social, cultural y política (Pocock, Collett, y Baulch, 2015). Un constructo que cada grupo social reconoce, selecciona y adopta voluntariamente, y que permanece en una continua reformulación de contenido y de concepto. En este cambio de mentalidad, ha influido según Carrera (2009) el concepto antropológico de cultura que entiende el patrimonio cultural como la expresión de la identidad de un pueblo, y también como la representación simbólica de la misma. Otro aspecto confluyente y determinante hacia un concepto más amplio del patrimonio cultural ha sido el auge de los movimientos sociales en pro del reconocimiento de su diversidad y especificidad cultural (Arizpe, 2004), donde el patrimonio actúa como "marcador de la identidad" adoptado como elemento de cohesión o diferenciación y se convierte en una herramienta para los grupos olvidados y silenciados en las prácticas patrimoniales (Carrera, 2005; García, 1999). Estos dos aspectos son determinantes en el origen de nuevos valores identitarios atribuibles a otro tipo de bienes culturales centrados en las expresiones y manifestaciones de una comunidad (Fontal y Martínez, 2017). Así, se incorpora la dimensión intangible o inmaterial ${ }^{5}$ al concepto de patrimonio cultural, que permite facilitar la evocación de los procesos históricos en los que se han gestado los bienes y comprender la significación social de los mismos (González, 2016). Incluso autores como Pocock et al., dan un paso más y consideran que, "rather than identifying the physical expression of heritage as the initial point of heritage assessment, the stories (or intangible values) of a region or national history can form the primary mechanism for identifying physical heritage sites" (2015, p. 962).

Todo ello deriva en el replanteamiento social de la idea de patrimonio, donde el pensamiento decimonónico dominante durante los dos pasados siglos que se centraba en los grandes monumentos occidentales (Foley, 2014), va evolucionando y se va

\footnotetext{
5 En castellano se utilizan ambas acepciones mientras que los francófonos utilizan la fórmula de patrimoine culturel immatérielle y los anglófonos la de intangible cultural heritage.
} 
incubando una nueva forma de pensar que supone un profundo cambio en relación con lo que consideramos posible y necesario legar (Fontal y Martínez, 2016b). Se ha producido una valorización tanto global como globalizada de nuevas dimensiones del concepto de patrimonio, que hasta entonces no gozaban del reconocimiento institucional y social o bien eran menos preciados. En palabras de Santamarina, asistimos a una "democratización del patrimonio", como proceso de reconocimientos ya conocidos y de puesta en valor de nuevos referentes y agentes (2013). Este proceso, es moldeado por las cartas, recomendaciones y resoluciones adoptadas por los organismos internaciones como la UNESCO y el Consejo de Europa (Ahmad, 2006).

A continuación, hacemos un repaso al camino en el que la dimensión inmaterial del patrimonio se ha ido introduciendo en las normativas, declaraciones, recomendaciones y convenciones de los organismos internacionales, destacando los hitos fundamentales que han configuración su conceptualización, y que nos permitan conocer las causas que han influido en este proceso. Uno de los primeros vestigios sobre la aparición de un cambio de mentalidad fue la Convención para la protección del Patrimonio mundial, cultural y natural, de 1972, donde a pesar de clarificar sobremanera que su ámbito de actuación se limita a lo material, incluye un marco de salvaguarda del folclore de la mano de algunos países que lo consideran oportuno (UNESCO, 1972a). Esta convención según Santamarina supuso una de las transformaciones más significativas en la concepción del patrimonio en la posmodernidad, simboliza la ruptura de la noción clásica del patrimonio -globalización patrimonial- (2013, p. 271) y el comienzo de la expansión de la cosmocultura (Arizpe, 2004), donde el patrimonio se torna como un bien común de la humanidad que es necesario custodiar.

No fue hasta 1982 cuando en la Conferencia Mundial sobre las Políticas Culturales celebrada en México se utiliza por primera vez en las actas la expresión "Patrimonio Inmaterial”. A la conferencia acudieron representantes de 126 Estados Miembros, que solicitaron a la UNESCO ampliar los programas de salvaguarda para incluir el patrimonio inmaterial, otorgando especial atención a las tradiciones orales (UNESCO, 1982). Podemos apreciar que surge una creciente preocupación por sensibilizar a la sociedad sobre la cultura popular como elemento de identidad, la defensa de las tradiciones y los valores heredados del pasado, y se adopta la primera Recomendación 
sobre la Salvaguarda de la Cultura Tradicional y Popular en 1989, que define la cultura tradicional y popular como:

Conjunto de creaciones que emanan de una comunidad cultural fundada en la tradición, expresada por un grupo o por individuos y que reconocidamente responden a las expectativas de la comunidad en cuanto expresión de su identidad cultural y social; las normas y los valores se transmiten oralmente, por imitación o de otras maneras. Sus formas comprenden, entre otras, la lengua, la literatura, la música, la danza, los juegos, la mitología, los ritos, las costumbres, la artesanía, la arquitectura y otras artes (UNESCO, 1989, p. 254) .

Otro de los principales aspectos que influyeron en este proceso fue la Declaración Universal sobre la Diversidad Cultural, donde se comienza a reflejar la importancia de entender el patrimonio inmaterial como crisol y a la vez fuente de riqueza de la diversidad cultural. En su artículo 7, El patrimonio cultural, fuente de la creatividad se afirma que:

Toda creación tiene sus orígenes en las tradiciones culturales, pero se desarrolla plenamente en contacto con otras culturas. Esta es la razón por la cual el Patrimonio, en todas sus formas, debe ser preservado, realzado y transmitido a las generaciones futuras como testimonio de la experiencia y de las aspiraciones humanas, a fin de nutrir la creatividad en toda su diversidad e inspirar un verdadero diálogo entre las culturas (UNESCO, 2001a, Art. 7).

Un año después, en septiembre de 2002, la III Mesa Redonda de Ministras y Ministros de Cultura apoyó la Declaración de Estambul sobre Patrimonio Inmaterial, que entiende el Patrimonio Cultural Inmaterial como:

Un conjunto vivo y en perpetua recreación de prácticas, saberes y representaciones, que permite a los individuos y a las comunidades, en todos los niveles de la sociedad, expresar las maneras de concebir el mundo a través de sistemas de valores y referencias éticas. El patrimonio cultural inmaterial crea en las comunidades un sentido de pertenencia y de continuidad y es considerado como una de las fuentes principales de la creatividad y de la creación cultural. En esta perspectiva es conveniente establecer un enfoque global del patrimonio cultural que dé cuenta del lazo dinámico entre patrimonio material e inmaterial y de su profunda interdependencia (UNESCO, 2002, Art. 2). 
El PCI se comienza a entenderse como un elemento vivo, que genera sentimiento de pertenencia a una comunidad (Agulló, 2010). Así la concepción se va ampliando hacia un enfoque más global, que defiende la interdependencia de su doble naturaleza (Craith y Kockel, 2016). Estos antecedentes sirven como base de las reuniones intergubernamentales que desembocan en la Convención para la Salvaguarda del Patrimonio Cultural Inmaterial aprobada el 17 de octubre de 2003 (Aikawa, 2004). Esta convención equipara en su marco normativo a la Convención para la protección del Patrimonio mundial, cultural y natural, de 1972. Establece treinta años después la igualdad conceptual entre el patrimonio cultural e inmaterial generando una Lista del Patrimonio Inmaterial de la humanidad y dotándolo de un cuerpo jurídico. En su artículo 2 acuña y define el término PCI como:

Los usos, representaciones, expresiones, conocimientos y técnicas -junto con los instrumentos, objetos, artefactos y espacios culturales que les son inherentes- que las comunidades, los grupos y en algunos casos los individuos reconozcan como parte integrante de su patrimonio cultural. Este patrimonio cultural inmaterial, que se transmite de generación en generación, es recreado constantemente por las comunidades y grupos en función de su entorno, su interacción con la naturaleza y su historia, infundiéndoles un sentimiento de identidad y continuidad y contribuyendo así a promover el respeto de la diversidad cultural y la creatividad humana. (UNESCO, 2003 , art. 2)

Dos años más tarde en la Convención sobre la Protección y la Promoción de la Diversidad de las Expresiones Culturales, se hace alusión explícita a la riqueza de la diversidad cultural y reconoce:

La importancia de los conocimientos tradicionales como fuente de riqueza inmaterial y material, en particular los sistemas de conocimiento de los pueblos autóctonos y su contribución positiva al desarrollo sostenible, así como la necesidad de garantizar su protección y promoción de manera adecuada (UNESCO, 2005, p. 2).

Este es el momento en el que las comunidades y los grupos sociales se convierten en actores protagonistas y se reafirma la idea de que el PCI promueve el respeto y la diversidad cultural y potencia la creatividad humana, siempre desde la óptica del respeto. Es importante recordar que la convención es un instrumento normativo pero que no puede ser aplicada por sí misma, sino que son los estados miembros con su aceptación los encargados de poner en marcha sus acciones. Esta Convención fue adoptada por los 
Estados Miembro con gran rapidez en comparación con la Convención de 1972 o la Convención de La Haya de 1954. Sobre el motivo de la agilidad para ratificar la convención por los Estados Miembros coincidimos con González (2016) al atribuir esta premura a la consideración de los bienes inmateriales como elemento fundamental de la construcción de las identidades nacionales (Prutsch, 2017). Esta preocupación ya surge y se mantiene desde los nacionalismos del siglo XIX, con el interés por el origen de los monumentos nacionales, originalmente constituidos por obras de arquitectura. A lo largo de este proceso, es evidente que los bienes patrimoniales han dejado de ser percibidos como exclusivamente tangibles o materiales, pero aun así se han seguido aplicando las etiquetas.

Otro de los organismos que también ha contribuido en buena medida a desarrollar la gestión y la formación de la conciencia europea sobre estos bienes inmateriales, ha sido el Consejo de Europa. En su Recommendation No R (98) 5 of the Committee of Ministers to Member States Concerning Heritage Education define el patrimonio cultural europeo, tanto tangible como intangible como:

Our common wealth - our inheritance from previous generations of Europeans and our legacy for those to come. It is an irreplaceable repository of knowledge and a valuable resource for economic growth, employment and social cohesion. It enriches the individual lives of hundreds of millions of people, is a source of inspiration for thinkers and artists, and a driver for our cultural and creative industries. Our cultural heritage and the way we preserve and valorise it is a major factor in defining Europe's place in the world and its attractiveness as a place to live, work, and visit (Committee of Ministers, 1998).

En este punto debemos destacar la fuerte convicción del Consejo de Europa de que la riqueza del patrimonio cultural europeo común, reside en la diversidad de manifestaciones. Al mismo tiempo, en su Resolution (85) 6 on European cultural identity señala que las tradiciones comunes y la identidad europea, como productor de una historia cultural común, no están delimitadas por las fronteras que separan los diferentes sistemas políticos en Europa (Committee of Ministers, 1985). En esta misma línea Lähdesmäki defiende que las iniciativas de la Unión Europea "seek to make a European cultural heritage concrete by fixing its abstract and intangible meanings to material objects and physical sites”. (Lähdesmäki 2016, p. 768). 
En la Convention on the Value of Cultural Heritage for Society, firmada por España en diciembre de 2018, se define el patrimonio cultural como:

A group of resources inherited from the past which people identify, independently of ownership, as a reflection and expression of their constantly evolving values, beliefs, knowledge and traditions. It includes all aspects of the environment resulting from the interaction between people and places through time (Council of Europe, 2005).

En esta definición están presentes términos relativos al campo semántico del patrimonio inmaterial como son la palabra expresiones o tradiciones, que generan un concepto de patrimonio que es global en su naturaleza. También es importante destacar la alusión explícita a la necesidad relacional entre el entorno y las personas como origen de cualquier bien patrimonial (Fontal, 2013).

Sin duda esta dimensión más intangible está fuertemente relacionada en los textos del Consejo de Europa con la diversidad cultural y la identidad. En este sentido la Asamblea Parlamentaria, en su Recommendation 2038 Europe's endangered heritage, destaca la importancia del patrimonio en la configuración de la identidad cultural individual y colectiva y en la promoción del entendimiento mutuo (Parlamentary Assembly, 2014). Esta recomendación aunque también hace alusiones al patrimonio material centra su atención en los bienes inmateriales, más frágiles en los aspectos relativos a su salvaguarda y reafirma la necesidad de preservar la estabilidad democrática en Europa dentro de las sociedades interculturales, mediante el cultivo de sociedades abiertas, vibrantes, culturalmente diversas y cohesivas. La relación del patrimonio cultural con la identidad es desarrollada en numerosos artículos de la Communication from the Commission to the European Parliament, the European Council, the Council, the European Economic and Social Committee and the Committee of the Regions. Toward an integrated approach to cultural heritage for Europe, que destaca que los valores culturales locales "artistic, literary, audiovisual and architectural creation, creative work, contemporary culture, crafts, folklore, archaeological, historical and ethnographic heritage, dialects, music, food and gastronomy, countryside and natural features, traditional expertise and knowledge, know-how, living traditions, etc." (European Comission, 2014, art.12) están fuertemente ligados a la identidad, que está enraizada en el patrimonio tangible, intangible y natural de las comunidades. Se hace hincapié en que es el PCI el que determina la identidad de una región y que se fomenta el desarrollo 
regional haciendo un buen uso de esta y defiende que en la cooperación transfronteriza y transnacional, se han registrado numerosos ejemplos de buenas prácticas en el diseño de estrategias basadas en recursos culturales intangibles (European Comission, 2014, art.13).

A continuación, presentamos una línea del tiempo con los hitos fundamentales en el desarrollo conceptual del término PCI en la normativa internacional.

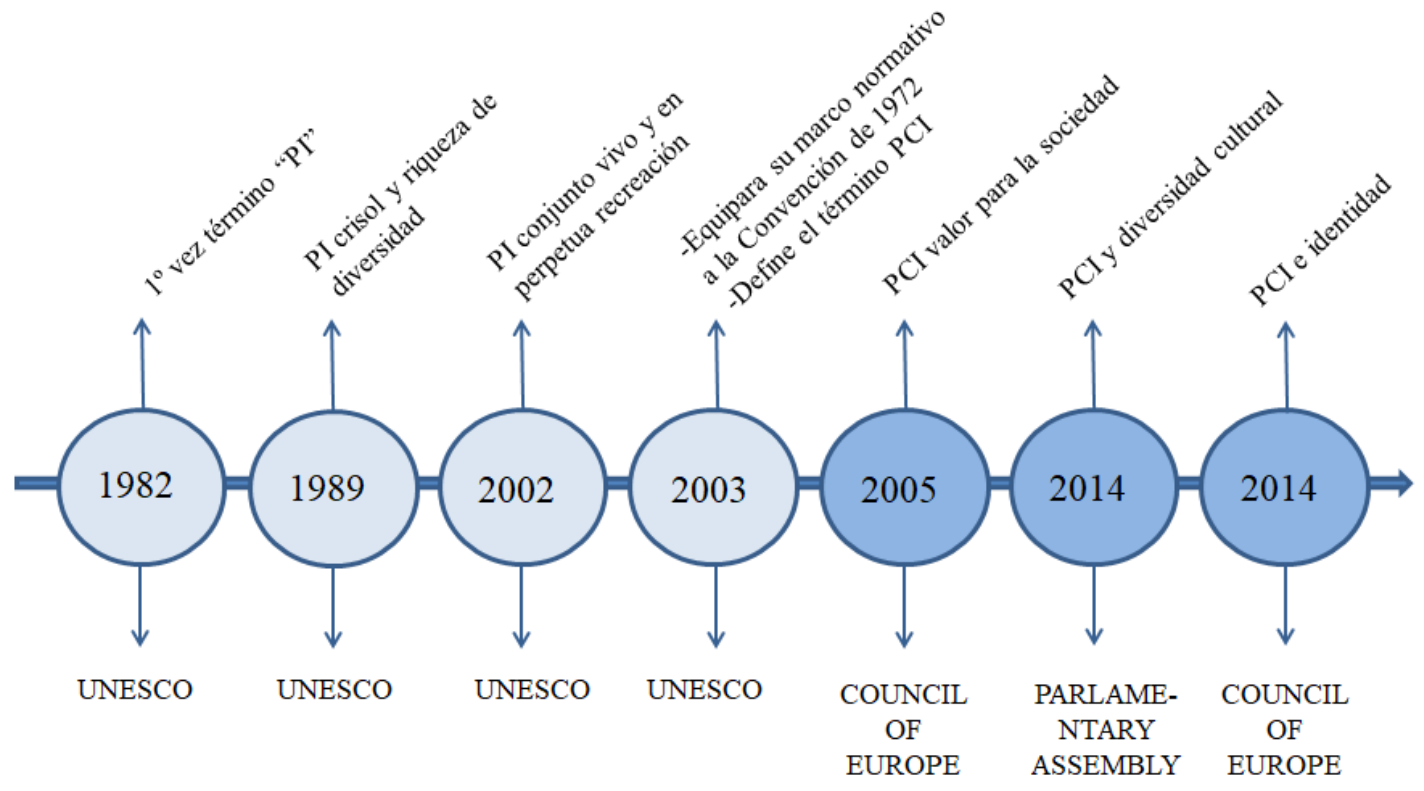

Figura 1. Línea del tiempo sobre la evolución del PCI en la normativa internacional.

Desde que el discurso político internacional reconoce como patrimonio, tanto los objetos tangibles como las manifestaciones intangibles (Vecco, 2010), la académica ha debatido y teorizado sobre la dicotomía tangible e intangible generada dentro del concepto patrimonio cultural (Ahmad, 2006; Malpas, 2008; Pocock et al., 2015). Una primera vertiente afirma que la polarización entre patrimonio tangible e intangible responde a distinciones institucionales, organizativas y asumidas (Kuutma, 2012). Por otro lado, varios estudios rechazan la dicotomía categórica entre ambas dimensiones, y argumentan que estas están estrechamente vinculadas y entrelazadas en un sentido epistemológico debido a su naturaleza, aunque presenten una divergencia semántica según la normativa internacional (Munjeri, 2004; Smith y Akagawa, 2009; Lähdesmäki, 2016). Desde nuestro punto de vista y de acuerdo con González esta dicotomía se trata de una "separación artificiosa y construida, falaz y simplista que, no obstante, ha resultado práctica para la gestión del Patrimonio Cultural Inmaterial (2016, p. 6). Pero esta nueva 
conceptualización no debe ser simplemente el resultado de la introducción de la tipología patrimonio inmaterial, sino que debe considerarse un proceso más complejo, estimulado por un replanteamiento social de la idea general de patrimonio (Bortolotto, 2010; 2015). Autores como Lähdesmäki (2016), plantean la existencia de un proceso cíclico entre lo tangible e intangible en el discurso político sobre patrimonio, y consideran que, debido a su naturaleza situacional, relacional y discursiva, estas dimensiones están en constante movimiento. Coincidimos con la idea de una naturaleza móvil entre ambas dimensiones y dinámica, puesto que al estar integrada en la vida de una comunidad se modifica con ella. Consideramos el patrimonio intangible como un patrimonio emergente, tanto a nivel conceptual como semántico, ya que partimos de un dinamismo intrínseco en la conceptualización del término patrimonio cultural. Entendemos así, que la conceptualización del patrimonio es líquida (Bauman, 2000), y seguirá avanzando en un sentido rizomático, generando nuevos elementos y valores. Esta evolución es explicada por Maffesoli que toma como referencia la concepción del filósofo Nicolás de Cuse sobre la forma de espiral que adopta la posmodernidad, y nos habla del patrimonio como "una experiencia viva ligada a las raíces locales, donde las relaciones no son ni mecánicas, ni predecibles, ni controladas por la razón” (2018, p. 245). Por ello, consideramos el patrimonio como un proceso social que no puede ser pensado como un conjunto de compartimentos neutros y estancos. En esta misma línea, podemos relacionar su conceptualización con la idea de "capital cultural" de Bourdieu (1997) que se acumula, se reconvierte y es apropiado en forma desigual. 


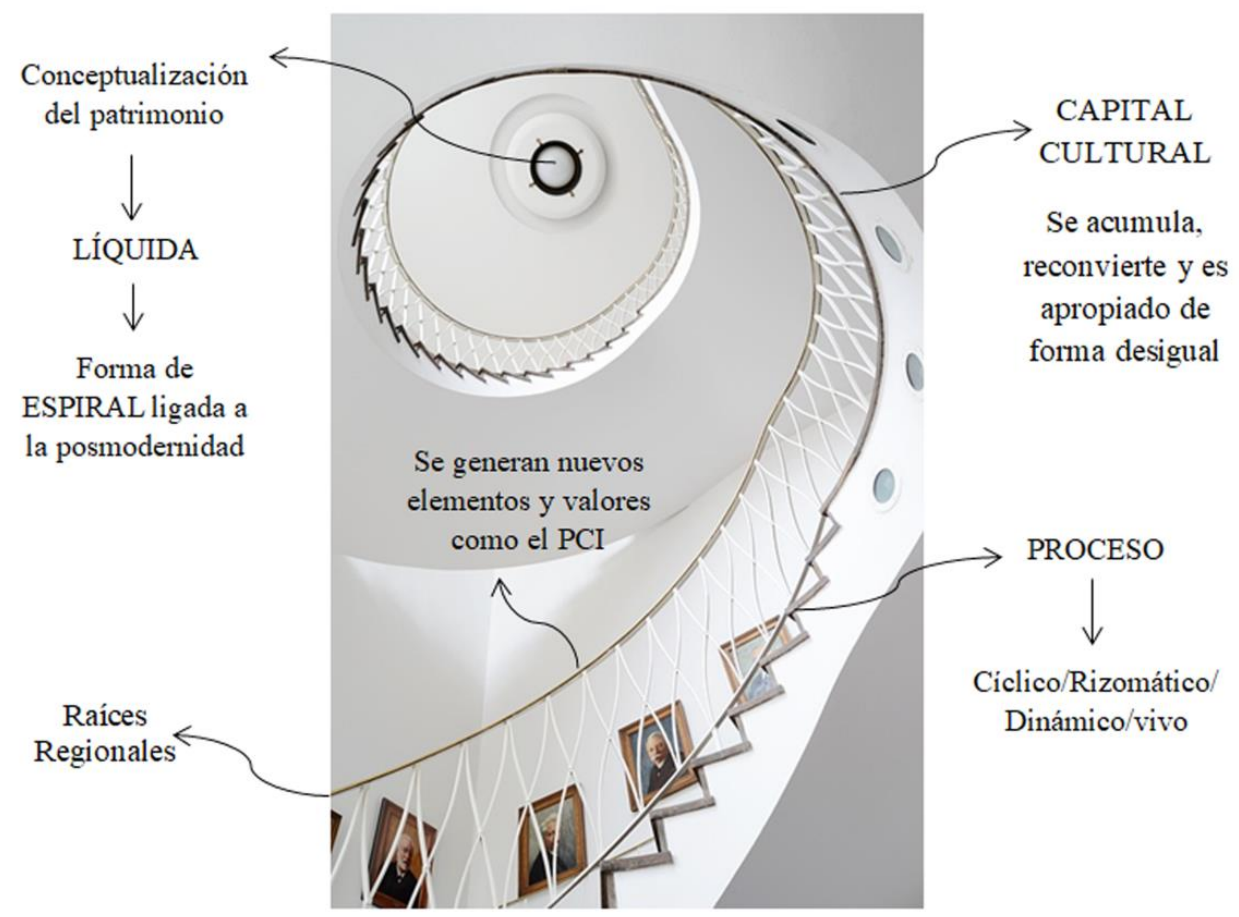

Figura 2. Dinamismo inserto en la conceptualización del Patrimonio Cultural.

En el momento que aceptamos e interiorizamos esta conceptualización dinámica y cambiante, estamos asumiendo que los bienes culturales no tienen un valor intrínseco y objetivo, si no que esos valores son atribuidos por el hombre. En este sentido, resta señalar que el patrimonio no es una realidad inmanente que se descubre, sino un constructo social y político marcado por la invención, el pasado y la identidad (Hobsbawm y Ranger, 1988; Lowenthal, 1998, Prats, 1997). Fontal (2013) entiende el patrimonio como un objeto donde el valor patrimonial reside en el vínculo entre el patrimonio y las personas. Es el individuo quien, al otorgar valores, da identidad a la obra y se identifica frente a ella -identización individual-, o con ella frente a la sociedad en un proceso en el que la obra forma ya, parte del yo -identización colectiva- (Ballar y Tresseras, 2001; Gómez-Redondo, 2013). Estos valores atribuidos, derivan de la experiencia y de las relaciones y dan lugar al proceso de patrimonialización (Fontal y Gómez-Redondo, 2016) que transforma los bienes culturales en patrimonio.

Por tanto, en la medida en que comprendemos que el hombre es el que otorga y da valor a los bienes a través del desarrollo de vínculos, entendemos la posibilidad de miradas hacia el patrimonio (Fontal, García-Ceballos e Ibáñez-Etxeberria, 2015). Tras todo lo argumentado, debemos defender que cualquier futura definición de patrimonio debe ser 
"siempre abierta, negociable, dialógica, transformadora y reflexiva" (Santamarina, 2013, p. 48), y en la cual deben participar distintos operadores sociales. Autores como Tiley (2006) o Smith (2006) hacen hincapié en la necesidad de que los individuos sean agentes activos en este proceso de mediación. Para definir el patrimonio, se parte de múltiples visiones: antropológica, temporal y socio-crítica (Lowenthal, 1985; Sibony, 1998), a lo que se suman un enfoque holístico (Cuenca, 2002) y las relaciones identitarias que confluye en el enfoque relacional planteado por Fontal (2013). Desde este enfoque, donde entendemos que el patrimonio se construye de forma relacional entre bienes y personas se generan los vínculos patrimoniales, que pueden comprenderse según Fontal y Marín como, "una suerte de puente entre las personas y el contexto en el que viven. Son construidos y proyectados por las personas hacia su entorno cultural, ya sean bienes patrimoniales tangibles, intangibles, situaciones, experiencias, vivencias y, sobre todo, otras personas" (2018, p. 485). Las autoras expones que estos hilos son los que constituyen el andamiaje identitario del individuo. Este andamiaje identitario está, por tanto, en continuo proceso de construcción a lo largo de la vida desde la esfera emotiva y cognitiva (Capel, 2014; Gómez-Redondo, 2013), donde interviene el bagaje de la persona que podríamos denominar universo referencial (Rodrígo, 2003, p. 299 citado en Gómez-Redondo, 2012).

\subsection{Del folclorismo a la salvaguarda del PCI: La educación como conclusión lógica.}

El término folclore o cultura tradicional se ha venido utilizando en la normativa internacional hasta que el término de Patrimonio Inmaterial aparece en las actas de la Conferencia Mundial sobre las Políticas Culturales celebrada en 1982. Aunque no es hasta la Conferencia Internacional Evaluación global de la Recomendación de 1989 sobre la salvaguarda de la cultura tradicional y popular: autonomía local y cooperación internacional celebrada en Washington, donde se remarca de manera explícita la petición de no emplear la palabra folclore -por las asociaciones históricas negativas/peyorativas contenidas en su enunciado- proponiéndose en su lugar la fórmula de "patrimonio cultural inmaterial" (UNESCO, 1998). La necesidad de crear un nuevo instrumento vinculante para proteger lo que ya se había consagrado como "patrimonio cultural inmaterial" se comienza a debatir y culmina con el Estudio preliminar sobre la conveniencia de regular internacionalmente, a través de una nueva norma. Instrumento, 
la protección de la cultura tradicional y el folclore por Janet Blake en el año 2001, que se examinó en una reunión de expertos en la ciudad de Turín (Italia), que emitió un dictamen favorable y aprobó un Plan de Acción, antes de su evaluación y aceptación por la Asamblea General de la UNESCO (Arante, 2019). Uno de los puntos a destacar de este estudio es que considera inadecuado el uso del concepto de folclore e insta a la UNESCO a "utilizar la terminología y las definiciones de trabajo" propuestas en el Plan de Acción de Turín (UNESCO, 2001b). Ese mismo año, Koichiro Matsuura, el entonces Director General de la UNESCO, también presentó un informe en defensa del uso de la expresión "Patrimonio Cultural Inmaterial" en lugar de "Folclore" (Brugman, 2005, p. 60), abogando por la necesidad de promover. En este informe presenta el primer borrador con la definición y los ámbitos de manifestación del Patrimonio Inmaterial. Según Santamarina (2013) asistimos a un "re-bautizo" (vieja política discursiva de las prácticas hegemónicas cuando sufren alguna perturbación o crisis) de lo antes llamado científicamente "folck-lore" (pueblo-conocimiento, saber del pueblo). Bortolotto interpreta el folclore como "el producto de una documentación cosificada (un objeto artesanal que se halla en un museo, una leyenda transcrita por un etnólogo, un canto transcrito por un etno-musicólogo)". En cambio, entiende el PCI, “como el proceso contextual de recrear esos elementos a manos de los mismos grupos que, mediante esas operaciones, inician un proceso de identificación cultural” (2014, p. 7). Otros autores consideran que existen relaciones y diferencias entre las problemáticas que encierran ambos términos (Santamarina, 2013; Ortiz, 2012), o que el PCI sería simplemente un elemento más que cabe en el marco del primero (Santoyo, 2010). Por lo tanto, es necesario que presentemos y analicemos el conjunto de ideas y características que dan lugar al folclore para establecer sus relaciones y diferencia con el PCI.

En primer lugar, podemos definir el folclore, según Martí (2000), como el legado de tipo tradicional del medio rural de cuya existencia y valor se tomó conciencia con el romanticismo y el nacionalismo, que instrumentalizó el folclore como marcador de etnicidad y pertenencia a una comunidad. A finales del S. XIX se comienza a producir una progresiva desaparición del folclore, y esta progresiva desaparición en conjunto con el surgimiento de los regionalismos a nivel nacional, provocó que la población del medio urbano tomara conciencia en la necesidad de conservación y difusión de este legado tradicional (Carrera, 2015). De modo, que estas manifestaciones culturales que eran una manera de vida en el pasado, sufrieron un proceso de instrumentalización en la nueva 
sociedad urbana, y estas nuevas prácticas, que ahora tenían fines políticos, estéticos o comerciales, recibieron el nombre de folclorismo. Uno de los principales aspectos que debemos destacar en torno al folclorismo según Martí es la "instrumentalización social y política que le rodea, y que se ve impulsada en los ámbitos geográficos con un fuerte sentimiento de diferencialidad étnica" (Martí, 2000, p. 13). Así el folclorismo cae en manos del regionalismo y se convierte en un caracterizador.

Por ello, debemos apelar a un uso crítico del folclorismo y al conocimiento de su funcionamiento para poder aportar valores positivos para nuestra sociedad y huir de finalidades idealistas. Esta problemática es compartida por el PCI, ante la avidez de consumo patrimonialista (Heinich, 2008), contraria a la propia edificación de su concepto como bien escaso (Lacarrieu, 2008). A pesar de los lineamientos establecidos por la Convención de la UNESCO del 2003, la patrimonialización de las expresiones culturales con frecuencia resulta en la folclorización, mercantilización y alteración del sentido sociocultural de dichas prácticas debido a que la autoridad de las proclamaciones sigue recayendo en los actores institucionales, quienes aún poseen una visión esencialista y consensual de la cultura, impregnada de concepciones tradicionalistas (Villaseñor y Zolla, 2012). En este sentido el marketing heritage en palabras de Santamarina ha introducido la etiqueta inmaterial que ha ido ganando la partida, al imponerse "nuevos modelos de consumo patrimonial neoliberal, mercantilizando a sujetos y objetos, que responden a tecnologías gubernamentales” (2013, p. 266).

Según Ortiz (2012), la noción de folclore presenta tres características que son importantes analizar:

1. Ha de ser tradicional, o lo que es lo mismo, su transmisión pasa de generación a generación, como una base cultural del pueblo.

2. Será anónimo, esto quiere decir que es de autor desconocido.

3. Este saber es colectivo, o sea, conocido y compartido por una gran parte de los miembros de una determinada cultura o comunidad (pp.76-78).

Dentro de estas características se hace remarcable la idea de pueblo en estrecha relación con los términos de comunidad o colectivo. También se utiliza una idea de pueblo como nación asociada a su identidad, y la idea de tradición relacionada con la transmisión, la cultura y el pasado. Por tanto, en el campo semántico y subyacente al concepto del folclore nos encontramos las palabras de pueblo, identidad y tradición. Así, podemos 
resumir que las expresiones folclóricas son concreciones de estos tres aspectos, cuya interpretación se da en el marco general de la construcción de una nación. El término de -nación (Estado)- como "único modelo para ordenar y organizar a las sociedades a nivel político, socioeconómico y cultural desde el siglo XVII, se convierte en el punto de referencia más extendido de identidad colectiva" (Prutsch, 2017, p. 17)

Una de las principales problemáticas en torno al folclorismo es la autenticidad, ya que la manera de rescatar el folclore en muchas ocasiones es artificial y recreada, y ello provoca la pérdida de la etiqueta de originalidad ligada a las manifestaciones tradicionales (Martí, 2000, p. 19). Por ello, no se deben adoptar posturas que fosilicen o cristalicen dichas manifestaciones, sino que las manifestaciones deben ser mutables y adaptarse a los nuevos intereses de la sociedad urbana, aunque sin olvidar la comunidad portadora. En lo relativo a la autenticidad ligada a la tradición, la Convención para la Salvaguarda del Patrimonio Cultural Inmaterial (en adelante), la Recomendación de 2003), nos dice que el PCI es tradicional, pero también nos dice que es contemporáneo y viviente a un mismo tiempo, ya que no solo incluye tradiciones del pasado, sino también usos rurales y urbanos contemporáneos característicos de diversos grupos sociales (UNESCO, 2003). Este camino en el cambio de conceptualización de la autenticidad comenzó con la Declaración de Nara sobre la autenticidad, celebrada en Japón en 1984, que reclamaba una ampliación del concepto de autenticidad como modelo disciplinario exportado y revindicó la autenticidad como una construcción social, reconociendo así el relativismo cultural del término (Bartoloto, 2010). Por tanto, el concepto de tradición adopta un nuevo sentido enmarcada dentro del PCI. No debe ser entendido como un constructo atemporal, inmutable y sin presente ni futuro, que ata a los actores a un pasado invariable (Barañano, García, Cátedra, y Devillard, 2007), sino como una articulación entre pasado y presente en la que la mezcla y adecuación de las prácticas pasadas con el tiempo actual, proporciona una continuidad espacio-temporal que permite tanto situar nuestros orígenes como dotarnos de sentido de pertenencia a un grupo (Hernández y Martí, 2005 citado en González, 2016). La tradición no es, por tanto, el conjunto de costumbres de una época sino un "elemento dinámico que se configura progresivamente con el influjo de cada período" (Ortiz, 2012, p. 69).

El interés actual de nuestra sociedad por el folclore o la cultura tradicional se puede manifestar de manera pasiva y de manera activa. En este segundo caso, se incluyen las 
actitudes que tratan de reproducir la tradición fuera de su contexto original (espacio, tiempo, función). Esta vivencia de la vivencia, sufre una descontextualización y en ocasiones es denominada "tradición de segunda mano" (Martí, 2000, p. 20). En torno a este aspecto, se genera una preocupación sobre la transformación que han sufrido ciertas tradiciones para adaptarse a los gustos y necesidades de un público predominantemente urbano, perdiendo relación con su origen. Este hecho parece un proceso natural, ya que el folclorismo se piensa desde el presente y remite a un pasado rural idealizado. Por ello, una de las principales características del folclorismo es su pertenencia a dos realidades diferentes, distantes entre sí por el tiempo y/o el espacio (Iglesias, 1991). Esta doble pertenencia del folclorismo a dos realidades, provoca una discontinuidad que se opondría a la continuidad que ofrece el folclore y que puede desembocar en un espectáculo folclorístico grotesco o cómico cuando estas realidades no se presentan bien ensambladas (Martí, 2000)

Por el contrario, el Patrimonio Cultural Inmaterial no busca validar su autenticidad con la similitud o la relación con su origen (Bendix, 2009; Smith y Akagawa, 2009), ya que este no es una vivencia de una vivencia, sino que podemos decir que éste es vivo, cambiante y evoluciona constantemente ante la necesidad de adaptarse a los "nuevos usos y funciones" de las que ya nos hablaba el antropólogo y etnomusicólogo Alan Merrian (1964, p. 210) que la comunidad portadora le otorgue. A este respecto la Convención de 2003 nos dice que el PCI solo puede serlo si es reconocido como tal por las comunidades, grupos o individuos quienes lo crean, mantienen y transmiten (UNESCO, 2003). Sin este reconocimiento, nadie puede decidir por ellos que una expresión o un uso determinado forman parte de su patrimonio. La comunidad puede realizar cambios conscientes sobre la tradición, "adoptando sus características culturales a los procesos de modernización" (González, 2016, p. 7), e incorporando rasgos característicos de la sociedad post-moderna (Maffesoli, 2018).

Tanto en el folclorismo como en la salvaguarda del patrimonio cultural inmaterial, está presente la preocupación por el cambio y la vulnerabilidad de las expresiones culturales. En el primero, el gran peligro para las expresiones culturales es el proceso de modernización, mientras en el segundo lo es la globalización. 


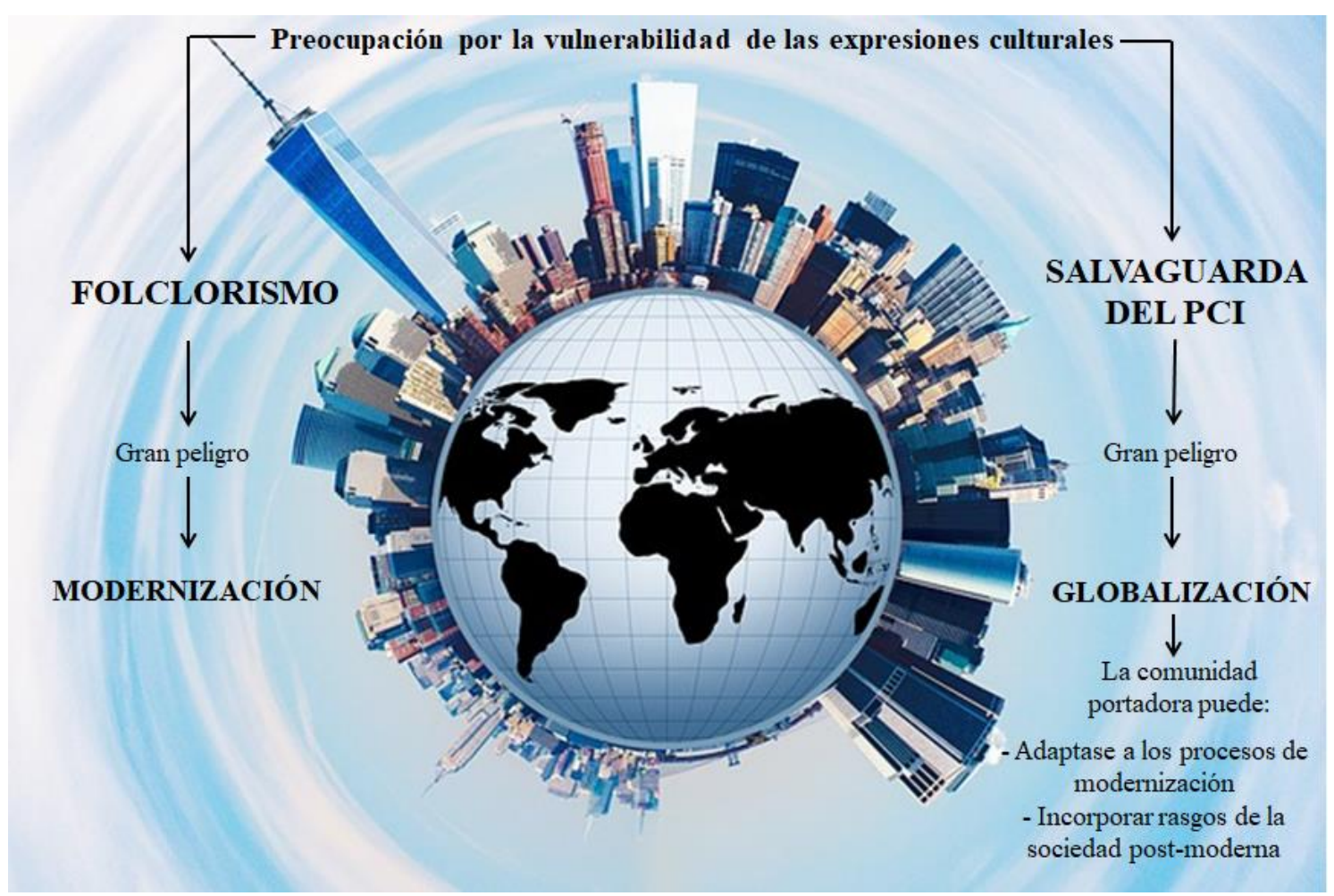

Figura 3. La modernización como peligro para el folclore y la globalización para el PCI.

Según Santoyo (2010), el primer elemento amenazador para el folclore, asociado a la modernización, es la inclusión de elementos mecánicos en la elaboración o ejecución de los hechos folclóricos. Por consiguiente, los grupos populares urbanos son percibidos como agentes disruptivos que atentan contra el purismo que se pretende rescatar con la ejecución aséptica. Al negar cualquier posibilidad de considerar como folclor las expresiones populares urbanas, acentuando la oposición, ya señalada por Williams (1972), entre el urbano y rural. En este punto se encierra una paradoja importante, ya que si no existiera un proceso de modernización o cambio, no existiría la preocupación social por establecer y difundir nuestros orígenes.

Por otro lado, la globalización que amenaza al PCI, hace referencia "a procesos que se dan en el orden mundial cuyos efectos se hacen sentir en lugares específicos, propendiendo por un nuevo acomodamiento de las sociedades nacionales" (Santoyo, 2010, p. 121). Así el PCI en su discurso global, actúa como herramienta para la difusión de ideas universales como podemos ver en su definición que hace alusión a la promoción de la diversidad cultural, la creatividad humana, los derechos humanos y al desarrollo sostenible (UNESCO, 2003). También se rompe la idea del patrimonio como símbolo de 
la identidad nacional ya que se desarrollan nuevas manifestaciones que no tienen vinculación con la idea de Estado-nación.

En cuanto a la posición que ocupa el término PCI con respecto al folclore y viceversa, Ochoa (2003) consideran que el término PCI desplaza al de folclore, aunque hereda muchos de sus rasgos. Sin embargo, el término de patrimonio inmaterial "posee más conflictos que el de folclore" (Ochoa, 2003, p. 115). En primer lugar, el término inmaterial o intangible encierra una trampa dialéctica, ya que remite a la no existencia material o la imposibilidad de dar forma. Esta paradoja terminológica según Santamarina adquiere sentido en su relación con "el poder, en su acepción más versada y sintética: como capacidad de generar verdad -autenticidad- a partir de la definición de la realidad" (2013, p. 268). Por lo tanto, en su configuración conceptual influyen por un lado los procesos constitutivos genealógicos, y en la otra vertiente, la racionalidad que ha delimitado las demarcaciones gracias a normativas reguladoras. Además, podemos decir que el PCI viene definido por su indefinición, ya que es un concepto que se define a través de la condición relación (in-) con el patrimonio material que hace que epistemológicamente presente un grado menor por su dependencia, y también a través de la negación, que inevitablemente conlleva valoraciones negativas de negación, prohibición, censura, etc. (Santamarina, 2013). Es en este punto donde debemos destacar que todas estas demarcaciones y adjetivaciones remiten a un valor intrínseco, por tanto, al negar el significado semántico considerando el lenguaje como un producto ideológico, es necesario tratar de realizar la difícil tarea de matizar y delimitar un concepto indefinido que permite la entrada a toda suerte de manifestaciones. Según la Convención de 2003, este se manifiesta en los siguientes ámbitos:

a) Tradiciones y expresiones orales, incluido el idioma como vehículo del patrimonio cultural inmaterial;

b) Artes del espectáculo;

c) Usos sociales, rituales y actos festivos;

d) Conocimientos y usos relacionados con la naturaleza y el universo;

e) Técnicas artesanales tradicionales (UNESCO, 2003, art. 2).

A continuación, presentamos una tabla que resume las diferencias de concepto que hemos desarrollado a lo largo de este epígrafe sobre el folclore y el Patrimonio Cultural Inmaterial. 
Tabla 1

Comparativa de términos pertenecientes al folclore y al Patrimonio Cultural Inmaterial

\begin{tabular}{|c|c|}
\hline Folclore & Patrimonio Cultural Inmaterial \\
\hline Acento en la distinción & Énfasis en la diferencia \\
\hline Tradicional & Tradicional, Contemporáneo y viviente \\
\hline Rural & Rural y urbano \\
\hline Modernización & Globalización \\
\hline Colonialismo & Nuevo imperialismo "Globalización" \\
\hline Símbolo de identidad nacional & No perpetua la idea de Estado-Nación \\
\hline Conservación & Salvaguarda \\
\hline
\end{tabular}

Definir los problemas conceptuales nos permiten, por un lado, entender el discurso del PCI, y por otro, como señala Lacarrieu (2008) abordar la gestión del mismo. Los diferentes instrumentos de gestión del PCI se han ido desarrollando paralelamente al interés por desarrollar un instrumento jurídico internacional para su protección. Un hito importante en este proceso se produce en 1989 cuando la UNESCO en La Recomendación sobre la Salvaguarda de la Cultura Tradicional y Popular adoptada en Paris, señala que "la cultura tradicional y popular forma parte del patrimonio universal de la humanidad". Esta afirmación abre las puertas a que los bienes inmateriales puedan englobarse en el concepto de patrimonio mundial y es el punto de partida al conjunto de actividades con el objetivo de salvaguardar el PCI que inicia la UNESCO. En 1992 se creaba la Sección de Patrimonio Cultural Inmaterial de la UNESCO. Un año después gracias al acuerdo entre Japón y Unesco se origina el Funds-in-Trust for the Preservation and Promotion of the Intangible Cultural Heritage. Según Bortolotto (2010) Japón adquiere un lugar privilegiado en la definición del paradigma de patrimonio inmaterial de la UNESCO. Ese mismo año, en 1993, se crea a propuesta de la República de Corea, el programa de Tesoros Humanos Vivos, que buscaba otorgar reconocimiento oficial a los portadores y practicantes de la tradición contribuyendo así a la transmisión de sus conocimientos y habilidades a las generaciones más jóvenes. Estos eran definidos como "individuos que poseen en grado sumo las habilidades y técnicas necesarias para crear o producir determinados elementos del Patrimonio Cultural Inmaterial, y que son testimonio de sus tradiciones culturales vivas y del talento creativo de grupos, comunidades o individuos presentes en su territorio" (UNESCO, 1993).

A finales de la década de los noventa, se crea una distinción para el patrimonio intangible como Patrimonio de la Humanidad en la Consulta internacional de Expertos 
sobre la preservación de Espacios Culturales Populares (UNESCO, 1997) con la intención de aspirar a la Lista del Patrimonio Mundial. Según Santamarina, esta búsqueda de la distinción universal "fue simbólica ya que la denominación y el procedimiento eran distintos por lo que la equivalencia no era total” (2013, p. 274). Este reconocimiento no tuvo lugar hasta la llegada del programa de Obras Maestras del Patrimonio Oral e Intangible de la Humanidad adoptado por el Consejo de Ejecutivos de la UNESCO en 1998. Se comenzaba a vislumbrar la idea de elaborar un convenio y un inventario de Patrimonio Oral Inmaterial. Este concepto de patrimonio de la Humanidad es una producción metacultural que genera diferencias y desigualdades a partir de una jerarquización global de valores (Kirshenblatt-Gimblett, 2004). Esta jerarquización de valores hace peligrar desde nuestro punto de vista el entramado de significados y valores que cada individuo construye para sí a lo largo de la vida y que el sociólogo Bauman acuña como "Hábitat de significado".

Todos estos antecedentes servirían de base a la Convención de 2003, que presenta novedades en su marco de protección y adopta el término de Salvaguarda frente al de conservación. La idea de salvaguarda siempre ha estado unida a la protección y conservación del patrimonio, pero esta idea entra en conflicto con la necesidad de trasmisión y continuidad relativa al patrimonio inmaterial, que puede provocar la fosilización de sus manifestaciones (Lacarrieu, 2008; Timón, 2012). Es necesaria la hibridación, el intercambio, y la constante evolución del patrimonio inmaterial, que no se estanque en la mera recreación, sino que evolucione y adopte nuevas funcionalidades para evitar su cristalización y extinción. Siguiendo a Kurin (2007), Salvaguardar el PCI no puede corresponderse con documentar la práctica o protegerla en los espacios de conservación (museos, archivos, bases de datos), sino que conlleva procesos de tipo indirecto (educativos, sociales, políticos) que permiten a los grupos reproducir las manifestaciones en cuestión. Sin embargo, la aplicación efectiva de este discurso resulta según Bortolotto ser "infinitamente problemática, no sólo para los profesionales y las instituciones del patrimonio, sino también para los agentes sociales que llevan consigo y reproducen estas expresiones culturales" (2014, p. 7).

Este conflicto se intenta solventar con la nueva idea de salvaguarda, encaminada a "garantizar la viabilidad del patrimonio cultural inmaterial, con medidas relativas a la identificación, documentación, investigación, preservación, protección, promoción, 
valorización y transmisión" (UNESCO, 2003, Art. 2.1). Entre las iniciativas promovidas por la UNESCO destaca la constitución de La Lista Representativa del Patrimonio Cultural Inmaterial, que se inició en el año 2001 y que contenía un inventario de los Bienes Culturales Inmateriales de la Humanidad. En la actualidad (invierno de 2019), la Lista Representativa y el Registro de buenas prácticas de salvaguarda cuentan con 508 elementos. Junto a ella se encuentra La Lista del Patrimonio Inmaterial que requiere medidas urgentes de salvaguarda, que fue diseñada con el propósito de proteger las manifestaciones culturales inmateriales de importancia que, por encontrase en peligro, requieren medidas urgentes.

Además del desarrollo de las listas y de inventarios de actualización regular, los Estados también deberán establecer otros sistemas de protección como la creación de órganos gestores competentes, el fomento de los estudios científicos y técnicos, y la creación o fortalecimiento de la educación formal y no formal (Art. 2.3), que garantice el acceso de la ciudadanía al PCI (Cuenca Martín-Cáceres, y Schugurensky, 2017; Muñoz, y Torres, 2014). En este sentido, se ratifica la necesidad de la educación y sensibilización como dimensiones fundamentales para la salvaguardia, dentro de un patrimonio que necesita la participación de la comunidad para su continuidad y desarrollo (UNESCO, 2003, art. 14 y 15). Si abordamos la gestión del PCI desde una perspectiva de sostenibilidad, el empoderamiento de las comunidades y la participación social (Texeira, 2006), nos permiten generar mecanismos de gestión desde un enfoque integral. Por lo tanto, la educación se convierte en la herramienta que garantice "conectar al ciudadano con su diversidad cultural y su entorno social, trabajando desde los valores culturales locales más próximos a las personas, para luego proyectar los valores universales" (García, 2009, p. 274). Esta postura también es defendida por Pinto y Zarbato (2017) Bajo esta perspectiva la protección del patrimonio va más allá del bien en sí, abarcando un complejo sistema de valores que lo rodea y le dan sentido. Numerosos autores han hablado de la educación patrimonial como herramienta que garantice el desarrollo de vínculos entre los bienes y la sociedad en vista a una gestión sostenible del patrimonio (Cuenca 2002; Colom, 1998; Fontal y Juanola, 2015). Otros autores como Ning (2018) o Ahmet (2018), defienden la educación como un modo importante de transferir la memoria cultural. 


\subsection{EI Plan Nacional y la ley 10/2015 para la Salvaguarda del PCI}

La gestión y salvaguarda del PCI implica dentro de nuestro ámbito nacional a múltiples marcos normativos e institucionales. En el año 2006, España ratifica la Convención para la Salvaguarda del Patrimonio Inmaterial, y desde entonces se comienza a trabajar con la finalidad de cumplir los objetivos planteados en ella. Este proceso tiene uno de sus hitos fundamentales en 2011, con la entrada en vigor del Plan Nacional para la Salvaguarda del Patrimonio Cultural Inmaterial (en adelante PNSPCI). El Plan considera Patrimonio Cultural Inmaterial los "usos, representaciones, expresiones, conocimientos y técnicas -junto con los instrumentos, objetos, artefactos y espacios culturales que les son inherentes- que las comunidades, los grupos y en algunos casos los individuos reconozcan como parte integrante de su patrimonio cultural" (Domingo y Timón, 2011, p. 5). Una de las características más destacadas sobre el PCI, a la que se hace alusión a lo largo de documento y que lo diferencia de todos los demás tipos de patrimonio, es que está interiorizado en los individuos a través de los aprendizajes y experiencias. Podemos decir que es un patrimonio inherente a la comunidad portadora y como consecuencia se considera el ethos de un pueblo (Castro y Ávila, 2015). En cuanto a las principales características que presenta el PCI resumimos a continuación aquellas recogidas en el Plan Nacional.

- Interiorizado en los individuos y comunidades, como parte de su identidad.

- Compartido por los miembros de una colectividad.

- Está vivo y es dinámico.

- Es transmitido y recreado.

- Es transmitido generacionalmente desde la infancia

- Es preservado tradicionalmente por la comunidad.

- Forma parte de la memoria colectiva viva, como una realidad socialmente construida.

- Es experimentado como vivencia.

- Está interconectado por la dimensión material de la cultura.

- Está habitualmente contextualizado en un tiempo y en un marco espacial.

- Se desarrolla y experimenta en tiempo presente.

- Remite a la biografía individual y a la colectiva.

- Está imbrincado en las formas de vida.

- No admite copia.

- Está ritualizado.

- Constituye una experiencia desde la perspectiva sensorial. 
- Tiene efecto regenerador en la orden social.

- Es vulnerable (Domingo y Timón, 2011, p. 7-13).

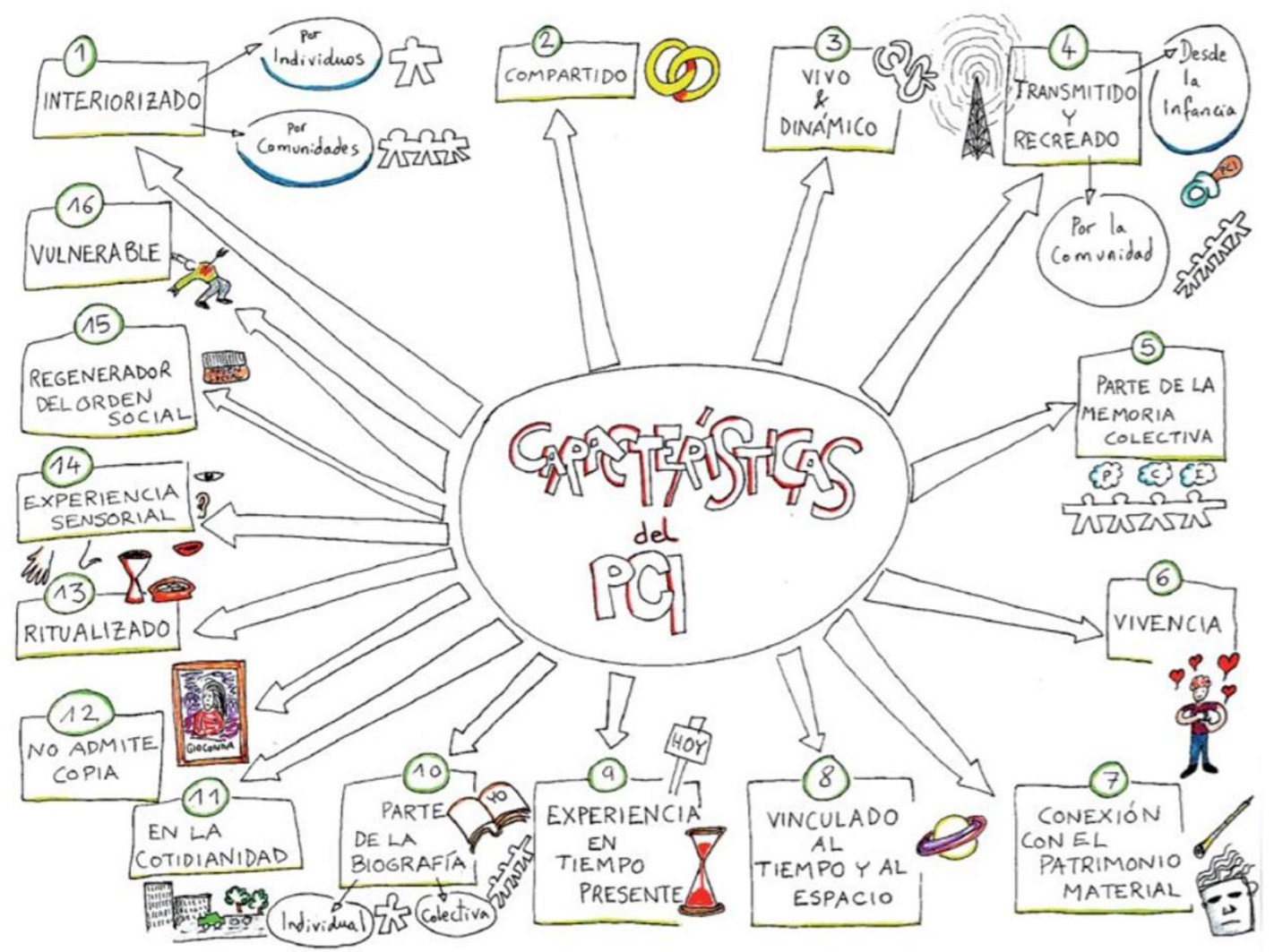

Figura 4. Características del PCI. Unidades didácticas (2014). Fuente: IPCE.

El PNSPCI establece diversos ámbitos en los que se manifiesta el patrimonio cultural inmaterial, dentro de los cuales se encuentra la gran diversidad de tradiciones, formas de alimentación y de socialización, manifestaciones musicales, rituales festivos, actividades productivas o particularidades lingüísticas y que se concretan en siete ámbitos, que amplían los cinco que presenta la Convención de 2003.

a) Conocimientos tradicionales sobre actividades productivas, procesos y técnicas

b) Creencias, rituales festivos y otras prácticas ceremoniales

c) Tradición oral y particularidades lingüísticas

d) Representaciones, escenificaciones, juegos y deportes tradicionales

e) Manifestaciones musicales y sonoras.

f) Formas de alimentación

g) Formas de sociabilidad colectiva y organizaciones (Domingo y Timón, 2011, p. 11-13). 


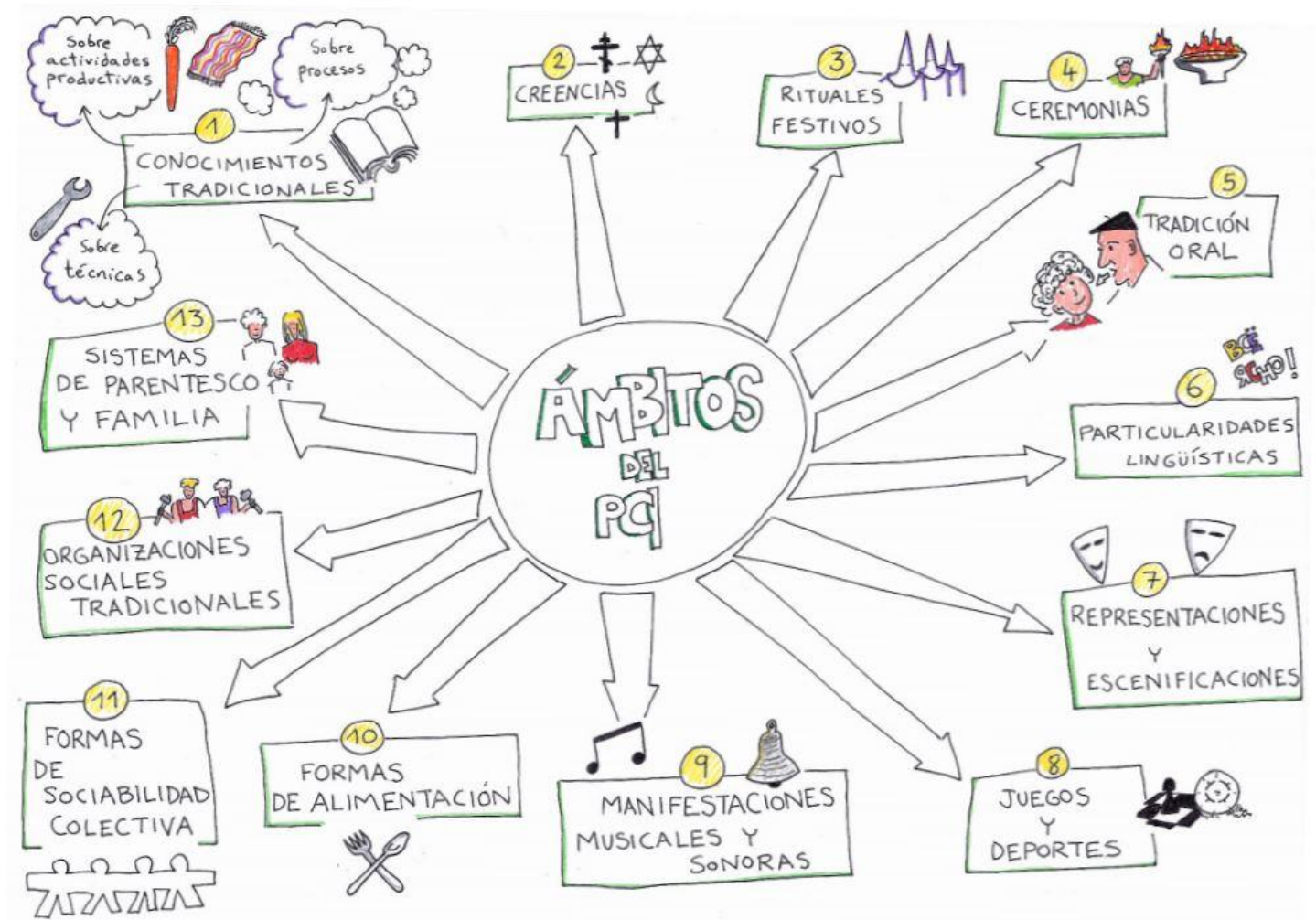

Figura 5. Ámbitos del PCI. Unidades didácticas (2014). Fuente: IPCE.

La diversidad de manifestaciones que se enmarcan dentro del Plan nos hace reflexionar sobre la problemática que surge ante el abanico de métodos de recuperación, catalogación, análisis y sensibilización que se deberían utilizar. Ante esta situación nos planteamos la necesidad de desarrollar protocolos específicos de salvaguarda relativos a las particularidades de cada manifestación y con una metodología específica que sirva de guía en el desarrollo de acciones concretas. El PCI también presenta numerosos riesgos que presentamos de modo gráfico en la figura 6. 


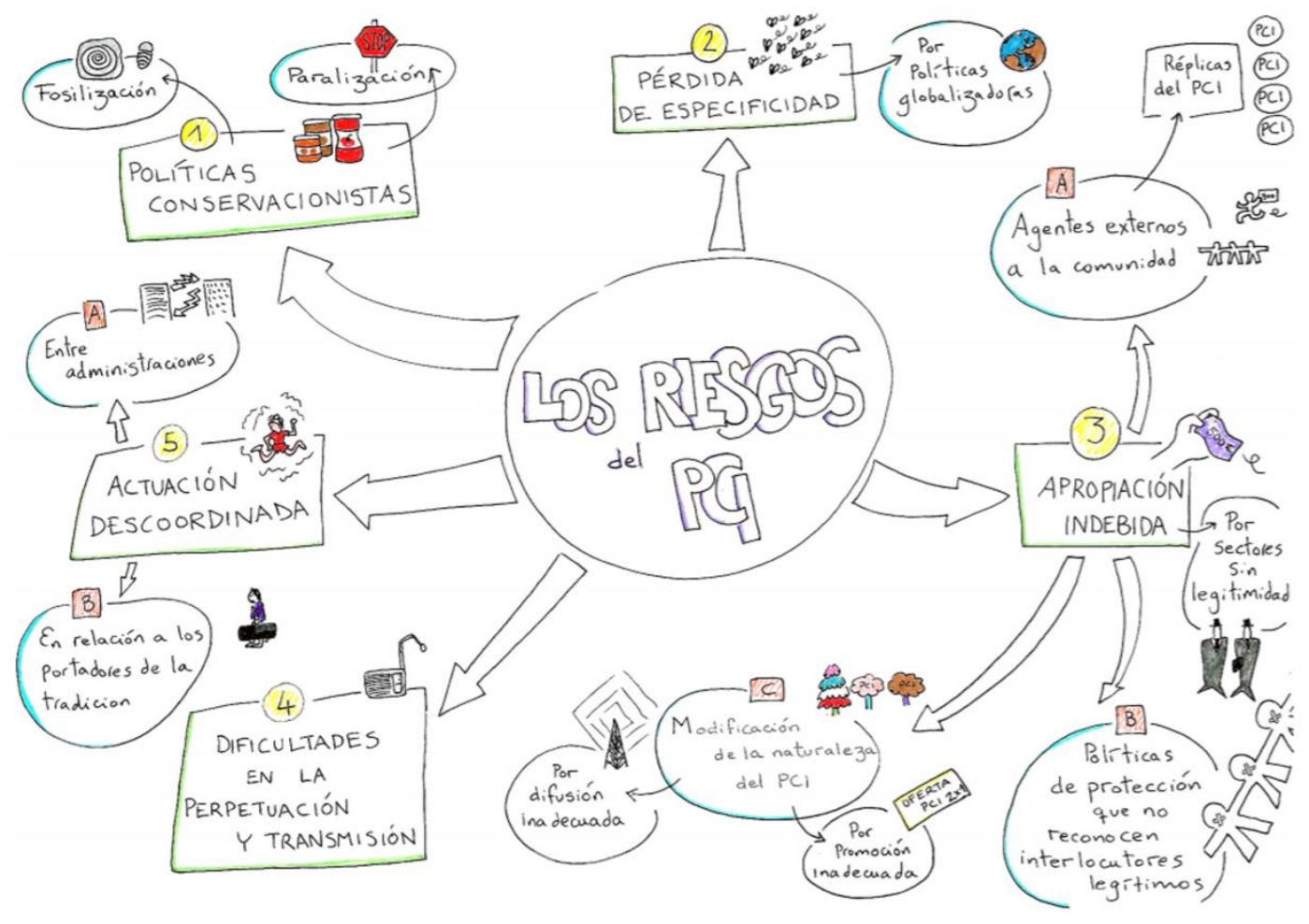

Figura 6. Riesgos del PCI. Unidades didácticas (2014). Fuente: IPCE.

El Plan presenta líneas de actuación y plantea tres programas: Programa de investigación y documentación del PCI; Programa de conservación de los soportes materiales del PCI y el Programa de formación, transmisión, promoción y difusión del PCI. Este último destaca que los principales agentes de salvaguarda son "las comunidades y organizaciones de ámbito local, regional, nacional y transnacional; las instituciones museísticas; las instituciones educativas y los centros de formación, [...]” (Domingo y Timón, 2011, p. 40). En esta cita y a lo largo de todo el documento, es clara la intención de remarcar la necesidad de la presencia social y comunitaria en cualquier acción de salvaguarda. Al mismos tiempo las líneas de actuación que se desarrollan dentro de los diferentes programa presentan como eje transversal la educación enfocada a la sociedad, y nos recuerda su importancia para la gestión y conservación del patrimonio, ya planteada en 2013 en el Plan Nacional de Educación y Patrimonio (Domingo et al., 2013), que abordamos en el punto 2.4.5.

En este sentido, consideramos que sensibilizar a la población asegurará el reconocimiento, el respeto y la valorización del patrimonio inmaterial, con la máxima finalidad de empoderar a la sociedad para que se conviertan en agentes activos en su 
gestión (Texeira, 2006; Fontal y Juanola, 2015; Pinto y Zarbato, 2017). Es fundamental trabajar hacia una gestión activa de la sociedad y concienciar sobre la fragilidad de esta tipología patrimonial. La falta de sistemas y métodos universales para la catalogación y la digitalización, unido a la abundancia de documentos audiovisuales y a la diversidad y rápida obsolescencia de los soportes juegan en nuestra contra (Diaz-Emparanza, 2015).

La preocupación entorno a la gestión y salvaguarda del PCI continua, y el 27 de mayo de 2015 se publica en el BOE la Ley 10/2015, para la Salvaguardia del Patrimonio Cultural Inmaterial, que tiene como objetivo fundamental "regular la acción general de salvaguardia que deben ejercer los poderes públicos (estatales, autonómicos...) sobre los bienes que integran el patrimonio cultural inmaterial, en sus respectivos ámbitos de competencias" (Ley 10/2015, art. 1). Con esta ley se afirma que se da cumplimiento a la Convención de 2003, que completa la Ley 16/1985, de 25 de junio de Patrimonio Histórico Español (LPHE). Las medidas de tutela y el régimen específico de la Ley 16/1985, en favor de las actividades inmateriales del patrimonio etnográfico no disfrutaban de tutela jurídica sino únicamente administrativa, al no formar parte de la definición legal (Ley 16/1985, art 1.2). En consecuencia, los mecanismos de tutela administrativa previstos por el art. 47.3 -cuya prescripción se circunscribe a los intangibles amenazados de extinción-, se limitan a la documentación (Martínez, 2011). Es la institución por la LPHE del interés etnográfico y el valor antropológico como factores definitorios de la patrimonialidad de los bienes mueble e inmuebles, la que reguló sobre el papel la protección indirecta del patrimonio inmaterial mediante la protección jurídica del sustrato material asociado en las figuras de los Bienes de Interés Cultural (BIC) inmuebles. De las cinco figuras declarativas establecidas por el artículo 14.2 y reguladas por el art. 15 -monumentos, jardín histórico, conjunto histórico, sitio histórico y zona arqueológica- sólo una, la de sitio histórico, admite los valores etnológicos y antropológicos como intereses calificativos (Ley 16/1985, p. 11).

A nivel terminológico, debemos destacar que, a pesar de su vinculación con la tradición, se denota a lo largo del documento un giro terminológico hacia los conceptos "oral e intangible, dejando en desuso el término de folclore ya años atrás "re-bautizado" en palabras de Santamarina (2013) por la normativa internacional. Otro de los aspectos a destacar, es la creación de una categoría jurídica específica denominada "Manifestación Representativa del Patrimonio Cultural Inmaterial" (en adelante MRPCI) para la protección de los bienes inmateriales de mayor representatividad y relevancia cultural de 
España. Esta categoría pretende homogeneizar las diferentes manifestaciones, olvidando la necesidad de respetar la diversidad cultural de cada CC. AA. y jerarquizándolas. Este hecho presenta según Carrera (2015) grandes incongruencias, ya que no por declarar una MRPCI va a suponer que se vuelva representativa de todo un Estado. Por otro lado, siguiendo con Carrera, debemos destacar que "las competencias autonómicas en patrimonio cultural no están reñidas con que las CC. AA. puedan asumir de un modo coordinado la salvaguarda de un PCI y convenir medidas conjuntas” (2015, p. 22).

La concreción de la regulación de la tutela del PCI por la legislación autonómica refleja la progresiva mejora de la comprensión de su naturaleza y particularidades y problemáticas, aunque de acuerdo con Martínez "la disparidad de las propuestas muestra que todavía no se ha superado el estadio inicial, de orden experimental" (2011, p. 145). Algunos de los aspectos más reseñables de la legislación autonómica, es el interés de articular la tutela del PCI a través de la educación, los centros de depósito cultural y las políticas territoriales entre otros.

A pesar de esta gran evolución administrativa y jurídica que ha tenido lugar en las últimas décadas, resulta evidente que existe un largo camino por recorrer, si tenemos en cuenta la relación causal entre el tiempo que el ser humano lleva produciendo manifestaciones artísticas inmateriales y el tiempo que la humanidad ha empezado a prestarles atención, desarrollando una preocupación en torno a su gestión, conservación, trasmisión y relación con la sociedad.

\subsection{El binomio patrimonio y educación en los textos institucionales y legislativos}

\subsubsection{La Educación Patrimonial en los textos internacionales de UNESCO}

En este epígrafe realizamos una revisión documental centrada en las convenciones y acuerdos desarrollados por la UNESCO como instrumentos internacionales, con la finalidad de conocer el papel y el enfoque que recibe la educación y la cultura, así como revisar los textos que hablan del binomio patrimonio y educación. La UNESCO es la Organización de las Naciones Unidas para la Educación, la Ciencia y la Cultura, que trata de establecer la paz y orientar a los pueblos en la gestión más eficaz de su propio desarrollo, a través de los recursos naturales y los valores culturales, con la finalidad de modernizar y hacer progresar a las naciones del mundo, sin que por ello se pierdan la identidad y la diversidad cultural (UNESCO, 1945). La constitución de la UNESCO se 
firmó el 16 de noviembre, y veinte estados la ratificaban un año después, el 4 de noviembre de 1946. Entre sus temas de actuación podemos decir que la educación ocupa el centro de su misión, ya que considera que la educación transforma vidas, consolida la paz, erradica la pobreza e impulsa el desarrollo sostenible, que son algunos de sus principales objetivos.

La UNESCO considera que la educación es un derecho humano para todos, a lo largo de toda la vida, y que el acceso a la instrucción debe ir acompañado de la calidad. Reflejo de todo ello, es el lugar que ocupa la educación en la Agenda 2030 para el Desarrollo sostenible $^{6}$, y dentro de sus objetivos de desarrollo sostenible (Asamblea General Naciones Unidas, 2015). La esencia de estas aspiraciones y metas en el campo de la educación se concreta en el Marco de Acción para la realización del Objetivo de Desarrollo Sostenible 4 (OSD4), que pretende garantizar una educación inclusiva y equitativa de alta calidad, y promover oportunidades de aprendizaje permanente para todos (UNESCO, 2016). En el Foro Mundial de la Educación en 2015 se aprobó la Declaración de Incheon ${ }^{7}$ (UNESCO, 2015a), que confió a la UNESCO la dirección y coordinación del OSD4, que plasma las ambiciones entorno a la educación de la Agenda 2030 para el Desarrollo Sostenible. La hoja de ruta para conseguir las diez metas que se encuentran dentro del objetivo de la educación en el Marco de Acción Educación 2030, para la realización del ODS 4, considera la educación como un mecanismo para responder a los desafíos que enfrenta la humanidad en la actualidad (UNESCO, 2016).

Por otro lado, la UNESCO también otorga gran poder de transformación a la cultura dentro del mundo interconectado en el que vivimos. Considera que la diversidad cultura es una fuente de enriquecimiento común, y que constituye una seña de identidad y favorece la cohesión de las comunidades, aspecto defendido por numerosos autores (Chaves, Montenegro, y Zambrano, 2010; Gelabert, 2006; Tilley, 2006). Esta

\footnotetext{
${ }^{6}$ The 2030 Agenda for Sustainable Development is an ambitious, aspirational and universal agenda to wipe out poverty through sustainable development by 2030. When it adopted the new Agenda in September 2015, the international community recognized that education was essential for the success of all 17 of its goals and 169 related goals of integrated and indivisible character. Transforming our world: the 2030 Agenda for Sustainable Development.

${ }^{7}$ Incheon Declaration. UNESCO together with UNICEF, the World Bank, UNFPA, UNDP, UN Women and UNHCR organized the World Education Forum 2015 in Incheon, Republic of Korea, from $19-22$ May 2015, hosted by the Republic of Korea. Over 1,600 participants from 160 countries, including over 120 Ministers, heads and members of delegations, heads of agencies and officials of multilateral and bilateral organizations, and representatives of civil society, the teaching profession, youth and the private sector, adopted the Incheon Declaration for Education 2030, which sets out a new vision for education for the next fifteen years.
} 
concepción se desarrolla en la Convención sobre la Protección y la Promoción de la diversidad de las expresiones culturales que destaca:

la necesidad de incorporar la cultura como elemento estratégico a las políticas de desarrollo nacionales e internacionales, así como a la cooperación internacional para el desarrollo, teniendo en cuenta asimismo la Declaración del Milenio de las Naciones Unidas (2000), con su especial hincapié en la erradicación de la pobreza (UNESCO, 2005, p. 2).

Ante esta necesidad podemos observar la creencia de que únicamente se conseguirán resultados sostenibles, inclusivos y equitativos, si se aborda la cuestión del desarrollo dándole prioridad al ser humano, basándose en el respeto mutuo y el diálogo entre las diferentes comunidades. La UNESCO entiende que sin cultura no hay desarrollo sostenible, puesto que la cultura forma parte de nuestro ser y configura nuestra identidad.

La UNESCO garantiza que el papel de la cultura se tenga en cuenta en la mayoría de los Objetivos de Desarrollo Sostenible de la Agenda 2030 para el Desarrollo sostenible, incluidos aquellos que se centran en la educación de calidad, las ciudades sostenibles, el medio ambiente, el crecimiento económico, las pautas de consumo y producción sostenibles, las sociedades inclusivas y pacíficas, la igualdad entre géneros y la seguridad alimentaria (Asamblea General Naciones Unidas, 2015a).

El desarrollo sostenible, está según la UNESCO, estrechamente ligado con la creatividad y considera que desde el patrimonio cultural a las industrias culturales creativas, la cultura es catalizador y motor de las dimensiones económica, social y ambiental del desarrollo sostenible. En esta línea destacamos la Declaración de Florencia. La cultura y las industrias culturales: Cultura, creatividad y desarrollo sostenible. Investigación, innovación, oportunidades, que en el punto número cinco de sus principios y prioridades básicas establece una clara interrelación entre cultura y educación:

Para conseguir una educación de calidad inclusiva y equitativa y oportunidades de aprendizaje a lo largo de toda la vida se debe invertir a la vez en la cultura y en la creatividad para todos. El aprendizaje local, la innovación y los procesos de desarrollo se fortalecen fomentando nuevos talentos y nuevas formas de creatividad. Esto puede conducir a la plena capacitación de las mujeres y las niñas como creadoras y productoras 
de expresiones culturales y como ciudadanas que participan en la vida cultural (UNESCO, 2014, p. 3).

La acción normativa de la Organización y los programas que lleva a cabo por todo el mundo pretenden reforzar la cultura como motor del desarrollo. Esto engloba la protección del patrimonio material e inmaterial en cualquiera de sus formas, así como las expresiones culturales. Para asegurarse de que los planes y estrategias de desarrollo tienen en cuenta la cultura, la UNESCO ha adoptado una táctica basada en tres ejes: Además de encabezar la defensa de la cultura y el desarrollo a nivel mundial, también colabora con la comunidad internacional para establecer acuerdos y marcos reglamentarios, y lleva a cabo actividades en el terreno para ayudar a los gobiernos y a los actores locales en la conservación del patrimonio, el fortalecimiento de las industrias creativas y el fomento del pluralismo cultural. También incluye apoyar las políticas nacionales de desarrollo, especialmente mediante programas conjuntos, como los del Fondo para el logro de los Objetivos de Desarrollo del Milenio en el territorio Español ${ }^{8}$.

Queda patente la preocupación de la UNESCO por la educación, la cultura y el patrimonio, y sobretodo el convencimiento ante la necesidad de sensibilizar a la sociedad como motor de cambio. Aunque son muchos los documentos desarrollado ante el compromiso de protección, conservación y salvaguarda, nos vamos a centrar en aquellos más relevantes en torno al binomio patrimonio y educación.

La perspectiva de la educación ha figurado en los principales documentos doctrinales internacionales desde sus inicios. La Carta de Atenas de 1931 (UNESCO, 1931) hacía alusión a directa al papel de la educación dentro de su punto siete relativo a la conservación de monumentos y la colaboración internacional y expone que:

la mejor garantía de conservación de los monumentos y obras de arte viene del afecto y del respeto del pueblo, y considerando que estos sentimientos pueden ser favorecidos por una acción apropiada de los poderes públicos, emite su voto para que los educadores tengan a su cargo habituar a la infancia y a la juventud a abstenerse de todo acto que pueda degradar los monumentos y les induzca a entender el significado y a interesarse por la protección de los testimonios de cada civilización (UNESCO, 1931, p. 3).

\footnotetext{
${ }^{8}$ El Fondo para el logro de los Objetivos de Desarrollo del Milenio (F-ODM) surge del acuerdo entre el Gobierno de España y Naciones Unidas, a través del PNUD (Programa de Desarrollo de las Naciones Unidas), para mejorar las condiciones de vida de miles de personas en todo el mundo que se encuentran en situación de pobreza extrema.
} 
Este documento, a pesar de estar centrado en la conservación y restauración de monumentos, ya hace noventa años considera que la mejor garantía para lograr su conservación era alcanzando el respeto del pueblo a través de la educación. Además, aludía a la gran labor y responsabilidad que tienen los educadores en trasmitir a los niños y a los jóvenes la necesidad de protección de los testimonios de cada civilización.

Décadas más tarde en la Convención sobre la Protección del Patrimonio Mundial Cultural y Natural (UNESCO, 1972a) se presenta en el artículo 27 los programas educativos como medio de estimulación del respeto y el aprecio por el patrimonio cultural.

Los Estados Partes en la presente Convención, por todos los medios apropiados, y sobre todo mediante programas de educación y de información, harán todo lo posible por estimular en sus pueblos el respeto y el aprecio del patrimonio cultural y natural. Se obligarán a informar ampliamente al público de las amenazas que pesen sobre ese patrimonio y de las actividades emprendidas en aplicación de la presente Convención (UNESCO, 1972a, art. 27).

A partir de este momento se comienzan a suceder documentos como la Recomendación sobre la Protección, en el Ámbito Nacional, del Patrimonio Cultural y Natural (UNESCO, 1972b), la Recomendación relativa a la Salvaguardia de los Conjuntos Históricos o Tradicionales y su Función en la Vida Contemporánea (UNESCO, 1976) y la Recomendación sobre la Protección de los Bienes Culturales Muebles (UNESCO, 1978). En ellos siempre se tiene en cuenta los valores que es necesario transmitir a la sociedad, y se comienza a generar una nube de verbos estrechamente ligada a la finalidad educativa como, concienciar del valor, conservar la identidad cultural, despertar el interés, aumentar el respeto, motivar su protección, concienciar de la necesidad de protección, revalorizar, reconstruir identidades.

Otra de las Convenciones que también busca conseguir a través de la educación el reconocimiento, el respeto y la valorización del patrimonio, y que presentan gran interés en el desarrollo de esta tesis, es la Convención sobre la Salvaguarda del Patrimonio Cultural Inmaterial. En el punto relativo a los programas, proyectos y actividades de salvaguarda del patrimonio cultural inmaterial podemos ver un interés de empoderar a la sociedad e involucrar a los Estados Partes como agentes activos en su gestión. 
Basándose en las propuestas presentada por los Estados Partes, y ateniéndose a los criterios por él definidos y aprobados por la Asamblea General, el Comité seleccionará periódicamente y promoverá los programas, proyectos y actividades de ámbito nacional, subregional o regional para la salvaguardia del patrimonio que a su entender reflejen del modo más adecuado los principios y objetivos de la presente Convención, teniendo en cuenta las necesidades particulares de los países en desarrollo (UNESCO, 2003, art 17).

Uno de los principales focos de la UNESCO para el desarrollo de esta labor formativa y de sensibilización son los museos. En la Recomendación sobre la Protección y Promoción de los Museos y Colecciones. Su Diversidad y su Función en la Sociedad se indica que:

Para la transmisión cultural, el diálogo intercultural, el aprendizaje, el debate y la formación, los museos desempeñan también una importante función en la educación (formal y no formal, y el aprendizaje a lo largo de toda la vida), la cohesión social y el desarrollo sostenible. Los museos encierran un gran potencial de sensibilización del público acerca del valor del patrimonio cultural y natural y la responsabilidad de todos los ciudadanos de contribuir a su cuidado y transmisión (UNESCO, 2015b, p. 4).

Además de señalar que la sensibilización de la sociedad es una de sus principales funciones, también hace alusión a la necesidad de vincular el museo con la escuela en el desarrollo de programas educativos, que permitan elaborar diseños didácticos más contextualizados y eficientes.

Los museos imparten educación formal y no formal y aprendizaje a lo largo de toda la vida mediante la elaboración y transmisión de conocimientos y programas educativos y pedagógicos en asociación con otras instituciones docentes, en particular la escuela. Los programas educativos de los museos contribuyen [...] a crear una mayor conciencia de la importancia de preservar el patrimonio y promover la creatividad (UNESCO, 2015b, p. $5)$.

Un aspecto que echamos en falta en los textos de la UNESCO es la alusión a la necesidad de garantizar una sensibilización y educación con, desde y hacia el patrimonio dentro del ámbito formal de la educación en los Estados Partes, ya que consideramos imprescindible que la educación patrimonial tenga su espacio dentro de la educación reglada y llegue a todos los niveles educativos (Fontal, Ibáñez-Etxeberria, Martínez y Rivero, 2017). Aunque comprendemos que desarrollar un documento normativo que regule la educación patrimonial dentro de la educación formal, que pueda ser ratificada 
por todos los Estados Partes no sería operativo atendiendo a las peculiaridades e idiosincrasia de cada Estado. Consideramos que sí sería práctico y necesario elaborar una Recomendación, que abordará la importancia de que cada Estado miembro tome consciencia y regule a su favor.

\subsubsection{La Educación Patrimonial en los textos de la Unión Europea}

En las últimas décadas, Europa ha reforzado su compromiso de aumentar y valorizar el conocimiento y la conciencia del patrimonio cultural. Este hecho, no podía ser de otro modo, si analizamos que dentro de los países de la Unión Europea, además de todos los activos declarados como parte del patrimonio por sus propias legislaciones, hay 388 activos que figuran en la Lista del Patrimonio Mundial. Esta cifra representa el 36,8\% del total de 1052 activos (814 son activos culturales, 203 activos naturales y 35 activos mixtos), ubicados en 165 estados miembros. Los 28 países que conforman la Unión Europea han reconocido bienes patrimoniales. Italia (51), España (44), Francia (42) y Alemania (42) son las que más reconocimiento han recibido. Por su parte, Italia es el país con el mayor número de productos reconocidos del mundo, seguido de China y España. La educación sobre todo este legado cultural ha figurado en los principales documentos doctrinales internacionales como hemos visto en los apartado anterior, y se ha consolidado, como una disciplina esencial en la gestión del patrimonio (Fontal y Juanola, 2015), capaz de abordar cuestiones muy importantes para el contexto europeo, como la identidad y la pertenencia cultural (Cuenca, Molina-Puche, y Martin-Caceres, 2018; Lobovikov-Katz, 2009; Scalise, 2015).

Esto ha llevado a un aumento en los programas educativos, regulaciones y objetivos específicos relacionados con la conservación y la socialización del patrimonio. La Unión Europea, para cumplir con este compromiso, desarrolla el programa Europe, a common heritage, dentro del cual ha desarrollado un programa integral para la difusión y el acceso al Patrimonio Europeo. Otra de las iniciativas desarrolladas por la Unión Europea fue aprobada por el Parlamento Europeo y el Consejo de la Unión Europea, el 17 de mayo de 2017, por la que se establece la declaración del European Year of Cultural Heritage 2018 (European Parliament, 2017). Su principal objetivo fue animar a más personas a descubrir y participar en el patrimonio cultural de Europa, y reforzar el sentido de pertenencia a un espacio europeo común. 
encourage and support the efforts of the Union, the Member States and regional and local authorities, in cooperation with the cultural heritage sector and broader civil society, to protect, safeguard, reuse, enhance, valorise and promote Europe's cultural heritage (European Parliament, 2017, art.1).

El lema para el año fue: "Nuestra herencia: donde el pasado se encuentra con el futuro". Entorno a él se han llevado a cabo numerosas iniciativas y eventos en toda Europa, para que las personas puedan estar más cerca y más involucradas con su patrimonio cultural. Las acciones incluyen:

1) Iniciativas a largo plazo para el patrimonio cultural: las 10 iniciativas europeas del año europeo. Para garantizar que el Año Europeo deje una huella más allá de 2018, la Comisión Europea, junto con socios clave, lanzó las 10 Iniciativas Europeas para el Año Europeo del Patrimonio Cultural. Cada iniciativa agrupa varias acciones y proyectos a largo plazo, que se corresponden con 4 principios clave: compromiso, sostenibilidad, protección e innovación.

2) Proyectos financiados por la UE. Como el programa Creative Europe, que utiliza el patrimonio cultural como uno de los principales sectores de actuación.

Este programa cambia el enfoque desde abajo hacia arriba. Otorga herramientas a la sociedad para producir una activación real de la población hacia la conservación, cuidado y disfrute de su patrimonio cultural.

Otra de las grandes acciones a destacar es The European Heritage Days, iniciativa conjunta entre la Unión Europea y el Consejo de Europa desarrollada desde 1999. Se organiza en estrecha colaboración con los coordinadores nacionales y en ella participan 50 estados europeos firmantes de la European Cultural Convention. Esta convención ya indicaba que "Each Contracting Party shall take appropriate measures to safeguard and to encourage the development of its national contribution to the common cultural heritage of Europe" (Council of Europe, 1954, art.1). The European Heritage Days, conocidas en castellano como las Jornadas Europeas del Patrimonio, reconocen que los patrimonios culturales son recursos para desarrollar el diálogo, el debate democrático y la apertura entre culturas, y busca defender estos valores. Su portal web ${ }^{9}$ define The European Heritage Days como, "an essential instrument for fostering a tangible

\footnotetext{
${ }^{9}$ http://www.europeanheritagedays.com/
} 
experience of European culture and history in addition to raising the awareness of the public about the many values of our common heritage and the continuous need for its protection", y presenta a través de cinco puntos sus principals objetivos:

- Raise the awareness of European citizens to the richness and cultural diversity of Europe;

- Create a climate in which the appreciation of the rich mosaic of European cultures is stimulated;

- Counter racism and xenophobia and encourage greater tolerance in Europe and beyond the national borders;

- Inform the public and the political authorities about the need to protect cultural heritage against new threats;

- Invite Europe to respond to the social, political and economic challenges it faces.

El programa anual también ofrece oportunidades para visitar edificios, monumentos y sitios, muchos de los cuales normalmente no son accesibles al público. Además, la página cuenta con un buscador de eventos por países, tipología patrimonial o fecha de los eventos, que permiten a los ciudadanos e instituciones conocer y participar de los mismos. Las Jornadas Europeas del Patrimonio suponen el evento cultural participativo más importante en el ámbito europeo, donde todos los eventos que se desarrollan abrazar los principios de cooperación y diversidad, y la visión de construir una mejor sociedad basada en la paz, la cooperación y el respeto mutuo.

Europa necesita establecer modelos de acción que permitan cuidar su enorme patrimonio cultural y natural, así como convertirse en un punto de referencia global y líder en la creación de procesos de conciencia social que empoderen a la población (Teixeira, 2006; Jagielska-Burdul y Piotr, 2019). La educación sobre el patrimonio garantiza procesos de empoderamiento social, que nos permiten preservar de manera competente un pasado común y nuestro propio patrimonio cultural como ciudadanos europeos. Por lo tanto, el desafío consiste en promover el compromiso de la sociedad con los principios de la educación patrimonial en todos los niveles y en todos los ámbitos, ya que es la sociedad la que constituye el principal receptor y legatario del patrimonio. Por esta razón es fundamental establecer canales de comunicación entre las partes involucradas en la 
gestión del patrimonio, y asegurarse de que dichos canales permitan intercambios bidireccionales en los tres niveles: local, regional y europeo.

A pesar de los numerosos proyectos que se han desarrollado en el ámbito europeo en torno a la educación patrimonial (Cerri, 2007; Emiliani, 2007; Dusan, 2015; Poce, Agrusti y Re, 2017; Potočnik, 2017), se debe seguir fomentando el desarrollo de redes de trabajo multidisciplinares y marcos autónomos para la gestión y conservación del patrimonio cultural. Así como, establecer un marco conjunto de análisis y evaluación capaz de generar principios y estándares metodológicos, sobre los cuales construir una política común para la gestión educativa del patrimonio y la educación patrimonial. Consideramos fundamental ampliar esfuerzos en la investigación que integra diferentes países, perspectivas disciplinarias, epistemológicas y metodológicas, capaces de coordinar a todos los participantes en una sola propuesta: investigadores, profesores, estudiantes, educadores de museos, empresas, ciudadanos, comunidades de patrimonio, empresas, agentes políticos y administraciones responsables de la educación del patrimonio. En este sentido proponemos la necesidad de generar una red interdisciplinaria y de múltiples agentes, que permita desarrollar modelos normalizados donde la educación patrimonial se convierta en una disciplina indispensable, que sea verdaderamente internalizada por todas las administraciones y partes interesadas que trabajan en el patrimonio cultural. En este sentido, la publicación elaborada por Fontal y Martínez (2019) presenta el desafío de construir una Red de investigación de Patrimonio y Educación: la relación con los esfuerzos existentes a nivel europeo y/o internacional; el impacto esperado; el potencial de innovación frente al nivel de riesgo; el plan para involucrar a las partes interesadas relevantes y la descripción del plan de trabajo de la Red.

\subsubsection{La Educación Patrimonial en los textos del Consejo de Europa}

El Consejo de Europa fue constituido por el Tratado de Londres el 5 de mayo de 1949, y es la organización internacional más antigua que persigue los ideales de la integración europea, y que no debemos confundir con La Comisión Europea, que es la rama ejecutiva de la Unión Europea. Desde sus inicios, y con gran intensidad en los últimos años, está involucrado de manera muy específica en cuestiones de patrimonio y educación patrimonial. Este aspecto no podía ser de otro modo, al presentar entre sus objetivos el logro de una unión más estrecha entre sus Estados miembros, para 
salvaguardar y promover los ideales y principios basados en el respeto de los derechos humanos, la democracia y el Estado de derecho, que constituyen su patrimonio común.

El Parlamento y el Consejo de Europa han prestado su apoyo para fomentar los usos culturales y educativos del patrimonio. A continuación hacemos un recorrido por las declaraciones, recomendaciones, resoluciones y programas que aluden a la educación patrimonial, destacando la Recommendation No. $R$ (98) 5 concerning heritage education (Committee of Ministers, 1998), el Faro Convention. Convention Action Plan Handbood 2018-2019 (Council of Europe, 2005; 2018), la Recommendation CM/Rec (2017)1 to member States on the "European Cultural Heritage Strategy for the 21st century" (Committee of Ministers, 2017) o European Cultural Heritage Information Network (HEREIN). Para abordar los principales programas educativos desarrollados por el Consejo de Europa tomaremos como referencia la publicación Heritage Education for Europe, que recoge las opiniones de expertos sobre aspectos políticos e identitarios en torno al desarrollo de la educación patrimonial en Europa (Branchesi, 2007).

En 1969 la Resolution I of the European Conference of Ministers responsible for the Protection and Conservation of the Immovable Cultural Heritage recomienda tener en cuenta el patrimonio en la planificación de las políticas educativas, por ejemplo, mediante la incorporación de módulos en los planes de estudio diseñados para aumentar la conciencia de los jóvenes sobre el entorno cultural, y llamar la atención sobre sus responsabilidades al respecto (Cerri, 2007). En 1975 The Declaration of Amsterdam establece el concepto de "conservación integrada", reconociendo el papel decisivo que desempeña el patrimonio en la educación, destacando la importancia de hacer que las personas, especialmente las generaciones más jóvenes, se den cuenta de la necesidad de proteger este activo invaluable, para asegurar su transmisión a las generaciones futuras como uno de los mayores imperativos (Council of Europe, 1975).

A partir de 1989 se desarrolla una de las primeras iniciativas prácticas en materia de patrimonio y educación que son las "European Heritage Classes" (EHC). Este nuevo enclave era seleccionado por su valor histórico, artístico literario, arqueológico, ect., con la intención de permitir a los más jóvenes - de cualquier nivel o tipo de enseñanzadescubrir la riqueza del patrimonio en su contexto y comprender la dimensión europea del mismo. Las Clases del Patrimonio Europea tuvieron gran éxito en Francia y Bélgica, y posteriormente un gran número de países se fueron sumando. En 1992 se produce el 
coloquio celebrado en Maisons-Laffitte sobre "European Heritage Classes", organizado por responsables políticos y autoridades educativas y culturales, con el fin de crear conciencia sobre la educación patrimonial y sus características principales, además de garantizar la organización de dichas clases en otros países europeos. Un año más tarde se publica el "European Heritage Classes handbook" que presenta su filosofía subyacente, objetivos que persigue, metodología de actuación y ejemplos prácticos (Council of Europe, 1993). Continuando en esta línea, en 1995 se produce en Bruselas el coloquio sobre el patrimonio y su educación, factor de tolerancia, buena ciudadanía e integración social. Según nos explica Cerri (2007), durante su desarrollo se proporcionaron ejemplos prácticos de la educación sobre el patrimonio y su papel en la lucha contra las formas de degradación y promoción de la integración y la inclusión social.

Un momento importante en el trabajo de la Organización fue la Recommendation No. $R$ (98) 5 concerning heritage education, que supuso el comienzo en la construcción de un marco formalizando en la materia, que recomienda a los Estados miembros adoptar las medidas legislativas, reglamentarias, administrativas, financieras y de otro tipo para iniciar y desarrollar programas educativos sobre patrimonio, con la finalidad de promover la conciencia del patrimonio entre los jóvenes. Esta recomendación se dirigía a la atención de los gobiernos, y se agregó un texto explicativo para facilitar su difusión en todos los Estados miembros (Committee of Ministers, 1998). Dentro de esta recomendación se hace alusión a dos de los aspectos principales que presuponen los objetivos de partida de nuestro trabajo. El primero de ellos, es la importancia de la formación de los docentes en educación patrimonial y la correlación que debe existir entre esta formación y los planes de estudios de los alumnos (tema de estudio del primer artículo que se presenta en esta tesis por compendio de publicaciones):

Heritage education presupposes a link with school programmes and appropriate training for teachers. Theoretical and practical training courses should, wherever possible, be organised for both teachers and cultural professionals. Heritage staff, at all levels, should be made aware of questions relating to heritage education and, if possible be given training in catering for young visitors (Committee of Ministers, 1998, p. 32).

Otro de los aspectos de los que parte nuestra investigación, y que ya fue planteado en la Recomendación No. $R$ (98) 5, es la necesidad de evaluación de las prácticas educativas en torno a la educación patrimonial a todos los niveles dentro de la gestión educativa, 
"Evaluation of the results of each action should be undertaken by the partners and/or the relevant ministries, especially that taken at educational, cultural, organisational and financial levels" (Committee of Ministers, 1998, p. 32). (Tema de estudio del segundo y tercer artículo de esta tesis).

Desde entonces se desarrollan numerosos los proyectos educativos en torno al patrimonio promovidos por el Consejo de Europa. Entre los principales destacamos: El proyecto/competición educativo lanzado dentro del Plan Europeo de Arqueología para estudiantes de seis a doce años llamado "The city beneath the city" (en colaboración con ICROM, the International Centre for the Study of the Preservation and Restoration of Cultural Property, y English Heritage). El proyecto "One School - one monument" lanzado por la asociación "Seixmo" en la ex República Yugoslava de Macedonia. Este proyecto también se incorporó al "Confidence-building Measures Programme", dirigido por la Dirección General de Asuntos Políticos del Consejo de Europa. Uno de los proyectos que más duración ha tenido ha sido en Proyecto titulado "Europe: from one street to the Other" (EOSO). El folleto educativo producido para la ocasión se ha distribuido a todos los Estados miembro de la Convención Cultural Europea y existe en siete idiomas (inglés, francés, alemán, italiano, ruso, español y sueco).

En el año 2005 se desarrolla el Framework Convention on the Value of Cultural Heritage for Society, también conocida como la Convención de Faro. Esta convención reconoce la necesidad de que la persona y los valores humanos ocupen un lugar central dentro de un concepto más amplio e interdisciplinar de patrimonio cultural, donde se plantea el derecho de todos los ciudadanos a participar en la vida cultural, ya enunciado en la Declaración Universal de los Derechos Humanos (ONU, 1948). Esta convención supone un punto de inflexión al colocar el centro de interés en las personas, que son las únicas que pueden atribuir valores y significados a esos bienes, lugares u objetos que son potenciales patrimonios. Este enfoque relacional ya fue planteado por Fontal (2003) y ha dado lugar a los procesos de patrimonialización (Fontal y Gómez-Redondo, 2016), donde los vínculos son la clave dentro de dicho proceso (Fontal y Marín, 2018). La Convención presenta la educación como herramienta de diálogo entre culturas y el patrimonio cultural como recurso para revindicar la diversidad como factor potencial de la creatividad humana, que mejora en entendimiento social y la convivencia pacífica: "the role of cultural heritage in the construction of a peaceful and democratic society, 
and in the processes of sustainable development and the promotion of cultural diversity" (Council of Europe, 2005, art. 1). Al mismo tiempo subraya el valor y el potencial del patrimonio cultural, utilizado prudentemente como recurso para el desarrollo sostenible y la calidad de vida de una sociedad en continua evolución.

El documento aborda, en su segunda sección, la contribución del patrimonio cultural a la sociedad y al desarrollo humano como recurso para abordar la coexistencia pacífica. Al mismo tiempo se reconoce el derecho a establecer o modificar vínculos desde la libre elección de cada individuo. La tercera sección presenta las responsabilidades compartidas respecto del patrimonio cultural y participación pública:

Promote an integrated and well-informed approach by public authorities in all sectors and at all levels; develop the legal, financial and professional frameworks which make possible joint action by public authorities, experts, owners, investors, businesses, nongovernmental organisations and civil society (...). Encourage everyone to participate in: the process of identification, study, interpretation, protection, conservation and presentation of the cultural heritage; public reflection and debate on the opportunities and challenges which the cultural heritage represents (Council of Europe, 2005, art. 11 y 12).

Con la consideración del patrimonio como un recurso social, económico y político, la Convención de Faro del Consejo de Europa sugiere una visión y una nueva forma de ver el patrimonio, al sentar las bases para replantear las relaciones entre todas las partes interesadas, destacando el papel esencial de la sociedad y las comunidades patrimoniales. En este sentido, se desarrolla años más tarde el Convention Action Plan Handbook 2018-2019 ${ }^{10}$ (Council of Europe, 2018), que promueve acciones dirigidas hacia el patrimonio y centradas en las personas en torno a un interés común definido. Argumenta que cuando se considera el patrimonio como una fuente y un recurso, la opinión, los intereses y las aspiraciones de todos cuentan. Además, reconoce que la presencia de la diversidad de pueblos, lugares y narraciones puede llevar a situaciones

\footnotetext{
${ }^{10}$ The Framework Convention on the Value of Cultural Heritage for Society (the Faro Convention) has been ratified by 18 member states and signed by 5 additional states. The Faro Convention Action Plan focuses on the main ingredients of commons, narratives and cooperation, considering heritage as a social, economic and political resource. It works with the local dynamics and pace, in line with the Faro Convention spirit, and the principles of social inclusion, human rights and community well-being.
} 
conflictivas. En este sentido el principal objetivo del Plan de Acción de la Convención de Faro es:

Illustrate the richness and novelty of the principles of the Faro Convention, as well as providing possibilities for interpretation in relation to current societal challenges. It further generates common references, and creates mechanisms and tools in order to encourage initiatives in line with the Faro Convention's principles and criteria. Based on the Faro Convention Action Plan motto "Peoples, Places and Stories", the Council of Europe's ongoing reflection on the Faro Convention draws on three main ideas:

- Prioritising inhabitants in their relationship with cultural heritage;

- Reaching out to heritage communities and groups;

- Strengthening linkages between all the local, regional and national heritage stakeholders, through synergetic action (Council of Europe, 2018).

En consecuencia, el Plan de acción presenta un enfoque distintivo y un conjunto de herramientas para examinar tales situaciones y, junto con las comunidades, identificar buenas prácticas para contribuir a sociedades inclusivas con respeto por la dignidad y las múltiples identidades. Al hacer visible lo invisible, el enfoque de la Convención de Faro permite a las comunidades tomar un papel activo en la toma de decisiones hacia la democracia directa y contribuir a la formulación de políticas y estrategias con respecto a sus recursos locales. Además, el aumento del número de Estados miembros signatarios de la Convención alentará aún más a las instituciones europeas a prestar más atención a las comunidades, para ser conscientes de su papel activo en el desarrollo de enfoques innovadores hacia el patrimonio y los procesos de democratización. A través de la Convención de Faro, el Consejo de Europa continúa asumiendo su papel en el lanzamiento y guía de un debate paneuropeo sobre los desafíos de la sociedad, con especial atención a los derechos humanos, la democracia y el estado de derecho.

En 2014 se publican dos documentos clave con una clara intención de definir la política sobre educación patrimonial en Europa a lo largo de la próxima década: Toward an integrated approach to cultural heritage for Europe ${ }^{11}$ (European Comission, 2014), y la cartografía integrada que lo completa, Mapping of Cultural Heritage actions in

\footnotetext{
${ }^{11}$ The European Commission has adopted the policy 'Towards an integrated approach to cultural heritage for Europe'. This important policy document calls for stronger cooperation at EU level, which can feed into national heritage policies and governance. It highlights the opportunities for EU countries and stakeholders to work more closely across borders to ensure that cultural heritage contributes more to sustainable growth and employment. Brussels, 22.7.2014 COM (2014) 477 final
} 
European Union policies, programmes and activities ${ }^{12}$ (European Comission, 2017). En ambos textos se reconocen las deficiencias y necesidades relacionadas con el tratamiento del patrimonio cultural, y se apunta directamente a la educación como un medio para superarlos. Consideran la educación una disciplina clave en la gestión del patrimonio cultural, para lograr un crecimiento económico sostenible y la cohesión social (Copeland, 2007; Koutrelakos, 2013). Este mismo año, también se pone en marcha el programa Horizon $2020^{13}$, dirigido al espacio europeo de investigación dentro del que destacamos la iniciativa: Joint Programming Initiative in Cultural Heritage and Global Change $^{14}$, que insta a los Estados miembro a desarrollar líneas estratégicas de investigación relacionadas con la preservación y el uso del patrimonio cultural en el contexto del cambio global. Siempre bajo la óptica del esfuerzo para la cooperación interdisciplinaria entre las ciencias, las artes y las humanidades en beneficio de los ciudadanos. Otro componente del programa Horizon 2020 en el que el patrimonio cultural y la educación tienen especial importancia es el desafío social "Europe in a changing world, inclusive, innovative, and reflective societies", cuyo objetivo es promover una mejor comprensión de Europa, ofrecer soluciones y respaldar proyectos inclusivos e innovadores para las sociedades europeas reflexivas, en un contexto de transformaciones sin precedentes y creciente interdependencia global (Jurion de Waha, 2007).

En el año 2017 se lanza la Estrategia del patrimonio europeo para el siglo XXI, que se basa en los valores fundamentales del Consejo de Europa: democracia, respeto de los derechos humanos y libertades fundamentales, apertura y diálogo, la igual dignidad de todas las personas, respeto mutuo y sensibilidad a la diversidad. Se busca incentivar y

\footnotetext{
12 Mapping of Cultural Heritage actions in European Union policies, programmes and activities. Contribute to the development of a strategic approach to the preservation and valorisation of European heritage. Its first edition (July 2014) was prepared in response to the "Conclusions on cultural heritage as a strategic resource for a sustainable Europe" (2014/C 183/08) adopted by the Council of the European Union on 20th May 2014, and complements the European Commission Communication "Towards an integrated approach to cultural heritage for Europe", published on 22nd July 2014 (COM/2014/0477 final).

${ }^{13}$ Horizon 2020 is the biggest EU Research and Innovation programme ever with nearly $€ 80$ billion of funding available over 7 years (2014 to 2020) - in addition to the private investment that this money will attract. It promises more breakthroughs, discoveries and world-firsts by taking great ideas from the lab to the market.

${ }^{14}$ The Joint Programming Initiative in Cultural Heritage and Global Change is a concept introduced by the European Commission in July 2008 as the core of the 10 Joint Programming Initiatives (JPIs) aimed at implementing the European Research Area (ERA). The concept intends to tackle a few current challenges that cannot be solved solely on the national level and allows Member States and Associated Countries to deal with critical issues through a joint transnatinal approach.
} 
facilitar la implementación de las actividades relacionadas con el patrimonio. Aboga por un enfoque compartido y unificador del patrimonio cultural y sobre cómo debería ser administrado. Esta estrategia tiene como objetivo sensibilizar y formar a los ciudadanos para la gestión de su patrimonio, en continua relación con los marcos legales, políticos y administrativos.

Heritage is a non-renewable common good whose conservation, protection, restoration and enhancement are the responsibility of society as a whole, including in the political, legal and administrative spheres. Consequently, there is a need to define the roles of everyone involved and to give citizens in particular the means of shouldering their responsibilities. Awareness raising, research and training are therefore essential. Training is imperative to maintain and pass on European knowledge and skills which themselves constitute a form of heritage on which to capitalize (Committee of Ministers, 2017, p. 6)

La estrategia se organiza en tres componentes: componente "social" (S) se centra en la relación entre el patrimonio y las sociedades, la ciudadanía, la transmisión y el intercambio de valores democráticos a través de la gobernanza participativa, y la gestión participativa; el componente de "desarrollo territorial y económico" (D) se centra en la relación entre el patrimonio cultural y el desarrollo espacial, la economía y la gobernanza local y regional, teniendo debidamente en cuenta los principios del desarrollo sostenible. El Componente de "conocimiento y educación" (K) se centra en la relación entre el patrimonio y el conocimiento compartido, que abarca la sensibilización, la capacitación y la investigación (Committee of Ministers, 2017, p. 6).

\section{Tabla 2}

Recomendaciones del Comité de Ministros a los Estados miembros sobre la Estrategia del patrimonio cultural europeo para el siglo XXI en relación al componente el educativo y de conocimiento

\section{Recomendaciones}

K1. Incorporar la educación del patrimonio de manera más efectiva en el currículo escolar

\section{Líneas de acción recomendadas}

\begin{tabular}{|l|} 
Adaptar planes de estudios, capacitar a maestros, instructores, etc. \\
\hline $\begin{array}{l}\text { Establecer un diálogo entre el sector educativo y los departamentos responsables del } \\
\text { patrimonio, museos, archivos, bibliotecas, etc. }\end{array}$ \\
\hline Iniciar proyectos educativos interdisciplinarios que incluyen el patrimonio \\
\hline Promover la cooperación con asociaciones, sociedades de historia, etc. \\
\hline $\begin{array}{l}\text { Desarrollar actividades externas: visitas, viajes, entrevistas, documentales, etc., e } \\
\text { invitar a especialistas en patrimonio a las escuelas }\end{array}$ \\
\hline $\begin{array}{l}\text { Buscar que la información digital relacionada con el patrimonio sea más abierta, más } \\
\text { accesible y más fácil de usar }\end{array}$ \\
\hline
\end{tabular}




\begin{tabular}{|c|c|}
\hline & $\begin{array}{l}\text { Desarrollar programas de apoyo organizados por profesionales de museos, que tienen } \\
\text { lugar en museos }\end{array}$ \\
\hline \multirow{6}{*}{$\begin{array}{l}\text { K2. Implementar medidas } \\
\text { para alentar a los jóvenes a } \\
\text { practicar el patrimonio }\end{array}$} & $\begin{array}{l}\text { Introducir planes de cultura o patrimonio para grupos de edad específicos y evaluar } \\
\text { el éxito del plan }\end{array}$ \\
\hline & Fomentar la organización de eventos específicos para jóvenes \\
\hline & Ofrecer una entrada gratuita o a precio reducido \\
\hline & Desarrollar incentivos ideados en consulta con los jóvenes \\
\hline & $\begin{array}{l}\text { Promover y fomentar las prácticas de los jóvenes (medios de comunicación, } \\
\text { concursos) }\end{array}$ \\
\hline & Organizar eventos basados en el patrimonio con un aspecto innovador \\
\hline \multirow{5}{*}{$\begin{array}{l}\text { K3. Fomentar la creatividad } \\
\text { para captar la atención de la } \\
\text { audiencia de patrimonio }\end{array}$} & $\begin{array}{l}\text { Resaltar las interrelaciones entre el patrimonio y las tecnologías de vanguardia en los } \\
\text { campos de la arqueología, la conservación y la restauración }\end{array}$ \\
\hline & Mostrar el patrimonio en eventos culturales o turísticos \\
\hline & Idear herramientas interactivas para crear conciencia o fomentar el conocimiento \\
\hline & Fomentar la creación de juegos centrados en el patrimonio y sus valores \\
\hline & $\begin{array}{l}\text { Organizar eventos multidisciplinarios (entretenimiento en vivo, arte callejero, artes } \\
\text { visuales, etc.) que se basen y expresen el valor patrimonial de un sitio. }\end{array}$ \\
\hline \multirow{7}{*}{$\begin{array}{l}\text { K4. Proporcionar una } \\
\text { capacitación óptima para } \\
\text { jugadores no profesionales y } \\
\text { para profesionales de otros } \\
\text { sectores con una conexión } \\
\text { con el patrimonio }\end{array}$} & $\begin{array}{l}\text { Organizar sesiones de capacitación / iniciación: incentivos para guías locales, } \\
\text { trabajadores estacionales, aprendices, proveedores de servicios. }\end{array}$ \\
\hline & $\begin{array}{l}\text { Desarrollar sesiones que introduzcan los conceptos básicos para identificar y evaluar } \\
\text { el patrimonio local }\end{array}$ \\
\hline & Introducir sesiones de sensibilización para los propietarios del patrimonio \\
\hline & Obtener profesionales involucrados en transmitir conocimientos y habilidades \\
\hline & Fomentar el descubrimiento del patrimonio con profesionales \\
\hline & Apoyar la tutela de profesionales no profesionales por parte de profesionales \\
\hline & $\begin{array}{l}\text { Incorporar el patrimonio y sus características específicas en los planes de respuesta a } \\
\text { emergencias }\end{array}$ \\
\hline \multirow{11}{*}{$\begin{array}{l}\text { K5. Diversificar los sistemas } \\
\text { de capacitación para } \\
\text { profesionales del patrimonio }\end{array}$} & $\begin{array}{l}\text { Proporcionar información sobre los sistemas e incentivos existentes, a nivel nacional } \\
\text { y europeo }\end{array}$ \\
\hline & $\begin{array}{l}\text { Evaluar: realizar un análisis y proponer mejoras propuestas para la formación de } \\
\text { profesionales }\end{array}$ \\
\hline & Asegurar la sostenibilidad de las medidas apropiadas \\
\hline & Apoyar el uso generalizado de cuentas de entrenamiento personal \\
\hline & Mejorar la cooperación entre universidades, escuelas y centros de capacitación \\
\hline & Asegurar la coordinación entre los sistemas de capacitación y las redes profesionales \\
\hline & $\begin{array}{l}\text { Organizar sesiones de capacitación internas con el apoyo de expertos (temáticos, } \\
\text { técnicos y específicos, situación actual, diálogo interdisciplinario o intersectorial, } \\
\text { etc.) }\end{array}$ \\
\hline & Introducir becas para profesionales \\
\hline & Aprovechar las oportunidades brindadas por el programa Erasmus + \\
\hline & $\begin{array}{l}\text { Apoyar los intercambios de buenas prácticas y movilidad, tanto nacionales como } \\
\text { internacionales: aprendices, jóvenes profesionales, formación continua }\end{array}$ \\
\hline & Apoyar la tutela en Europa \\
\hline \multirow{4}{*}{$\begin{array}{l}\text { K6. Desarrollar bancos de } \\
\text { conocimiento sobre } \\
\text { materiales, técnicas y } \\
\text { conocimientos locales y } \\
\text { tradicionales }\end{array}$} & $\begin{array}{l}\text { Crear lugares dedicados para la conservación del conocimiento y el know-how, tanto } \\
\text { tradicionales como generados por la gestión del patrimonio }\end{array}$ \\
\hline & Utilizar las nuevas tecnologías para documentar y preservar el know-how \\
\hline & Crear un centro europeo de habilidades y conocimiento \\
\hline & Crear y expandir "bibliotecas de materiales" \\
\hline K7. Asegurar que el & Apoyar a los maestros artesanos para garantizar la transmisión de conocimientos y \\
\hline
\end{tabular}


conocimiento y las

habilidades involucradas en

patrimoniales se transmiten

\section{K8. Garantizar las}

competencias de los

profesionales que trabajan en

el patrimonio de la lista los intercambios

habilidades

Adoptar medidas para facilitar la realización de talleres por parte de personas más jóvenes

Ayudar a las empresas a enfrentar a los jóvenes

Organizar exhibiciones y demostraciones

Promover incentivos a través de competências

Exhibir proyectos manuales (en escuelas, medios de comunicación, etc.)

Desarrollar la enseñanza y la práctica de operaciones manuales (bocetos, medidas, etc.) junto con el diseño asistido por ordenador

Apoyar la creación y expansión de centros de capacitación para artesanías patrimoniales

Apoyar a la Fundación Europea de Habilidades del Patrimonio (FEMP)

Introducir arreglos para verificar las competencias de los profesionales que trabajan en activo

Alentar a los representantes electos y a las autoridades locales a involucrarse

Reclutar al sector privado y fomentar un sentido de responsabilidad entre los creadores del proyecto y las empresas

Asegurar la consulta entre los departamentos competentes: empleo, formación, empresa, cultura

Adoptar medidas de apoyo (de las autoridades locales) para empresas de alta calidad

K9. Desarrollar programas de estudio e investigación que reflejen las necesidades del sector del patrimonio y compartir los hallazgos

Identificar los clientes potenciales relevantes para estos estudios de investigación y temas (enfoques descendentes y ascendentes)

Fomentar un enfoque interdisciplinario e internacional del patrimonio

Estudiar cómo el patrimonio puede ayudar a satisfacer las necesidades de otros sectores

Difundir los resultados de los estudios e investigaciones a profesionales, gestores y usuarios

Evaluar y garantizar la sostenibilidad de los estudios y la investigación

Introducir programas de estudio temáticos en varias regiones

Desarrollar programas de divulgación (conferencias, cursos, programas de radio y televisión, publicaciones para lectores específicos, etc.)

Abrir centros de investigación al público

Organizar reuniones públicas entre profesionales, investigadores y usuarios (cuestiones patrimoniales y debates)

Resaltar los temas que vinculan las disciplinas (ciencias y patrimonio, innovación y patrimonio)

Apoyar la cooperación de investigación europea e internacional basada en la red

K10. Fomentar y apoyar el desarrollo de redes

Proporcionar asistencia para la creación de redes

Reconocer las redes existentes y facilitar su desarrollo

Establecer relaciones con redes existentes en otros sectores que tienen intereses comunes

Establecer un diálogo entre las redes y considerar cursos de acción comunes concertados

K11. Explorar el patrimonio como una fuente de

Utilizar sitios patrimoniales como residencias artísticas para explicar lo que significan estos sitios

conocimiento, inspiración y

creatividad
Yuxtaponer el patrimonio y los objetos contemporáneos

Introducir talleres de descubrimiento del patrimonio dedicados a los artesanos y creadores 
Cada una de las once recomendaciones presenta ejemplos de buenas prácticas que tienen lugar dentro de los ámbitos de la educación formal o no formal en sus Estados miembros. Estos ejemplos aparecen clasificados según su relación y proximidad a las líneas de actuación recomendadas en relación al componente educativo y de conocimiento.

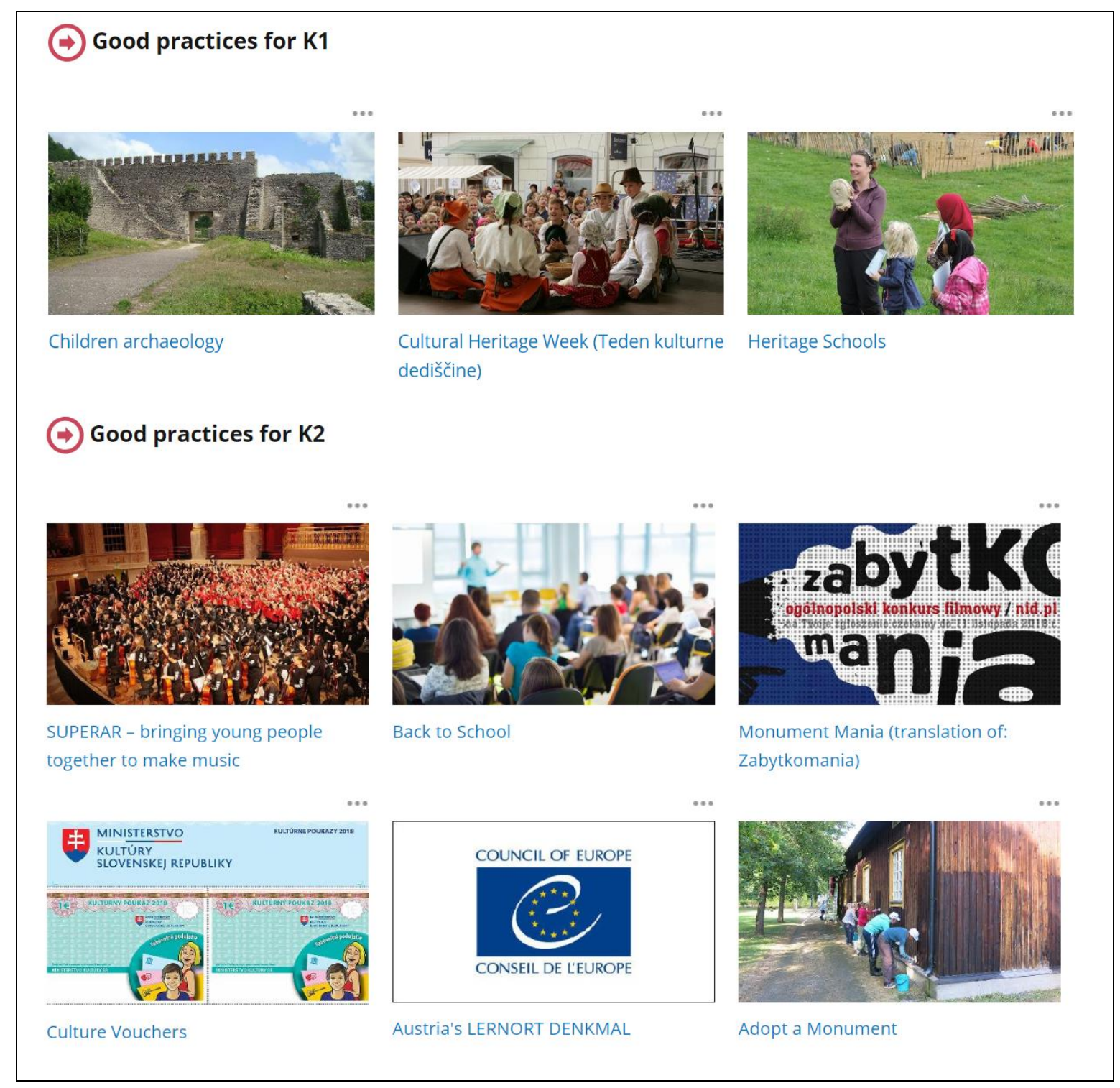

Figura 7. Captura del portal web Cultural heritage at the Council of Europe. Ejemplos de buenas prácticas en relación a las recomendaciones sobre el componente educativo y de conocimiento.

A su vez, cada una de las once recomendaciones en relación al componente educativo y de conocimiento se vincula a los desafíos que ofrecen diferentes cursos de acción, que persiguen un enfoque interdisciplinario y participativo para tener un efecto en cada uno de los tres componentes de la estrategia: componente "social" (S); componente de "desarrollo territorial y económico" (D); componente de "conocimiento y educación" 
(K). Los desafíos de los tres componentes que se pretende alcanzar y que se relacionan con las recomendaciones del componente de conocimiento y educación son:

Desafíos sociales (DS):

- Conservando la memoria colectiva (DS1).

- Desafíos de conocimiento y educación (DCE):

- Fomentar una sociedad del conocimiento compartida (DCE1).

- Identificar, preservar, transmitir y compartir conocimientos y habilidades patrimoniales (DCE2).

- Sensibilizar sobre los valores transmitidos por el patrimonio (DCE3).

- Afianzar el compromiso de los jóvenes con el patrimonio (DCE4).

- Ayudar a fomentar una sociedad del conocimiento compartida (DCE5). Garantizar que las partes interesadas en el patrimonio tengan acceso a la formación continua (DCE6).

- Garantizar un alto nivel técnico para todos los oficios patrimoniales y artesanales (DCE7).

Desafíos de desarrollo (DD):

- Desarrollar la prosperidad de Europa recurriendo a sus recursos patrimoniales (DD1).

- Preservar y desarrollar la capacidad de los servicios públicos para abordar los problemas del patrimonio (DD2).

- Apoyar, fortalecer y promover la cooperación intergubernamental (DD3).

A continuación presentamos una tabla resumen que nos permite distribuir estos desafíos en cada una de las Recomendación del componente educativo y de conocimiento (K).

Tabla 3

Relación de las recomendaciones del componente educativo y de conocimiento $(K)$ con cada uno de los desafíos relativos a los tres componentes (DS, DCE, DD) de la Estrategia XXI

\section{Recomendaciones (K1) Desafíos}

K1. Incorporar la educación del patrimonio de manera más efectiva en el DS1- DCE1- DCE2- DCE3 currículo escolar

K2. Implementar medidas para alentar a los jóvenes a practicar el DCE2- DCE3- DCE4 patrimonio

K3. Fomentar la creatividad para captar la atención de la audiencia de DCE2- DCE3- DCE5- DCE6 


\begin{tabular}{|l|l|}
\hline patrimonio & \\
\hline $\begin{array}{l}\text { K4. Proporcionar una capacitación óptima para jugadores no } \\
\text { profesionales y para profesionales de otros sectores con una conexión } \\
\text { con el patrimonio }\end{array}$ & $\begin{array}{l}\text { DCE2- DCE3- DCE5- DCE6- } \\
\text { DCE7 }\end{array}$ \\
\hline $\begin{array}{l}\text { K5. Diversificar los sistemas de capacitación para profesionales del } \\
\text { patrimonio }\end{array}$ & $\begin{array}{l}\text { DCE2- DCE3- DCE5- DCE6- } \\
\text { DCE7 }\end{array}$ \\
\hline $\begin{array}{l}\text { K6. Desarrollar bancos de conocimiento sobre materiales, técnicas y } \\
\text { conocimientos locales y tradicionales }\end{array}$ & $\begin{array}{l}\text { DS1- DCE2- DCE6- DD1- } \\
\text { DD2- DD3 }\end{array}$ \\
\hline $\begin{array}{l}\text { K7. Asegurar que el conocimiento y las habilidades involucradas en los } \\
\text { intercambios patrimoniales se transmiten }\end{array}$ & $\begin{array}{l}\text { DS1- DCE2- DCE3- DCE4- } \\
\text { DCE5- DCE6- DCE7 }\end{array}$ \\
\hline $\begin{array}{l}\text { K8. Garantizar las competencias de los profesionales que trabajan en el } \\
\text { patrimonio de la lista }\end{array}$ & $\begin{array}{l}\text { DCE2- DCE3- DCE5- DCE6- } \\
\text { DCE7 }\end{array}$ \\
\hline $\begin{array}{l}\text { K9. Desarrollar programas de estudio e investigación que reflejen las } \\
\text { necesidades del sector del patrimonio y compartir los hallazgos }\end{array}$ & $\begin{array}{l}\text { DCE2- DCE3- DCE4- DCE6- } \\
\text { DCE7 }\end{array}$ \\
\hline $\begin{array}{l}\text { K10. Fomentar y apoyar el desarrollo de redes } \\
\text { K11. Explorar el patrimonio como una fuente de conocimiento, } \\
\text { inspiración y creatividad }\end{array}$ & $\begin{array}{l}\text { DCE1- DCE2- DCE3- DCE6- } \\
\text { DCE7 }\end{array}$ \\
\hline $\begin{array}{l}\text { DCE6- DCE7 } \\
\text { DCE2 DCE3- DCE4- }\end{array}$
\end{tabular}

Además, la Estrategia XXI destaca la experiencia y los logros de los países de Europa, difundiéndolos y compartiéndolos a través del sistema HEREIN, una red de información sobre el patrimonio cultural europeo. Esta red busca crear sinergias y recopila datos e información relacionados con los mecanismos de financiamiento, legislaciones, sistemas de documentación, estrategias de conservación integradas y acciones de sensibilización, para el diálogo y el intercambio que facilita la cooperación entre los ministerios y las instituciones a cargo de la gestión del patrimonio europeo. Reúne a las administraciones públicas de 42 Estados miembro y cuenta con una base de datos donde se inventaría los documentos, así como un tesauro de terminología. Además, funciona como una herramienta de "observatorio", ya que sigue la implementación de las convenciones europeas sobre el patrimonio, la evolución de las políticas y el fortalecimiento de los valores del mismo para la sociedad; como factor de diálogo intercultural y mejora de las condiciones de vida.

Por último, destacamos una de las futuras acciones que el Consejo de Europa prevé destinar el año 2020 al tema "Patrimonio y Educación" dentro del marco estratégico. Esta acción se gestó en la 13 $3^{\text {a }}$ reunión desarrollada a finales de 2017 en las anualidades del Steeting Committee for Culture, Heritage and Landscape (CPCPP), que se reúne para reflexionar sobre los logros, aspectos destacados y acciones futuras. 


\subsubsection{La Educación Patrimonial en los textos nacionales y en la ley de Educación}

La preocupación en torno al patrimonio y la educación también se traslada a los textos legislativos y normativos de las instituciones encargadas de la tutela patrimonial a nivel nacional. Comenzamos realizando una revisión documental sobre la presencia y el enfoque de la educación dentro de los textos que regulan la gestión del patrimonio; por otro lado, analizamos también la presencia y el tratamiento que recibe el patrimonio en los textos que regulan la educación formal dentro del territorio español.

En el proceso legislativo a nivel normativo de los bienes patrimoniales en el territorio español debemos comenzar haciendo alusión a la Real Academia de la Historia, como institución referente en la conservación y gestión en materia de patrimonio. Algunos autores como Tortosa y Mora (1996), desatacan a través de la información manuscrita e inédita de sus archivos, el peso de la Real Academia de la Historia en el proceso de conformación y definición del Patrimonio Español y su gestión. Por otro lado, otras investigaciones manifiestan un anquilosamiento de la institución, argumentando que, durante la segunda mitad del siglo XVIII, el Ministerio de Fomento reclama a la Real Academia la elaboración de una Ley de Antigüedades que nunca se llega a realizar (Yañez y Lavín, 1999; Santos, 2002). Desde entonces son numerosas las leyes que se articulan para gestionar los distintos tipos de patrimonios del Estado, que permanecen vigentes hasta la entrada en vigor de la actual Ley de Patrimonio Histórico Español 16/1985. Esta ley supone un importante avance para la consagración de los derechos culturales, y establece normas para la conservación y defensa de los Bienes Culturales por parte de los particulares, referido como Acción Positiva de los Poderes Públicos (Fontal y Martínez, 2016b). La ley crea una nueva figura jurídica de protección del patrimonio histórico español, tanto mueble como inmueble, que son los llamados BIC (Bienes de Interés Cultural). También presenta un sentido más amplio del concepto de patrimonio cultural, ya que se incluye el patrimonio etnográfico, tanto bienes muebles e inmuebles y los conocimientos y actividades que son o han sido expresión relevante de la cultura tradicional del pueblo español en sus aspectos materiales, sociales o espirituales.

En la Ley 16/1985 encontramos las primeras referencias al ámbito educativo, donde se detalla la necesidad de establecer "una política que complemente la acción vigilante con 
el estímulo educativo, técnico y financiero, en el convencimiento de que el Patrimonio Histórico se acrecienta y se defiende mejor cuanto más lo estiman las personas que conviven con él” (Ley 16/1985, p. 20342), aunque se entiende como un estímulo que complemente las acciones de conservación no como una línea sólida en su gestión. Al mismo tiempo se indicaba la labor de las bibliotecas como instituciones culturales al servicio de la educación, la investigación, la cultura y la información (Ley 16/1985, art. 63). Dentro de la ley se presenta en su artículo tercero, el organismo del Consejo del Patrimonio Histórico y se detalla su marco jurídico y de actuación:

La comunicación y el intercambio de programas de actuación e información relativos al Patrimonio Histórico Español serán facilitados por el Consejo del Patrimonio Histórico, constituido por un representante de cada Comunidad Autónoma, designado por su Consejo de Gobierno, y el Director General correspondiente de la Administración del Estado, que actuará como Presidente (Ley 16/1985, art 3).

Entre las principales funciones del Consejo del Patrimonio histórico debemos destacar:

- Conocer los programas de actuación, tanto estatales como regionales, relativos al Patrimonio Histórico Español, así como los resultados de los mismos.

- Elaborar y aprobar los Planes Nacionales de Información sobre el Patrimonio Histórico, que tienen como objeto fomentar la comunicación entre los diferentes servicios y promover la información necesaria para el desarrollo de la investigación científica y técnica.

- Elaborar y proponer campañas de actividades formativas y divulgativas sobre el Patrimonio Histórico.

- Informar de las medidas que se deben adoptar para asegurar la necesaria colaboración con objeto de cumplir los compromisos internacionales contraídos por España que afecten al Patrimonio Histórico Español (Real Decreto 111/1986, p. 220).

Queda claro el interés en la formación de la sociedad, aunque es cierto que este enfoque estaba principalmente dirigido a la divulgación más que a la necesidad de conectar y crear vínculos entre los jóvenes y no tan jóvenes con estos bienes patrimoniales, que es el enfoque actual de la educación patrimonial (Fontal y Marín, 2018). Con la intención de aplicar la Ley 16/1985, se implementa el Real Decreto 111/1986 que completa y precisa dichos aspectos. El Real Decreto regula en su Título I la organización y funcionamiento de los órganos colegiales, por resultar decisiva su intervención en la 
aplicación de las normas, así como en la planificación y coordinación de las actividades tendentes a la protección y enriquecimiento del Patrimonio Histórico Español.

Otro de los organismos con competencias en patrimonio en la Dirección General de Bellas Artes y Patrimonio Cultural del Ministerio de Educación, Cultura y Deporte, que se encarga de "la propuesta y ejecución de la política de Gobierno en materia educativa, de formación profesional y de universidades; así como de la promoción, protección y difusión del patrimonio histórico español” (Real Decreto 284/2017, p. 21316). Son numerosos los programas de acción cultural que se desarrollan para impulsar la participación de la sociedad en procesos de creación, dinamización cultural y obtención de recursos. A nivel autonómico, también encontramos organismos de gestión como las Direcciones Generales de Patrimonio dependientes de las Conserjerías de Cultura y Turismo.

Otro de los órganos fundamentales en la gestión del patrimonio cultural es la Subdirección General del Instituto de Patrimonio Cultural (IPCE), adscrita a la Dirección General de Bellas Artes. El desempeño de sus funciones se articula en torno a 4 ejes:

- La conservación y restauración de los bienes integrantes del Patrimonio Cultural de España

- La investigación del Patrimonio Cultural.

- La conservación y gestión del fondo documental gestionado por el Instituto

- La difusión de los proyectos de la institución (Real Decreto 817/2018).

Dentro del eje de difusión se enmarcan todas las acciones y proyectos educativos desarrollados por la institución. Además, el Observatorio de Educación Patrimonial en España dentro del cual se enmarca el desarrollo de esta tesis doctoral, ha colaborado en la elaboración de múltiples informes sobre el tratamiento del patrimonio en la legislación educativa vigente y sobre la evaluación de la calidad de los diseños educativos de los programas sobre educación patrimonial (Fontal, Marín y Pérez, 2013; Fontal y Martínez, 2016a). Al mismo tiempo, varios de sus miembros (Dr. Ibáñez-Etxeberria y Dra. Fontal) han participado en la creación y desarrollo teórico del Plan Nacional de Educación y Patrimonio (Domingo et al., 2013), que abordaremos de manera más detallada en el siguiente punto. 
En la segunda parte de este apartado analizamos el papel que juega el patrimonio dentro de la legislación educativa vigente en la enseñanza obligatoria. En primer lugar, comenzamos exponiendo las dispares posiciones ideológicas sobre la voluntad de uniformidad o diferenciación territorial que surgen en España, y que nos sitúan en 1990 ante un complejo escenario en el proceso de descentralización educativa, que no es tanto el resultado de un análisis educativo (Gimeno, 2005; Frías del Val, 2007), sino que responde a un cambio del Estado central al Estado de las autonomías (Puelles, 1992). La descentralización política en España surge de los principios emanados de la Constitución Española de 1978, y desde entonces se han implantado 3 leyes educativas: La Ley Orgánica de Ordenación General del Sistema Educativo (LOGSE) de 1990, que derogaba la Ley de 1970 del régimen franquista y descentraliza el currículo; la Ley Orgánica de Educación (LOE) de 2006, que introduce el aprendizaje basado en competencias y amplía la presencia del patrimonio en una dirección más integral y holística; y la Ley Orgánica para la mejora de la calidad educativa (LOMCE) de 2013 que modifica la anterior y se encamina a superar la dimensión actitudinal en la enseñanza del patrimonio para acercarse a los procesos de sensibilización (Fontal, 2016a). Una mirada retrospectiva muestra una aceleración del proceso, que parece indicar una respuesta a los cambios en el poder político, más que a las necesidades sociales. Esta reforma fue analizada por autores como Puelles $(1992 ; 2016)$ que no se oponían a la idea del currículo nacional en sí, sino que defendían que, bajo otra dirección política, el currículo nacional podría actuar dentro de una perspectiva emancipadora. Se criticaba un determinado currículo asociado a determinada coyuntura político económica, y se rechazaba la asociación del currículo con el neoliberalismo y las políticas de mercado (Casimiro, 2008).

A lo largo del proceso de desarrollo doctoral se ha realizado un análisis exhaustivo de la legislación educativa en torno al tratamiento del patrimonio en al ámbito nacional y autonómico dentro de la Educación Primaria y Secundaria en varios momentos temporales. En un primer momento a través de un informe para el IPCE (Fontal y Martínez, 2016a), y posteriormente un análisis actualizado con los nuevos Decretos, en base al tratamiento, la tipología patrimonial y el enfoque metodológico del patrimonio focalizado en el currículum de Educación Patrimonial (Fontal et al., 2017), cuyos datos y resultados se presentan en el primer artículo de esta tesis doctoral por compendio de publicaciones. A continuación, para el desarrollo de este apartado nos centraremos en la 
Educación Primaria por interés y proximidad profesional con la intención de clarificar su organización administrativa y facilitar la comprensión de los datos resultantes.

La Educación Primaria en España, tiene un carácter obligatorio y gratuito, y comprende seis cursos académicos, organizados en áreas con carácter global e integrador. Actualmente, la Educación Primaria está regulada por la LOE, modificada por la LOMCE. El nuevo artículo 6 de la LOE define el currículo como "la regulación de los elementos que determinan los procesos de enseñanza y aprendizaje para cada una de las enseñanzas" (Art. 6.1). Los elementos que componen el currículo son: los objetivos; las competencias; los contenidos organizados en áreas; la metodología didáctica; los estándares de aprendizaje evaluables y los criterios de evaluación (LOMCE, Art. 6.2). El artículo 6 bis distribuye las competencias entre las distintas administraciones educativas y los centros. En esta distribución competencial el Gobierno del Estado a través del Ministerio de Educación Cultura y Deporte dicta el Real Decreto (RD) 126/2014, de 28 de febrero, por el que se establece el currículo básico de la Educación Primaria, para garantizar el carácter oficial y validar las titulaciones en el territorio nacional. El diseño curricular organiza las asignaturas en tres bloques: asignaturas troncales comunes a todos los alumnos; asignaturas específicas y asignaturas de libre configuración autonómica. Por su parte, cada comunidad autónoma mediante sus respectivos decretos y órdenes regula la ordenación del currículo de Educación Primaria según las peculiaridades de su sistema educativo, donde muchas aprovechan para introducir asignaturas de libre configuración que abordan contenidos sobre la lengua propia de la comunidad, su cultura y patrimonio. A su vez, los centros docentes desarrollan la concreción curricular y organizan las actividades docentes en el uso de su autonomía pedagógica. A continuación desgranamos la configuración curricular en función de las competencias del Estado, de las autonomías y de los centros para cada uno de los tres bloques de asignaturas. 
Tabla 4

Distribución de competencias según Real Decreto 126/2014 y organización de las áreas

\begin{tabular}{|c|c|c|c|}
\hline Bloques de asignaturas & $\begin{array}{l}\text { Competencia del } \\
\text { Gobierno del Estado }\end{array}$ & $\begin{array}{l}\text { Competencia de la } \\
\text { Comunidad Autónoma }\end{array}$ & $\begin{array}{l}\text { Competencia } \\
\text { de los centros }\end{array}$ \\
\hline $\begin{array}{l}\text { Asignaturas troncales } \\
\text { - Ciencias de la Naturaleza. } \\
\text { - Ciencias Sociales. } \\
\text { - Lengua Castellana y } \\
\text { Literatura. } \\
\text { - Matemáticas. } \\
\text { - Primera Lengua Extranjera. }\end{array}$ & $\begin{array}{l}\text { - Determinar los contenidos } \\
\text { comunes, los estándares de } \\
\text { aprendizaje evaluables y el } \\
\text { horario lectivo mínimo. } \\
\text { - Determinar los criterios de } \\
\text { evaluación del logro de los } \\
\text { objetivos, el grado de } \\
\text { adquisición de las } \\
\text { competencias y las } \\
\text { características generales de la } \\
\text { prueba evaluación final EP. }\end{array}$ & $\begin{array}{l}\text { - Complementar los } \\
\text { contenidos. } \\
\text { - Realizar recomendaciones } \\
\text { metodológicas a los centros } \\
\text { de su competencia. } \\
\text { - Complementar los criterios } \\
\text { de evaluación. } \\
\text { - Fijar el horario lectivo } \\
\text { máximo. }\end{array}$ & $\begin{array}{l}\text { - } \text { Complementar los } \\
\text { contenidos y configurar su } \\
\text { oferta formativa. } \\
\text { - Diseñar e implantar métodos } \\
\text { pedagógicos y didácticos } \\
\text { propios. } \\
\text { - Determinar la carga horaria } \\
\text { de las diferentes asignaturas. }\end{array}$ \\
\hline $\begin{array}{l}\text { Asignaturas específicas } \\
\text { - Educación Física. } \\
\text { - Religión, o Valores Sociales y } \\
\text { Cívicos (s/ padres o tutores). } \\
\text { Al menos una de las áreas: } \\
\text { - } 1^{\circ} \text {. Educación Artística. } \\
\text { - } 2^{\circ} \text {. Segunda Lengua } \\
\text { Extranjera. }\end{array}$ & $\begin{array}{l}\text { - Determinar los estándares de } \\
\text { aprendizaje evaluables. } \\
\text { - Determinar los criterios de } \\
\text { evaluación del logro de los } \\
\text { objetivos, el grado de } \\
\text { adquisición de las } \\
\text { competencias y las } \\
\text { características generales de la } \\
\text { prueba evaluación final EP. }\end{array}$ & $\begin{array}{l}\text { - Establecer los contenidos. } \\
\text { - Complementar los criterios } \\
\text { de evaluación. } \\
\text { - Realizar recomendaciones } \\
\text { metodológicas a los centros } \\
\text { de su competencia. } \\
\text { - Fijar el horario. }\end{array}$ & $\begin{aligned}- \text { - } & \text { Complementar los } \\
& \text { contenidos y configurar su } \\
& \text { oferta formativa. } \\
\text { - } & \text { Diseñar e implantar métodos } \\
& \text { pedagógicos y didácticos } \\
\text { propios. } & \\
\text { - } & \text { Determinar la carga horaria } \\
& \text { de las diferentes asignaturas. }\end{aligned}$ \\
\hline $\begin{array}{l}\text { Asignaturas de libre } \\
\text { configuración autonómica } \\
\text { - Lengua cooficial y Literatura } \\
\text { (Comunidades con lengua } \\
\text { cooficial). } \\
\text { - Oferta educativa que } \\
\text { establezca cada } \\
\text { Administración educativa. }\end{array}$ & & $\begin{array}{l}\text { - Establecer los contenidos. } \\
\text { - Establecer los estándares de } \\
\text { aprendizaje evaluables. } \\
\text { - Establecer los criterios de } \\
\text { evaluación. } \\
\text { - Realiza recomendaciones } \\
\text { metodológicas a los centros } \\
\text { de su competencia. } \\
\text { - Fijar el horario. }\end{array}$ & 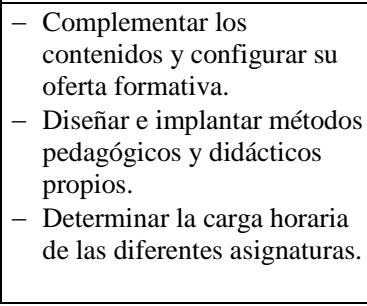 \\
\hline
\end{tabular}

La descentralización curricular que surge de la distribución competencial provoca que sean las Administraciones educativas de cada comunidad, según sus peculiaridades, las que fijan el mayor o menor grado de sensibilización hacia el patrimonio cultural, y así lo reflejan en la organización de las áreas en las que tienen competencias. El RD 126/2014, aborda el patrimonio cultural y natural de forma generalizada y recoge como criterio metodológico para la enseñanza-aprendizaje del patrimonio cultural la secuencia de sensibilización -Conocer, comprender, respetar, valorar, sensibilizar, cuidar, transmitir-, planteada por Fontal (2003) y recogida en el Plan Nacional de Educación y Patrimonio (Domingo et al., 2013). La frecuencia con la que encontramos la secuencia de sensibilización, está en relación directa con la presencia del patrimonio como contenido curricular, y esta varía en función de la oferta educativa de cada comunidad en el bloque de asignaturas de libre configuración. En la Tabla 5 mostramos una relación por comunidades. 
Tabla 5

Oferta de asignaturas específicas y de libre configuración por comunidades.

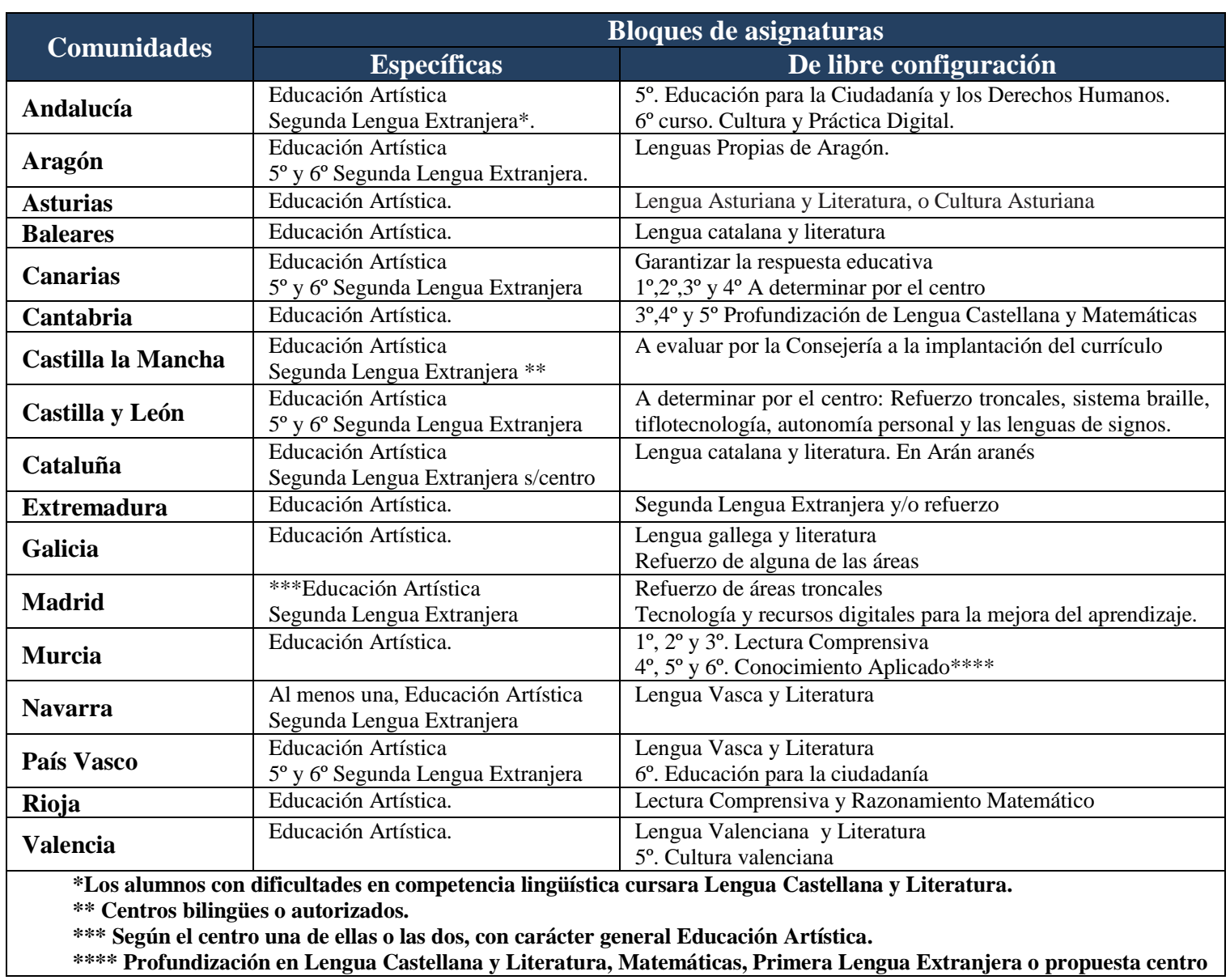

Las comunidades de Andalucía, Asturias y Valencia ofertan una asignatura de la cultura de su comunidad al menos en algún curso de la etapa. Si comparamos estos datos con los resultados de las figuras 8 y 9 observamos que las comunidades que desarrollan asignaturas específicas con objetivos como conocer y valorar el patrimonio natural y cultural y contribuir activamente a su conservación y mejora; entender la diversidad linguí́stica y cultural como un valor de los pueblos y de los individuos; y desarrollar una actitud de interés y respeto hacia la misma, son las que mejores resultados presentan.

Para lograr la consecución de los objetivos que se plantean en las distintas áreas, la normativa vigente potencia un aprendizaje basado en competencias siguiendo la Recomendación 2006/962/CE, de 18 de diciembre, del Parlamento Europeo y del Consejo. El -marco de referencia- considera 8 competencias clave que define "como una combinación de conocimientos, capacidades y actitudes adecuadas al contexto" (Recomendación 2006/962/CE, p. 394/13). Las competencias que se caracterizan por: su 
carácter transversal, abordado desde las distintas áreas de conocimiento y todos los ámbitos; su carácter dinámico, las personas van alcanzando mayores cotas de desempeño en el uso a través del proceso de desarrollo necesario y su carácter integral. Las competencias integradas en los elementos curriculares propician nuevos enfoques en el proceso enseñanza-aprendizaje, la docencia y la evaluación. Este enfoque curricular favorece una visión interdisciplinaria y pretende lograr un nuevo modelo docente, que sea capaz de generar situaciones donde el alumno sea agente de su propio proceso de aprendizaje contextualizando funcionalmente los procesos cognitivos. Estas competencias se detallan en el Real Decreto 126/2014: '1. Comunicación lingüística; 2. Competencia matemática y competencias básicas en ciencia y tecnología; 3. Competencia digital; 4. Aprender a aprender; 5. Competencias sociales y cívicas; 6. Sentido de iniciativa y espíritu emprendedor; 7. Conciencia y expresiones culturales (Art. 2.2). Para adquirir la competencia clave -conciencia y expresiones culturales-, el Parlamento Europeo y del Consejo en su Recomendación 2006/962/CE, propone una serie de conocimientos, capacidades y actitudes que toda persona debe poseen:

La expresión cultural precisa una conciencia de la herencia cultural a escala local, nacional y europea y de su lugar en el mundo. Abarca conocimientos básicos de las principales obras culturales, incluida la cultura popular contemporánea. Es esencial comprender la diversidad cultural y lingüística en Europa y otras regiones del mundo, la necesidad de preservarla y la importancia de los factores estéticos en la vida cotidiana.

Las capacidades (...): la apreciación y el disfrute de las obras de arte y de las artes escénicas, así como la expresión de uno mismo a través de distintos medios gracias a las capacidades individuales innatas. (...) la habilidad para comparar las opiniones creativas y expresivas de uno mismo con las de otros y para determinar y realizar las oportunidades sociales y económicas de una actividad cultural. La expresión cultural es fundamental para el desarrollo de las aptitudes creativas, que pueden trasladarse a una variedad de contextos profesionales.

La base del respeto y de una actitud abierta a la diversidad de la expresión cultural es una buena compresión de la cultura propia y un sentimiento de identidad. (...) en la creatividad y en la voluntad de cultivar las capacidades estéticas mediante la expresión artística y la participación en la vida cultural (p. L394/18).

Desarrollar la competencia "Conciencia y expresiones culturales" en los alumnos les permitirá conocer su herencia cultural, apreciar la diversidad cultural y generar un 
sentimiento identitario con los bienes culturales que pasarán a formar parte de su patrimonio, el cual querrán disfrutar, cuidar y legar.

A continuación, presentamos una fase investigativa dentro de la exposición del marco teórico, que busca la incidencia de las variables relativas al campo semántico del PCI, a través de un análisis de frecuencias y análisis comparativo, con la intención de conocer su presencia y enfoque en los currículos correspondientes a Educación Primaria (EP) y Educación Secundaria Obligatoria (ESO), buscando cómo se refleja esta idea en la normativa nacional y autonómica.

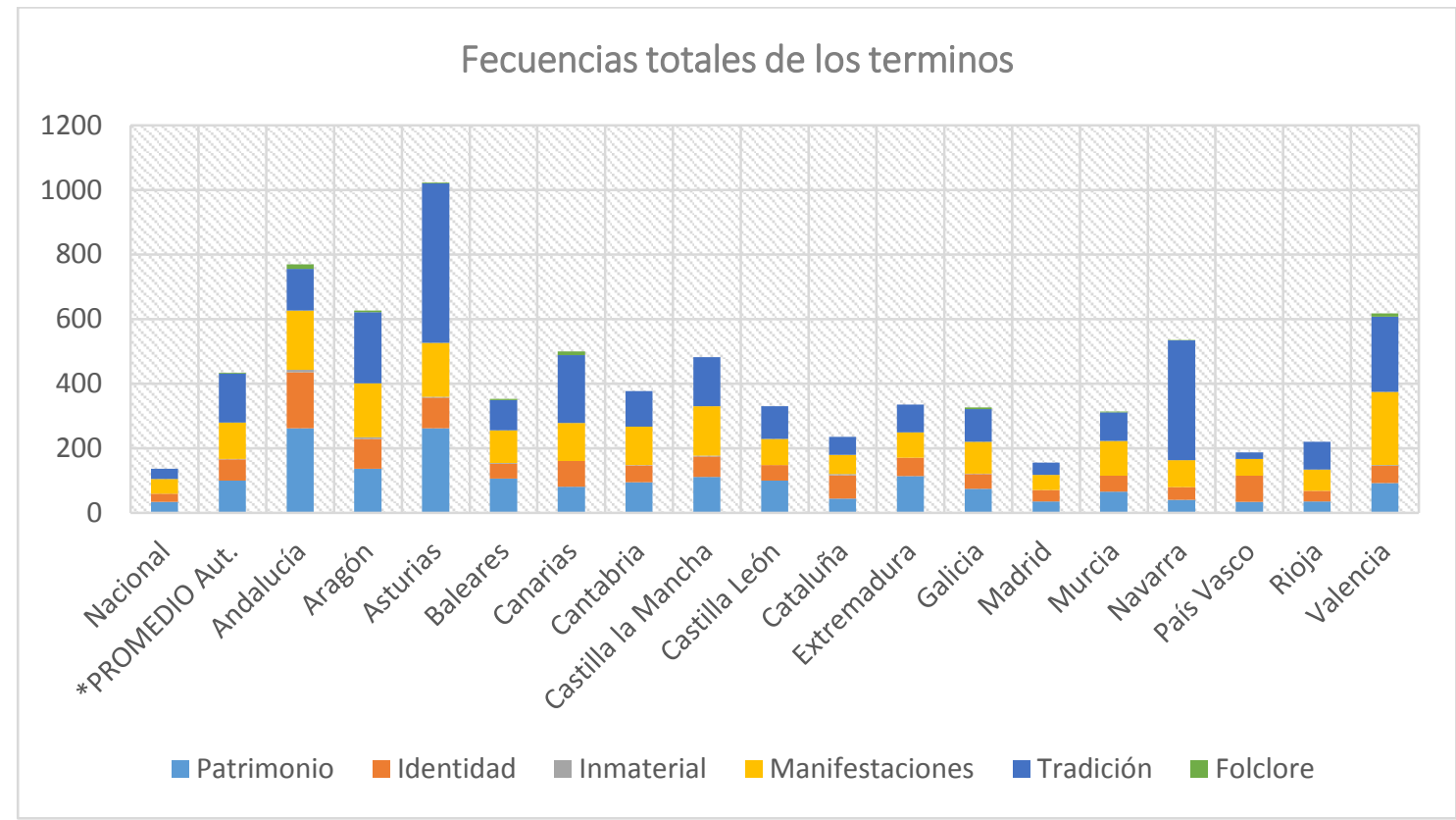

Figura 8. Frecuencias de los términos nacionales, autonómicos y promedio de las autonomías.

Las Comunidades Autónomas que abordan en mayor medida los conceptos empleados en los dos niveles educativos y que exceden ampliamente el promedio autonómico son Asturias, Andalucía y Aragón, ocupando los últimos lugares Madrid, País Vasco y La Rioja. Cabe destacar el número de entradas que presentan las comunidades de Asturias y Navarra con el descriptor tradición. Así como la comunidad de Andalucía y Asturias con el término patrimonio.

Por niveles educativos y atendiendo a la EP, las CC AA de Andalucía, Asturias y Canarias muestran un mejor tratamiento e interés hacia patrimonio, rebasan ampliamente el promedio autonómico. En al caso contrario se encuentran Madrid, Cataluña y La Rioja, en las cuales las entradas de la terminología buscada son muy reducidas y casi nula en el caso de Madrid (ver Figura 9). 


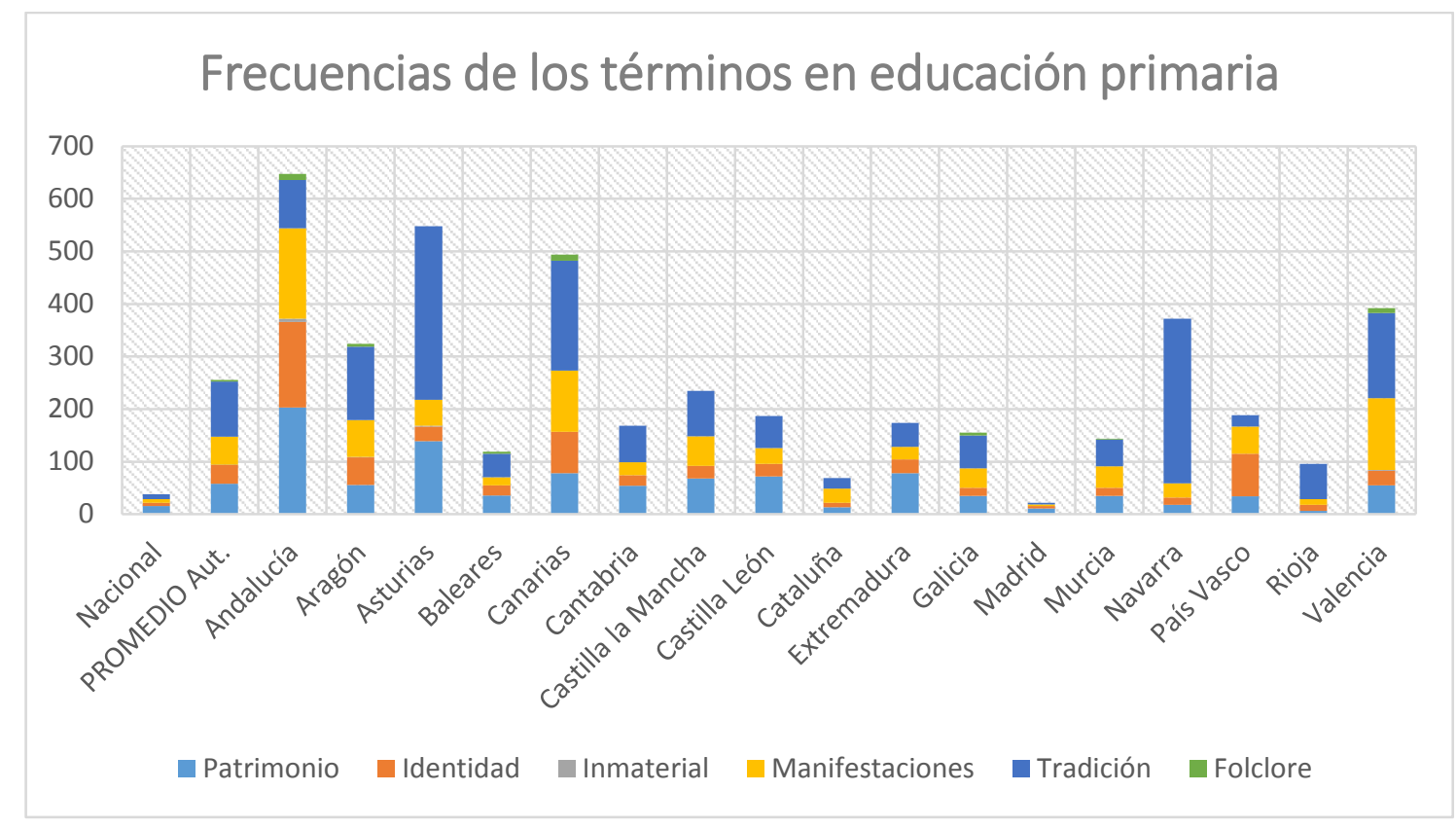

Figura 9. Frecuencias de los términos nacionales, autonómicos y promedios de las autonomías en educación primaria.

Respecto a la ESO, las autonomías más concienciadas con el patrimonio según el reflejo de su legislación educativa son Asturias y Aragón, con menor sensibilidad encontramos a Canarias y La Rioja. Destaca la Comunidad Asturiana con el empleo de los términos patrimonio y tradición, dotando de gran protagonismo a sus manifestaciones y representaciones tradicionales.

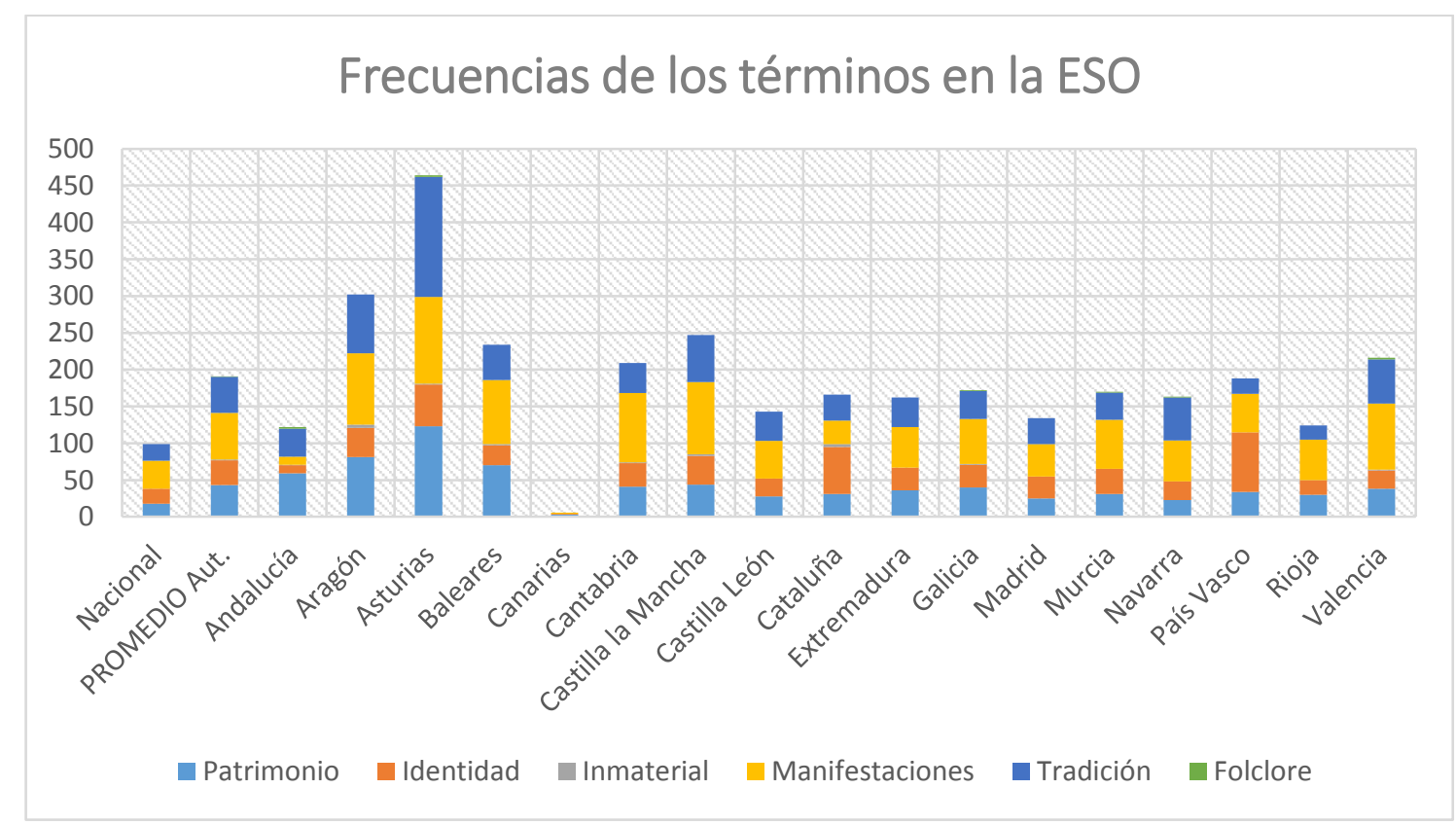

Figura 10. Frecuencias de los términos nacionales, autonómicos y promedios de las autonomías en la ESO. 
Comparando los niveles educativos, si bien en el ámbito nacional, se aprecia un claro incremento de la terminología buscada en el RD correspondiente a la ESO respecto del RD de EP. Esta tendencia es tratada por las CC AA de forma desigual, 6 comunidades suman un valor superior en EP, 6 en ESO y las cinco restantes, presentan valores muy similares en ambos niveles.

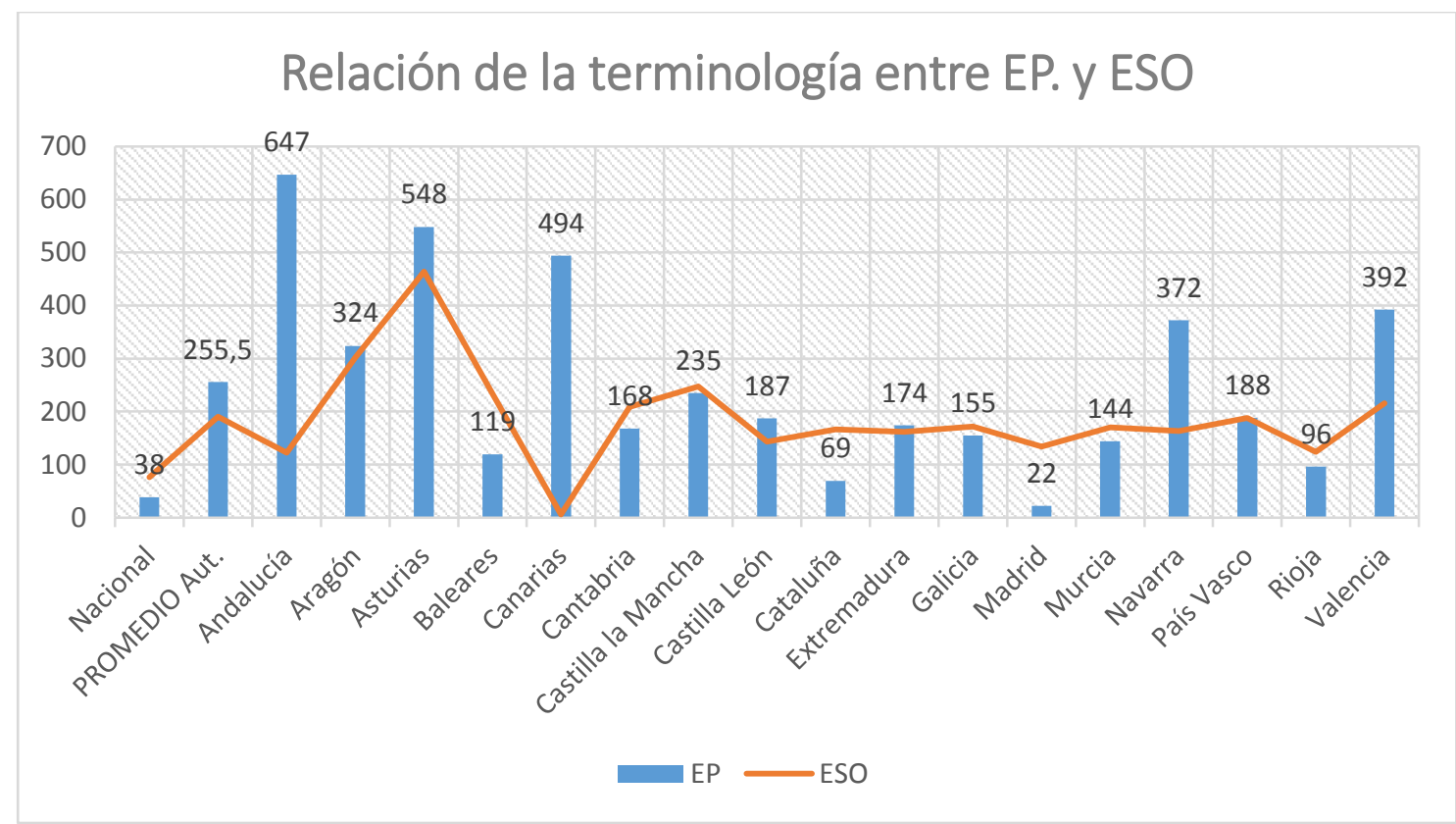

Figura 11. Comparación niveles educativos nacional, autonómicos y promedio.

Los términos buscados se encuentran de modo desigual en las normas nacionales y autonómicas, teniendo una mayor relevancia en la legislación autonómica, debido a que son estas últimas las que desarrollan los currículos, cuyos textos reflejan con más o menos fuerza el papel que el patrimonio ostenta en (la legislación educativa dentro de la educación obligatoria) los currículos escolares en la educación obligatoria.

En las normas analizadas, los descriptores buscados aparecen vinculados en muchas ocasiones, siendo el más frecuente patrimonio y manifestaciones, aunque no suelen aparecer literalmente vinculado, si se encuentra una gran relación entre los términos, y se observa también, que en muchas ocasiones hacen alusión al patrimonio inmaterial sin nombrarlo directamente. Los términos, patrimonio e identidad también aparecen vinculados y su relación se trabaja conceptualmente (...). El término identidad se utiliza de forma variable según los niveles educativos. Así, la identidad se centra en la configuración y reafirmación de la persona, relacionada directamente con el desarrollo evolutivo del niño. Sin embargo, según van madurando los alumnos, apreciamos cómo la identidad pasa a trabajarse desde una conciencia más cultural, entendiendo al 
alumnado como grupo inserto en una comunidad escolar, local, nacional e internacional" (Martínez, 2016, p. 196).

A pesar de las ausencias detectadas en ciertas comunidades, se detecta un interés general hacia el patrimonio como elemento capaz de vehicular la comprensión de las identidades, conocimiento de técnicas y recursos, promotor de actitudes. También se detecta una redacción que parte desde lo más cercano para comprender otras realidades, desde el patrimonio local hasta el universal o colectivo, siempre con una visión enfocada a la cadena de sensibilización que pretende conocer para valorar, valorar para respetar y respetar para conservar, partiendo de lo más cercano para comprender lo ajeno (Fontal, 2003).

En último lugar analizamos las categorías de patrimonio que se presentan en los contenidos curriculares de EP en las distintas CC AA. Los descriptores temáticos para analizar el contenido de la muestra en base a la tipología patrimonial se configuran a partir de las definiciones sobre patrimonio de las convenciones de la UNESCO (1972, art.1-2; 2005; 2014). En base a ello elaboramos una clasificación con las 3 categorías principales de patrimonio, que se desgranan en subcategorías. Patrimonio cultural: Monumentos, obras arquitectónicas, escultura o pintura, elementos arqueológicos, inscripciones, cavernas, grupos de construcciones aisladas o reunidas, lugares creados por el hombre, lugares históricos, estéticos, etnológicos, etc. Patrimonio cultural inmaterial: Tradiciones y expresiones orales, el idioma, artes del espectáculo, usos sociales, rituales y actos festivos, conocimientos relacionados con la naturaleza y el universo, técnicas artesanales, gastronomía, música y danza tradicionales. Patrimonio natural: Monumentos naturales de formaciones físicas o biológicas, formaciones geológicas o fisiográficas hábitat de especies y lugares de belleza natural.

Los resultados en la figura 12 muestran como el patrimonio cultural y el patrimonio cultural inmaterial tiene una mayor presencia que el patrimonio natural, que incluso es inexistente en algunas comunidades como Murcia o Madrid. Por lo tanto, el patrimonio se trabaja desde una perspectiva holística (Cuenca, 2002; Desantes, 2013), donde se hace referencia a sus tres categorías intrínsecas. 


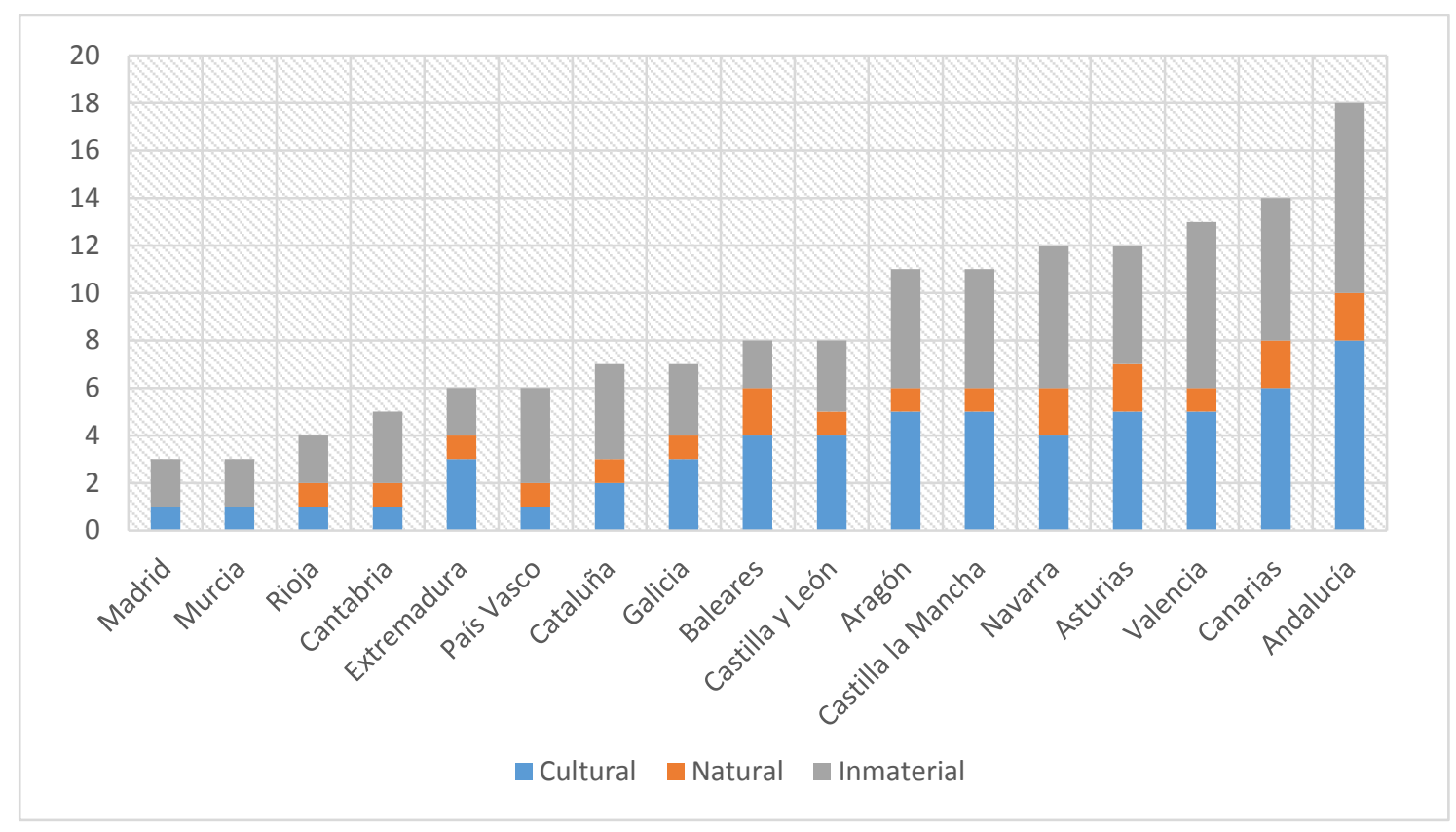

Figura 12. Tipologías patrimoniales que se trabajan en los contenidos curriculares de EP en las distintas comunidades.

Hay una amplia alusión a los ámbitos del patrimonio cultural inmaterial. Estos datos coinciden con la investigación realizada por Barghi, Zakaria, Hamzah y Hashim (2017), cuyos resultados revelan un foco en el patrimonio cultural inmaterial en algunas asignaturas, como historia, el idioma Bahasa Malaysia, arte y educación musical dentro del curriculum de educación primaria en Malaysia.

A pesar de la amplia presencia que revelan los datos, la terminología patrimonio cultural inmaterial no se utiliza de manera específica en la legislación educativa española, sino que el término patrimonio cultural engloba ambas concepciones, material e inmaterial. Por ello, en multitud de ocasiones no se especifica ni se utiliza el término inmaterial en su particularidad.

\subsubsection{El Plan Nacional de Educación y Patrimonio.}

La primera vez que la normativa nacional plantea la necesidad de estimular la gestión del patrimonio a través de la educación es en la Ley 16/1985 de Patrimonio Histórico Español. Desde entonces se inicia un proceso de trabajo que tiene su hito más importante en el año 2013 cuando ve la luz el Plan Nacional de Educación y Patrimonio (PNEyP en adelante) (Domingo et al., 2013). Este nuevo plan se enmarca dentro de los planes nacionales que nacieron en la segunda mitad de la década de 1980. El fundamento legal de los planes nacionales se enmarca en la citada ley que declara que "la Administración 
del Estado adoptará las medidas necesarias para facilitar la colaboración con los restantes poderes públicos y la de éstos entre sí, así como para recabar y proporcionar cuanta información fuera precisa" (Ley 16/1985, art. 2). También declara en su artículo treinta y cinco que "para la protección de los bienes integrantes del Patrimonio Histórico Español y al objeto de facilitar el acceso de los ciudadanos a los mismos, fomentar la comunicación entre los diferentes servicios y promover la información necesaria para el desarrollo de la investigación científica y técnica se formularán periódicamente Planes Nacionales de Información sobre el Patrimonio Histórico Español” (Ley 16/1985, art. 35). La competencia para elaborar y aprobar dichos planes se atribuye al Consejo de Patrimonio Histórico Español.

El primer Plan Nacional fue el de Catedrales, elaborado a partir de 1987 y aprobado en 1990, al que siguieron los de Patrimonio Industrial, Arquitectura Defensiva, Paisaje Cultural, y Abadías, Monasterios y Conventos en la primera década del siglo XXI. En el año 2010 el Ministerio de Educación Cultura y Deporte propuso al Consejo de Patrimonio la revisión y actualización de los planes nacionales existentes y la formulación de nuevos planes que con un carácter más transversal dieran respuesta a los nuevos campos patrimoniales. Es en este contexto una comisión integrada por técnicos de la Administración General del Estado, de las Comunidades Autónomas y expertos en la materia, comienza a trabajar en la redacción del PNEyP para su posterior aprobación por parte del Consejo de Patrimonio Histórico.

El plan surge ante la necesidad de tratar de responder al gran volumen de patrimonio desde el punto de vista de la coordinación desde administraciones autonómicas y estatales en materia de educación. Por otro parte, si bien es cierto que se llevan a cabo muchas propuestas educativas, en la mayoría de las ocasiones están aisladas y es importante que se conecten los ámbitos formal, no formal e informal de la educación (Domingo et al., 2013). Además los públicos son muy diversos y tienen necesidades muy particulares, por lo que es necesario desarrollar propuestas que no solo respondan a esos públicos de manera individual, sino a la combinación de estos públicos entre sí. En este sentido el Plan tiene un enfoque inclusivo ante la diversidad de públicos y las diferentes necesidades educativas, por lo que se desarrolla con una línea de trabajo hacia la accesibilidad universal (Buckley y Graves, 2016; Fontal y Marín, 2016; Marín, García, Vicent, Gillate y Gómez-Redondo, 2017), y considera que la esencia de la 
diversidad del Patrimonio reside en la propia diversidad del ser humano. Esta diversidad también debe trasladarse al marco de los procesos educativos como elemento nuclear, ya que "si no hay diversidad en la concepción y diseño educativos relacionados con el Patrimonio, no podremos garantizar la diversidad de los aprendizajes” (p. 16).

Otra de las necesidades que justifican la elaboración del Plan es la existen de materiales didácticos que no están fundamentados sobre una base psicopedagógica y didáctica. Por lo tanto, el Plan dentro de su apartado de aspectos metodológicos plantea que las acciones educativas que se desarrollen dentro de su marco se deben basar en un enfoque holístico y multidisciplinar del patrimonio y ser flexibles al contexto de aprendizaje. Deben buscar la rentabilidad social e identitaria, responder a las necesidades y expectativas del público al que van dirigidos y desarrollar planteamientos teóricometodológicos sólidos y de calidad. Para ello propone un proceso sistemático de evaluación desde el diseño hasta la implementación, "con una serie de criterios que establecen los parámetros de calidad establecidos y unos instrumentos y técnicas que permiten comprobar el grado de eficacia de los programas" (p. 15).

El proceso de evaluación de la calidad de un programa educativo se divide en tres secciones: Evaluación de la calidad de los diseños, evaluación de la implementación y evaluación de los resultados. Desarrollamos a continuación el apartado referente a la calidad de los diseños, por ser el que guarda una estrecha relación con el instrumento de evaluación de los diseños educativos de los programas sobre patrimonio cultural desarrollado por el observatorio y utilizado en dos artículos de esta tesis.

La calidad de los diseños: Deben establecerse parámetros (indicadores de calidad) que nos permitan determinar si un diseño se adecúa al contexto, si responde a los objetivos propuestos, si estos son de naturaleza didáctica, si son alcanzables a corto y medio plazo, si se definen estrategias didácticas aplicables, si tiene una estructura flexible, capaz de recoger toda variable propia de la naturaleza cambiante intrínseca a todo proceso de enseñanza-aprendizaje o si es consecuente con los últimos avances en materia de gestión de Patrimonio, entre otras muchas variables. Todo ello nos permite evaluar la calidad de un diseño educativo. (Domingo et al., 2013, p. 16).

Igualmente importante es la evaluación de la calidad de la implementación que atiende al grado de cumplimiento y adecuación de la planificación y de la consecución de los objetivos establecidos en el diseño. Muchas son las investigaciones en materia de 
educación patrimonial que evalúan la calidad de la implementación de acciones o programas educativos a través de la realización de estudios de caso (Alkateb, 2013; García-Ceballos, do Amaral y Olivar, 2017; Rivero, Fontal, García-Ceballos y Martínez, 2018a: Rivero, Fontal, Martínez y García Ceballos, 2018b). En último lugar, el Plan hace referencia a la calidad de los resultados planteando la estrecha relación entre los procesos y resultados, así como la necesidad de comparación entre los objetivos iniciales y los resultados para determinar su eficacia. La importancia de todo ello reside en el proceso de feedback continuo que nos permite determinar la eficacia y el nivel de logro o los cambios obtenidos tras una acción educativa, para obtener ideas o propuestas que guíen el diseño de futuros programas educativos. El Plan hace referencia a la necesidad de "definir modelos de evaluación, capaces de analizar el impacto de todas las medidas y actuaciones llevadas a cabo en el marco de la Educación Patrimonial” (p. 23).

Esto va estrechamente ligado a la necesidad de tener en cuenta la capacitación y formación del personal que se vincula a estas actividades educativas, ya que cuanto más en profundidad conozcan el ámbito de lo patrimonial, métodos y estrategias relacionadas con su enseñanza, mayor calidad tendrá el proceso de enseñanza-aprendizaje. En este sentido existen investigaciones que buscan analizar el grado de competencias de los profesionales tanto en el ámbito de la educación no formal (Cuenca, Estepa, MartínCáceres, 2017; Cuenca et al., 2018), como formal (Avci y Memişoğlu, 2016; Barghi et al., 2017; Pinto y Molina-Puche, 2015) y trabajos que buscan analizar la formación dentro de la educación universitaria que están recibiendo los futuros maestros en materia de patrimonio (Almansa y López, 2017; Fontal et al., 2017; Luna, Vicent, Reyes y Quiñones, 2019). Los futuros docentes necesitan ampliar sus conocimientos en otros ámbitos en relación con la naturaleza dinámica de sus elementos, con su gestión y con la metodología específica para su enseñanza dentro de la educación formal.

Por otra parte, según Fontal (2011), España tiene una legislación en materia educativa más que suficiente y muy destacable en cuanto al tratamiento que hace del patrimonio cultural, aunque considera que la realidad educativa no responde a esa extensión de la legislación. Por tanto, es necesario que se implemente la normativa educativa en cuanto a los contenidos patrimoniales. En este sentido el Plan velará por "la implementación de la normativa educativa para un progresivo incremento cualitativo y cuantitativo de los contenidos patrimoniales en los currículos, así como por la mejora de la capacitación del 
profesorado y de los recursos destinados a la transmisión del Patrimonio Cultural" (p. 5). Aunque es de destacar la presencia del Patrimonio en la base curricular (Fontal et al., 2017), que lo incorpora a las aulas como parte de los objetivos, competencias básicas y contenidos, según el PNEyP no cuenta con una adecuada implementación educativa dentro de la enseñanza formal. Este aspecto es especialmente relevante ya que considera que el aula "es uno de los lugares donde los niños y jóvenes pasan más tiempo y donde se debe contribuir a sensibilizar y formar al alumnado para que sea capaz de desarrollar una actitud crítica y comprometida con los bienes culturales" (p. 6).

En esta línea de trabajo, el Observatorio de Educación Patrimonial en España se convierte en un instrumento que ayuda a cumplir los objetivos del Plan, realizando evaluaciones tanto dentro de la educación formal como no formal. En un primer lugar, realiza análisis comparativos de la imagen del patrimonio en la legislación nacional y autonómica, dentro de la educación obligatoria (Fontal, Martín y Pérez, 2013; Fontal y Martínez, 2016a; Fontal et al., 2017). Por otro lado, son muy numerosos las investigaciones realizadas para evaluar el diseño educativo de programas sobre patrimonio que abarcan diferentes tipologías de patrimonio, tanto desde un enfoque más cualitativo (Fontal, García-Ceballos, Asos y Martínez, 2017; García-Ceballos et al., 2017) como más cuantitativo (Fontal y Gómez-Redondo, 2016; Fontal y Marín, 2016; Fontal y Martínez, 2017, 2018; Marín et al., 2017; Rivero et al., 2018a). Así el trabajo desarrollado en el marco del OEPE se enmarca en la línea de actuación investigación en Educación Patrimonial e innovación en didáctica del Patrimonio, que pretende observar de manera sistemática que se está haciendo en materia de patrimonio, potenciar la investigación y plantear la necesidad de desarrollar modelos de evaluación para innovar y mejorar la calidad de los futuros diseños educativos.

\subsection{Trayectoria y prospectiva de la educación patrimonial}

La evolución de la educación patrimonial, además de verse plasmada en la normativa institucional, como hemos desarrollado a lo largo del punto anterior, también se ve reflejada en el ámbito académico. Con la intención de conocer este proceso realizamos a lo largo de este apartado un repaso por los proyectos, publicaciones y tesis en el ámbito de la educación patrimonial, que nos permiten ver la evolución de la trayectoria en el campo de la educación patrimonial. Para ello, analizamos los focos de investigación a 
nivel nacional y europeo, y generamos mapas de conocimiento que nos permiten ver las genealogías y nodos de interés en torno a los datos bibliométricos del campo de la educación patrimonial desde un enfoque internacional. Por último, nos aproximamos a las tesis doctorales sobre educación patrimonial que han sido presentadas en los últimos años en el ámbito nacional. Tomamos como referencia el estudio realizado por Fontal e Ibáñez-Etxeberria (2017) publicado dentro del monográfico dedicado a la educación patrimonial de la Revista de Educación.

En el ámbito nacional son numerosos los instrumentos generados a nivel gestor y organizativo en torno a la educación patrimonial que han derivado del conocimiento científico generado en los proyectos de I+D+i financiados por las autoridades nacionales. Estos instrumentos se crearon como resultado de la investigación básica pero se han transformado en instrumentos para la gestión administrativa de la educación patrimonial con un impacto científico, político y social: 1. El Observatorio de Educación Patrimonial en España (OEPE) ${ }^{15}$ (Fontal, 2016) y 2. El Plan Nacional de Educación y Patrimonio (Domingo et al., 2013), que ya hemos abordado en el epígrafe 2.4.5. Los dos instrumentos están interrelacionados (el OEPE se ha incorporado como uno de los puntos de acción del PNEyP) y esto ha llevado a la creación de un tercer instrumento, 3. La Red Internacional de Educación sobre el Patrimonio (RIEP-INHE) ${ }^{16}$, que no es una red de expertos o científica, sino de personas e instituciones interesadas en el patrimonio y su educación, y que acomete a uno de sus principales objetivos del plan, que es incentivar la presencia de nuestro país en redes actualmente activas que se ocupen de la difusión y comunicación del Patrimonio.

Estos instrumentos, además de ser evidencia de la transferibilidad de la investigación básica, nos proporcionan un panorama general de la educación patrimonial y facilitan la gestión educativa del patrimonio. En este sentido, también existen países como Italia, Francia o Portugal que han tratado de liderar la gestión de la educación patrimonial (Bhatawadekar y Yedurkar, 2016; Emiliani, 2007). Estos avances individuales así como las herramientas de gestión desarrollados por las diferentes administraciones nacionales de los países de la UE, deben ser compartidas y evaluadas con la intención de generar modelos basados en la investigación, que termine en la trasferencia y que aspiren a ser

\footnotetext{
${ }^{15} \mathrm{https}: / / \mathrm{www}$.oepe.es

${ }^{16} \mathrm{http}: / / \mathrm{www}$. riep-inhe.com/
} 
utilizados en un contexto europeo. Trabajar desde un enfoque cooperativamente y en red, compartir ejemplos de buenas prácticas y desarrollar proyectos conjuntos financiados en el marco de la UE debe ser el camino a seguir (Branchesi, 2007). Pretendemos, de esta manera, converger con los criterios europeos recopilados en Horizonte 2020, de modo que la cultura digital pueda utilizarse para promover la creatividad y el intercambio (Ott y Pozzi, 2011; Ibáñez-Etxeberria, Fontal y Rivero, 2018), facilitar las interpretación del patrimonio cultural y ofrecer nuevas perspectivas sobre la identidad y herencia compartida (Jagielska-Burduk y Piotr, 2019; Copeland, 2007; Scalise, 2015), dando como resultado beneficios económicos y sociales y siempre desde un enfoque cooperativo y de coordinación entre los diferentes países.

A estos instrumentos de la administración central podemos agregar otra serie de acciones por parte de administraciones o instituciones locales y autónomas. Por ejemplo, destacamos el diseño de un Plan de Educación Patrimonial para la iniciativa públicoprivada "Duero Douro, patrimonio para el desarrollo" que cubre España y Portugal (Rivero et al., 2018b). Otro de los indicadores del avance científico de la disciplina son los diversos congresos que han tenido lugar en la última década. Por un lado, aquellos congresos específicos en el campo donde debemos destacar el Congreso Internacional de educación patrimonial ${ }^{17}$, desarrollado conjuntamente por la comunidad científica junto con el apoyo de la administración, del que ya se han celebrado cuatro ediciones en 2012, 2014, 2016 y 2018 con un crecimiento considerable en cuanto a magnitud de asistentes, alcance geográfico y reconocimiento político y social. Las I y II Jornadas de Prácticas y Reflexiones en Educación del Patrimonio (2015 y 2017), así como el Taller internacional de investigación sobre educación del patrimonio y museos (2017), asumiendo el liderazgo en la organización de eventos internacionales de investigación científica en este campo. Otros congresos específicos en el área son el Congreso Internacional Creando Ciudadanos construyendo identidades ${ }^{18}$; el Congreso Internacional de Educación: Patrimonio y Creatividad, en su segunda edición ${ }^{19}$; el Congreso Internacional de Patrimonio Cultural Inmaterial ${ }^{20}$ o el segundo encuentro de

\footnotetext{
${ }^{17}$ https://sites.google.com/site/educacionpatrimonial2012/home; http://www.congreso.oepe.es/; http://www.ciep3.oepe.es/; http://www.ciep4.oepe.es/

${ }^{18} \mathrm{http}: / /$ congresos.um.es/conintciudident/conintciudident 2016

${ }^{19} \mathrm{http}: / /$ epac.es/

${ }^{20} \mathrm{https}$ ///www.unavarra.es/actualidad/congresos?contentId=227469
} 
Prácticas y reflexiones en educación patrimonial ${ }^{21}$. Otros congresos que abordan una línea temática sobre educación patrimonial pero que no son específicos, son el Simposio Internacional de Didáctica de las Ciencias Sociales ${ }^{22}$; el Simposio Internacional de Didáctica de las Ciencias Sociales en el Ámbito Iberoamericano ${ }^{23}$, o el Congreso Internacional Educación Histórica y Adquisición de Competencias Clave ${ }^{24}$, entre otros.

A todo esto, también debemos sumar la coordinación por parte de diferentes investigadores de 6 estudios monográficos sobre Educación y Patrimonio en publicaciones de impacto: Clío. History and History Teaching en 2014 (ANEP); Educatio siglo XXI en 2015 (WOS-ESCI); Revista de Educación en 2017 (WOS-JCR y SCOPUS); Revista de Estudios Pedagógicos en 2017 (SCOPUS); MIDAs en 2017 (ERIH PLUS); ARBOR. Ciencia, Pensamiento y Cultura en 2018 (WOS-A\&HCI y SCOPUS) y REIFOP. Revista Inter universitaria de formación del profesorado en 2018 y 2019 (WOS-ESCI y SCOPUS), que han generado 74 artículos en revistas indexadas sobre este tema, 3 libros monográficos, 3 libros de coautoría y 42 capítulos, todos ellos producidos por editores que están bien ubicados en el SPI (Trea, Aranzadi, Paraninfo, etc.).

Unido a todo lo anterior, en territorio nacional se han defendido más de 50 tesis doctorales sobre educación patrimonial, algunas de las últimas son desarrolladas por Gómez-Redondo (2013), Vicent (2013), Marín (2014), Gillate (2014), Ferreras (2015) y García-Ceballos (2018). Además, se ha formado Red 14: Red de Investigación sobre la enseñanza de las Ciencias Sociales (EDU2014-51720-REDT), que cuenta con una línea de desarrollo sobre educación patrimonial. Como resultado de todo ello, España es uno de los países a nivel europeo con uno de los niveles más sofisticado de desarrollo en investigación sobre educación del patrimonio (Fontal e Ibáñez-Etxeberria, 2017), que influye en la gestión educativa del patrimonio y demuestra, con este ejemplo, la relación entre investigación, innovación y la transferencia de conocimiento científico a la sociedad.

\footnotetext{
${ }^{21}$ https://www.prep2-oepe.com/

$22 \mathrm{http}: / /$ didactica-ciencias-sociales.org/xxix-simposio-2018/

${ }^{23} \mathrm{http}: / / \mathrm{www} .7$ simposiodcs.com/

${ }^{24} \mathrm{http}: / /$ congresos.um.es/histedu/histedu2017/index
} 


\subsubsection{Focos de investigación que consolidan la disciplina}

Los focos de investigación normalmente están sustentados por proyectos de $\mathrm{I}+\mathrm{D}+\mathrm{i}$ que tiene como finalidad la contribución a la búsqueda de soluciones a los retos problemas sociales, económicos y tecnológicos, mediante la publicación de sus resultados en foros de alto impacto científico y la internacionalización de sus actividades. Dentro del Plan Estatal de Investigación Científica y Técnica y de Innovación orientada a los retos de la sociedad, desarrollado por el Ministerio de Economía y Competitividad (MINECO) y el Fondo Europeo de Desarrollo (FEDER) se conceden según García-Ceballos (2018) un total de 50 proyectos en materia de patrimonio. El análisis que se deriva de este trabajo nos permite apreciar como existe una gran variedad de tipologías patrimoniales, ya que los proyectos hacen referencia al patrimonio arqueológico, arquitectónico, rural, industrial, natural y paisajístico (García-Ceballos, 2018, p. 94).

También observamos que a pesar de que ningunos de los proyectos hace referencia directa en su título al patrimonio inmaterial, sí que encontramos muchos términos relativos a su ámbito, que se enmarcan dentro de las manifestaciones musicales y sonoras, las representaciones y escenificaciones y las particularidades lingüísticas (Domingo y Timón, 2011, p. 11-13). Otro de los aspectos a destacar son las líneas de trabajo sobre saliendo la acción de Conservación, recuperación y valorización, en cualquier caso y de acuerdo con García-Ceballos todas las acciones tienen como denominador común la salvaguarda del patrimonio.

A continuación, extraemos una relación de los proyectos de $\mathrm{I}+\mathrm{D}+\mathrm{i}$ concedidos en los últimos 5 años (2014-2018) dentro del Programa estatal de investigación, desarrollo e innovación, que se enmarquen dentro de la línea de investigación 6. Ciencias sociales y humanidades y ciencias con y para la sociedad. Los proyectos responden específicamente al ámbito concreto de la educación patrimonial, aunque desde una perspectiva multidisciplinar. 
Tabla 6

Relación de Proyectos $I+D+i$ concedidos en materia de educación y patrimonio entre 20142018

AYUDAS CONCEDIDAS - CONVOCATORIA 14/15/16/17/18 - PROYECTOS I+D+I Programa estatal de investigación, desarrollo e innovación orientada a los retos de la sociedad

\begin{tabular}{|c|c|c|c|}
\hline REFERENCIA & TÍTULO & BENEFICIARIO & CENTRO \\
\hline EDU2014- 52675-R & $\begin{array}{l}\text { Análisis evaluativo de Aplicaciones } \\
\text { para m-learning de carácter Inclusivo } \\
\text { en espacios patrimoniales. }\end{array}$ & $\begin{array}{l}\text { Universidad de } \\
\text { Barcelona }\end{array}$ & $\begin{array}{l}\text { Facultad de Formación } \\
\text { del Profesorado }\end{array}$ \\
\hline $\begin{array}{l}\text { EDU2015- 65716-C2- } \\
1-R\end{array}$ & $\begin{array}{l}\text { Evaluación de los aprendizajes en } \\
\text { Programas de educación patrimonial } \\
\text { centrados en los procesos de } \\
\text { sensibilización, valorización y } \\
\text { socialización del patrimonio cultural. }\end{array}$ & $\begin{array}{l}\text { Universidad de } \\
\text { Valladolid }\end{array}$ & $\begin{array}{l}\text { Facultad de Educación y } \\
\text { Trabajo Social }\end{array}$ \\
\hline $\begin{array}{l}\text { EDU2015-65716-C2- } \\
2-\mathrm{R}\end{array}$ & $\begin{array}{l}\text { Evaluación de programas y } \\
\text { evaluación de Aprendizajes en los } \\
\text { ámbitos no formal e informal de la } \\
\text { educación patrimonial }\end{array}$ & $\begin{array}{l}\text { Universidad del País } \\
\text { Vasco Euskal Herriko } \\
\text { Unibertsitatea }\end{array}$ & $\begin{array}{l}\text { Facultad de Educación, } \\
\text { Filosofía y Antropología }\end{array}$ \\
\hline EDU2016-76589-R & $\begin{array}{l}\text { Iconografía y recreación histórica en } \\
\text { la didáctica del patrimonio. El caso } \\
\text { de la guerra civil española. }\end{array}$ & $\begin{array}{l}\text { Universidad de } \\
\text { Barcelona }\end{array}$ & Facultad de Educación \\
\hline EDU2016-78163-R & $\begin{array}{l}\text { Educomunicación web } 2.0 \text { del } \\
\text { patrimonio }\end{array}$ & $\begin{array}{l}\text { Universidad de } \\
\text { Zaragoza }\end{array}$ & Facultad de Educación \\
\hline HAR2017-88671-R & $\begin{array}{l}\text { Estrategias digitales para la } \\
\text { documentación, conservación y } \\
\text { revalorización del patrimonio } \\
\text { arqueológico en Egipto aplicadas } \\
\text { al proyecto DJEHUTY }\end{array}$ & Universidad de Madrid & $\begin{array}{l}\text { Instituto de lenguas y } \\
\text { culturas del } \\
\text { mediterráneo y oriente } \\
\text { próximo (ILC) }\end{array}$ \\
\hline TIN2017-86576-R B & $\begin{array}{l}\text { Preservación del patrimonio de } \\
\text { música española manuscrita } \\
\text { mediante transcripción automática }\end{array}$ & $\begin{array}{l}\text { Universidad de } \\
\text { Alicante }\end{array}$ & $\begin{array}{l}\text { Instituto Universitario } \\
\text { de Investigación } \\
\text { Informática }\end{array}$ \\
\hline TIN2017-85259-R B & $\begin{array}{l}\text { Técnicas gráficas para el análisis, } \\
\text { visualización y documentación } 3 \mathrm{~d} \\
\text { aplicadas al patrimonio cultural }\end{array}$ & $\begin{array}{l}\text { Universidad de } \\
\text { Granada }\end{array}$ & $\begin{array}{l}\text { Centro de investigación } \\
\text { en tecnologías de la } \\
\text { información y las } \\
\text { comunicaciones } \\
\text { (CITICUGR) }\end{array}$ \\
\hline BIA2017-87131-R B & $\begin{array}{l}\text { Avances metodológicos en el estudio } \\
\text { del patrimonio artístico. La pintura } \\
\text { mural en la alhambra como expresión } \\
\text { arquitectónica. }\end{array}$ & Universidad de Jaén & Universidad de Jaén \\
\hline HAR2017-82591-R B & $\begin{array}{l}\text { Cambio sociocultural, memoria, } \\
\text { patrimonio e identidades en } \\
\text { contextos de desindustrialización. }\end{array}$ & Universidad de Oviedo & Dpto. historia \\
\hline
\end{tabular}

Esta relación de proyectos sirve de referencia a nuestra línea de trabajo y nos permite conocer los focos geográficos, así como las temáticas de trabajo que a su vez enmarcan gran parte de las publicaciones científicas sobre la materia. 
En primer lugar destacamos la Universidad de Huelva (UHU), que representa uno de los focos principales que trabaja la educación patrimonial, con tres I+D $\left(2003^{25}, 2008^{26}\right.$ y $2015^{27}$ ), todos ellos liderados por el Dr. Estepa y, en el último caso, también por el Dr. Cuenca. En el marco de estos proyectos se ha desarrollado una gran producción científica que muestra los resultados derivados de los años de investigación (Cuenca y López, 2014; Cuenca et al., 2017; Cuenca, et al., 2018; Estepa, Ávila, y Ferreras, 2008; Ferreras y Jiménez, 2013; Jiménez, Cuenca, y Ferreras, 2010; Martín-Cáceres, y Cuenca, 2011). Otro de los focos de investigación destacados a nivel nacional es la Universidad de Valladolid (UVa), liderada por la Dra. Fontal, quien ha obtenido tres I+D+i consecutivos que han dado origen y continuidad al OEPE $\left(2009^{28}, 2012^{29}\right.$ y $\left.2015^{30}\right)$. También son numerosas las publicaciones desarrolladas durante estos años que dan visibilidad y difusión al trabajo realizado desde el OEPE (Cepeda y Fontal, 2019; Fontal, 2016a; 2016b; Fontal e Ibáñez-Etxeberria, 2017 Fontal et al., 2017; Fontal et al., 2019; Fontal y Gómez-Redondo, 2016; Fontal y Marín, 2016; Fontal y Marín, 2018; Fontal y Martínez, 2017, 2018; García-Ceballos et al., 2018; Marín et al., 2017; Pablos y Fontal, 2018; Rivero et al., 2018b) Este último proyecto está coordinado junto al Dr. IbáñezEtxeberria, IP en la Universidad del País Vasco (UPV/EHU), muestra de este trabajo cooperativo son las siguientes publicaciones cuyos autores son miembros de ambos equipos (Ibáñez-Etxeberria et al., 2018; Ibáñez-Etxeberria, Kortabitarte, De Castro y Gillate, 2019; Ibáñez-Etxeberria, Vicent, Asensio, Cuenca y Fontal, 2014; Gillate, Vicent, Gómez-Redondo, Marín-Cepeda, 2017; Luna et al., 2019). En la convocatoria de 2016 se localizaron dos proyectos más estrechamente relacionados con la educación patrimonial, uno de ellos concedido a la Universidad de Zaragoza (UNIZAR) cuya IP es

\footnotetext{
${ }^{25}$ Ref. BS02003-07573 "Concepciones sobre el patrimonio desde una perspectiva holística”. Financiado por MINECO y FEDER.

${ }^{26}$ Ref. EDU2008-01968/EDUC "El patrimonio y su enseñanza: análisis de recursos y materiales para una propuesta integrada de educación patrimonial”. Financiado por Ministerio de Ciencia e Innovación.

${ }^{27}$ EDU2015-67953-P "Educación patrimonial para la inteligencia territorial y emocional de la Ciudadanía. Análisis de buenas prácticas, diseño e intervención en la Enseñanza obligatoria”. Financiado por MINECO y FEDER.

${ }^{28}$ Ref. EDU2009-09679 “Observatorio de Educación Patrimonial en España. Análisis Integral del estado de la educación patrimonial en España”. Financiado por Ministerio de Ciencia e Innovación.

29 EDU2012-37212 "La educación en España: consolidación, evaluación de programas e internacionalización del OEPE". Financiado por MINECO.

${ }^{30}$ EDU2015-65716-C2-1-R "Evaluación de los aprendizajes en programas de educación patrimonial centrados en los procesos de sensibilización, valorización y socialización del patrimonio cultural". Proyecto I+D coordinado con UPV/EHU con Ref. EDU2015-65716-C2-2-R "Evaluación de programas y evaluación de aprendizajes en los ámbitos no formal e informal de la educación patrimonial". Financiados por MINECO/FEDER.
} 
la Dra. Rivero (2016 ${ }^{31}$ ) (Rivero et al., 2018a; Vicent, Rivero y Feliu-Torruella, 2015), y un segundo proyecto coordinado ${ }^{32}$ liderado por la Dra. Feliu y el Dr. Hernández de la Universidad de Barcelona (UB) (González-Sanz, Feliu y Cardona-Gómez, 2017)

También desatacamos otros focos referentes por tratar líneas de investigación sobre el campo del patrimonio y su educación como la Universidad Autónoma de Madrid (UAM) (Asensio, 2015); la Universidad de Oviedo (UNIOVI) (Calaf y Gutiérrez, 2017; Calaf, San Fabián, y Gutiérrez, 2017; Gómez-Redondo, Calaf, y Fontal, 2016; Suárez, Calaf, y Fernández, 2017); la Universidad de Murcia (UM) (Gómez y Miralles, 2015; Gómez, Ortuño, y Molina-Puche, 2015; Pinto y Molina-Puche, 2015); la Universidad de Barcelona (UB) (Martínez, López, Asensio, y Santacana, 2018; Santacana y Martínez, 2018); la Universidad de Valencia (UV) (Huerta, 2015; Huerta y Hernández, 2015) la Universidad de Santiago de Compostela (USC) (Castro y López-Facal, 2019; Domínguez y López-Facal, 2017; Domínguez, Costa-Casais, López-Facal, 2019; LópezFacal, 2015).

Además de todos ellos, en el año 2014 se formó una red en la que participaron muchos de los grupos de investigación que anteriormente hemos citado. Esta red de investigación se consolidó con el proyecto de $2014^{33}$ de redes de excelencia que se concedió a la Universidad de Santiago de Compostela (USC), liderado por el Dr. LópezFacal, que generó una Red de Investigación en Enseñanza de las Ciencias Sociales (RED14). Con la intención de dar continuidad a esta iniciativa en el año 2018 se solicita un nuevo proyecto de la mano del Dr. Ibáñez-Etxeberria que permita seguir realizando labores de investigación de forma colaborativa y en red.

Como podemos observar, es en los últimos años cuando se produce un crecimiento palpable de la producción científica que parece ir a la par que la consecución de los $\mathrm{I}+\mathrm{D}+\mathrm{i}$ en los diferentes focos de investigación; este incremento exponencial, como citan Fontal e Ibáñez-Etxeberria (2017, p. 204), hace prever un aumento más notorio, si cabe, en la próxima década.

\footnotetext{
${ }^{31}$ EDU2016-78163-R "Educomunicación web 2.0 del patrimonio". Financiado por MINECO y FEDER.

${ }^{32}$ Ref. EDU2016-76589-R "Iconografia y recreacion histórica en la didáctica del patrimonio. El caso de la Guerra Civil Española”. IP: Maria Feliu Torruella y Dr. Francesc Xavier Hernández Cardona. Proyectos de I+D+I del Programa estatal de investigación, desarrollo e innovación orientada a los retos de la sociedad.

${ }^{33}$ Ref. EDU2014-51720- REDT, RED 1433: Red de investigación en enseñanza de las ciencias sociales, concedido en la convocatoria 2014 acciones de dinamización "Redes de excelencia" Programa estatal de investigación científica y técnica de excelencia, subprograma estatal de generación de conocimiento.
} 
A nivel europeo, es evidente el gran impulso que se ha llevado a cabo en los últimos años en torno al patrimonio, donde la educación se plantea como uno de los pilares fundamentales en la gestión sostenible del mismo (Branchesi, 2007; Jagielska-Burdul y Piotr, 2019). A pesar de este gran impulso en el ámbito europeo, si analizamos las resoluciones de los European Research Council (ERC). Supporting top researchers from anywhere in the world, observamos que no existen proyectos específicos sobre educación patrimonial, aunque si muchos relativos al patrimonio musical, literario, monumental o arqueológico. Algunos de estos títulos son: The Linguistic Roots of Europe`s Agricultural Transition; Classical Influences and Irish Culture; Handmade: Understanding Creative Gesture in Pottery Making; Traces of contact: Language contact studies and historical linguistics. El proyecto que presenta una mayor relación con nuestro campo de estudio es el proyecto titulado: EUROHERIT. Legitimation of European cultural heritage and the dynamics of identity politics in the EU. El proyecto es dirigido por Tuuli Kaarina Lähdesmäki y tiene como objetivo principal:

"Investigate the EU as a new heritage agent and its heritage politics as an attempt to create a new trans-European heritage regime in Europe: How does the EU aim to create common European cultural heritage in a politically shaking and culturally diversified Europe, and what kind of explicit and implicit politics are included in its aims? The project will focus on the legitimation processes of European cultural heritage at different territorial levels and the power relations formed in the processes between diverse agencies. The project aims to respond to this lack with a broad comparative empirical research including cases from various parts of Europe, penetrating different territorial scales (local, regional, national, and the EU), and theorizing cultural heritage from a multisectional perspective. The project participates in a critical discussion on the current identity and integration politics and policies in the EU and Europe" (ERC-2014-STG).

Al mismo tiempo existen otra convocatoria europea destacable que es la European Cooperation in Science and Techonology $\operatorname{COST}^{34}$, que se configura como una organización financiadora para la creación de redes de investigación, llamadas COST Actions $^{35}$. Estas redes ofrecen un espacio abierto para la colaboración entre científicos

\footnotetext{
${ }^{34}$ http://www.cost.eu/COST_Actions

${ }^{35}$ COST Action is a network dedicated to scientific collaboration, complementing national research funds. COST Actions are: open to researchers and innovators; collaborating in a field of science and technology of common interest to at least seven COST Members/Cooperating Members; based on a joint work programme lasting four years; answering to the COST Open Call for proposals. A COST Action is open to all: science and technology fields (including trans-, and interdisciplinary, new and emerging fields); institutions (academia, public institutions, SME/industry, NGO, European/international organisations,
} 
de toda Europa (y más allá) y, por lo tanto, impulsan la investigación y los avances. Desde 1971, COST recibe fondos de la UE en el marco de los diversos programas marco de investigación e innovación, como Horizon 2020. En este sentido, nos interesa conocer si existen redes de trabajo en torno al patrimonio, la educación y la cultura a nivel internacional. Para ello, analizamos y recogemos las COST Actions aprobadas en torno a la línea de acción "Science in Society Cluster" relacionadas de algún modo con Patrimonio/Educación/Cultura. Podemos observar ejemplos que nos hablan del patrimonio, la identidad en Europa, la sensibilización de la sociedad, la importancia de la educación, la diversidad cultural, pero ninguno específico sobre educación patrimonial.

\section{New COST Action proposals 2010 (OC-2010-1)}

IS1006 - Unraveling the grammars of European sign languages: pathways to full citizenship of deaf signers and to the protection of their linguistic heritage

\begin{tabular}{|c|c|}
\hline ABSTRACT & $\begin{array}{l}\text { Language policies for signing deaf Europeans require reliable reference grammars of their sign } \\
\text { languages (SLs), which are generally lacking or of limited validity if they exist. They constitute the } \\
\text { basis for teaching and training purposes. In addition, descriptive grammars are essential for the } \\
\text { documentation of a European linguistic and cultural heritage which is largely unrecognized to date } \\
\text { (...) }\end{array}$ \\
\hline $\begin{array}{l}\text { INTERESTED } \\
\text { COUNTRIES }\end{array}$ & $\begin{array}{l}\text { Proposer: ES } \\
\text { Network of Proposers: DE, FR, EL, IT, NL, PL }\end{array}$ \\
\hline & IS1007 - Investigating Cultural Sustainability \\
\hline ABSTRACT & $\begin{array}{l}\text { The Action will focus on the role of culture as a fundamental issue, even a precondition to be met } \\
\text { on the path towards Sustainable Development (SD). In order to better define understanding of } \\
\text { culture within the general frames of sustainability, the Action will conceptualise and mobilize the } \\
\text { cultural dimension of sustainable development, examine and compare best policy practices and } \\
\text { investigate frameworks and indicators for cultural sustainability assessments (...) }\end{array}$ \\
\hline $\begin{array}{l}\text { INTERESTED } \\
\text { COUNTRIES }\end{array}$ & $\begin{array}{l}\text { Interested Countries: } 7 \\
\text { Proposer. IT } \\
\text { AT, BE, CZ, DK, } \\
\text { EL, UK }\end{array}$ \\
\hline \multicolumn{2}{|r|}{ New COST Action proposals 2012} \\
\hline \multicolumn{2}{|r|}{ IS1203 In Search of Transcultural Memory in Europe (ISTME) } \\
\hline ABSTRACT & $\begin{array}{l}\text { The main objective of the Action is to investigate how memories of the twentieth century work as a } \\
\text { transcultural dynamic in Europe today by comparing a selection of case studies of transmission and }\end{array}$ \\
\hline
\end{tabular}

etc.); career stages (both young and experienced). COST Members: Non-COST Members are spread across the Near-Neighbour Countries ${ }^{1}$ and International Partner Countries ${ }^{2}$ and can join on the basis of mutual benefit. A COST Action is organised by a range of networking tools, such as meetings, conferences, workshops, short-term scientific missions, training schools, publications and dissemination activities. 


\begin{tabular}{|c|c|}
\hline & $\begin{array}{l}\text { reception of such memories across Europe's cultural and political borders. This Action aims to go } \\
\text { beyond the nationally oriented memory studies that tend to reify the bond between culture, nation } \\
\text { and memory. Instead it will investigate the transcultural dynamics of memory in Europe today (...) }\end{array}$ \\
\hline $\begin{array}{l}\text { NTERESTED } \\
\text { COUNTRIES }\end{array}$ & $\begin{array}{l}\text { Interested Countries : } 20 \\
\text { Proposer: SE } \\
\text { AT, CZ, DE, DK, EE, } \\
\text { ES, FI, FR, HR, HU, } \\
\text { LT, NL, NO, PL, RS, } \\
\text { SI, SK, TR, UK }\end{array}$ \\
\hline \multicolumn{2}{|r|}{ New COST Action proposals 2013} \\
\hline \multicolumn{2}{|r|}{ Action IS1306 New Speakers in a Multilingual Europe: Opportunities and Challenges } \\
\hline ABSTRACT & $\begin{array}{l}\text { Globalization, increased mobility and transnational networking transform the linguistic ecologies } \\
\text { of contemporary societies. In this COST Action the aim is to bring multilinguals into the focus of } \\
\text { these processes by investigating the challenges and opportunities involved in acquiring, using and } \\
\text { being understood as a "new speaker" of a language in the context of a multilingual Europe. The } \\
\text { aim of the Action is to bring into focus the challenges and opportunities involved in acquiring, } \\
\text { using and being understood as a "new speaker" of a language in the context of a multilingual } \\
\text { Europe (...) }\end{array}$ \\
\hline $\begin{array}{l}\text { INTERESTED } \\
\text { COUNTRIES }\end{array}$ & $\begin{array}{l}\text { Interested Countries: } 13 \\
\text { Proposer: UK } \\
\mathrm{BE}, \mathrm{CH}, \mathrm{DE}, \mathrm{EE}, \mathrm{ES} \text {, } \\
\mathrm{FI}, \mathrm{FR}, \mathrm{IE}, \mathrm{IT}, \mathrm{NL}, \mathrm{PL} \text {, } \\
\text { PT }\end{array}$ \\
\hline \multicolumn{2}{|r|}{ New COST Action proposals 2014} \\
\hline \multicolumn{2}{|r|}{ IS1403: Oceans Past Platform (OPP) } \\
\hline ABSTRACT & $\begin{array}{l}\text { The main aim of the Action proposal is to foster an interdisciplinary Integrative Platform to } \\
\text { measure and understand the historical significance and value to European societies of living marine } \\
\text { resource extraction (incl. fishing and mammal hunt) and production (incl. aquaculture) to help } \\
\text { shape the future of coasts and oceans. OPP asks when, how and with what socioeconomic, } \\
\text { political, cultural and ecological implications humans have impacted marine life, primarily in } \\
\text { European seas in the last two millennia (...) }\end{array}$ \\
\hline $\begin{array}{l}\text { INTERESTED } \\
\text { COUNTRIES }\end{array}$ & $\begin{array}{l}\text { Interested Countries: } 17 \\
\text { Proposer: IE } \\
\text { AT, BE, DE, DK, EE, } \\
\text { ES, FI, FR, IL, IS, IT, } \\
\text { NL, NO, PT, SE, UK }\end{array}$ \\
\hline & New COST Action proposals \\
\hline
\end{tabular}




\begin{tabular}{|c|c|}
\hline ABSTRACT & $\begin{array}{l}\text { The main objective is to enable the Social Sciences and Humanities (SSH) to demonstrate their } \\
\text { place in academia and society, by bringing together different strands of work consecrated to SSH } \\
\text { research evaluation in different parts of Europe, in order to gain momentum, to exchange best } \\
\text { practices, and to avoid unnecessary duplication (...) }\end{array}$ \\
\hline $\begin{array}{l}\text { INTERESTED } \\
\text { COUNTRIES }\end{array}$ & $\begin{array}{l}\text { Interested Countries: } 8 \\
\text { Proposer:IL. } \\
\text { BE, CZ, DE, IE, IT, } \\
\text { PL, UK }\end{array}$ \\
\hline \multicolumn{2}{|r|}{ New COST Action proposals 2016} \\
\hline \multicolumn{2}{|r|}{ CA15201 - Archaeological practices and knowledge work in the digital environment } \\
\hline ABSTRACT & $\begin{array}{l}\text { As nations and the EU are making considerable investments in technologies, infrastructures and } \\
\text { standards for all aspects of working with archaeological knowledge, critical understanding of how } \\
\text { this knowledge is produced and used remains fragmentary. This COST action will overcome this } \\
\text { fragmentation by forming a transdisciplinary network that brings together the knowledge from } \\
\text { individual research projects, national initiatives and EU projects (e.g. CARARE, LoCloud, } \\
\text { Europeana Cloud, ARIADNE, DARIAH) in the field of archaeological knowledge production and } \\
\text { use. The proposed work is an acute priority and prerequisite for ensuring the expected benefits of } \\
\text { the largescale investments in the cultural heritage sector (...) }\end{array}$ \\
\hline $\begin{array}{l}\text { INTERESTED } \\
\text { COUNTRIES }\end{array}$ & $\begin{array}{l}\text { Interested Countries: } 15 \\
\text { Proposer: NO } \\
\text { AT, CY, CZ, DE, DK, } \\
\text { ES, FI, FR, HR, IL, } \\
\text { NL, SE, SI, UK }\end{array}$ \\
\hline \multicolumn{2}{|r|}{ New COST Action proposals 2017} \\
\hline \multicolumn{2}{|r|}{ CA16206 - Empowering the next generation of social enterprise scholars } \\
\hline ABSTRACT & $\begin{array}{l}\text { Social enterprise (SE) are organizations which combine an entrepreneurial dynamic to provide } \\
\text { services or goods with a primacy of social aims. SE naturally cross various types of borders; } \\
\text { sectoral (public, business, cooperatives, associations), resources (drawing them from the market, } \\
\text { public procurement, grants, and philanthropy) and activity fields (personal services, finance, } \\
\text { recycling industry, energy and transport, food supply chains...). This EMPOWER-SE Action aims } \\
\text { at (1) contributing to a comprehensive understanding of the diversity of SE models emerging } \\
\text { across Europe and globally; their conditions of emergence and development; and their contribution } \\
\text { to key industries for the development of sustainable societies }\end{array}$ \\
\hline $\begin{array}{l}\text { INTERESTED } \\
\text { COUNTRIES }\end{array}$ & $\begin{array}{l}\text { Main Proposer: BE. } \\
\text { Network of Proposers: AT, BA, BE, BG, CH, CZ, DE, DK, EE, EL, ES, FI, FR, HR, HU, IE, IL, } \\
\text { IS, IT, MK, NL, NO, PL, PT, RO, RS, SE, SK, TR, UK (ITC share: 43\%) }\end{array}$ \\
\hline \multicolumn{2}{|r|}{ New COST Action proposals 2019} \\
\hline \multicolumn{2}{|r|}{ CA-15201. Underground built heritage as catalyser for community valorisation } \\
\hline ABSTRACT & $\begin{array}{l}\text { The proposed COST Action will establish and implement an expert network, aimed at promoting } \\
\text { balanced and sustainable approaches for conservation of underground heritage while, at the same } \\
\text { time, realising the potential of underground space in urban and rural areas for regeneration policies. } \\
\text { The experts will be organised into three working groups: } \\
\text { 1) underground space conservation and monitoring; 2) underground heritage-led urban and rural } \\
\text { regeneration; and 3) planning and governance tools. Each expert will share best } \\
\text { practices by reporting on governance mechanisms, planning framework, and stakeholders; }\end{array}$ \\
\hline
\end{tabular}




\begin{tabular}{|l|l|}
\hline & $\begin{array}{l}\text { involvement management, financing mechanisms, technical needs, and their direct } \\
\text { impacts on the underground built environment preservation, environment, society and economy, as } \\
\text { well as potential negative externalities }\end{array}$ \\
\hline $\begin{array}{l}\text { INTERESTED } \\
\text { COUNTRIES }\end{array}$ & $\begin{array}{l}\text { Main Proposer: SW. } \\
\text { Network of Proposers: GR, AL, IT, IC, LI, FI, UK, MA, AU, AS, PT, SL. }\end{array}$ \\
\hline
\end{tabular}

En aquel entonces, Europa era líder en el mundo con respecto a la cantidad de activos del Patrimonio Mundial reconocidos por la UNESCO (2015). Sin embargo, esta posición privilegiada a nivel internacional no se correspondió con un nivel relacional de desarrollo interno en lo que respecta a la educación del patrimonio, donde se hizo evidente que faltaban criterios para la gestión del patrimonio educativo. Lo mismo se aplica a su participación en proyectos internacionales de referencia como HEREDUC, que creen que los estudiantes serán los guardianes de nuestra herencia en el futuro y, por lo tanto, deben tener la oportunidad de aprender más sobre esto hoy (De Troyer, 2005).

\subsubsection{Mapas de conocimiento en torno a la producción científica en Educación Patrimonial}

En las últimas décadas se han desarrollado publicaciones que nos hablaban del binomio educación y patrimonio, y se ha trabajado en el desarrollo epistemológico y teórico con la intención de sentar las bases de modelos teóricos. Este proceso tiene uno de sus puntos de inicio en el 2003 con la publicación de la primera tesis doctoral en el ámbito nacional (Fontal, 2003), que sienta las bases para la configuración de la educación patrimonial como un cuerpo disciplinar con entidad propia, sin estar enmarcado dentro de la didáctica de las ciencias sociales como hasta entonces se había desarrollado (Cuenca, 2002). Esta nueva terminología de educación patrimonial también supone un nuevo enfoque en la concepción, donde las personas pasan a ser el centro de cualquier acción educativa (Fontal, 2013), y donde el enfoque divulgativo es superado por el enfoque relacional, que genera vínculos entre los bienes culturales y las personas como clave en el proceso de patrimonialización e identización (Gómez- Redondo, 2013; Fontal y Martín, 2018).

Desde entonces se comienza a producir un amplio desarrollo en la producción científica a nivel nacional, donde las publicaciones cada vez están mejor posicionadas en los índices de impacto, y por tanto logran un alcance más internacional. Al mismo tiempo, en otros países como Brasil, China, Italia o EEUU (Ver figura 19) también comienzan a trabajar en el desarrollo de publicaciones que consolidan la disciplina. Por lo tanto, es 
importante analizar todo este volumen de datos bibliométricos con la intención de conocer el estado de la cuestión, el momento temporal en que se produce esta eclosión, así como los países y autores con mayor producción científica considerados referentes. Para ello, realizamos gráficos que representan valores numéricos, y generaremos mapas de conocimiento o redes que nos permiten ver las genealogías y nodos de interés en torno al campo de la educación patrimonial. Con la intención de conocer las líneas actuales en la investigación en educación patrimonial, las relaciones de co-autoría, la tipología de documento científico y la fuente de publicación; así como los organismos, autores y países con una mayor producción. En este sentido, los análisis de redes bibliográficas y los mapas de conocimiento (Börner, Chen, y Boyack, 2003; Börner y Polley, 2014) son usados para analizar la estructura social y conceptual de la evolución de la educación patrimonial. Para llevar a cabo este análisis utilizamos la herramienta de análisis de datos bibliométricos VOSviewer ${ }^{36}$, que nos permite:

Creating maps based on network data. A map can be created based on a network that is already available, but it is also possible to first construct a network. VOSviewer can be used to construct networks of scientific publication, scientific journals, researchers, research organization, countries, keywords, or terms. Items in these networks can be connected by co-authorship, co-occurrence, citation, bibliographic coupling, or cocitation links- (Van Eck y Waltman, 2010, p. 3).

Los datos bibliométricos son extraídos de la base Web of Science (WoS), que tiene difusión internacional y suele se utilizan para análisis bibliomátricos de áreas específicas de conocimiento (Jiménez, Maz, y Brancho, 2013). Los criterios selección en base a nuestros objetivos son:

- Web of Science Category (WC): Colección principal de la Web of Science ${ }^{37}$.

- Subject Areas (SU): Todas

- Dominio de documento: Todos

- Años de publicación: Desde 1990 hasta la actualidad.

\footnotetext{
36 VOSwiewer is a software tool for creating maps based on network data and for visualizing and exploring these maps (Van Eck y Waltman, 2010).

${ }^{37}$ Indice de citas de la Colección principal de la Web of Science: Science Citation Index Expanded (SCIEXPANDED); Social Sciences Citation Index (SSCI); Arts \& Humanities Citation Index (A\&HCI); Conference Proceedings Citation Index- Science (CPCI-S); Conference Proceedings Citation IndexSocial Science \& Humanities (CPCI-SSH); Book Citation Index- Science (BKCI-S); Book Citation Index-Social Sciences \& Humanities (BKCI-SSH); Emerging Sources Citation Index (ESCI).
} 
- Tema: Buscada en el título, abstract, palabras clave de autor y más.

- Descriptor temático: "Heritage Education".

- Desactivar lematización.

Las comillas que encierran al descriptor temático simbolizan la desactivación de la lematización, que esta activada por defecto en los motores de búsqueda de la Web of Science. Cuando encerramos el término entre comillas desactivamos la lematización (OFF) para recuperar la palabra o palabras exactas. Es importante destacar que la búsqueda se realiza tanto en el título, como en los abstracts y palabras clave, reduciendo el sesgo de que podamos descartar un artículo de nuestro interés. Si no utilizáramos este recurso de búsqueda obtendríamos con los mismos criterios de inclusión una muestra de $\mathrm{n}=5.375$ publicaciones, que abarca campos afines en muchos casos pero que no se corresponde con estudios específicos sobre la disciplina de la educación patrimonial. Finalmente, se exportan un total de 220 documentos que se revisan individualmente para comprobar que se adecuaban al campo de conocimiento de la educación patrimonial, y la muestra resultante es de un total de 117 documentos.

Los resultados que se presenta a continuación analizan la evolución de la estructura conceptual e intelectual del campo de conocimiento y su evolución: se representan las conexiones entre las temáticas abordadas por los artículos, las conexiones entre coautorías, los autores más citados, así como los organismos y los países más representativos.

El primer análisis es relativo a los clústers temáticos donde podemos identificar cinco agrupamientos (Ver figura 13). Se selecciona un mínimo de 3 keywords de coocurrencia y de un total de 652 keywords, y son 42 los ítems que superan el umbral. El clúster 1 (en color azul) agrupa a 7 items y tiene como nodo central la palabra clave "Heritage Education". Este clúster aborda la educación patrimonial muy vincula a la enseñanza dentro del ámbito de la educación formal. Los principales ítems que se conectan con este nodo son "teacher training", "formal education", "curriculum" "primary education" o "teacher education". Entorno a este nodo se desarrollan diversas publicaciones entre las que destacamos por su actualidad (Akmehmet, 2017; Alves y Pinto, 2019; Álvarez, Martínez, y García, 2017; Avci y Memişoğlu, 2016); Barghi et al., 2017; Barthes y Blanc-Maximin, 2017; Cuenca y López, 2014; Cuenca et al., 2017; Dias y Cletes, 2016; Domínguez y López-Facal, 2017; Domínguez et al., 2019; Elena, 2018; 
Ferreras y Jiménez, 2013; Fontal, 2016a; Fontal et al., 2017; Fuhai, 2017; Gómez y Miralles, 2015; Gueler-Biyikli y Aslam, 2013; Hằng, Meijer, Bulte, y Pilot, 2017; Islamoglu, 2018; Lucas y Delgado, 2018; Miralles, Gómez, y Rodríguez, 2017; Molina, 2018; Pinto y Molina-Puche, 2015; Poce, Agrusti, y Re, 2018; Xie y He, 2017).

El clúster 2 en color verde aglutina a 8 items y tiene como nodo central "cultural heritage", los principales ítems que se conectan con este nodo son "serious game", “gamificación”, “aumented reality”, "mobile learning” o "museum education”. El clúster recoge una línea de la educación patrimonial estrechamente ligada con las nuevas tecnologías y que normalmente tiene una mayor presencia dentro del ámbito de la educación no formal (Aeila, Rönklö, y Crönman, 2016; Apostolopoulou, Carvoeiras, y Klonari, 2014; Ibáñez-Etxeberria, Vicent, y Asensio, 2012; 2018; 2019; Haddad, 2016; Konstantinov, Kovatcheva, y Palikova, 2018; Lobovikov-Katz, 2019; Morata et al., 2014; Poce et al., 2017; Shashayeva, Zhappasov, y Tasilova, 2016). El clúster 3 y 4, en color amarillo y morado respectivamente, cuentan con 6 y 5 items, son nodos que presentan menor densidad y presentan ítems como "museum" "identity" "citizenship", “art” o “city” (Aerila, Rönkkö, y Grönman, 2016; Bosić y Mihić, 2017; Calaf, Gillate, y Gutierrez, 2015; Calaf y Gutiérrez, 2017; Calaf et al., 2017; Cuenca et al., 2017, 2018; Gómez-Redondo et al., 2016; González-Sanz, et al., 2017; Fontal y Marín, 2016; Huerta y Hernández, 2015; Martín-Cáceres y Cuenca, 2011; 2016). El último clúster, en color rojo, es junto al nodo 1 y 2 uno de los más específicos. Aglutina 10 items y presenta una temática específica relacionada con la tipología patrimonial de la arqueología, en torno a la cual se han desarrollado numerosas investigaciones (Arias-Ferrer y Egea, 2017; Rivero et al., 2018a; Rivero et al., 2018b; Vicent et al., 2015). Presenta tópicos muy concretos "public archaeology", "archaeological heritage", "innovation", "ict" o "web 2.0", encontramos gran influencia de las nuevas tecnologías y el uso de la realidad aumentada en la mayoría de publicaciones relativa a esta temática. 


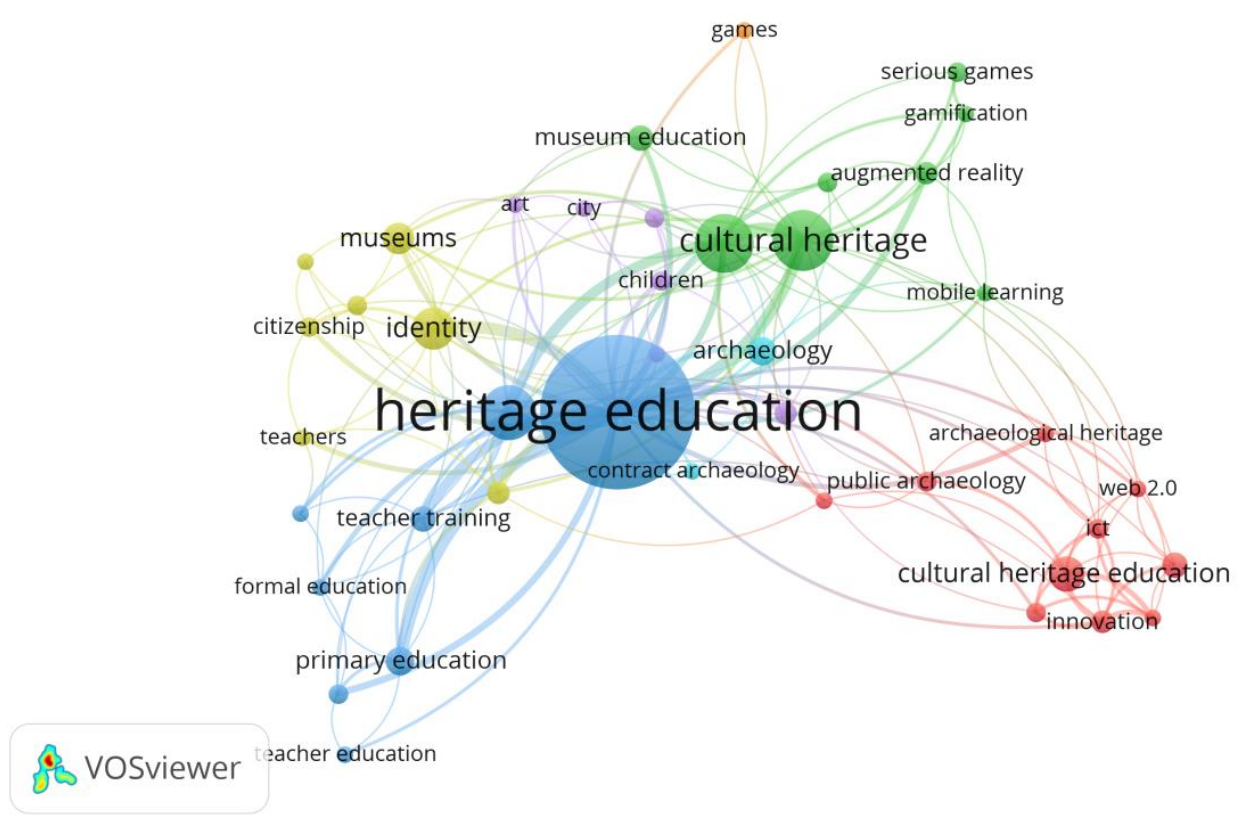

Figura 13. Red de co-ocurrencias en base a la unidad de análisis key words en network visualization.

En relación a la co-ocurrencia en base a la unidad de análisis keywords realizamos una nueva búsqueda que atiende a un mínimo de 4 keywords de co- ocurrencia y realizar el análisis sobre un total de 50 keywords. Presentamos los resultados en un overlay visulización, este tipo de representación "is identical to the network visualization except that ítems are colored differently. If ítems have scores, the color of an ítem is determined by the score of the ítem, where by default colors range from blue (low score) to yellow (high score)" (Van Eck y Waltman, 2010, p. 10; 2014). La red nos muestra como la línea de investigación actual se centra en la educación formal, formación de profesorado en torno a la educación patrimonial. Así el ítem "formal education" presenta un color verde y por el contrario "informal education" un color morado. En cuanto a las tipologías patrimoniales sobre sale en esta red el ítem "intangible cultural heritage" con una mayor afluencia de publicaciones en torno al año 2016, algunos de estos ejemplos son las investigaciones desarrolladas por (Ahmet, 2018; Apaydin, 2016; Bortolotto, 2015; Buckey y Graves, 2016; Cozzani, Pozzi, Dagnino, Katos, y Katsouli, 2017; Dagnino, Hadjileontiadis, Ott, y Pozzi, 2015; Kasapoglu, 2016; Lähdesmäki, 2016; Pinto y Zarbato, 2017) (Ver figura 14). 


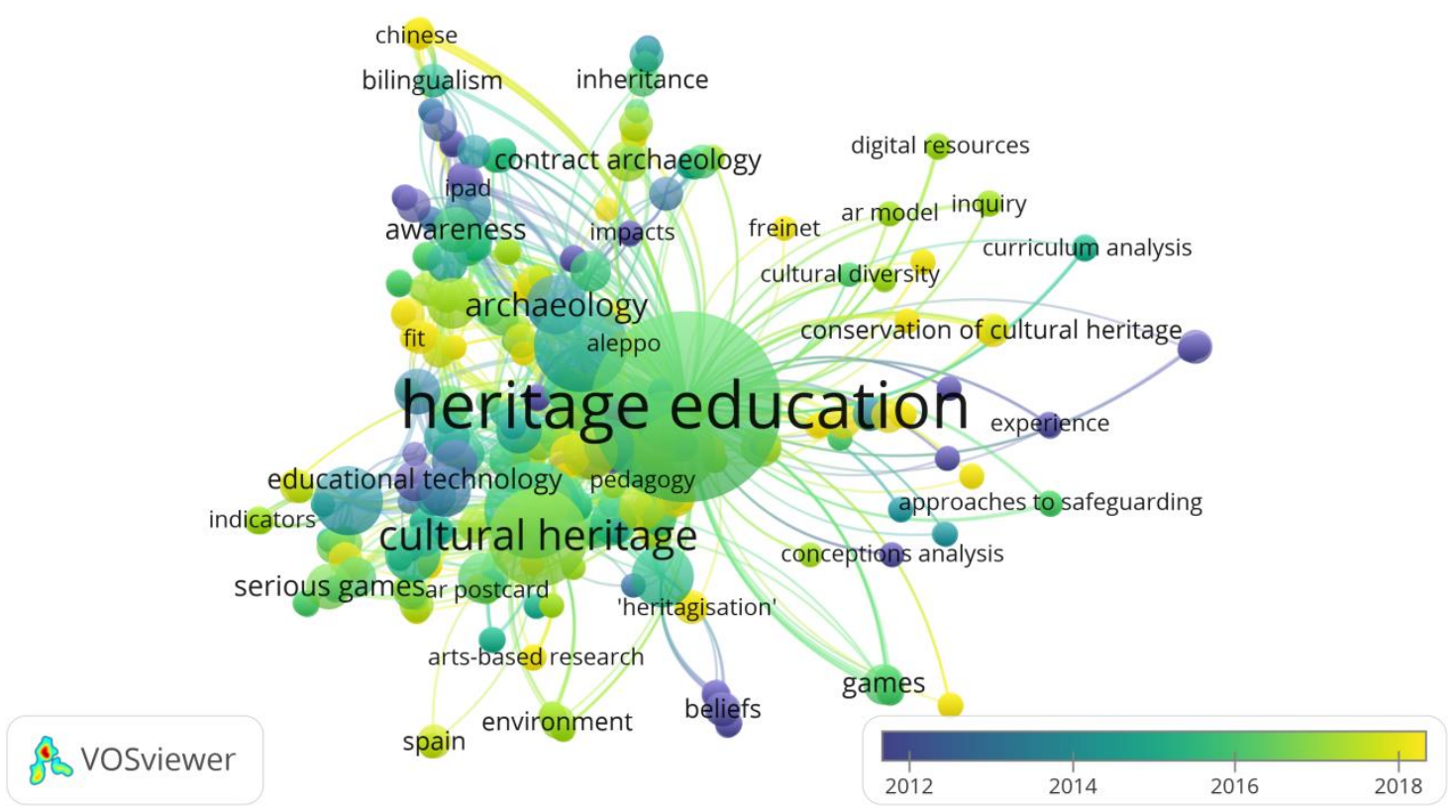

Figura 14. Red de co-ocurencias en base a la unidad de análisis keywords en overlay visualization.

Al mismo tiempo, nos interesa conocer las relaciones de co-autoria con la finalidad de conocer redes de colaboración y la estructura social del campo de conocimiento. En tanto que el análisis de las palabras clave y las referencias citadas permite estudiar la evolución conceptual e intelectual del campo, el análisis de las redes de coautoría posibilita analizar la estructura social. El análisis longitudinal, por su parte, hace posible describir los aspectos dinámicos (Scharnhorst, Börner, y van den Besselaar, 2012). Las relaciones que vinculan a los actores individuales en una comunidad son de importancia central (Dado y Bodemer, 2017). Las redes de co-autoría son una parte particularmente importante de la estructura social de la ciencia (Mali, Kronegger y Ferligoj, 2010; Kronegger, Mali, Ferligoj y Doreian, 2012). Las características estructurales de la red de colaboración son el resultado de una amplia variedad de factores organizativos, disciplinares geográficos y culturales (Leone Sciabolazza, Vacca, Kennelly Okraku, y McCarty, 2017).

De un total de $n=428$ autores seleccionamos, los ítems conectados entre sí, que son un total de $n=38$ en función de la unidad de análisis autores. En el nodo central de la red se encuentra la autora Fontal que presenta conexiones o relación de co-autoría con numerosos autores siendo los principales Ibáñez-Etxeberría, Cuenca, Calaf o GarcíaCeballos, Arías y Martínez, como indican los valores positivos que se representan 
gráficamente con una mayor fuerza en el vínculo. A su vez algunos de estos autores generan nodos, así Ibáñez-Etxeberria (en color verde) presenta co-autorias con Kortabitarte o Molero. Cuenca (en azul oscuro) presenta relación con los ítems Jiménez o Ferreras. En rojo la autora Vicent presenta trabajos en co-autoría con Luna, Rivero, Ibáñez-Etxeberría, Feliú-Torruella y Gómez-Redondo. En azul claro García-Ceballos cuenta con co-autorías con los autores Rivero, Marín, Martínez y Arias, y finalmente en morado destaca Calaf vinculada a Fernández y Gutierrez.

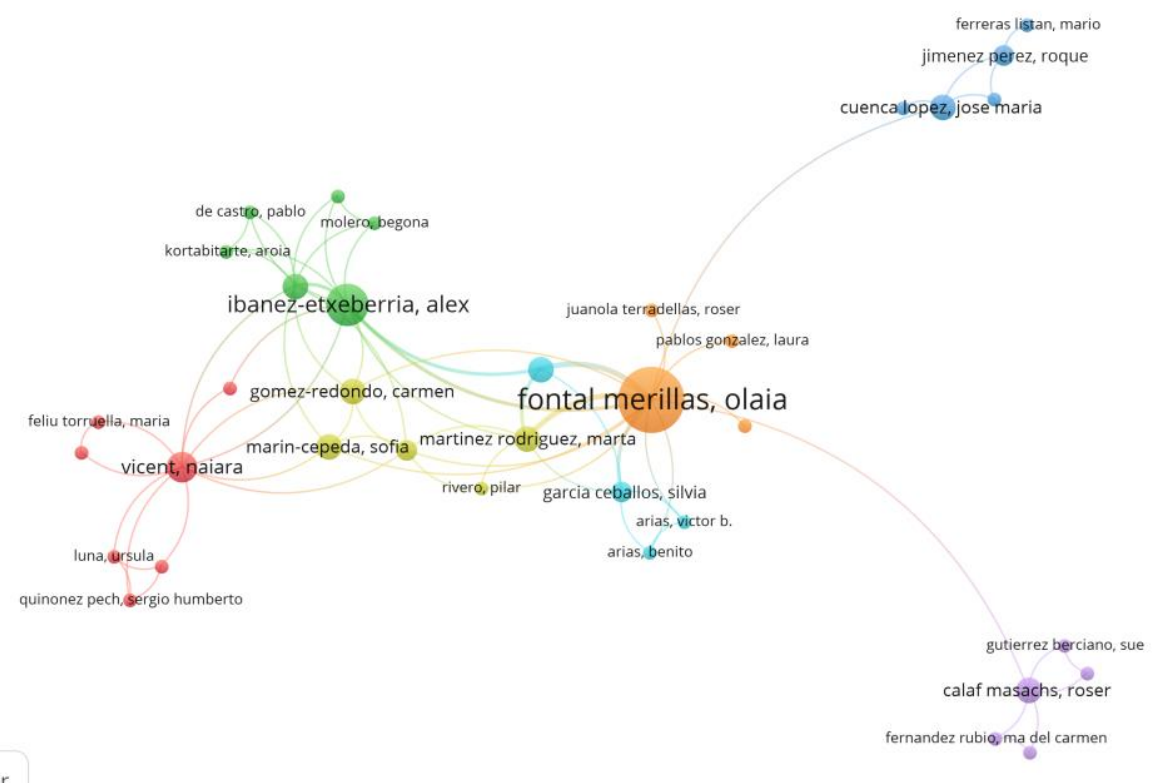

A vosviewer

Figura 15. Red de co-autoria en network visualization VOSviewer.

Además de conocer los equipos de trabajo que desarrollan investigaciones conjuntamente, también nos interesa descubrir la red de citaciones que existen entre los autores del campo: la estructura intelectual del campo de conocimiento. Para ello, realizamos un análisis atendiendo a la unidad de análisis autor, tipo de análisis citación, número mínimo de documento por autor 2, y obtenemos un total de 41 items que alcanzan el umbral.

El mapa nos muestra conexiones entre las autoras italianas Francesca Pozzi y Michela Ott con una gran producción en torno a la educación patrimonial, el patrimonio inmaterial y las TIC (Ott y Pozzi, 2011; Ott, Dagnino y Pozzi, 2015), que en sus publicaciones citan trabajos de autores como Cuenca y Fontal y viceversa. Aunque como 
podemos observar existen citaciones entre autores nacionales y extranjeros como (Poce et al., 2017; Barghi et al., 2017), pero la proximidad y densidad de las conexiones nos indican que estas se centran en el ámbito nacional. El programa nos permite visualizar cada una de las conexiones marcando las líneas de vínculos e indicándonos nombres de los autores que no se presentan en el screenshot, como Pinto, Gillate, Asensio, Gómez, Vicent, Santacana, Egea, García-Ceballos, Jiménez, Ferreras entre otros. Tras esta conclusión abogamos por la necesidad de realizar trabajos de revisión documental a nivel internacional y con un enfoque que sea de interés para la comunidad científica internacional dentro del campo.

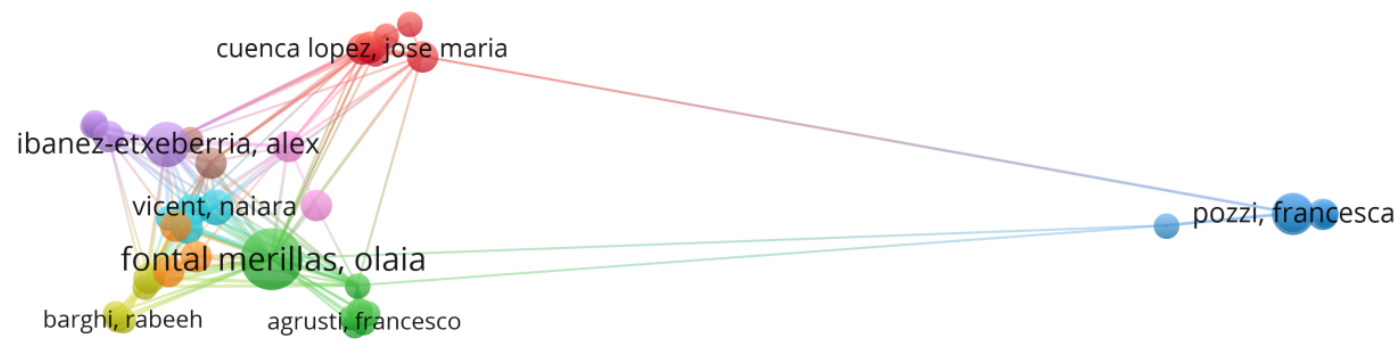

\section{Vosviewer}

Figura 16. Red de citación de autor en network visualization VOSviewer.

Del total de los 217 documentos analizados observamos un aumento en la producción científica dentro del campo, con mayor proliferación en los últimos años como podemos ver en la figura 17. 


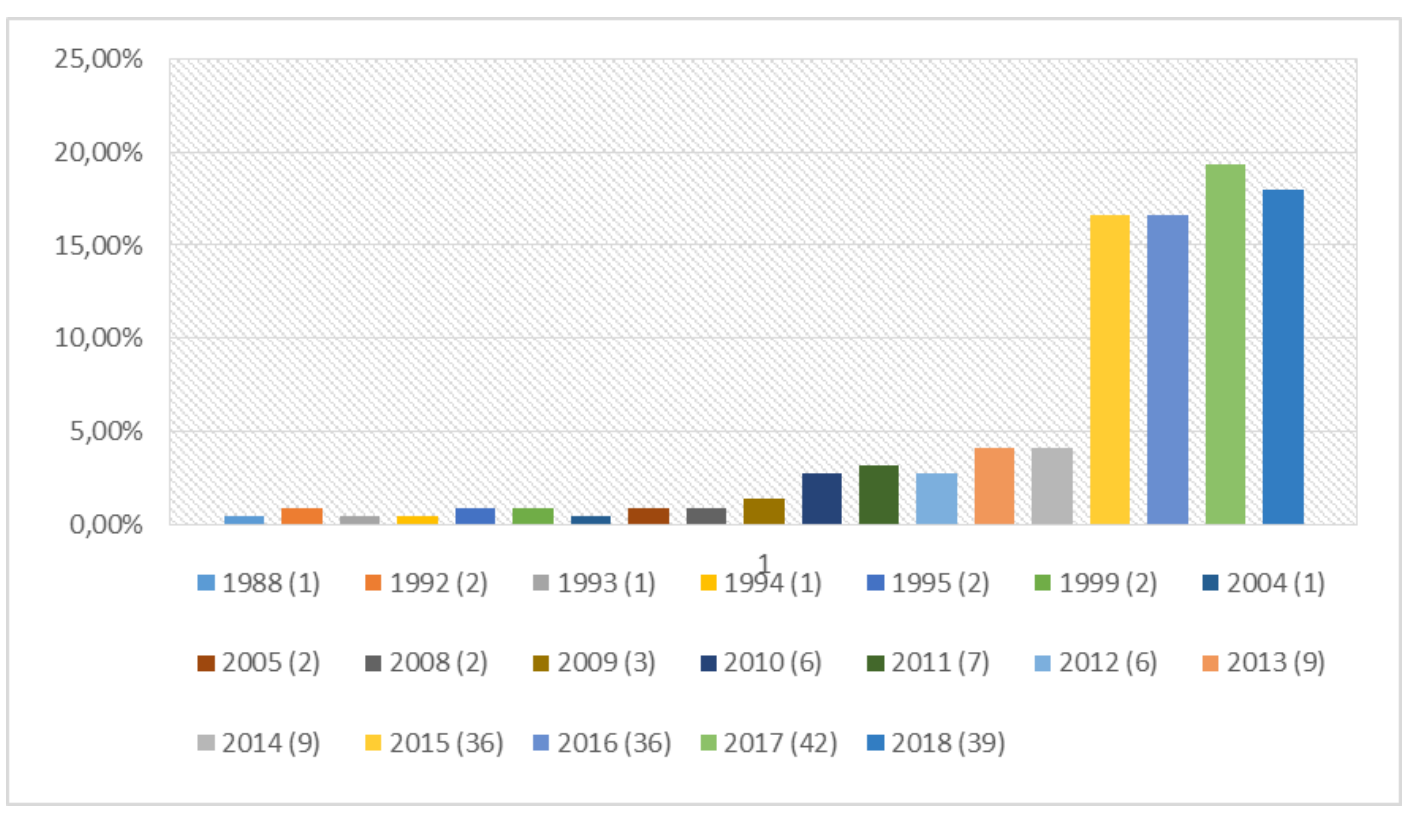

Figura 17. Evolución cronológica de la producción científica por anualidades.

A partir del año 2015 la producción se cuadruplica como podemos observar en el gráfico de dispersión, alcanzando en el 2017 su cuota de mayor producción con un total de 42 publicaciones. Este aspecto se relaciona con la política de creación de redes a través de la edición de monográficos desarrollados dentro de la disciplina, ya que los años de mayor producción en ambos casos se correlacionan (Ver figuras 17 y 19). Por otro lado, analizamos el tipo de documento que componen estas publicaciones. El gráfico 18 nos permite compara visualmente los porcentajes en función de las diferentes tipologías de documentos.

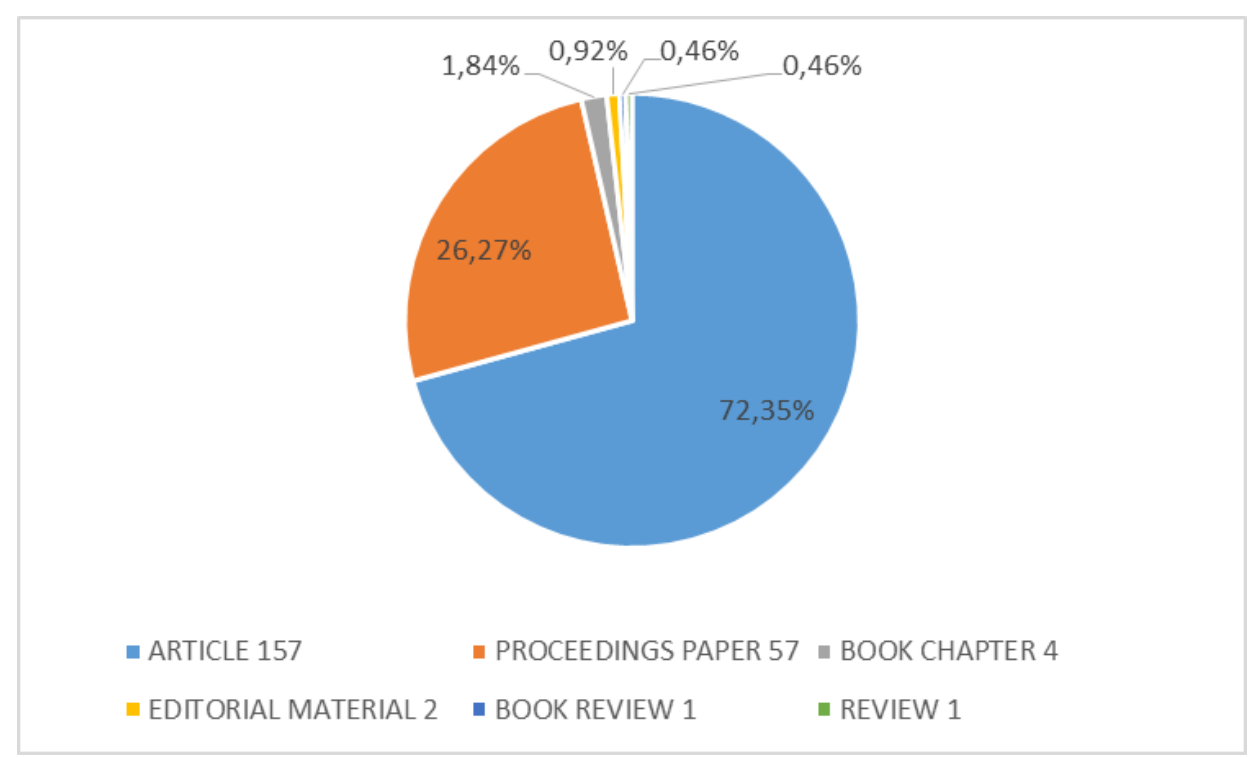

Figura 18. Tipología de documento de la producción científica del campo. 
Los resultados muestran que el 72,35\% de los documentos analizados se corresponden con artículos científicos, también destacan las reseñas con un $27 \%$ del total. El porcentaje restante es una suma de capítulos de libros, revisiones de libros, conferencias y encuestas.

Con la intención de conocer las principales fuentes en las que se publican estos artículos realizamos un mapa usando nuevamente el software VOSviewer, y realizamos un tipo de análisis relativo a la citación y unidad de análisis de la fuente o revista de procedencia. Seleccionamos 2 como el mínimo de documentos de cada fuente, y de un total de 157 fuentes solo 31 alcanzan el umbral, y de esas solo 17 presentan conexiones entre ellas. Presentamos la información en un mapa overlay visualization (Ver figura 19), que nos proporciona información sobre la fecha de publicación.

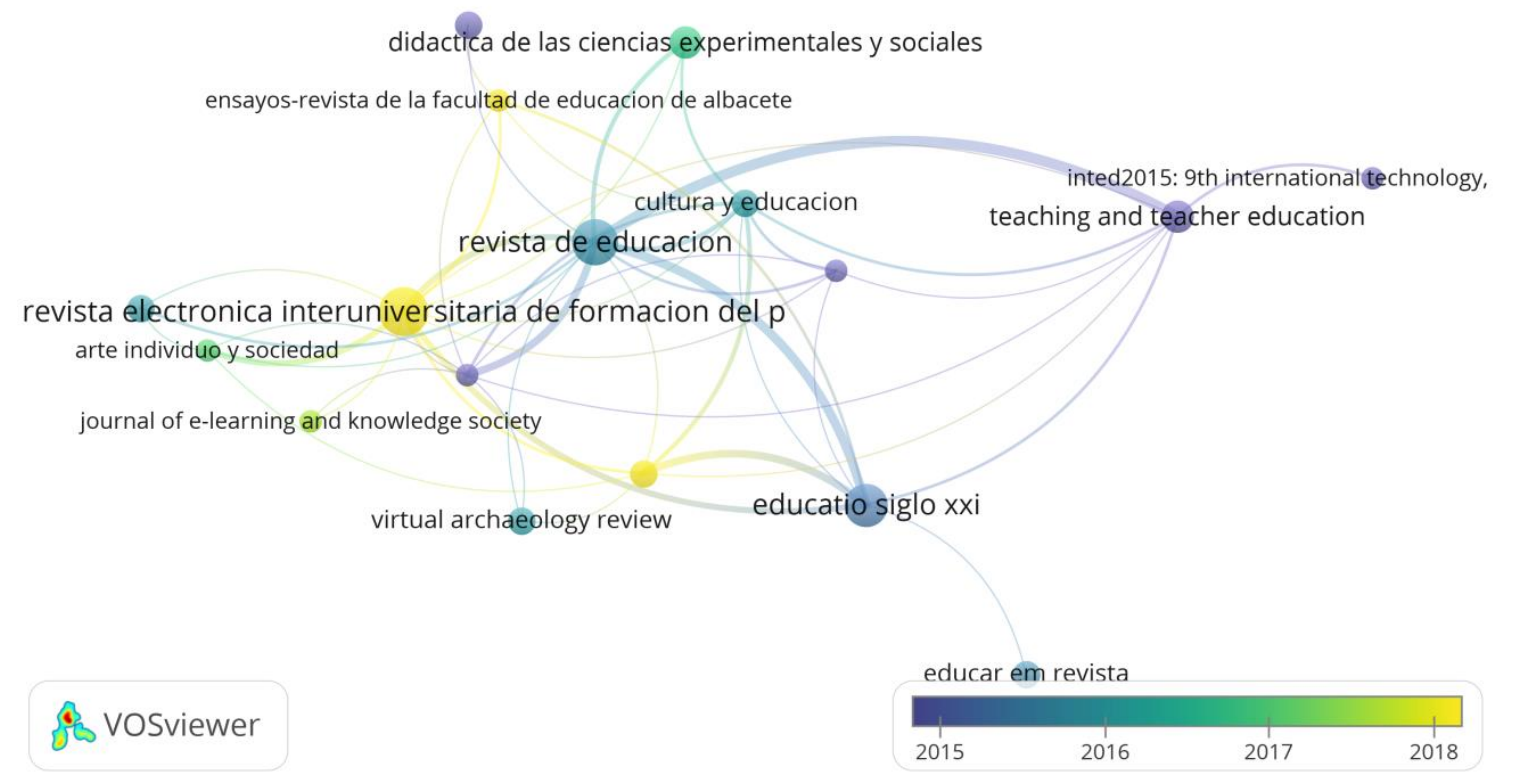

Figura 19. Red de citación de fuentes en overlay visualization VOSviewer.

Si hacemos una lectura de los resultados observamos que muchas de las fuentes que presentan altos índices de productividad se corresponden con el desarrollo de monográficos sobre educación patrimonial. Por este orden de antigüedad encontramos en monográfico Actualidad y Tendencias en Educación Patrimonial desarrollado en Educatio siglo XXI en el año 2015 (Calaf et al., 2015; Martín-Cáceres y Cuenca, 2015; Pinto y Molina-Puche, 2015; Vicent et al., 2015, etc). El monográfico Educación patrimonial epistemología, modelos e investigaciones referentes en Revista de 
Educación en el año 2017 (Almansa y López, 2017; Marín et al., 2017; Cuenca et al., 2017; Fontal e Ibáñez-Etxeberria, 2017, ect). Ensayos-revista de la facultad de educación de Albacete en el año 2018 dedica un monográfico a: Pensar históricamente: recursos, herramientas y estrategias para el desarrollo de las competencias históricas (Martínez, López, Asensio, y Santacana, 2018; Rivero et al., 2018a, ect). La revista electrónica interuniversitaria de formación del profesorado (REIFOP) también publica un monográfico en 2019 sobre la educación patrimonial que lleva por título: Patrimonio y Educación (Alves y Pinto, 2019; Cepeda y Fontal, 2019; Ibañez-Etxeberría, Kortabitarte, De Castro, y Gillate, 2019; Jagielska-Burduk y Piotr, 2019; LobovikovKatz, 2019; Luna et al., 2019)

Por otro lado, existen revistas que no han desarrollado monográficos temáticos específicos, pero que sí que dan cabida a la temática en función de sus objetivos y alcance, como es la revista Arte, individuo y sociedad (Calaf y Gutiérrez, 2017; Fontal, 2016a; Fontal y Marín; 2016; Gómez-Redondo, 2012), Culture and Education (Cuenca y López, 2014; Fontal, 2016b), Virtual Archeology Review (Vicent, Ibáñez-Etxeberria y Asensio, 2015; Haddad, 2016) o Teaching and Teacher Education (Barghi, 2017; Estepa et al., 2008; Jiménez et al., 2010; Koster, Brekelmans, Korthagen, y Wubbels, 2005; Nocus et al., 2012). Estos últimos artículos son los que en relación al resto presentan una mayor antigüedad.

Para finalizar realizamos un análisis de las organizaciones y los países con mayor producción. Utilizamos un análisis: Bibliographic coupling, y seleccionamos como unidad de análisis: Organización. De un total de n=202 organizaciones seleccionamos un mínimo de dos documentos de cada organización y obtenemos 31 organizaciones de las cuales presentan conexiones un total de $n=26$. 


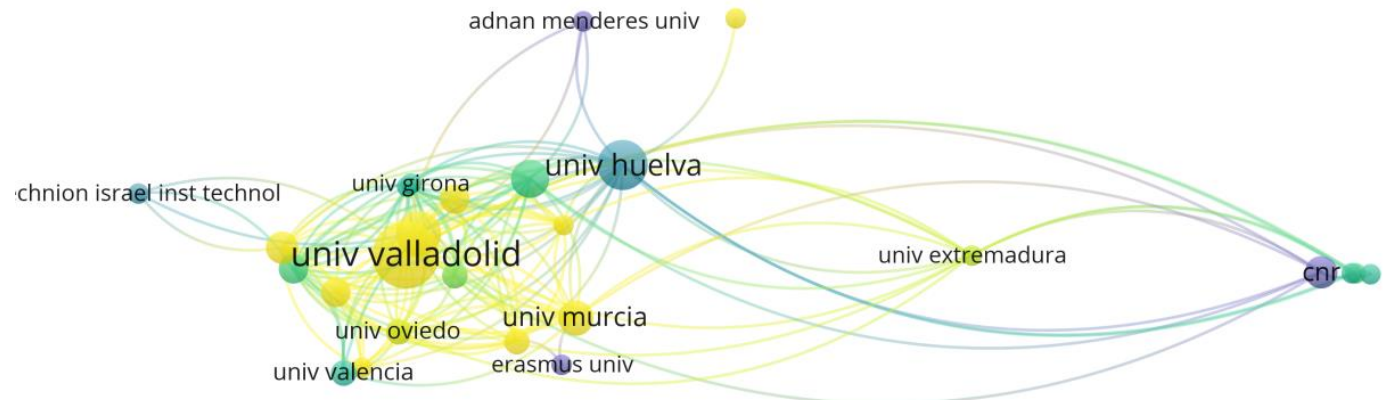

\section{VOSviewer}

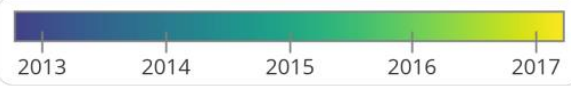

Figura 20. Red de organizaciones en overlay visualization VOSviewer.

Presentamos los resultados en un mapa overlay visualization, donde los ítems presentan diferentes colores en función de la leyenda, además de permitirnos visualizar los clusters más representativos. Encontramos nodos en torno a las universidades de Huelva, Valencia, Oviedo, Girona, Murcia, entre otros. Entre las organizaciones con una mayor producción en los últimos años destaca la universidad de Valladolid y la Universidad de Murcia. Con relación a organizaciones extranjeras encontramos The Israel Institute of Technology, la Universidad de Malasia o Istituto Tecnologie Didattiche.

Para finalizar analizamos los países con mayor producción científica a través de un gráfico de barras (Ver figura 21), así como las relaciones existentes entre ellos (Ver figura 22). Para ello, realizamos un análisis: Bibliographic coupling, seleccionamos como unidad de análisis: Países y un mínimo de 2 documentos por país. Del total de 38 países, 24 alcanzan el umbral establecido. 


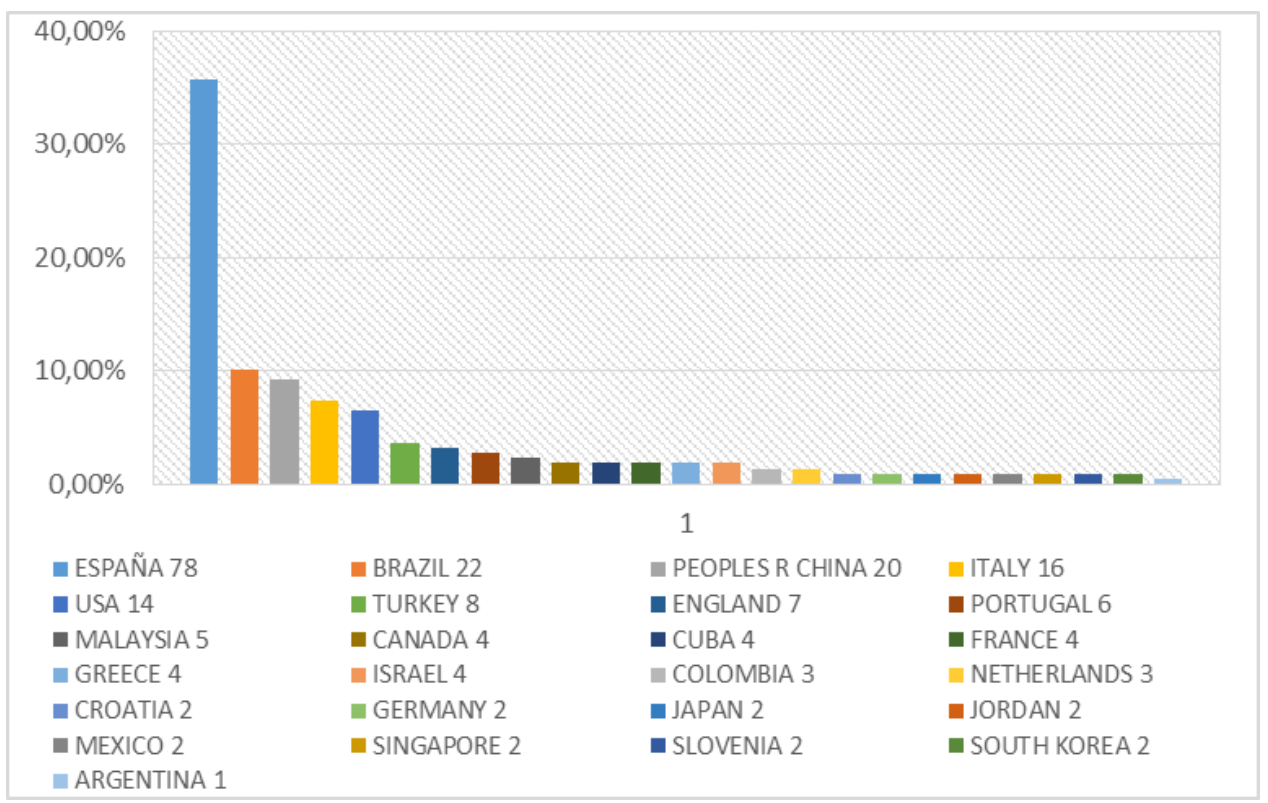

Figura 21. Relación de países en base a la producción científica en el campo.

España con un total de 78 publicaciones se sitúa a la cabeza seguido por Brazil, calificado por muchos autores como la cuna de la educación patrimonial (Cavalcanti, 2016; García-Ceballos et al., 2017). China (Xie y He, 2017), Italia (Ott y Pozzi, 2011; Ott et al., 2015) y EEUU también son países con una producción importante. Por otro lado, en menor porcentaje destacamos Turkia, cuya producción está encabezada por la Dra. Lobovikov-Katz y Malasia donde destacan las autoras Barghi, Zakaria y Hamzah. En el siguiente mapa (ver figura 22) observamos la red entre países, donde se forman 5 clúster principales.

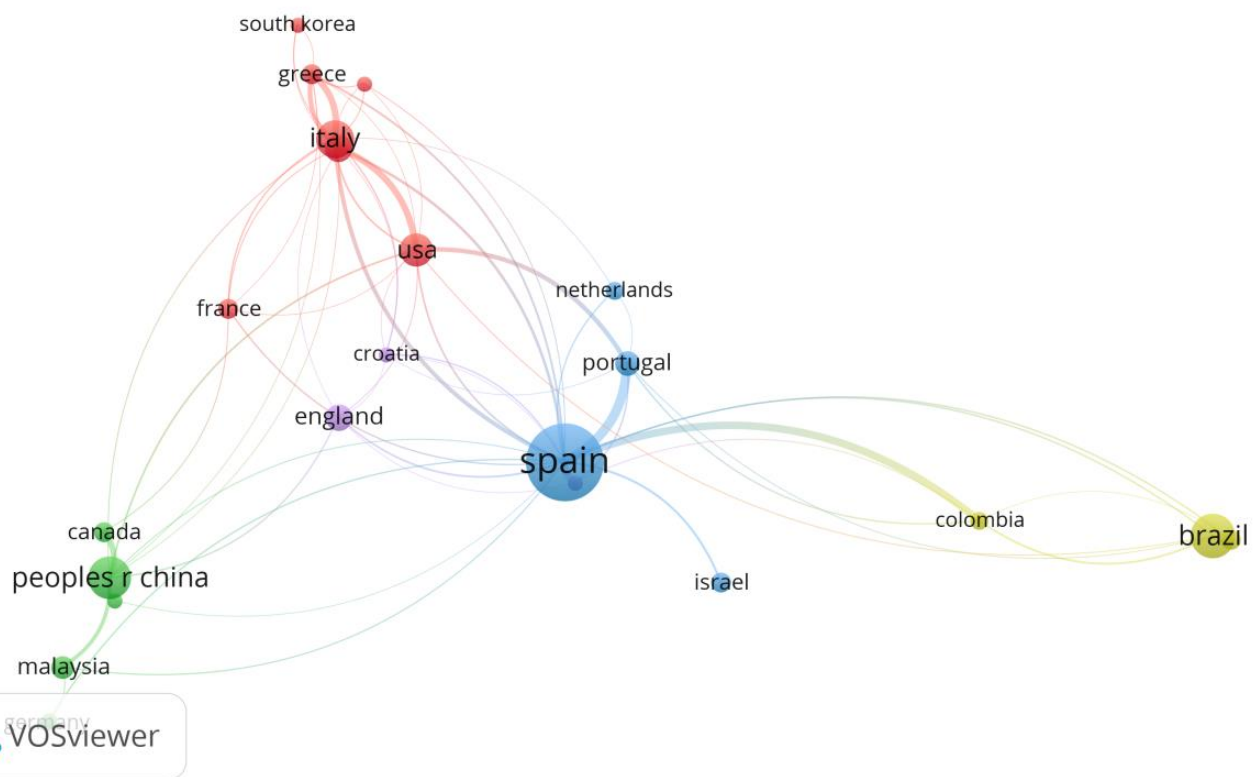

Figura 22. Red de países en network visualization VOSviewer 
El clúster 1 (en color azul) agrupa los ítems de España, Netherlans, Portugal e Israel y tiene como nodo centran a España. El clúster amarillo es relativo a Latinoamérica donde encontramos los ítems de Colombia y Brazil. Los clusters rojo, verde y morado se desarrollan en torno a los nodos de China, Italia e Inglaterra.

\subsubsection{Tesis doctorales sobre Educación Patrimonial, evaluación de programas y patrimonio cultural Inmaterial.}

Otro de los aspectos a revisar para conocer la trayectoria de la educación patrimonial en el ámbito nacional son las tesis doctorales, que han sido defendidas en relación a nuestro campo de estudio, con especial atención a aquellas que abordan aspectos sobre el PCI. Para ello tomamos como base de datos el buscador Teseo ${ }^{38}$, que es gestionado por el Ministerio de Educación Cultura y Deporte, y que cuenta con una base de datos que registra las tesis defendidas en España desde el año 1976. La metodología que utilizamos, tras registrarnos en Teseo es la opción de búsqueda avanzada usando el descriptor "educación patrimonial". Señalizamos la opción de búsqueda con todas las palabras. Otra de las búsquedas será relativa al descriptor temático "patrimonio cultural inmaterial", señalizando la opción de búsqueda con laguna de las palabras. Las búsquedas se realizan tanto en el título como en el resumen.

La búsqueda sobre educación patrimonial nos arroja una muestra de $n=157$, sobre la que realizamos un proceso de selección, en base a aquellas que presentan un claro enfoque de evaluación y/o análisis de programas educativos sobre patrimonio, y análisis del tratamiento del patrimonio dentro de la educación formal. Para ello realizamos una lectura crítica de los resúmenes y obtenemos una muestra de $n=20$, que presentamos ordenadas cronológicamente en función del año de defensa.

Tabla 7

Relación de tesis doctorales seleccionadas como resultado de la búsqueda en Teseo

\begin{tabular}{|c|c|c|c|c|}
\hline TESIS & AÑO & UNIVERSIDAD & AUTOR/A & DIRECTOR/ES \\
\hline $\begin{array}{c}\text { Evaluación de programas de educación } \\
\text { patrimonial para personas con trastorno } \\
\text { del espectro autista (TEA) en museos }\end{array}$ & 2018 & $\begin{array}{c}\text { Universidad de } \\
\text { Valladolid }\end{array}$ & $\begin{array}{c}\text { Laura Pablos } \\
\text { González }\end{array}$ & $\begin{array}{c}\text { Fontal Merillas, Olaia } \\
\text { (Director) } \\
\text { Arias González, Víctor } \\
\text { (Codirector) }\end{array}$ \\
\hline Evaluación de programas en educación & 2018 & Universidad de & Silvia García- & Fontal Merillas, Olaia \\
\hline
\end{tabular}

\footnotetext{
${ }^{38}$ La base de datos Teseo permite consultar las tesis doctorales leídas hasta la fecha en España (desde 1976) a través de un buscador online.

https://www.educacion.gob.es/teseo/irGestionarConsulta.do;jsessionid=4A0ADA20F5563328F77F00163 C6EA195
} 


\begin{tabular}{|c|c|c|c|c|}
\hline $\begin{array}{c}\text { patrimonial. Indicadores de calidad a } \\
\text { través del método SAEPEP-OEPE y su } \\
\text { instrumento basado en estándares } \\
\text { EBEB-OEPE. } \\
\end{array}$ & & Valladolid & Ceballos & $\begin{array}{l}\text { (Director) } \\
\text { Arias González, Víctor } \\
\text { (Codirector) }\end{array}$ \\
\hline $\begin{array}{c}\text { Enseñar y aprender historia con el } \\
\text { patrimonio. Evaluación cualitativa en } \\
\text { museos de Asturias. }\end{array}$ & 2017 & $\begin{array}{l}\text { Universidad de } \\
\text { Oviedo }\end{array}$ & $\begin{array}{c}\text { Suárez } \\
\text { Suárez, } \\
\text { Miguel Ángel }\end{array}$ & $\begin{array}{l}\text { Calaf Masachs, } \mathrm{M}^{\mathrm{a}} \text { del } \\
\text { Roser (Director) } \\
\text { Fernández Rubio, M. } \\
\text { del Carmen } \\
\text { (Codirector). }\end{array}$ \\
\hline $\begin{array}{l}\text { Educación Patrimonial, museos y } \\
\text { ferrocarril: un estudio de caso sobre el } \\
\text { Museo del Ferrocarril de Madrid }\end{array}$ & 2016 & $\begin{array}{l}\text { Universidad } \\
\text { Autónoma de } \\
\text { Madrid }\end{array}$ & $\begin{array}{l}\text { Méndez } \\
\text { Andrés, } \\
\text { Ramón }\end{array}$ & $\begin{array}{l}\text { De los Reyes Leoz, } \\
\text { José Luis (Director) } \\
\text { Cuéllar Villar, } \\
\text { Domingo (Codirector) }\end{array}$ \\
\hline $\begin{array}{l}\text { Cartografía autoetnográfica de una } \\
\text { genealogía de programas de Educación } \\
\text { Patrimonial desde la perspectiva del } \\
\text { aprendizaje basado en proyectos y la } \\
\text { investigación-acción. }\end{array}$ & 2016 & $\begin{array}{l}\text { Universidad de } \\
\text { Valladolid }\end{array}$ & $\begin{array}{c}\text { Pablo de } \\
\text { Castro Martín }\end{array}$ & $\begin{array}{c}\text { Ibáñez-Etxeberria, } \\
\text { Alejandro (Codirector) } \\
\text { Fontal Merillas, Olaia } \\
\text { (Codirector) }\end{array}$ \\
\hline $\begin{array}{l}\text { Educación Patrimonial y redes sociales. } \\
\text { Análisis y evaluación de acciones en } \\
\text { los medios de comunicación social para } \\
\text { la definición de una cartografía } \\
\text { educativa } \\
\end{array}$ & 2016 & $\begin{array}{l}\text { Universidad de } \\
\text { Valladolid }\end{array}$ & $\begin{array}{l}\text { Maldonado } \\
\text { Esteras, María } \\
\quad \text { Stella }\end{array}$ & $\begin{array}{l}\text { Fontal Merillas, Olaia } \\
\text { (Director) } \\
\text { Ibáñez-Etxeberria, } \\
\text { Alejandro (Codirector) }\end{array}$ \\
\hline $\begin{array}{c}\text { Memoria, identidad y comunidad: } \\
\text { evaluación de programas de Educación } \\
\text { Patrimonial en la Comunidad de } \\
\text { Madrid }\end{array}$ & 2016 & $\begin{array}{l}\text { Universidad de } \\
\text { Valladolid }\end{array}$ & $\begin{array}{c}\text { Sánchez Ferri, } \\
\text { Ana }\end{array}$ & $\begin{array}{l}\text { Fontal Merillas, Olaia } \\
\text { (Director) }\end{array}$ \\
\hline $\begin{array}{c}\text { El paisaje en la enseñanza secundaria } \\
\text { obligatoria: análisis de libros de textos } \\
\text { y del currículum oficial, el abordaje } \\
\text { patrimonial }\end{array}$ & 2016 & $\begin{array}{c}\text { Universidad de } \\
\text { Huelva }\end{array}$ & $\begin{array}{c}\text { Morón } \\
\text { Monge, María } \\
\text { del Carmen }\end{array}$ & $\begin{array}{c}\text { Doctor Cabrera, } \\
\text { Alfonso (Director) } \\
\text { Estepa Giménez, Jesús } \\
\text { (Director) }\end{array}$ \\
\hline $\begin{array}{l}\text { El patrimonio como contenido de } \\
\text { enseñanza. Análisis de concepciones y } \\
\text { de recursos didácticos }\end{array}$ & 2015 & $\begin{array}{c}\text { Universidad de } \\
\text { Huelva }\end{array}$ & $\begin{array}{c}\text { Ferreras } \\
\text { Listán, Mario }\end{array}$ & $\begin{array}{c}\text { Martín Cáceres, } \\
\text { Myriam J. (Director) } \\
\text { Estepa Giménez, Jesús } \\
\text { (Director) }\end{array}$ \\
\hline $\begin{array}{c}\text { ¿Qué aporta la educación patrimonial a } \\
\text { la enseñanza de las ciencias } \\
\text { experimentales?: "un análisis del } \\
\text { patrimonio en los libros de texto de } \\
\text { ciencias de la naturaleza de la eso }\end{array}$ & 2015 & $\begin{array}{c}\text { Universidad de } \\
\text { Huelva }\end{array}$ & $\begin{array}{c}\text { Hortensia } \\
\text { Morón Monje }\end{array}$ & $\begin{array}{c}\text { de las Heras Perez, } \mathbf{M}^{\mathrm{a}} \\
\text { Ángeles } \\
\text { (director)Cuenca } \\
\text { López, José María } \\
\text { (director) }\end{array}$ \\
\hline $\begin{array}{c}\text { Educación Patrimonial y diversidad: } \\
\text { evaluación de programas y definición } \\
\text { de un modelo basado en los procesos } \\
\text { de patrimonializacion }\end{array}$ & 2014 & $\begin{array}{l}\text { Universidad de } \\
\text { Valladolid }\end{array}$ & $\begin{array}{c}\text { Marín } \\
\text { Cepeda, Sofía }\end{array}$ & $\begin{array}{l}\text { Fontal Merillas, Olaia } \\
\text { (Director) }\end{array}$ \\
\hline $\begin{array}{l}\text { La educación patrimonial. análisis del } \\
\text { tratamiento didáctico del patrimonio en } \\
\text { los libros de texto de ciencias sociales } \\
\text { de la enseñanza secundaria }\end{array}$ & 2014 & $\begin{array}{c}\text { Universidad de } \\
\text { Huelva }\end{array}$ & $\begin{array}{l}\text { Inmaculada } \\
\text { López Cruz }\end{array}$ & $\begin{array}{c}\text { José María Cuenca } \\
\text { López (Director) }\end{array}$ \\
\hline $\begin{array}{l}\text { Educación artística y patrimonial para } \\
\text { la percepción, comprensión y reflexión } \\
\text { del colectivo sordo en el ámbito } \\
\text { museal. Estudio de casos evaluativo }\end{array}$ & 2014 & $\begin{array}{l}\text { Universidad de } \\
\text { Valladolid }\end{array}$ & $\begin{array}{l}\text { Pérez López, } \\
\text { Sara }\end{array}$ & $\begin{array}{c}\text { Fontal Merillas, Olaia } \\
\text { (Director) } \\
\text { Moriyón Mójica, } \\
\text { Carlos (Codirector) } \\
\end{array}$ \\
\hline $\begin{array}{l}\text { Programas de Educación Patrimonial } \\
\text { en contextos informales: análisis y } \\
\text { valoración de su influencia en el } \\
\text { alumnado de eso de la zona minero- } \\
\text { industrial de Bizkaia } \\
\end{array}$ & 2014 & $\begin{array}{c}\text { Universidad del } \\
\text { País Vasco }\end{array}$ & $\begin{array}{l}\text { Gillate Aierdi, } \\
\text { Iratxe }\end{array}$ & $\begin{array}{l}\text { Madariaga Orbea, José } \\
\text { María (Director) } \\
\text { Ibáñez-Etxeberria, } \\
\text { Alejandro }\end{array}$ \\
\hline $\begin{array}{c}\text { Evaluación de un programa de } \\
\text { Educación Patrimonial basado en } \\
\text { tecnología móvil }\end{array}$ & 2013 & $\begin{array}{l}\text { Universidad } \\
\text { Autónoma de } \\
\text { Madrid }\end{array}$ & $\begin{array}{l}\text { Vicent Otaño, } \\
\text { Naiara }\end{array}$ & $\begin{array}{l}\text { Asensio Brouard, } \\
\text { Mikel (Director) } \\
\text { Ibáñez-Etxeberria, } \\
\text { Alejandro }\end{array}$ \\
\hline $\begin{array}{l}\text { Procesos de patrimonialización en el } \\
\text { arte contemporáneo: diseño de un } \\
\text { artefacto educativo para la identización }\end{array}$ & 2013 & $\begin{array}{l}\text { Universidad de } \\
\text { Valladolid }\end{array}$ & $\begin{array}{c}\text { Gómez } \\
\text { Redondo, M.a } \\
\text { del Carmen }\end{array}$ & $\begin{array}{l}\text { Fontal Merillas, Olaia } \\
\text { (Director) }\end{array}$ \\
\hline La educación y la comunicación & 2012 & Universidad de & Martín & Cuenca López, José \\
\hline
\end{tabular}




\begin{tabular}{|c|c|c|c|c|}
\hline $\begin{array}{c}\text { patrimonial: una mirada desde el } \\
\text { museo de Huelva }\end{array}$ & Huelva & $\begin{array}{c}\text { Cáceres, } \\
\text { Myriam J. }\end{array}$ & María (Director) \\
\hline $\begin{array}{c}\text { Actividades educativas y didáctica del } \\
\text { patrimonio en las ciudades españolas. } \\
\text { Análisis, estado de la cuestión y } \\
\text { valoración para una propuesta de } \\
\text { modelización }\end{array}$ & 2011 & $\begin{array}{c}\text { Coma } \\
\text { Universidad de } \\
\text { Barcelona } \\
\text { Quintana, } \\
\text { Laia }\end{array}$ & $\begin{array}{c}\text { Santacana Mestre, Joan } \\
\text { (Director) }\end{array}$ \\
\hline $\begin{array}{c}\text { Educación y patrimonio: el caso de los } \\
\text { campos de trabajo en la comunidad } \\
\text { autónoma del País Vasco }\end{array}$ & 2005 & $\begin{array}{c}\text { Universidad del } \\
\text { Vasco/Euskal } \\
\text { Herriko } \\
\text { Unibertsitatea }\end{array}$ & $\begin{array}{c}\text { Ibáñez } \\
\text { Echeverría, } \\
\text { Alejandro }\end{array}$ & $\begin{array}{c}\text { Correa Gorospe, Jose } \\
\text { Miguel } \\
\text { (Director) }\end{array}$ \\
\hline $\begin{array}{c}\text { La Educación Patrimonial: definición } \\
\text { de un modelo integral y diseño de } \\
\text { sensibilización }\end{array}$ & 2003 & $\begin{array}{c}\text { Universidad de } \\
\text { Oviedo }\end{array}$ & $\begin{array}{c}\text { Fontal } \\
\text { Merillas, } \\
\text { Olaia }\end{array}$ & $\begin{array}{c}\text { Calaf Masachs, Roser } \\
\text { (Director) }\end{array}$ \\
\hline
\end{tabular}

Los resultados obtenidos bajo el descriptor temático "Educación Patrimonial" y nuestro foco de interés específico, nos arroja 20 registros, con una producción repartida a nivel nacional, aunque con un foco principal en Valladolid en torno a la Dr. Fontal, y otros en Huelva, País Vasco, Barcelona y Oviedo. Los resultados encuentran semejanzas con el estudio realizado por Fontal e Ibáñez-Etxeberria (2017), sobre el análisis de la producción de tesis doctorales defendidas en España entre 1955 y 2016 que define cuatro líneas de investigación: Educación y Patrimonio, Didáctica del Patrimonio, Educación Patrimonial y Currículo y Profesorado. Nuestra búsqueda se relaciona con la línea de investigación Educación Patrimonial que presenta un total de 17 trabajos en contraste con nuestra muestra de $n=20$ trabajos, y que es considerada por los autores la genealogía más interrelacionada. También debemos destacar que de estos 20 trabajos 6 de ellos emplean el método SAEPE-OEPE (Ver capitulo III). De Pablos (2018) realiza una evaluación de programas de educación patrimonial para personas con trastorno del espectro autista (TEA) en museos. García-Ceballos (2018) presenta tres estudios cuyo objetivo común ha sido la evaluación de programas educativos mediante la aplicación del método secuencial para el análisis y evaluación de programas de educación patrimonial. Maldonado (2016) desarrolla un análisis y evaluación de acciones educativas en torno al patrimonio en redes sociales, definiendo una cartografía educativa. De Castro (2016) nos aporta un enfoque autoetnográfico desde el punto de vista evaluativo del trabajo por proyectos de educación patrimonial y la investigaciónacción. Sánchez-Ferri (2016) aborda la evaluación de programas de educación patrimonial en la Comunidad de Madrid, desde los descriptores de memoria, identidad y comunidad y, finalmente, Marín-Cepeda (2014), trabaja desde la diversidad, confeccionando un modelo basado en los procesos de patrimonialización hasta proponer un modelo universal. El método también es utilizado desde tesis doctorales afines a la 
disciplina, como por ejemplo la de Rico (2016), quien desarrolla una evaluación del uso de Apps que abordan procesos creativos en el área de Educación artística, desde el ámbito formal de la enseñanza secundaria obligatoria o la tesis de Vicent (2013) que evalúa procesos de enseñanza-aprendizaje, sobre un programa educativo que implementa la tecnología móvil.

En cuanto al resto de líneas de investigación: Educación y Patrimonio con 12 tesis doctorales; Didáctica del Patrimonio con 14 trabajos focalizada en la Universidad de Barcelona bajo la dirección de J. Santacana y X. Hernández; Currículo y Profesorado con 9 registros donde se destaca la producción de la Universidad de Huelva de la mano de J. Estepa y de la Universidad de Oviedo con R. Calaf. A pesar de que los resultados no son sumamente dispares si permiten apreciar líneas y focos de trabajo. Los autores concluyen en la necesidad de buscar un cierto equilibrio de la producción entre las líneas (Fontal e Ibáñez-Etxeberria, 2017).

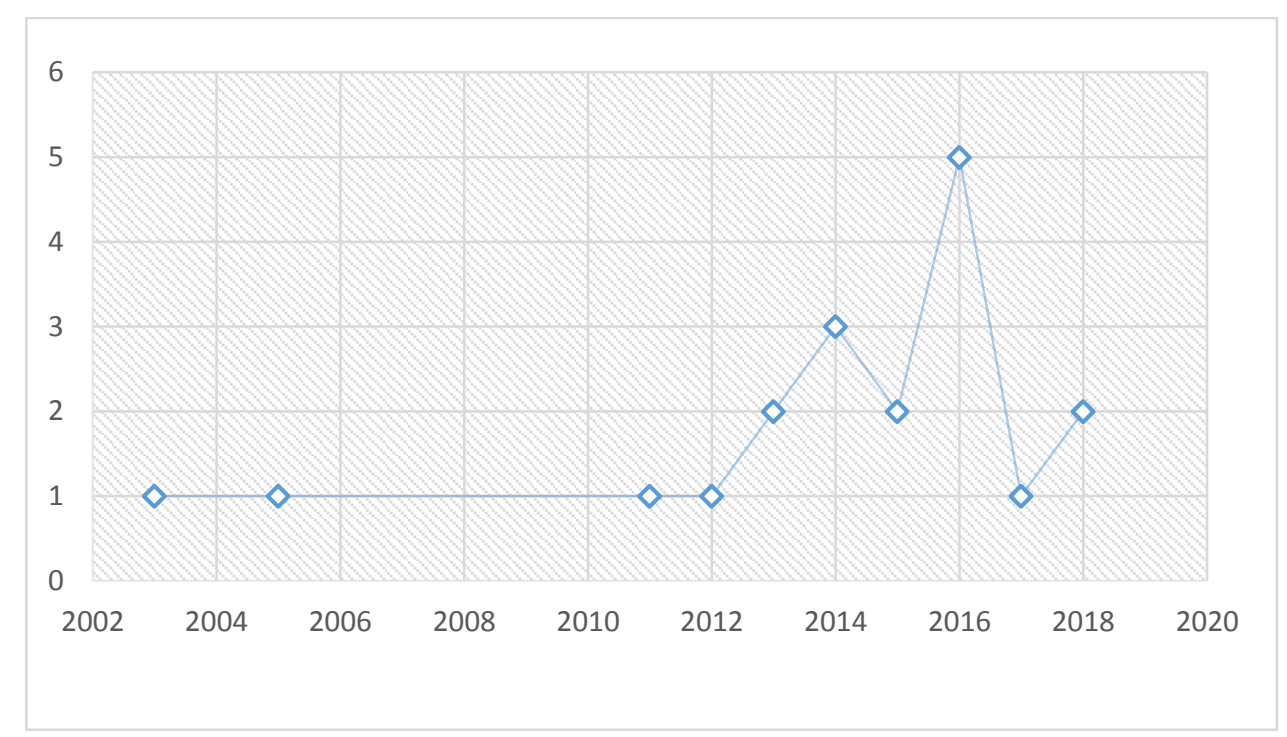

Figura 23. Proceso evolutivo de las tesis doctorales sobre la muestra de la tabla 7.

Por otro lado, realizamos una búsqueda con el descriptor temático "patrimonio cultural inmaterial" junto al descriptor "educación", señalizamos la opción de búsqueda con alguna de las palabras. Las búsquedas se realizan tanto en el título como en el resumen y obtenemos un total de $n=29$, sobre la que realizamos un proceso de selección buscando la intencionalidad de los análisis de procesos educativos en torno al patrimonio inmaterial. Para ello realizamos una lectura crítica de los resúmenes y obtenemos una muestra de $n=5$, que presentamos ordenadas cronológicamente en función del año de defensa. 
Tabla 8

Relación de tesis doctorales seleccionadas como resultado de la búsqueda en Teseo

\begin{tabular}{|c|c|c|c|c|}
\hline TESIS & A ÑO & UNIVERSIDAD & AUTOR/A & DIRECTOR/ES \\
\hline $\begin{array}{l}\text { Las rutas literarias en el marco de la } \\
\text { educación literaria y sus valores } \\
\text { patrimoniales, ambientales y turísticos }\end{array}$ & 2017 & $\begin{array}{l}\text { Universidad de } \\
\text { Extremadura }\end{array}$ & $\begin{array}{l}\text { Estíbaliz } \\
\text { Barriga } \\
\text { Galeano }\end{array}$ & $\begin{array}{l}\text { Martos Núñez, Eloy } \\
\text { (Director) } \\
\text { Martos García, } \\
\text { Aitana (Codirector) }\end{array}$ \\
\hline $\begin{array}{l}\text { El documental interactivo como un } \\
\text { instrumento educativo. propuesta } \\
\text { teórico práctica para la difusión digital } \\
\text { del patrimonio cultural colombiano }\end{array}$ & 2016 & $\begin{array}{l}\text { Universitat de } \\
\text { Valencia }\end{array}$ & $\begin{array}{l}\text { Ana Teresa } \\
\text { Arciniegas } \\
\text { Martínez }\end{array}$ & $\begin{array}{l}\text { Carbonell Tatay, } \mathrm{M}^{\mathrm{a}} \\
\text { Desamparados } \\
\text { (director) } \\
\text { Martínez de Pisón } \\
\text { Ramón, } \mathrm{M}^{\mathrm{a}} \text { José } \\
\text { (director) }\end{array}$ \\
\hline $\begin{array}{c}\text { Flamenco, educación y política: } \\
\text { Analítica de su inclusión en el aula de } \\
\text { primaria } \\
\end{array}$ & 2016 & Universidad de Jaén & $\begin{array}{c}\text { Rosa María } \\
\text { Perales Molada }\end{array}$ & $\begin{array}{l}\text { Castillo Ferreira, } \\
\text { Mercedes (director) }\end{array}$ \\
\hline $\begin{array}{l}\text { A experiencia da potencialidade } \\
\text { didáctica pedagógica da arte capoeira } \\
\text { como veiculo da educaçao nao formal } \\
\text { nos niveis de educaçao pública e } \\
\text { privada nas escolas da cidade de } \\
\text { salvador da bahía - brasil }\end{array}$ & 2014 & $\begin{array}{l}\text { Universidad de } \\
\text { Salamanca }\end{array}$ & $\begin{array}{l}\text { Odilon Jorge, } \\
\text { Daltro de Góes }\end{array}$ & $\begin{array}{l}\text { González Sánchez, } \\
\text { Margarita (director) }\end{array}$ \\
\hline $\begin{array}{c}\text { Diseño y evaluación de material } \\
\text { didáctico del día de los muertos de } \\
\text { México } \\
\end{array}$ & 2014 & $\begin{array}{l}\text { Universidad de } \\
\text { Málaga }\end{array}$ & $\begin{array}{c}\text { Mauricio Piñón } \\
\text { Vargas }\end{array}$ & $\begin{array}{l}\text { Sánchez Rodríguez, } \\
\text { José (director) }\end{array}$ \\
\hline
\end{tabular}

Los resultados obtenidos nos muestran por un lado una gran escasez en torno a la producción de tesis doctorales que aborden el PCI desde un enfoque educativo. A pesar de la gran producción que si existe sobre tesis que abordan el PCI desde enfoques de conservación, legitimación e inventario de patrimonio inmaterial. Obtenemos un total de $\mathrm{n}=121$ registros extraídos resultantes de buscar el descriptor "Patrimonio Cultural Inmaterial" en el título o en el resumen en la base de datos de Teseo.

Si analizamos el ámbito educativo en el que se desarrollan los trabajos encontramos que tres de ellas se enmarcan en un ámbito formal de la educación y 2 de ellas en un ámbito no formal. En cuanto al ámbito o tipología el patrimonio inmaterial, existe un gran variedad, y encontramos trabajos que abordan el ámbito de los rituales festivos y ceremonias (Arciniegas, 2016; Pinón, 2014), tradición oral (Barriga, 2017), juegos y deportes (Daltro, 2014) y manifestaciones musicales y sonoras (Perales, 2016). Aunque es cierto que Arciniegas (2016) y Barriga (2017) hacen alusión a la consideración holística del patrimonio cultural (Desantes, 2013), al integrar lo tangible-material con lo intangible-inmaterial, así como la recreación de dicho patrimonio a través de la escucha, lectura y escritura activas de los alumnos. Otro de los aspectos que debemos resaltar es la elaboración de un diseño educativo propio en cuatro de las tesis doctorales (Barriga, 
2017; Arciniegas, 2016; Daltró, 2014; Piñón, 2014), aunque solamente Piñón hace alusión a la evaluación de dicho material educativo.

Destacamos el trabajo realizado por Perales (2016), puesto que ha sido de gran interés para el desarrollo de la presente tesis doctoral, ya que estudia el modo de introducir dentro del nivel de la educación primaria en la educación formal el PCI. La autora considera que aún quedan muchos interrogantes sobre la conveniencia de introducir el flamenco dentro del currículum escolar, sobre todo debido a la utilización ideológica y política que se ha hecho del mismo desde sus orígenes. Para ello, realiza un análisis sobre la presencia del flamenco en los Programas de Cultura Andaluza y en las leyes educativas. Además, examina las diferentes perspectivas que aportan tanto maestros como profesionales del ámbito del flamenco sobre su inclusión en las aulas, así como la presencia del flamenco en los libros de texto del área de Música de Educación Primaria.

\subsubsection{La investigación en Educación Patrimonial dentro de la educación formal con especial atención al PCI.}

En el análisis del discurso teórico también se ve reflejada la evolución en la concepción de la Educación Patrimonial, que inicialmente planteaba una división dentro de la educación patrimonial: educación sobre el patrimonio que únicamente presentaba una función transmisora de contenidos patrimoniales; y educación a través del patrimonio, donde el patrimonio se utilizaba como un recurso interdisciplinario para la enseñanza de las áreas curriculares (Copeland, 1991). Esta clasificación planteada por Copeland se ve superada cuando Fontal (2003), afirma la necesidad de entender la educación patrimonial como un proceso vinculante, relacional y experiencial entre el bien cultural y la persona. Esta nueva visión pone el acento en el proceso de patrimonialización donde la persona es la única capaz de atribuir valor a los bienes culturales para convertirlos en patrimonio, el cual querrá cuidar, disfrutar y trasmitir (Fontal y Gómez-Redondo, 2016). Por lo tanto, el autosignificado otorgado a los bienes culturales evoluciona en función de las experiencias educativas (Copeland, 2006). Esta perspectiva deriva en un nuevo enfoque de carácter globalizador, integrador y simbiótico; educación desde y hacia el patrimonio, que coloca el acento en el proceso relacional y en el acto de patrimonialización. Así, la educación patrimonial adquiere un carácter doblemente relacional, donde "el patrimonio es el contenido de ese aprendizaje y las formas de 
relación se refieren a la identidad, la propiedad, el cuidado, disfrute, transmisión, etc." (Domingo et al., 2013, p. 10).

En los últimos años existe una proliferación de investigaciones, que han comenzado a analizar la normativa educativa con la intención de conocer el uso, el tratamiento, y el enfoque que recibe en ellas el patrimonio (Gueler-Biyikli y Aslam, 2013; Fontal, 2016; Pinto y Molina-Puche, 2015). Sus resultados muestran que el patrimonio es un contenido presente desarrollado de forma trasversal y siempre desde un sentido simbólicoidentitario, aunque recalcan la necesidad de superar la aproximación actitudinal en su enseñanza hacia los procesos de sensibilización.

Otra de las corrientes de investigación en el campo de la educación patrimonial, aborda la dicotomía generada sobre el enfoque en la enseñanza del patrimonio dentro del currículum. La mayoría de los autores se posicionan en la defensa de la enseñanza del patrimonio de un modo trasversal, como un medio a través del cual ordenar y facilitar la enseñanza de las áreas curriculares, a la vez que fomenta la conciencia y el respeto hacia el patrimonio (Barghi et al., 2017; Hằng et al., 2017; Punja, 2010). Hunter defiende que el mejor modo de incluir la educación patrimonial en el currículo es a través de la fusión-integración de materiales existentes en las áreas curriculares como base para la educación patrimonial (1988). Por otro lado, otras investigaciones como la realizada por Fuhai (2017) argumentan la falta de coherencia del currículo con los objetivos y requisitos para transmitir el patrimonio étnico a través de la educación escolar, y defienden la necesidad de integrar el conocimiento local en un formato apropiado dentro del plan de estudios de la escuela como clave para el éxito. La relación entre el patrimonio local y el currículum, también ha sido analizada por McAnany y Parks (2012), que sostienen que cuando la identidad nacional subestima una parte de su pasado evidente en el currículum escolar se producen consecuencias negativas para este tipo de patrimonio.

Existen investigaciones que analizan el currículum desde otros enfoques, y centran su objeto de estudio en conocer las opiniones y concepciones del profesorado de educación primaria y secundaria sobre la enseñanza del patrimonio y la educación patrimonial (Estepa et al., 2008; Jiménez et al., 2010; Lucas y Delgado, 2018; Trivino y Rico, 2016). En esta misma línea, Avci y Memişoğlu (2016) analizan las opiniones de los docentes en ciencias sociales y concluyen que los contenidos patrimoniales no están lo 
suficientemente presentes, a pesar de su importancia, por lo que consideran necesario hacer arreglos dentro de los planes de estudios. En esta misma línea Pinto y Zarbato constatan "un desfase significativo entre el potencial didáctico del patrimonio para la enseñanza de la historia y su presencia en las directrices de los planes de estudio" (2017, p. 225). A este respecto, Fontal 2016 discrepa en cierto sentido, ya que aun defendiendo la necesidad de aumentar los contenidos y las competencias que trabajen la educación patrimonial en el currículo de primaria, recalca la necesidad de promover el máximo aprovechamiento de las que sí se han incluido en los currículums vigentes. Autores como Cuenca et al. (2017) estudian el patrimonio desde una visión compleja e interdisciplinaria, analizan las opiniones de profesores y libros de texto de primaria y secundaria, que presentan un predominio de visiones estéticas y temporales. En la misma línea, también se desarrollan investigaciones que analizan el patrimonio en los libros de texto (Cuenca y López, 2014; Cuenca et al., 2017; Ferreras y Jiménez, 2013; Hernández y Guillen, 2017; Meseguer, Arias, y Egea, 2017; Moron, 2016) buscando estrategias de comunicación y relaciones de identidad, y asignan al patrimonio un papel no crítico y simplista. En este punto es importante destacar el estudio desarrollado por Fontal et al. (2017), que se plantea si los futuros maestros de educación primaria están recibiendo la formación necesaria que les permita adquirir competencias para trabajar la educación patrimonial en las aulas. La investigación concluye que es mayor la presencia de contenidos patrimoniales en las áreas del currículum de educación primaria que, en los planes de estudios del grado de educación primaria, y apela a su revisión. Sobre la formación de los futuros docentes también se encontramos las investigaciones desarrolladas por Domínguez, Costa-Casais y López-Facal (2019).

Otros estudios centran la atención en el periodo de prácticas de los futuros docentes y afirman que la educación patrimonial es un instrumento eficaz para la formación inicial de los futuros maestros y para el desarrollo de competencias cívicas entre el alumnado de primaria (Domínguez y López-Facal, 2017), a pesar de que el patrimonio no es un referente clave en los procesos de enseñanza-aprendizaje dentro de los programas universitarios (Fontal et al., 2017). Ante la preocupación por proporcionar una formación adecuada a los estudiantes de ciencias de la educación y futuros docentes, que les capacite para trabajar la educación patrimonial en las aulas, se desarrollan diversos programas educativos. Algunos de los ejemplos a destacar son el proyecto DICHE que realiza una formación e-learning a través de un MOOC, para diseñar recursos de 
educación cultural y patrimonial con el objetivo de integrar la educación patrimonial en la educación primaria (Poce et al., 2017; 2018). También con un enfoque muy innovador se encuentra el proyecto desarrollado por Bosić y Mihić (2017), que trabaja con los estudiantes del grado de maestro la educación cultural a través de la educación artística. Existe una proliferación mundial en el desarrollo de programas educativos sobre patrimonio que abordan diferentes tipologías patrimoniales, públicos y metodologías. Encontramos programas de educación patrimonial que buscan desarrollar un pensamiento crítico y transmitir la cultura como un activo a los jóvenes de Siria (Alkateb, 2013), o programas para la enseñanza de la historia en los Países Bajos que utilizan el patrimonio como una experiencia sensorial que estimula el compromiso emocional con el pasado (Klein, Grever, y van Boxtel, 2011).

En cuanto a los programas relacionadas de manera más específica con el patrimonio inmaterial, destacamos las investigaciones realizadas dentro del proyecto i-Treasures, que se integra en el $7^{\circ}$ Programa Marco de la Unión Europea. Este proyecto ha generado una plataforma que contiene recursos educativos innovadores sobre patrimonio cultural inmaterial (Cozzani et al., 2017; Dagnino et al., 2015; Díaz-Emparanza, Peruarena, y Jiménez, 2017; Ott et al., 2015; Ott y Pozzi, 2011). Así como la investigación realizada por Nocus et al. (2012) ligada al patrimonio inmaterial oral, que examinan la efectividad de programas de educación patrimonial para le enseñanza del patrimonio oral, diseñados para las escuelas de primaria de la polinesia francesa. Muchos de estos programas utilizan recursos tecnológicos cada vez más presente en la educación y en la sociedad, desde el el m-learning (Angelopoulou et al., 2012; Ibáñez- Etxeberria et al., 2012; 2018; Poce et al., 2018), el e-learning (Lobovikov-Katz et al., 2014), y el concepto de edutainment y serious games (Haddad, 2016). Esta relación entre las TIC y el Patrimonio Cultural Inmaterial, es la base del proyecto ICHPEDIA desarrollado en Corea, cuyo principal objetivo es elaborar un inventario nacional que sea utilizado para la difusión y sensibilización de esta tipología patrimonial (Soon, 2014). Otro ejemplo es el proyecto desarrollado en Turkia dentro del ámbito formal, que plantea un programa educativo sobre patrimonio intangible utilizando la aplicación tecnológica educativa “WebQuest” (Kasapoglu, 2016). Finalmente hacemos alusión a la necesidad de analizar estos recursos digitales empleados dentro de la educación formal. Con esta intención se desarrolla la investigación llevada a cabo por Álvarez, Bellido y Atencia (2019), que busca analizar los recursos empleados en la educación artística con cierta garantía de 
calidad y ofrecer una valoración de los mismos, según criterios de calidad recomendados y la opinión de los propios alumnos.

Ante la gran cantidad de proyectos educativos parece clara la necesidad de medir la calidad de sus diseños y la eficacia de sus resultados. Son numerosos los autores que defienden la necesidad de evaluación de todas estas propuestas educativas (Fontal, et al., 2019; Fontal y Martínez, 2018; Gómez y Miralles, 2015; Stake, 2006), ya que consideran la evaluación como un medio de mejora hacia la calidad educativa. En esta línea se encuentra la investigación realizada por Dussan (2015) que se encargan de analizar los resultados del programa NAKI -National and Cultural Identity-, que han sido implementados en centros escolares en el ámbito de la educación formal en la república Checa. Así mismo, la investigación desarrollada por Potočnik (2017) evalúa la inclusión de contenidos patrimoniales en el plan de estudios del área de educación artística en la escuela de primaria en Eslovenia, y muestra como los alumnos desarrollan una mayor capacidad de juicio crítico y cuidado del patrimonio. La investigación en educación patrimonial sobre la evaluación de programas educativos relativos al PCI, también refleja esta amalgama y dispersión de las manifestaciones que abordan los programas educativos. Por otro lado, encontramos investigaciones que evalúan los diseños didácticos de programas de educación patrimonial dentro del ámbito formal y no formal (Fontal y Martínez, 2017; 2018; Marín et al., 2017), con la intención de generar estándares de calidad que mejoren el diseño de nuevas propuestas.

Esta necesidad de evaluación también se observa en las investigaciones que analizan el grado de conciencia patrimonial y compromiso de los alumnos (Curtis y Seymour, 2004; Azman, Halimb, Liuc, Saidinb y Komoo, 2010; Jaafar, Noor y Rasoolimanesh, 2015). Todas ellas destacan los bajos niveles de conciencia patrimonial de los estudiantes. Este aspecto supone un problema, ya que de acuerdo con Scalise (2015), la educación es una variable fundamental en la dinámica de la formación de la identidad cultural y patrimonial. Por ello, es imprescindible la revisión y mejora de los planes curriculares para alcanzar una educación de calidad (Dello-lacovo, 2009; Mcculloch, 2005), que conduzcan a construir valores identitarios, fomentando el respecto intercultural y el desarrollo de una juventud socioculturalmente comprometida con el patrimonio. 



\section{CAPITULO III}

\section{Trayectoria y prospectiva del OEPE}

Ópera Carmen. Habanera (George Bizet, 1875)

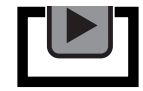

Carmen - Habanera (Anna Caterina Antonacci, The Royal Opera).mp3

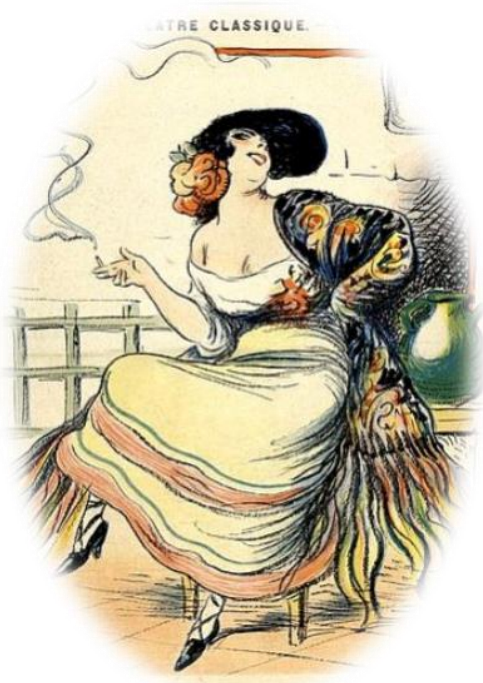

Le Theatre Classique. (Teatro Nacional de la Opèra Comique, 1875) 



\section{Trayectoria y prospectiva del OEPE: su método e instrumento de análisis.}

El Observatorio de educación patrimonial en España (OEPE) comienza su trayectoria en el año 2010 como proyecto subvencionado por el Ministerio de Ciencia e Innovación, dentro de la convocatoria de Investigación fundamental no orientada y, años más tarde con otros dos proyectos subvencionados por el Ministerio de Economía y Competitividad. El objetivo principal es localizar, discriminar, inventariar, analizar y evaluar programas de educación patrimonial desarrollados desde el año 2000 hasta la actualidad (Fontal, 2016b).

El primer proyecto, denominado "Observatorio de Educación Patrimonial en España. Análisis Integral del estado de la educación patrimonial en España” (Ref. EDU200909679), se ha centrado en conocer, analizar y diagnosticar el estado de la educación patrimonial a través de una evaluación basada en estándares de una selección de programas en el territorio nacional; para ello, el proyecto se estructura en tres fases de trabajo: Conocimiento, análisis y diagnóstico; Sistematización y estandarización y Divulgación Científica y generación de redes de trabajo.

Con la intención de coordinar el trabajo de los investigadores miembros del proyecto se generaron dos instrumentos, la hoja de criterios de inclusión y exclusión para el inventario de programas y la ficha de catalogación de los mismos. Este segundo instrumento permite realizar un análisis estadístico-descriptivo del que se extraen datos frecuenciales, en función de los aspectos de interés como la tipología patrimonial, el tipo de estrategias de enseñanza-aprendizaje o la metodología que utilizan, entre otros. Este instrumento ha permitido extraen 3 informes estadísticos a través de los cuales se analizan muestras de $n=350, n=644$ y $n=1120$ programas educativos (Fontal, 2016b), cuyos resultados han servido para generar nuevos instrumentos, que conformarán el método secuencial de análisis y evaluación de programas de educación patrimonial (SAEPEP-OEPE en adelante), que se genera en el marco del segundo proyecto.

El segundo proyecto -al que se vincula la presente investigación- se inicia en 2012 (Ref. EDU 2012/37212), y persigue la continuidad del OEPE con un enfoque hacia su internacionalización con especial atención a Europa y Latinoamérica. Este proyecto se estructura de nuevo en tres fases de trabajo definidas como consolidación, evaluación de 
programas e internacionalización, entre las que destacamos la segunda de ellas, a la que contribuye la presente investigación. Para alcanzar este nuevo objetivo, se amplían las redes de colaboración y al equipo de trabajo del OEPE se suman 12 expertos internacionales, que provienen de ámbitos multidisciplinares y que participan en el diseñó del método SAEPEP-OEPE (Fontal et al., 2019 Fontal y Juanola, 2015). Este método se fundamenta en una evaluación basada en estándares para la selección de programas, atendiendo al enfoque teórico, las metas, la calidad del diseño y planificación de las actuaciones, el grado de cumplimiento y adecuación de la planificación (implementación) y, por último, la calidad y la utilidad de los resultados e impactos generados.

En la actualmente, se encuentra activo un tercer proyecto coordinado (Ref. EDU 2015/65716-C2-1-R), que responde a la unión de las dos áreas científicas de conocimiento que más incidencia tienen en la investigación en educación patrimonial: Didáctica de la Expresión Plástica (Dra. Fontal) y Didáctica de las Ciencias Sociales (Dr. Ibáñez-Etxeberria). Ambas áreas se ocupan de la didáctica de las dos áreas curriculares con mayor presencia de contenidos patrimoniales en las etapas de primaria y secundaria (áreas artística y social), por lo que su vinculación -especialmente en el ámbito formal-, es clave (Fontal, 2011).

Este tercer proyecto, se ocupa de la evaluación de los aprendizajes en programas de educación patrimonial centrados en los procesos de sensibilización, valorización y socialización del patrimonio (Fontal y Gómez-Redondo, 2016). Por su carácter coordinado, plantea seis fases de trabajo en lugar de tres: Conceptualización y teorización de modelos de Educación Patrimonial; Estudio de casos de programas de Educación Patrimonial seleccionados y evaluados a partir del Método OEPE; Definición de criterios de accesibilidad para el aprendizaje de contenidos patrimoniales; DIE-EP Diseño de nuevos instrumentos de recogida de datos para la evaluación de aprendizajes; Extensión del OEPE para potenciar procesos de sensibilización, valorización y socialización del patrimonio y Difusión e internacionalización de la investigación en Educación Patrimonial).

Este proyecto trata de concluir el proceso evaluativo, incorporando la evaluación de los aprendizajes, elemento esencial y fin último de la educación patrimonial, en tanto permitirá conocer con precisión, la naturaleza, proceso y alcance de los aprendizajes 
generados en los programas referentes en educación patrimonial. Además de continuar con la labor de inventario, análisis y evaluación de programas de educación patrimonial; así como la permanente difusión e internacionalización de los resultados.

Sin perder de vista la proyección internacional, el observatorio se presenta a la Convocatoria de Acciones de Dinamización: Europa investigación ${ }^{39}$, con un proyecto que lleva por título "Observatorio Europeo de educación y patrimonio" (EUIN201784639), que obtiene una evaluación positiva y permite a la Dra. Fontal solicita un proyecto europeo European Research Council (ERC) ${ }^{40}$ en el marco de la convocatoria Reflective 6 (H2020). Este proyecto tiene como principal finalidad centrase en el estudio del patrimonio, la memoria y la identidad culturales de Europa (colecciones, archivos y museos culturales y científicos) y busca generación de un Observatorio Europeo de Educación Patrimonial y un Plan Europeo de Educación y Patrimonio.

Siguiendo con esta línea de internacionalización el observatorio también se presenta a la convocatoria COST Action. European Cooperation in Science \& Technology ${ }^{41}$, con la intención de "generate an interdisciplinary, multi-agent network that makes it possible to develop normalized models where heritage education becomes an indispensable discipline that is truly internalized by all administrations and stakeholders working on cultural heritage".

En lo relativo a la estructura del observatorio, esta se compone de dos partes diferenciadas. Por un lado, una base de datos interna de uso exclusivo para los investigadores del proyecto, donde se inventarían los programas educativos localizados a través de una hoja de registro. Esta hoja de registro sirve para catalogar todas las acciones de educación patrimonial localizadas, y se divide en 5 grandes apartados que explicamos con mayor profundidad en el punto 3.2. La base de datos cuenta con motores de búsqueda que nos permiten obtener muestras en base a los parámetros de interés definidos por el investigador. Para manejar la base de datos se ha redactado un manual

\footnotetext{
${ }^{39}$ Programa Estatal de I+D+I orientada a los retos de la sociedad 2017.

${ }^{40}$ European Research Council funded by the European Union's Horizon 2020 Framework Programme for Research and Innovation.

41 The European Cooperation in Science and Technology (COST) is a funding organisation for the creation of research networks, called COST Actions. These networks offer an open space for collaboration among scientists across Europe (and beyond) and thereby give impetus to research advancements and innovation.
} 
de uso con la intención de facilitar su funcionamiento a investigadores que realizan una estancia en investigación en el OEPE, o a las nuevas incorporaciones.

En la actualidad, el grupo de investigación está formado por 33 miembros provenientes de 8 universidades españolas y extranjeras y 9 áreas de conocimiento: Didáctica de la Expresión Plástica, Didáctica de las Ciencias Sociales, Psicología, Didáctica y Organización Educativa, Didáctica de la Expresión Corporal, Didáctica de la Lengua y la Literatura, Música, Sociología y Expresión gráfica arquitectónica. Por otro lado, el observatorio cuenta un espacio externo ${ }^{42}$ que puede ser consultado por cualquier persona interesada, donde se hacen visibles las acciones de transferencia, ejemplos de buenas prácticas y desarrollo de eventos científicos.

En cuanto al impacto y la trasferencia que se han conseguido durante estos años, debemos comenzar destacando la labor del OEPE en torno a la investigación e innovación en educación patrimonial, que lo convierte en uno de los instrumentos referentes que ayuda a cumplir los objetivos de protección, preservación y difusión planteados en el Plan Nacional de Educación y Patrimonio (Domingo et al., 2013; Fontal et al., 2013; Fontal y Martínez, 2016a).

A nivel internacional el observatorio ha desarrollado trabajos en colaboración con el $\mathrm{CEAQ}^{43}$, que fue fundada en 1982 por Michel Maffesoli y Balandier. Este laboratorio de investigación internacional se centra en las nuevas formas de sociabilidad y la imaginación. Por otro lado, y en un contexto iberoamericano el observatorio colabora con la REPEP $^{44}$ que podemos definir como un observatorio informal establecido en la provincia de São Paulo, que trabaja junto con el IPHAN en el proyecto "Plataforma paranapiacaba. Memória y experimentación" que se configura como un Observatorio Experimental del Patrimonio Cultural.

En su labor de trasferencia social, el observatorio pone en marcha numerosas actuaciones en el año 2015, financiadas por FECYT ${ }^{45}$ (FCT-14-9015), cuyo objetivo era sensibilizar y acercar la necesidad de la educación patrimonial a los diferentes sectores sociales. Algunas de las acciones que se llevaron a cabo fue la web personas y

\footnotetext{
42 www.oepe.es

${ }^{43}$ Centro de Investigación sobre la actual y cotidiano.

${ }^{44}$ Rede Paulista de Educação Patrimonial

${ }^{45}$ Fundación española para la ciencia y la tecnología.
} 
patrimonios $^{46}$, diversos proyectos audiovisuales, como cortometrajes y entrevistas a personal experto y no experto, que dieron lugar a un largometraje. También se llevaron a cabo concursos artísticos, concursos sobre innovación docente y concursos dirigidos a personas con diversidad funcional. Dentro de estas acciones o como recopilación de las mismas y de otras muchas se desarrolló un libro titulado "Educación y Patrimonio. Visiones caleidoscópicas" (Fontal et al., 2015).

El observatorio también ha colaborado con el proyecto Duero Douro ${ }^{47}$, que tiene como principal objetivo desarrollar y fomentar la cooperación interterritorial del territorio Duero Douro, con el fin de reforzar la cohesión tanto económica como social. El proyecto en el que están inmersas diversas asociaciones y empresas, otorgan gran importancia al patrimonio como un recurso para el desarrollo del territorio. Desde el OEPE hemos comenzado a colaborar en el diseño de actividades educativas y de sensibilización que implementamos en la Bienal de Restauración y Gestión del Patrimonio celebrada en Valladolid. También se ha desarrollado un Plan de Educación y Patrimonio del Proyecto Duero Douro, que pretende ayudar al cumplimiento de los objetivos del proyecto desde la acción educativa y social (Rivero et al., 2018b).

Con la intención de sintetizar gráficamente el desarrollo del OEPE desde su origen, hasta la actualidad, realizamos la infografía desplegable de la figura 24

\footnotetext{
${ }^{46} \mathrm{https} / / /$ personasypatrimonios.com/

${ }^{47}$ http://www.duero-douro.com/
} 


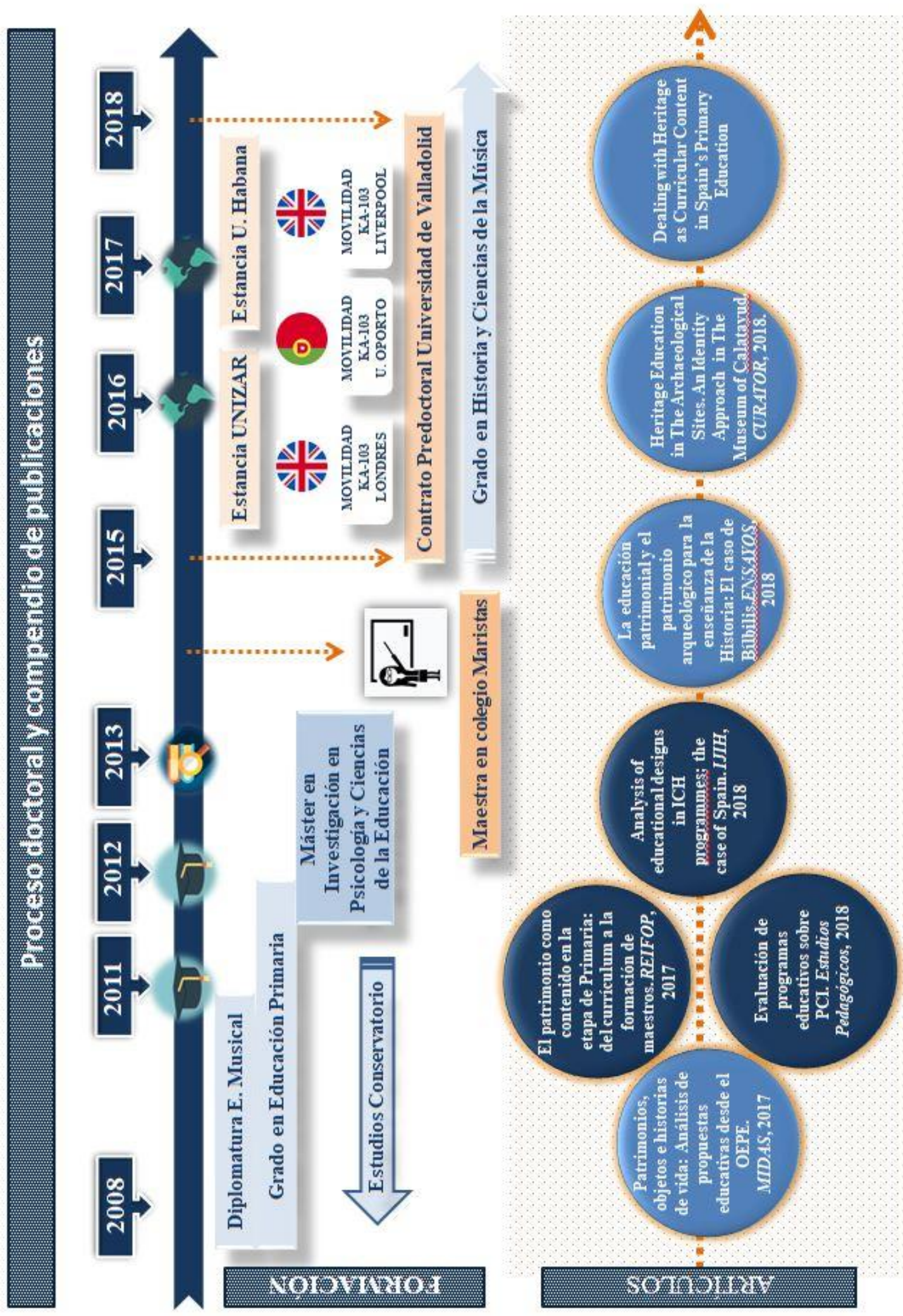

Figura 24. Infografía sobre la trayectoria del OEPE, proyectos I+D+i y fases de trabajo. 


\subsection{Enfoque y paradigma del Método}

El método Secuencial de Análisis y Evaluación de Programas de Educación Patrimonial (SAEPEP-OEPE), se configura como una secuencia de análisis con un enfoque mixto. La utilización de los diseños de método mixto se constituye, día a día, en una excelente alternativa para abordar temáticas de investigación en el campo educativo (Pereira, 2011). Este proceso comienza con un enfoque cuantitativo y evoluciona hacia uno cualitativo, que nos permite presentar descriptivamente valores números y también explicar el cómo o el porqué de los mismos (Uribe, Covarrubias y Uribe, 2009). Existen diferentes tipos de modelos mixtos, según la clasificación elaborada por Pereira enmarcamos el método SAEPEP en el tipo VIII: Secuencial, por etapas, "cada etapa presenta un enfoque diferente que fortalece al anterior" (2011, p. 20).

Este proceso analítico está articulado en 8 fases que podemos dividir a su vez en tres secuencias: de registro, exploratoria y explicativa (Ver figura 26). En la secuencia exploratoria se evalúa la muestra mediante pruebas estadístico-descriptivas y estándares de evaluación (Stake, 2006). Los estándares son clasificados mediante escala Likert, que permite excluir los programas menos significativos y destacar los ejemplares que serán objeto del estudio pormenorizado en una fase cualitativa a través del estudio de caso (Stake, 2010). Esta fase cualitativa se corresponde con la secuencia explicativa dentro del proceso (Simons, 2011). Posteriormente, se efectúa una triangulación concurrente que busca confirmar, correlacionar o corroborar (Creswell, 2008), con la intención no solo de apoyar, complementar y enriquecer los resultados obtenidos a través de las diferentes fases, sino de comprender y describir los fenómenos.

Con este modelo mixto se pretende cubrir un enfoque pragmático que busque el equilibrio entre los paradigmas empírico-analítico, fenomenológico y socio-crítico, basándonos en los principios expuestos por Pereira (2011). El paradigma empíricoanalítico se enmarca dentro de la secuencia exploratoria, que busca describir el estado de la cuestión a través de datos cuantitativos extraídos de las fichas de inventario de los programas. Para cumplimentar las fichas de inventario se elaboran rúbricas para cada ítem en una escala Likert, con la finalidad de unifican criterios y reducir el sesgo investigador (Cook y Reichardt, 2005). El paradigma fenomenológico se centra en los significados y el conocimiento en profundidad de un contexto determinado. El significado solo puede ser creado a través de la interacción, a partir de las articulaciones 
del propio investigador con el contexto, los sujetos, modelos, etc., implicados en el proceso (Arraiz y Sabirón, 2012). Un último paradigma, el socio-crítico (Popkewitz, 1988), hace referencia a una intencionalidad futura. El paradigma se orienta hacia la transformación de la realidad y es pragmático en tanto esta se transforme y determine o no la validez de los resultados.

Por lo tanto, podemos decir que el método analiza en primer lugar el diseño educativo escrito sobre papel. En una segunda fase se aproxima al campo de estudio para la conocer de primera mano la implementación, y dialogar con los agentes educativos implicados en el proceso educativo. Finalmente, extrae las claves procesuales con el fin de plantear nuevos modelos que aumenten la calidad educativa de futuros programas.

\subsection{Descripción del método SAEPEP-OEPE}

Este método se estructura a través de 8 fases de trabajo secuenciales y discriminatorias, que inicialmente eran 7 a las que se ha sumado la evaluación de aprendizaje. El método, es un proceso que va filtrando programas de educación patrimonial a través de tablas de estándares que actúan como sistema de filtros consecutivos. A continuación se describen las fases de trabajo estructuradas en tres secuencias, y los instrumentos para la selección de la muestra, el inventario de datos y la evaluación:

(F1) Búsqueda y localización de programas:

Es el primer paso en la secuencia de registro que consiste en localizar a través de la red, revisiones bibliográficas o encuentros científicos, las acciones educativas, proyectos o programas, así como herramientas, recursos, actividades aisladas, itinerarios didácticos, aplicaciones móviles y todas aquellas propuestas que tengan que ver con la educación patrimonial.

(F2) Discriminación mediante criterios de inclusión y exclusión:

Los programas localizados son filtrados en esta fase a una serie de criterios de inclusión y exclusión para delimitar aquellos que deben ser inventariados en la base de datos interna del OEPE. Algunos de estos criterios de inclusión son acciones educativas que se realizan dentro del ámbito formal o no formal, acción afín al ámbito educativo, organizados por una institución pública, privada o ambas, entre otros. En cuanto a los criterios de exclusión destacamos aquel que 
excluye todas las acciones que son únicamente informativas o material divulgativo.

(F3) Inventario de programas:

Mediante una ficha de registro se realiza el inventario de los programas seleccionados a través de las 2 primeras fases. Esta hoja de registro se divide en 5 apartados y posee 42 campos a cumplimentar referidos a la identificación, localización, descripción, diseño educativo y anexo documental del proyecto.

(F4) Análisis estadístico descriptivo:

Esta fase nos permite analizar los programas inventariados a través de un análisis estadístico-descriptivo de la muestra extraída, cuyos resultados nos permiten conocer el estado de la cuestión en base a la localización de las propuestas, el tipo de públicos, las adaptaciones o sistemas de inclusión implementados, el uso de dispositivos electrónicos, etc. Del mismo modo, esta fase nos permite desarrollar análisis sobre el contenido de los programas para determinar la metodología de trabajo, los objetivos propuestos o los sistemas de evaluación implementados.

(F5) Selección discriminatoria a través de Evaluación basada en estándares básicos:

Mediante una tabla de estándares conformada por 15 ítems -instrumento EBEBOEPE- que posteriormente dará lugar a la escala Q-Edutage, evaluamos los programas de la muestra seleccionada para conocer el grado de calidad en base a los estándares establecidos.

(F6) Evaluación de programas basada en estándares específicos:

Los programas que mejores puntuaciones o mayor nivel de adecuación hayan presentado en la fase 5, serán evaluados mediante una nueva tabla de estándares específicos compuesta por 28 ítems -instrumento EBEE-OEPE-, que serán seleccionados y definidos ad-hoc por parte del investigador en base a los intereses de su investigación; para profundizar en la particularidad de los programas y que pueden referirse a la tipología patrimonial, educativa, al contexto geográfico, a los destinatarios y al ámbito educativo fundamentalmente.

(F7) Estudio de caso:

Consiste en un análisis en profundidad los casos que hayan resultado sobresalientes a lo largo de la implementación de la secuencia metodológica, 
mediante el uso de entrevistas, cuestionarios, análisis pormenorizados de los documentos que conforman los diseños educativos, materiales didácticos. Los instrumentos pueden ser hojas de registro o rúbricas de observación de las implementaciones in situ (Simons, 2011; Stake, 2010).

(F8) Evaluación de aprendizajes:

Esta última fase busca conocer las competencias adquiridas o conocimientos interiorizados tras la implementación de un programa (Stake y Munson, 2008). Así mismo, este proceso nos permite comparar y/o estudiar la correlación existente entre el planteamiento del programa y su implementación, con la intención de definir modelos de aprendizaje en educación patrimonial y ofrecer una retroalimentación formativa para el diseño de futuros programas.

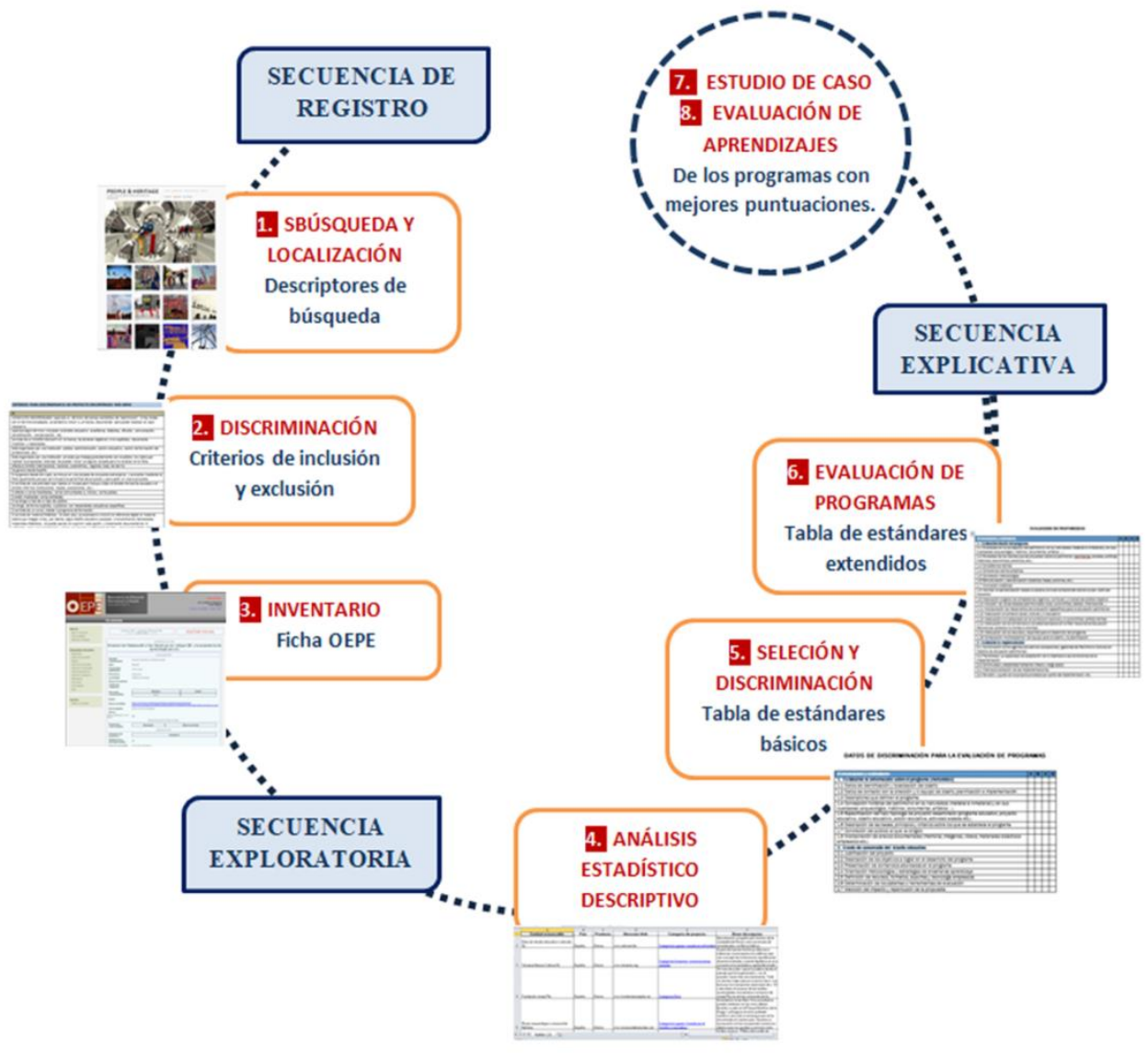

Figura 25. Método SAEPEP-OEPE. Procedimiento secuencial para la evaluación de programas.

Las tres primeras fases responden a una secuencia de registro que delimita los programas susceptibles de inventario y las muestras de análisis. Las fases 4, 5 y 6 componen una 
secuencia exploratoria estadístico-descriptiva con las muestras resultantes, que deriva en las fases 7 y 8 de naturaleza explicativa (Simons, 2011), que estudia en profundidad los programas que hayan resultado destacados en las fases anteriores. Finalmente, los resultados son sometidos a una triangulación concurrente (Creswell, 2008) que permite contrastar los datos obtenidos con el fin de confirmar, correlacionar o corroborar los resultados (Pereira, 2011).

Las fases comprendidas en la secuencia de registro y exploratoria, así como los instrumentos han sido utilizados en dos de las tres publicaciones adjuntas. Su utilización ha significado el replanteamiento de la herramienta, detectando que en la disciplina no existen instrumentos validados para la evaluación de programas, por lo que, se ha llevado a cabo un proceso de validación, que explicamos en el siguiente punto.

\subsubsection{Conceptualización y diseño del instrumento EBEBE-OEPE.}

Ante este incremento en las acciones educativas en torno a la educación patrimonial surge la necesidad de mejorar la evaluación de la calidad de los programas, que se convierte en uno de los principales objetivos de investigación de la disciplina. Esta necesidad de evaluación también se constituye como una de las líneas de actuación establecidas dentro del PNEyP (Domingo et al., 2013). Al mismo tiempo la evaluación implica un criterio esencial para la evolución y adecuada transmisión del patrimonio a las generaciones futuras de acuerdo con el artículo primero de la Ley 16/1985, de 25 de junio, del Patrimonio Histórico Español ${ }^{48}$. Por otro lado, la necesidad de mejorar la calidad de los sistemas de evaluación, también se refleja en la legislación educativa, que no solo habla de la evaluación del rendimiento académico de los estudiantes, sino que se centra en la necesidad de evaluación de los diseños educativos, indicado como aspecto que presenta grandes ausencias (Ley Orgánica 2/2006, pp. 8-9).

Estos programas y acciones educativas se localizan e inventarían en el OEPE diariamente, y por tanto surge la necesidad de crear un instrumento que nos permita conocer la calidad de estas prácticas. Un instrumento es "una herramienta concreta y operativa que facilitará al investigador la recolección de los datos, producto de una relación interdependiente entre paradigma, epistemología, teorías y metodologías" (Soriano, 2014, p. 20). Es en definitiva "una técnica o conjunto de técnicas que

\footnotetext{
${ }^{48}$ Última actualización, publicada el 27/05/2015, en vigor a partir del 28/05/2015.
} 
permitirán una asignación numérica que cuantifique las manifestaciones de un constructo que es medible solo de manera indirecta" (Herrera, 1998 citado por Soriano, 2014, p. 20). Este instrumento nos debe permitir conocer si las prácticas educativas están bien diseñadas y planificadas, con la intención de no perpetuar errores y analizar los ejemplos sobresalientes para definir indicadores y claves de actuación para el diseño de futuros programas.

Por ello, el observatorio con la intención de cumplir uno de sus principales objetivos y también con el propósito de convertirse en un organismo que ayuda a cumplir los objetivos del PNEyP, desarrolla inicialmente el instrumento Evaluación Basada en Estándares Básicos (EBEB-OEPE en adelante) que permite conocer el grado de adecuación de todos los aspectos o estándares que deben estar presentes en el diseño de cualquier acción educativa.

Este instrumento ha sido diseñado a través de un método hipotético-deductivo (Prieto y Delgado, 2010), elaborado por el equipo de trabajo mediante la realización de 3 análisis de contenido y estadístico-descriptivos sobre diferentes muestras de programas $(n=350$, 644 y 1.120), extraídas de la base de datos OEPE (Fontal, 2016a). La revisión de la literatura, junto con las conclusiones obtenidas del análisis y "los criterios derivados del PNEyP, especialmente los definidos como aspectos metodológicos" (Fontal y Juanola, 2015, p. 265), han definido los 15 ítems que lo componen, que recogen aspectos referentes a la calidad de la información del programa y al grado de concreción en el diseño educativo. Los ítems responden a todos los criterios esenciales que debe tener un diseño satisfactorio, dividiendo así los componentes a valorar en identificación institucional, modelo educativo, estructura didáctica y difusión del proyecto.

Tabla 9

Instrumento de evaluación basada en estándares básicos EBEB-OEPE.

Dimensiones y estándares \begin{tabular}{l|l|l|l|} 
A & B & C & D
\end{tabular}

1. Calidad de la información sobre el programa (metadatos)

\begin{tabular}{|l|l|l|l|}
\hline 1.1 Datos de identificación y localización del diseño & & & \\
\hline $\begin{array}{l}\text { 1.2 Datos de contacto con la dirección y/o equipo de diseño, planificación e } \\
\text { implementación. }\end{array}$ & & & \\
\hline 1.3 Descriptores que definen el programa. & & & \\
\hline $\begin{array}{l}\text { 1.4 Concepción holística del patrimonio en su naturaleza (material e inmaterial) y en } \\
\text { sus cualidades (arqueológico, histórico, documental, artístico...). }\end{array}$ & & \\
\hline $\begin{array}{l}\text { 1.5 Especificación del tipo/tipología de proyecto desarrollado (programa educativo, } \\
\text { proyecto educativo, diseño educativo, acción educativa, actividad aislada etc.) }\end{array}$ & & & \\
\hline
\end{tabular}




\begin{tabular}{|l|l|l|l|}
\hline $\begin{array}{l}\text { 1.6 Descripción de las bases, principios y criterios sobre los que se establece el } \\
\text { programa }\end{array}$ & & & \\
\hline 1.7 Concreción del público al que va dirigido & & & \\
\hline $\begin{array}{l}\text { 1.8 Incorporación de anexos documentales (memoria, imágenes, vídeos, materiales } \\
\text { didácticos empleados etc.) }\end{array}$ & & & \\
\hline 2. Grado de concreción del diseño educativo & & & \\
\hline 2.1 Justificación del proyecto & & & \\
\hline 2.2 Descripción de los objetivos a lograr en el desarrollo del programa & & \\
\hline 2.3 Presentación de contenidos abordados en el programa & & & \\
\hline 2.4 Orientación metodológica y estrategias de enseñanza aprendizaje & & \\
\hline 2.5 Definición de recursos, formatos, soportes y tecnología empleados & & \\
\hline 2.6 Determinación de los sistemas o herramientas de evaluación & & \\
\hline 2.7 Medición del impacto y repercusión de la propuesta & & \\
\hline (4. Se alcanza con calidad, 3. Se alcanza, 2. Se alcanza con condiciones, 1. No se alcanza) & \\
\hline
\end{tabular}

Esta escala de puntuación se confecciona inicialmente con etiquetas cualitativas ordinales y, posteriormente, pasan a ser codificados en una escala ordinal cuantitativa. Se trata de una escala clara, simple y de fácil aplicación por cualquier investigador, que permite un registro y análisis sistematizado y objetivo (Alaminos y Castejón, 2006). La clasificación analítica del instrumento nos permite evaluar las partes de forma independiente -es decir, requiere una elaboración más costosa y con mayor nivel de especificidad en los criterios, sin embargo, posee ventajas en la cantidad de información recopilada de manera independiente- $\mathrm{y}$, finalmente, se aplica la suma de las puntuaciones para obtener una calificación total (Nitko, 2001). Con la intención de reducir sesgos humanos y buscar la objetividad con independencia del investigador, se desarrolla un manual del usuario para la base OEPE que facilita en trabajo a nuevos investigadores, así como rúbricas para manejar el instrumento que permite unificar criterios.

Sin embargo, según Fontal et al. (2019) no se dispone de un instrumento que sea breve, objetivo y que permita el uso de un estándar común para la comparación insesgada de la calidad entre distintos programas. Por ello, el observatorio se propone calibrar el instrumento mediante modelos de la Teoría de la Respuesta al Ítem, a partir de la evaluación de 330 programas de educación patrimonial, para que pueda ser aplicable por cualquier investigador garantizando su fiabilidad y validez, bajo la denominación de escala $Q$-Edutage. 


\subsubsection{El proceso de validación: La escala Q-Edutage.}

Bajo el interés de validar los instrumentos existentes en el Observatorio, según Fontal et al. (2019) se genera la necesidad de elaborar un instrumento que fuera breve, objetivo, no dependiente de las características individuales del evaluador, con propiedades métricas robustas, y que permitiera el uso de un estándar común para la comparación insesgada de la calidad entre programas de educación patrimonial. Con este objetivo se genera un instrumento para la evaluación de la calidad de programas de educación patrimonial, que mantenga un equilibrio adecuado entre precisión y brevedad, y que pueda ser utilizado tanto en solitario (p. ej., con propósitos de cribado cuando el número de programas a evaluar es elevado), como en apoyo a sistemas de evaluación más amplios (tales como el método SAEPEP-OEPE).

A continuación explicamos resumidamente el proceso de construcción y calibración de la escala Q-Edutage remitiéndonos al artículo publicado por Fontal el al. (2019) en la Revista Psicodidáctica, donde se puede consultar la investigación al completo. Este proceso es articulado en tres etapas:

(1) identificación mediante la revisión de la literatura relevante de los principales indicadores básicos de calidad de los programas de educación patrimonial.

(2) selección de los indicadores con mayores garantías de validez de contenido mediante un estudio de jueces expertos.

(3) la calibración y construcción de la versión final del instrumento mediante procedimientos enmarcados en la Teoría dela Respuesta al Ítem (TRI) (Fontal et al., 2019, p. 2).

La muestra de calibración del instrumento consiste en 330 programas seleccionados aleatoriamente a partir de los 1719 programas de educación patrimonial que estaban registrados en el momento de realizar la investigación en la base de datos de OEPE. Los autores extraen tres submuestras aleatorias que son asignadas a tres evaluadores expertos del ámbito de la Didáctica de la Expresión Plástica, la Didáctica de las Ciencias Sociales y Psicología, quienes han recibido previamente un breve entrenamiento en el uso de la rúbrica de evaluación de los ítems.

La primera fase de construcción del instrumento consiste en la revisión de la literatura sobre evaluación de la calidad en educación patrimonial (Web of Science y Scopus). Los 
autores revisan un total de 311 artículos que encuentran mediante los descriptores «heritage», «education»y «quality». Esta búsqueda es posteriormente acotada según Fontal et al., (2019) por el descriptor «standard», obteniendo un total de 29 artículos, de los cuales solo seis son relevantes para los objetivos del estudio.

Para la selección del primer conjunto de indicadores siguen el modelo propuesto por Stake (2006), donde se buscan el valor ideal de los objetivos a conseguir, el enfoque racional por encima del intuitivo y la especificidad de los estándares mediante una hoja de control que permite el control del sesgo. Así mismo, realizan tres análisis de contenido sobre diferentes muestras extraídas de la base de datos del OEPE ( $\mathrm{n}=$ 350, 644 y 1120 programas) teniendo en consideración los criterios metodológicos derivados del Plan Nacional de Educación y Patrimonio. De esta fase se construye un primer conjunto de 21 indicadores de calidad.

En la segunda fase, 17 jueces expertos evalúan la relevancia de los 21 indicadores (Cabero y Llorente, 2013). Los expertos son académicos pertenecientes a áreas relacionadas directa o transversalmente con la educación patrimonial (Didáctica de la Expresión Plástica, Didáctica delas Ciencias Sociales, Psicología, Didáctica y Organización Escolar, Didáctica de la Expresión Corporal, Didáctica de la Lengua y la Literatura, Música, Sociología y Expresión gráfica arquitectónica). Los expertos evaluaron los indicadores de acuerdo a su coherencia, relevancia y congruencia respecto del objeto de evaluación en una escala de 4 puntos, así como la claridad en su redacción, formato y extensión (Bolívar, 2013; Corral, 2009 citado en Fontal et al., 2019). A continuación nos explican que dada la naturaleza ordinal de la escala de medida, se calculan las medianas de las puntuaciones otorgadas por los jueces a la coherencia, relevancia y congruencia de los ítems. Así como la concordancia de los jueces mediante el coeficiente ponderado de BangdiwalaBWN (Bangdiwala, 1987) obteniéndose valores muy satisfactorios. A partir de los resultados de esta fase se eliminan seis indicadores. Se considera que cuatro son altamente redundantes en el contenido, y que dos no corresponden a estándares generales de calidad sino a estándares específicos. El contenido de los 14 indicadores seleccionados para la primera versión de la escala se resume en la Tabla 10. 
Tabla 10

Codificación de las variables de la escala Q-Edutage en función de los estándares de calidad (Fontal et al., 2019).

\begin{tabular}{lll}
\hline Ítem & Estándar & Codificación \\
\hline i01 & Datos de contacto con la dirección y/o equipo de diseño, planificación e implementación & Contacto \\
i02 & Descriptores que definen el programa & Descriptores \\
i03 & Concepción holistica del patrimonio en su naturaleza (material e inmaterial) y en sus cualidades & Patrimonio \\
& (arqueológico, histórico, documental, artístico, etc.) & \\
i04 & Especificación del tipo/tipología de proyecto desarrollado (programa educativo, proyecto educativo, diseño & Tipología \\
& educativo, acción educativa, actividad aislada etc.) & Criterios \\
i05 & Descripción de las bases, principios y criterios sobre los que se establece el programa & Público \\
i06 & Concreción del público al que va dirigido & Anexos \\
i07 & Incorporación de anexos documentales (memoria, imágenes, vídeos, materiales didácticos empleados, etc.) & Justificación \\
i08 & Justificación del proyecto & Objetivos \\
i09 & Descripción de los objetivos a lograr en el desarrollo del programa & Contenidos \\
i10 & Presentación de contenidos abordados en el programa & Metodología \\
i11 & Orientación metodológica y estrategias de enseñanza aprendizaje & Recursos \\
i12 & Definición de recursos, formatos, soportes y tecnología empleados & Evaluación \\
i13 & Determinación de los sistemas o herramientas de evaluación & Impacto y repercusión \\
i14 & Medición del impacto y repercusión de la propuesta & \\
\hline
\end{tabular}

Para puntuar cada indicador se construye una escala de clasificación de cuatro categorías ordenadas («no se alcanza», «se alcanza con condiciones», «se alcanza» y «se alcanza con calidad»). Analizan los datos con el programa IRTPRO 4.0 (Cai, Thissen, y du Toit, 2015), y el modelo de respuesta graduada o GradedResponse Model (GRM) (Samejima, 1997). Según Fontal el al. "el objetivo de la calibración es garantizar que el test fuera máximamente preciso en zonas medias y altas de la variable latente (calidad)" (2019, p. 3). En este punto remitimos a la publicación para ver el desarrollo de los supuestos usuales en el TRI, los criterios de retención de ítems y los resultados de comprobación de la unidimensionalidad e independencia local que son dos requisitos básicos en la TRI. 


\section{CAPITULO IV \\ Compendio de publicaciones}

Sinfonía No 9 del nuevo mundo (Op. 95) mi menor (Antonín Dvořák, 1893)

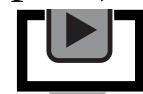

Sinfonia del Nuevo Mundo - A. Dvorak - 4 Allegro.mp3

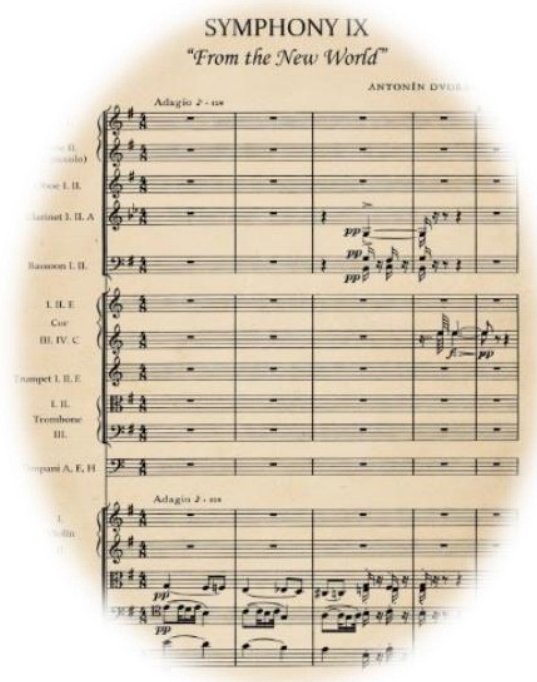





\section{Presentación y contexto del compendio de publicaciones}

Mi interés por la investigación se despertó con la realización del Máster de Investigación en Psicología y Ciencias de la Educación, y sobre todo con el desarrollo del trabajo fin de máster titulado "Competencias docentes del docente de música de educación primaria: Formación y uso", donde ya nace la curiosidad por investigar acerca de la formación inicial del profesorado. Al mismo tiempo mi formación inicial y mi labor profesional como maestra en el Colegio Maristas La Inmaculada de Valladolid, ha vinculado mis objetivos de investigación con la educación formal focalizada en la educación primaria, como no podía ser de otro modo. En este marco surge la curiosidad de conocer de qué modo se trabaja la educación patrimonial en las aulas, qué dice la legislación educativa al respecto, y cuál es la presencia y el enfoque dentro del currículo (Fontal y Martínez, 2016).

Dentro de esta línea de trabajo, también nace la necesidad por conocer las competencias que consideran tener los maestros para trabajar la educación patrimonial. Tras analizar las investigaciones que han abordado esta temática (Avci y Memişoğlu, 2016; Estepa et al., 2008; Jiménez et al., 2010; Lucas y Delgado, 2018; Moron, 2018). En esta misma buscamos ir al origen y ahondar en la formación que están recibiendo los futuros maestros en el grado de educación primaria. Es imprescindible desde nuestro punto de vista analizar los planes de estudios con la finalidad de realizar un análisis descriptivo y comparativo también con el currículo de educación primaria. A todas estas preguntas busca dar respuesta el primera artículo (Fontal el al., 2017), que presentamos en esta tesis por compendio.

De forma paralela, mi formación musical y la sensibilidad adquirida en los años de conservatorio por la música y el arte en general, se refleja en la elección de la especialidad en Educación Musical. También marca el camino hacia el interés por la rama más intangible e inmaterial del patrimonio, que recoge dentro de sus ámbitos de actuación las manifestaciones musicales o de tradición oral, entre otros muchos (Domingo y Timón, 2011). Dentro de este marco de interés se comienza desde el inicio del periodo doctoral a realizar búsquedas e inventario de programas y acciones educativas en torno al patrimonio cultural inmaterial con la intención de conocer el estado de la cuestión en el ámbito nacional. Esta investigación se refleja en la segunda publicación (Fontal y Martínez, 2018), que analiza el ámbito del PCI, le etapa educativa, 
el ámbito escolar, la tipología de estrategia de enseñanza-aprendizaje y la presencia de adaptación a personas con diversidad funcional o $\mathrm{NEE}^{49}$, así como el uso de instrumentos de evaluación. El análisis se realiza sobre un total de 42 programas educativos desarrollados en torno al patrimonio inmaterial en España, que han sido inventariados dentro de la base del OEPE. Todo ello con la finalidad de determinar estándares de calidad en la educación patrimonial, dentro de un patrimonio tan frágil, como es el inmaterial, que se presentan a modo de decálogo.

Finalmente la tercera publicación que forma parte de esta compendio (Fontal y Martínez, 2017), presenta un enfoque más cuantitativo donde el análisis estadístico cobra mayor peso, al mismo tiempo que se amplía de manera considerable la muestra de análisis. El artículo presenta un análisis estadístico-descriptivo y relacional de un total de 202 acciones educativas generadas en torno al PCI en el ámbito nacional, que nos permite conocer sus enfoques y categorías (Tipología de programa, ámbito educativo, tipo de público, adaptación y diseño educativo). Además se analiza la correlación existente entre las variables: Tipo de proyecto * Tipo de público y el ámbito del programa * Diseño educativo. Con la intención de buscar relaciones y los motivos de las mismas.

Estos tres artículos de investigación han sido aceptados en revistas indexadas dentro de los listados de Journal Citation Report (JCR) o Scimago Journal Rank (SJR), y conforman la presente tesis doctoral por compendio de publicaciones.

\subsection{Contexto investigador}

Esta tesis doctoral ha estado asociada al Departamento de Didáctica de la Expresión Musical, Plástica y Corporal (área de Didáctica de la Expresión Plástica) de la Facultad de Educación y Trabajo Social de la Universidad de Valladolid. Esta se ha desarrollado en el marco de un contrato predoctoral para la formación de doctores, financiado por la Universidad de Valladolid y vinculado al proyecto "Educación Patrimonial en España: consolidación, evaluación de programas e internacionalización del observatorio de educación patrimonial en España (OEPE)" $37 \mathrm{~F}^{50}$, con el que presenta objetivos comunes:

\footnotetext{
${ }^{49}$ Necesidades Educativas Especiales.

${ }^{50}$ Referencia del proyecto: EDU2012-37212
} 
1. Continuar el inventario de nuevos programas en la base de datos, atendiendo a criterios de concreción, subclasificación, ampliación documental, diversificación tipológica en lo referente a la atención a la diversidad e internacionalización.

2. Ampliar el espectro territorial de los programas inventariados, atendiendo a referentes internacionales de especial interés.

3. Vincular el OEPE a organismos nacionales e internacionales, generando nexos de intercambio de información, emisión de informes, apoyo científicotecnológico y difusión de resultados.

4. Difundir internacionalmente los resultados obtenidos en el OEPE de manera estable, en aquellos organismos internacionales de máxima referencia, no sólo en el ámbito de la educación patrimonial, sino en el de la gestión del patrimonio en general.

A lo largo de los cuatro años del disfrute de la beca se han realizado diversas estancias de investigación, que sin duda han enriquecido el proceso doctoral. La primera de ella de carácter nacional se desarrolló en la Universidad de Zaragoza, dentro de la Facultad de Educación en el Dpto, de Didáctica de las Lenguas y de las Ciencias Humanas y Sociales, bajo la supervisión de la Dra. Rivero. Donde se realiza una evaluación de programas de las principales acciones educativas desarrolladas en torno al patrimonio arqueológico como tipología patrimonial trabajada dentro del grupo de investigación ARGOS dirigido por la Dra. Rivero. En base al programa más destacado tras los análisis, se realiza un estudio de caso, con la intención de conocer en mayor profundidad su diseño educativo, así como el entorno social y cultural. De esta estancia de investigación han derivado dos publicaciones (Rivero et al., 2018a) relativa al estudio de caso, y (Rivero et al., 2018b) que presenta el análisis de programas.

La segunda estancia de investigación de carácter internacional se realiza en el Gabinete de Patrimonio Musical Esteban Salas, que se encuentra en la Colegio Universitario San Gerónimo. Universidad de La Habana. La estancia se desarrolló bajo la dirección de la Dra. Miriam Escudero y en ella se llevó a cabo una revisión de los programas culturales que desarrollan desde la Oficina del Historiador de la Ciudad de la Habana. Los programas educativos analizados fueron el programa socio-cultural y patrimonial Rutas y andares, el Programa social infantil (Aula-Museo), el a+ Programa adolescente, y los 
programas educativos desarrollados en el Museo Nacional de la Música, la Casa de los Árabes, la Casa de África y el Museo Vitrina de Balonia. Sobre este último se realizó un estudio de caso, y sobre él que se está trabajando en el desarrollo de una futura publicación.

Por otro lado, se ha disfrutado de 3 ayudas de movilidad en el marco del programa Erasmus +. La primera de ellas para formación del PDI desarrollada en la facultad de Letras de la Universidad de Oporto bajo la dirección de la Dra. Alice Semedo. Las otras dos movilidades destinadas al perfeccionamiento de idiomas, que tuvieron lugar en Londres y Liverpool respectivamente. Las competencias adquiridas en el dominio del inglés nos han permitido participar en Congresos Internacionales destacados como el 6th International Congress of Educational Sciences and Development y el Canada Internacional Conference on Education. University of Toronto Missisauga, difundiendo a nivel internacional los datos de nuestra investigación.

Otro punto a destacar ha sido las colaboraciones llevadas a cabo con diversas instituciones relacionadas con la gestión del patrimonio. Destacamos en este sentido el informe titulado Análisis del tratamiento del Patrimonio Cultural en la legislación educativa vigente, tanto nacional como autonómica, dentro de la educación obligatoria, realizado en el marco del Observatorio para el Instituto del Patrimonio Cultural de España (Fontal y Martínez, 2016) para el Instituto del Patrimonio Cultural de España (IPCE). También queremos remarcar el informe realizado para la Dirección General de Patrimonio Cultural de la Comunidad de Madrid, que tiene por título Análisis sobre la percepción del patrimonio de la comunidad de Madrid y del Plan de Educación y Patrimonio de la Comunidad de Madrid, que se enmarca en la XI bienal ibérica de patrimonio cultural: AR\&PA 2018.

En cuanto a la planificación de la investigación se ha desarrollado una fase documental permanente de recogida de información y análisis del estado de la cuestión sobre la disciplina de la educación patrimonial. A lo largo de este proceso, se han localizado programas referentes en base al patrimonio cultural, dentro del territorio nacional y algunos casos excepcionales de otros puntos de la geografía internacional. Desde un inicio se ha acotado y planificado la investigación definiendo las preguntas, hipótesis, objetivos y metodología a desarrollar en cada uno de los estudios. A continuación, 
visibilizamos el proceso de trabajo a través de una tabla que permite ordenar visualmente las acciones desarrolladas, a través de fases:

Tabla 11

Proceso de trabajo durante el desarrollo de la tesis doctoral

\begin{tabular}{|c|c|}
\hline \multirow{4}{*}{$\begin{array}{l}1^{\mathbf{a}} \text { FASE } \\
\text { Análisis y periodo de } \\
\text { Documentación }\end{array}$} & A.1 Búsqueda y análisis de investigaciones y publicaciones sobre PCI \\
\hline & A.2 Elaboración de un estudio sobre el estado de la cuestión. \\
\hline & A.3 Diseño de sistemas de clasificación y estandarización de programas. \\
\hline & A.4 Desarrollo del marco teórico. \\
\hline \multirow{2}{*}{$\begin{array}{l}\mathbf{2}^{\mathbf{a}} \text { FASE } \\
\text { Diseño de la } \\
\text { Investigación }\end{array}$} & A.5 Acotación de las preguntas de investigación, hipótesis y objetivos. \\
\hline & A.6 Elección de la metodológica y modos de registro, análisis y evaluación. \\
\hline \multirow{3}{*}{$\begin{array}{l}\mathbf{3}^{\mathbf{a}} \text { FASE } \\
\text { Análisis Documental }\end{array}$} & A.7 Conocimiento y análisis de los órganos reguladores y gestores. \\
\hline & $\begin{array}{l}\text { A.8 Búsqueda de documentación legislativa y oficial expedida por los } \\
\text { órganos. }\end{array}$ \\
\hline & A.9 Revisión y análisis de los documentos obtenidos. \\
\hline \multirow{6}{*}{$\begin{array}{l}\mathbf{4}^{\mathbf{a}} \text { FASE } \\
\text { Evaluación de Programas }\end{array}$} & A.10 Búsqueda y localización de programas. \\
\hline & A.11 Discriminación a través de los criterios de inclusión/exclusión. \\
\hline & A.12 Inventario de programas a través de la ficha de datos OEPE \\
\hline & A.13 Análisis estadístico descriptivo \\
\hline & A.14 Selección de discriminación a través de la tabla de estándares básicos \\
\hline & A.15 Evaluación de programas a través de la tabla extendida de estándares \\
\hline \multirow{2}{*}{$\begin{array}{l}\mathbf{5}^{\mathbf{a}} \text { FASE } \\
\text { Estudio de Casos }\end{array}$} & A.16 Estudio de casos de los programas destacados en la evaluación. \\
\hline & A.17 Diseño de los instrumentos a utilizar en el estudio de caso. \\
\hline \multirow{4}{*}{$\begin{array}{l}\mathbf{6}^{\mathbf{a}} \text { FASE } \\
\text { Difusión, Conclusión, } \\
\text { Consolidación }\end{array}$} & A.18 Difusión e internacionalización de la investigación. \\
\hline & A.19 Revisión del estado de la cuestión \\
\hline & A.20 Reflexiones finales y conclusivas \\
\hline & tinuidad \\
\hline
\end{tabular}

La tesis doctoral, se enmarca dentro del trabajo desarrollado por el Observatorio y supone un aporte a la labor de evaluación basada en el método OEPE (Maldonado, 2016; Sánchez-Ferri, 2016; García-Ceballos, 2019). Toma como referentes teóricos las tesis desarrolladas por Fontal (2003), Gómez-Redondo (2013) y Marín-Cepeda (2014). Todas ellas dan respaldo al presente trabajo, abordan y argumentan de forma metateórica la necesidad de conocer, documentar, analizar y evaluar las acciones educativas en el marco de la educación patrimonial.

\subsection{Contexto temático}

Hace más de 4 décadas se comienza a reflejar en la normativa internacional la obligación de concienciar y estimular el respeto y aprecio al patrimonio a través de la educación (UNESCO, 1972; 2003; Council of Europe, 1993, 2005; Committe of Ministers, 2017). A lo largo de este periodo el patrimonio cultural ha experimentado una evolución en su concepción y desarrollo. En los diversos ámbitos encargados de su tutela se va 
introduciendo el germen del patrimonio ligado al concepto antropológico de cultura, que crea una nueva mentalidad, que entienden la cultura como "la expresión de la identidad de un pueblo, que se origina como resultado de la adaptación al entorno" (Carrera, 2009, p. 195). Por lo tanto esa idea de Patrimonio Cultural, dominante durante los pasados siglos, que se centraba en los grandes monumentos occidentales, va evolucionando. Se produce un replanteamiento social, que va gestando un nuevo pensamiento que propicia interés por los bienes culturales inmateriales (Bortolotto, 2010; 2015).

El contexto temático del estudio surge de los análisis iniciales desarrollados por el Observatorio de Educación Patrimonial en España (Fontal et al., 2013), que lleva más de diez años localizando, inventariando y analizando programas de educación patrimonial. Estos análisis de programas de educación patrimonial, nos indican que el patrimonio inmaterial no es un contenido prioritario en los programas educativos (solo un 14\% de entre 18 tipologías de Patrimonio se refieren al inmaterial), pese a que existen propuestas muy interesantes y de alto valor pedagógico. Además se observa una gran variedad -y también dispersión- entre las propuestas desarrolladas en el ámbito no formal, que conviene ordenar y categorizar adecuadamente.

Esta situación ocurre en un país, que cuenta con un total de 47 bienes inscritos en la Lista de Patrimonio Mundial, de los cuales 41 son relativos a cultural places, 4 a natural places y 2 a mix places. Por otro lado, cuenta con 15 bienes declarados como patrimonio inmaterial por la UNESCO, y 3 acciones en el registro de buenas prácticas de salvaguarda. Esto hace que España sea el $3^{\circ}$ país con mayor número de bienes incluidos en la lista del patrimonio mundial de la UNESCO por detrás de Italia y China, y el $2^{\circ}$ país de Europa con un mayor número de bienes declarados patrimonio cultural inmaterial, seguido de Croacia. Además, según el Instituto del Patrimonio Cultural de España (IPCE), las Comunidades Autónomas han protegido hasta el momento más de 60 manifestaciones culturales inmateriales a través de su declaración como Bien de Interés Cultural.

Todo ello, nos sitúa por ende, ante la necesidad de observar detenidamente las acciones educativas que en las últimas décadas se han realizado en España en torno al patrimonio cultural inmaterial, donde encontramos un campo emergente, que es conocer y aportar luz sobre la oferta educativa del patrimonio cultural inmaterial en España. La evaluación 
de estas acciones educativas nos permitirá determinar estándares de calidad en la educación patrimonial, dentro de un patrimonio tan sensible como es el inmaterial.

En el inicio del periodo doctoral la temática de la educación patrimonial enfocada en el PCI era incipiente, y existían en el año 2015 un total de 7 publicaciones en comparación con las 22 publicaciones, que se encuentran en la actualidad bajo los descriptores de búsqueda "heritage education" and "intangible" dentro de la colección general de la Web of Science. Por tanto, este aspecto también nos indicaba una era clara necesidad de investigar la vertiente más intangible del patrimonio cultural desde un enfoque educativo. Desde entonces se producido un gran aumento en la producción científica en torno al PCI y la educación, generando una línea de investigación en constante construcción y crecimiento. Además de los estudios que han teorizado y desarrollado un marco referencial (Ahmet, 2018; Bortolotto, 2010, 2014; Buckley y Graves, 2016; Kurin, 2007; Lähdesmäki, 2016; Munjeri, 2004; Vecco, 2010), han surgido un aumento en el desarrollo de investigaciones que tratan sobre la enseñanza del patrimonio inmaterial en el aula. Investigaciones que desarrollan programas educativos (Kasapoglu, 2016), que realizan análisis curriculares en torno al PCI (Barghi et al., 2017; Xie y He, 2017) o aquellas que abordan la evaluación de acciones educativas sobre PCI (Fontal y Martínez 2017, 2018). También existen investigaciones desarrolladas dentro del ámbito universitario (Apaydin, 2016; Chen, 2017; Jin-long, 2009; Kasapoglu, 2016; Zhang y Zhao, 2014), o como recursos emergente en la museología educativa dentro del ámbito de la educación no formal (Cavalcanti, 2016).

Una de las líneas más potentes está formada por el binomio PCI y TIC, que tratan de acercar el PCI a la sociedad del siglo XXI ayudándose de los avances tecnológicos. La utilización de recursos tecnológicos en la implementación de investigaciones, ha sido llevada a la práctica por numerosos autores (Cozzani et al., 2017; Dagnino et al., 2015; Haddad, 2016; Ott y Pozzi, 2011; Ott et al., 2015)

Todos los ejemplos de estudios referenciados están acrisolados por la necesidad de situar la educación patrimonial como una disciplina esencial en la salvaguarda y gestión del patrimonio cultural inmaterial. Entendiendo la educación patrimonial como un aval que despierta sensibilidades y activa la creación de nexos entre la cultura y la sociedad, garantizando la metamorfosis del bien cultural hacia el bien patrimonial. 


\subsection{Artículos seleccionados para la tesis}

Los artículos seleccionados están ordenados en función de las fases de investigación planteadas inicialmente y no de la publicación cronológica:

\subsubsection{El patrimonio como contenido en la etapa de Primaria: del currículum a la formación de maestros}

Fontal, O., Ibañez-Etxeberria, A., Martínez, M. y Rivero, P. (2017). El patrimonio como contenido en la etapa de Primaria: del currículum a la formación de maestros. Revista Electrónica Interuniversitaria de Formación del Profesorado, 20(2), 79-95. doi: http://dx.doi.org/10.6018/reifop.20.1.286321.

Fecha de aceptación: 25 de marzo de 2017

La Revista: Enfoque y alcance

La Revista Electrónica Interuniversitaria de Formación del Profesorado (REIFOP) es una revista de carácter internacional que publica artículos relacionados con la formación del profesorado desde una perspectiva amplia y multidisciplinar. Desde 1987 hasta la fecha viene publicando, de forma ininterrumpida, tres números anuales sobre un amplio espectro de temas asociados a la universidad, la educación, el currículo, los métodos de enseñanza/aprendizaje y las didácticas especiales.

\begin{tabular}{ll}
\hline Título: & REVISTA ELECTRÓNICA INTERUNIVERSITARIA DE \\
& FORMACIÓN DEL PROFESORADO \\
\hline ISSN: & $1975-0965$ \\
\hline País: & España \\
\hline URL: & http://revistas.um.es/reifop/index \\
\hline C. académico: & EDUCACIÓN EN GENERAL \\
\hline Indizada en: & Scopus; Google Scholar (puesto 195 sobre 450 revistas \\
& internacionales), Cuartil: Q2; Índice de impacto: 0.307; Percentil: 53. \\
& Emerging Sources Citation Index; DOAJj; Ebsco; IRESIE; DICE; \\
& RESH. ISOC; Dialnet, Índice de impacto 0,842, Cuartil: Q1. \\
& Redalyc; Qualis/Capes; PSICODOC; REBIUN; In-Recs; Universia. \\
& MIAR; Dulcinea; COPAC; Redinet; e-revist@ @; ANEP- A.Scopus; \\
& Google Scholar (puesto 195 sobre 450 revistas internacionales), \\
& Cuartil: Q2; Índice de impacto: 0.307; Percentil: 53. \\
\hline CARHUS Plus+ 2018; Directory of Open Access Journals; ERIHPlus \\
& LATINDEX. Catálogo v1.0 (2002 - 2017), Catálogo v2.0 (2018 - ). \\
\hline
\end{tabular}


Sello de calidad FECYT

ICDS:

ISSN: 1575-0965,0213-8646

Está en índices de citas (Emerging Sources Citation Index) $=+3.5$

Está en dos o más bases datos de indización y resumen o en DOAJ

(Fuente Academica Plus, Psicodoc, DOAJ) $=3+2=5$

Antiguiedad = 97 años (f. inicio: 1922 ); Pervivencia: $\log 10(30)=+1.5$

$\operatorname{ICDS}=10.0$ 


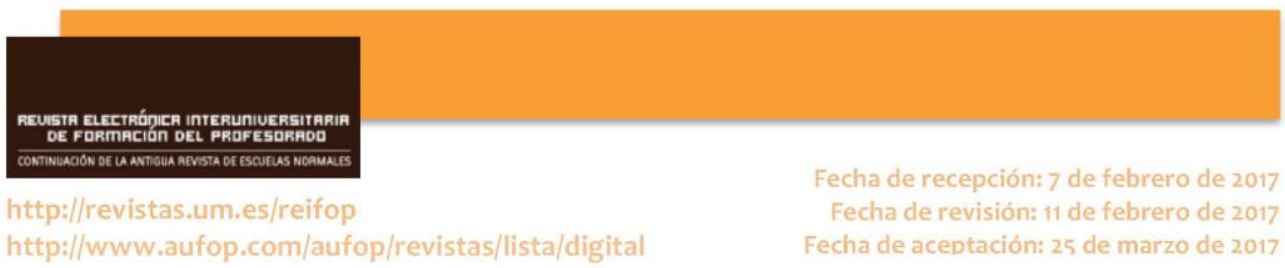

Fontal Merillas, O., Ibáńez-Etxeberria, A., Martínez Rodríguez, M. \& Rivero Gracia, P. (2017). El patrimonio como contenido en la etapa de Primaria: del currículum a la formación de maestros. Revista Electrónica Interuniversitaria de Formación del Profesorado, 20(2), 79-95.

\title{
El patrimonio como contenido en la etapa de Primaria: del currículum a la formación de maestros ${ }^{1}$
}

\author{
Olaia Fontal Merillas', Alex Ibáñez-Etxeberria², Marta Martínez Rodríguez', Pilar Rivero \\ Gracia $^{3}$ \\ ${ }^{(1)}$ Universidad de Valladolid, ${ }^{(2)}$ Universidad del País Vasco UPV-EHU, ${ }^{(3)}$ Universidad de \\ Zaragoza
}

\section{Resumen}

Si analizamos la presencia del patrimonio en la normativa educativa vigente encontramos que son numerosas las referencias al patrimonio en la etapa de Primaria, por lo que cabe preguntarse si la formación de maestros en España ofrece algún tipo de materia o contenido que garantice la impartición de esos contenidos curriculares en el aula de primaria. Para averiguarlo, proponemos un artículo en el que se analiza la correspondencia entre los contenidos curriculares relacionados con el patrimonio y su presencia en la formación de maestros en España. Los análisis nos permiten concluir que, salvo en los casos excepcionales analizados en los estudios de caso, se mantiene una gran distancia entre la presencia del patrimonio en el currículo escolar de la Educación Primaria y la presencia de contenidos relacionados con éste en los grados de maestro, lo cual es sin duda un punto de reflexión altamente significativo para la revisión de la formación del profesorado en España.

\section{Palabras clave}

Educación patrimonial; formación docente; currículum; educación primaria.

\section{Contacto:}

Olaia Fontal Merillas, olaia.fontal@uva.es, Facultad de Educación y Trabajo Social, D-126. Campus Miguel Delibes. UVa. 47011 Valladolid.

Vinculación del artículo a los proyectos EDU2015-65716-C2-1-R, EDU2015-65716-C2-2-R

${ }^{1}$ Esta investigación ha sido posible gracias a la financiación recibida desde MINECO/FEDER a través de los proyectos EDU2015-65716-C2-1-R, EDU2015-65716-C2-2-R y EDU2016-78163-R y desde el proyecto EHU $15 / 06$ 


\title{
Heritage as Content in Primary Education: From the Curriculum to Teacher Education
}

\begin{abstract}
An analysis of the presence of heritage in our current educational regulations reveals that there are numerous references to this topic in Primary Education. This raises the question whether teacher education in Spain includes courses or items that ensure the proper teaching of such curricular contents in the Primary Education classroom. In order to ascertain this, our paper sets out to analyze the correspondence between heritage-related curricular contents and their inclusion in teacher education official programs in Spain. Our study enables us to conclude that, with very few exceptions encountered in our case studies, there is a big gap between the presence of heritage in the Primary Education school curriculum and the inclusion of these contents in the official teaching degrees. Meaningful reflection on this issue may provide a turning point in the revision of teacher education in Spain.
\end{abstract}

\section{Key words}

Heritage Education; Teacher Education; Curriculum; Primary education

\section{Introducción}

La formación inicial de los maestros debe capacitarlos para lograr que los alumnos de su etapa alcancen los objetivos curriculares. Esto implica que adquieran conocimientos psicopedagógicos, curriculares y didáctico-disciplinares, fundamentalmente (De Juanas et al., 2009; Perrenoud, 2010). En este sentido, no podemos obviar la sistemática falta de acompasamiento que existe entre el currículum vigente en el momento de diseñar los planes de estudios de los futuros maestros, y el currículum vigente cuando éstos los cursan, incluso cuando ejercen su profesión, en una clara falta de sincronización (Barredo, colen y Arino, 2013). Por este motivo, si queremos averiguar qué formación tienen actualmente los estudiantes y egresados en el Grado de Maestro de Primaria en España para impartir en la escuela los contenidos relacionados con el patrimonio y alcanzar los objetivos relacionados con éste, no podemos obviar el hecho de que su plan de estudios fue diseñado bajo el foco de la LOE (entre 2008-2010), pero está siendo acreditado en el periodo de implantación de la LOMCE, periodo en el que han comenzado a ejercer su profesión las primeras promociones. Por este motivo, realizaremos un análisis previo abordando el contenido en el currículum de Primaria hasta la LOE para situar los antecedentes del estado actual y, posteriormente, dentro del diseño metodológico, efectuaremos un análisis estadístico descriptivo basándonos en descriptores del concepto patrimonio en la legislación educativa vigente.

\section{El patrimonio en el currículo de Primaria: análisis retrospectivo}

Una primera referencia implícita al patrimonio la encontramos en la Ley General de Educación de 1970, que consideraba “3. La incorporación de las peculiaridades regionales, que enriquecen la unidad y el patrimonio cultural de España, así como el fomento del espíritu de comprensión y de cooperación internacional", como una finalidad de la 
educación en todas sus etapas y niveles. En los 90, la L.O.G.S.E incorpora, de forma explícita, el patrimonio en los objetivos de Primaria y ESO, con una orientación marcadamente actitudinal. El décimo objetivo general de toda la Etapa de Primaria se redactaba en los siguientes términos: “j) Conocer el patrimonio cultural, participar en su conservación y mejora y respetar la actitud de interés y respeto hacia el ejercicio de este derecho". Las áreas curriculares de Conocimiento del Medio natural, social y cultural y de Educación Artística fueron las destinadas a su desarrollo y, particularmente, en la primera de estas áreas, en el bloque 10 de contenidos, el patrimonio ya se incluye en los contenidos actitudinales: "1. Respeto por el patrimonio cultural y natural (fiestas, artesanía, juegos, gastronomía, vestidos, vivienda, etc.) de la comunidad e interés por su mantenimiento y recuperación". Del mismo modo, el área de Educación Artística, se plantea el respeto hacia la diversidad: "La producción artística forma parte del patrimonio cultural de un pueblo. En consecuencia, la educación artística ha de permitir el acceso a ese patrimonio cultural, a su aprecio, al reconocimiento de las variaciones en los criterios y en los estilos a lo largo del tiempo y de unas sociedades a otras". Los objetivos generales de la Educación Artística, nuevamente insistían en el conocimiento y respeto hacia el patrimonio artístico: "Objetivo 11. Conocer y respetar las principales manifestaciones artísticas presentes en el entorno, así como los elementos más destacados del patrimonio cultural, desarrollando criterios propios de valoración" (Fontal, 2011, p. 21 y 55.).

En la L.O.E el patrimonio transita hacia un enfoque más completo, y complejo, del patrimonio entendido como un referente identitario, que debemos conocer, comprender, poner en valor y cuidar. Concretamente, el capítulo II de la L.O.E, dedicado a la Educación Primaria, incorpora un objetivo que alude, implícitamente, al concepto integral de patrimonio (Fontal, 2016): “d) Conocer, comprender y respetar las diferentes culturas y las diferencias entre las personas, la igualdad de derechos y oportunidades de hombres y mujeres y la no discriminación de personas con discapacidad". Justamente por ello, en la Educación Primaria el patrimonio se aloja, fundamentalmente, en la Competencia cultural y artística:

Esta competencia supone conocer, comprender, apreciar y valorar críticamente diferentes manifestaciones culturales y artísticas, utilizarlas como fuente de enriquecimiento y disfrute y considerarlas como parte del patrimonio de los pueblos. (...) La competencia artística incorpora asimismo el conocimiento básico (...) del patrimonio cultural. (...) Implica (...) un interés por participar en la vida cultural y por contribuir a la conservación del patrimonio cultural y artístico, tanto de la propia comunidad, como de otras comunidades (L.O.E, Anexo 1, p, 8).

Conocimiento del medio natural, social y cultural y Educación Artística serán, junto con otras como la Educación Física en menor medida, las áreas que más aportan al desarrollo de esta competencia. En el caso de la primera de ellas, su aportación "se centra en el conocimiento de las manifestaciones culturales, la valoración de su diversidad y el reconocimiento de aquellas que forman parte del patrimonio cultural". $\mathrm{Y}$, entre los objetivos del área, destacamos el quinto: “5. Analizar algunas manifestaciones de la intervención humana en el medio, valorándola críticamente y adoptando un comportamiento en la vida cotidiana de defensa y recuperación del equilibrio ecológico y de conservación del patrimonio cultural". En el área de Educación Artística también hallamos un objetivo dedicado al patrimonio: "6. Conocer y valorar diferentes manifestaciones artísticas del patrimonio cultural propio y de otros pueblos, colaborando en la conservación y renovación de las formas de expresión locales y estimando el enriquecimiento que supone el intercambio con personas de diferentes culturas que comparten un mismo entorno". En cuanto a la contribución del área 
de Educación física al desarrollo de la competencia cultural y artística, se refiere a: "La apreciación y comprensión del hecho cultural, y a la valoración de su diversidad, lo hace mediante el reconocimiento y la apreciación de las manifestaciones culturales específicas de la motricidad humana, tales como los deportes, los juegos tradicionales, las actividades expresivas o la danza y su consideración como patrimonio de los pueblos." (Fontal, 2011, p. 27 y 55.$)$.

Con todo, el desarrollo de la educación patrimonial en la LOE se extiende a través de las dimensiones conceptual, procedimental y actitudinal, de manera que ofrece un enfoque complejo y transversal, de lo patrimonial (Fontal, 2016).

\section{Metodología}

El objetivo del artículo es analizar la relación que existe entre los contenidos curriculares relacionados con el patrimonio y su presencia en la formación de maestros en España. Para abordarlo, hemos establecido un diseño metodológico ordenado en 4 fases:

$1^{a}$ Fase: Análisis de contenido de la normativa educativa vigente, centrado en la presencia del patrimonio como contenido curricular.

$2^{\mathrm{a}}$ Fase: Análisis de contenido y estadístico-descriptivo de todos los Planes de Estudio que imparten el grado de Maestro en Educación Primaria en España.

$3^{\mathrm{a}}$ Fase. Análisis comparativo entre los análisis del contenido extraído en las fases $1^{\mathrm{a}}$ y $2^{\mathrm{a}}$.

$4^{\text {a }}$ Fase: Estudio de casos en aquellos planes de estudio que tengan materias que destaquen por su amplia correspondencia con los contenidos curriculares o por su excepcionalidad en el enfoque o tratamiento de esos contenidos.

\section{Procedimiento y muestra}

En cuanto al análisis del contenido y análisis estadístico descriptivo ( $1^{\mathrm{a}}$ y $2^{\mathrm{a}}$ fase), continuando con el diseño metodológico de estudios previos (Fontal e lbáñez-Etxeberria, 2017), hemos seguido a López-Noguero (2002), empleando la técnica de la identificación y clasificación temática categorial derivada del análisis de la normativa referente en otros estudios previos (Fontal, 2011; Fontal 2016; Fontal y Martínez, 2016). Esas categorías se han transformado en los descriptores temáticos, sometiéndose a crítica y discusión con los «jueces codificadores» conformados por los investigadores de los proyectos EDU2012-37212 y HAR2013-48456-C3-3-P que nos sirvieron de "árbitros de control de la fiabilidad del análisis, que ayudaron a perfilar y enriquecer las distintas categorías" (López-Noguero, 2002, p. 176).

El proceso de análisis de la $1^{\text {a }}$ fase se centra en los Reales Decretos, Decretos y Órdenes vigentes que regulan el currículum en la etapa de Educación Primaria, en los ámbitos estatal y autonómico. La muestra resultante es de 3 leyes nacionales y 17 autonómicas, en ellas se busca la incidencia de los descriptores temáticos: patrimonio, identidad, manifestaciones, tradición e inmaterial. Todos ellos son relativos al campo semántico del concepto patrimonio cultural, y nos permiten aprovechar la información de un corpus y extraer listados de frecuencias (Pérez, 2006).

Para la $2^{a}$ fase, se han localizado los planes de estudio de todas las Universidades tanto públicas como privadas, efectuando un análisis del contenido de los programas de aquellas materias específicas en torno al patrimonio. Aunque en este análisis solo se recogen los programas específicos que abordan el patrimonio de una forma completa, no debemos olvidarnos de aquellas materias impartidas desde las didácticas específicas, que de un modo 
más parcial y transversal deben encargarse de los contenidos patrimoniales (Didáctica de las Ciencias Sociales y Educación Artística fundamentalmente). Para la recogida de datos se han utilizado los centros miembros y adscritos a la conferencia de decanos de educación ( $C D E, 2017$ ), resultando una muestra de $\mathrm{N}=100$, cuya distribución por titularidad se detalla en la figura 1.

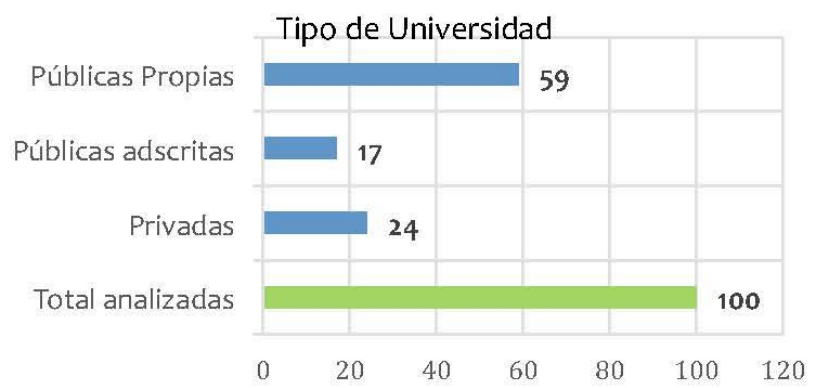

Figura 1. Frecuencias del tipo de universidad por titularidad de la muestra analizada

En la $3^{\circ}$ fase hemos efectuado un estudio correlacional en un único momento temporal buscando conocer la relación entre la normativa educativa vigente y los Planes de Estudio que imparten el grado de Maestro en Educación Primaria en España. Finalizamos la investigación (Fase $4^{\circ}$ ) analizando con detalle aquellos planes de estudios que destaquen por su correspondencia con los contenidos curriculares o por su excepcional enfoque o tratamiento de esos contenidos.

\section{Resultados}

La exposición de los resultados se va a estructurar en base a los estudios específicos realizados para cada una de las fases metodológicas que articulan la investigación.

\section{Análisis de contenido y estadístico-descriptivo de la normativa educativa}

Tras efectuar las búsquedas con los descriptores objeto de estudio en la legislación educativa vigente tanto estatal como autonómica que regula el currículo de la Educación Primaria (EP), se muestran en la tabla 1 los resultados de las frecuencias absolutas $\left(f_{i}\right)$ totales de las normas nacionales y de las distintas comunidades. En el ámbito autonómico, junto a las frecuencias absolutas, figuran los porcentajes referidos a las frecuencias relativas $\left(n_{i}\right)$.

Tabla 1.

$\boldsymbol{F}_{i}$ totales nacionales y autonómicas, porcentajes $\boldsymbol{n}_{i}$ en las autonomías.

\begin{tabular}{|l|c|c|c|c|c|c|}
\hline \multicolumn{1}{|c|}{ Ámbito } & Leyes E.P & Patrimonio & Identidad & Inmaterial & Manifesta. & Tradición \\
\hline Nacional & 3 & 16 & 6 & 0 & 7 & 9 \\
\hline Andalucía & 1 & $203=20 \%$ & $163=27 \%$ & $6=67 \%$ & $172=19 \%$ & $92=5 \%$ \\
\hline Aragón & 1 & $56=6 \%$ & $52=8 \%$ & $1=11 \%$ & $70=8 \%$ & $140=8 \%$ \\
\hline Asturias & 1 & $139=14 \%$ & $28=5 \%$ & $1=11 \%$ & $50=6 \%$ & $330=19 \%$ \\
\hline Baleares & 1 & $36=4 \%$ & $19=3 \%$ & $0=0 \%$ & $15=2 \%$ & $45=3 \%$ \\
\hline Canarias & 1 & $78=8 \%$ & $79=13 \%$ & $0=0 \%$ & $116=13 \%$ & $209=12 \%$ \\
\hline Cantabria & 1 & $54=5 \%$ & $20=3 \%$ & $0=0 \%$ & $25=3 \%$ & $69=4 \%$ \\
\hline
\end{tabular}




\begin{tabular}{|l|c|c|c|c|c|c|}
\hline \multicolumn{1}{|c|}{ Ámbito } & Leyes E.P & Patrimonio & Identidad & Inmaterial & Manifesta. & Tradición \\
\hline Castilla la M. & 1 & $68=7 \%$ & $24=4 \%$ & $0=0 \%$ & $56=6 \%$ & $87=5 \%$ \\
\hline Castilla y L. & 1 & $72=7 \%$ & $24=4 \%$ & $0=0 \%$ & $30=3 \%$ & $61=3 \%$ \\
\hline Cataluña & 1 & $13=1 \%$ & $9=1 \%$ & $0=0 \%$ & $24=3 \%$ & $20=1 \%$ \\
\hline Extremadura & 1 & $78=8 \%$ & $26=4 \%$ & $0=0 \%$ & $37=4 \%$ & $46=3 \%$ \\
\hline Galicia & 1 & $35=4 \%$ & $15=2 \%$ & $0=0 \%$ & $3=0 \%$ & $63=4 \%$ \\
\hline Madrid & 1 & $11=1 \%$ & $5=1 \%$ & $0=0 \%$ & $3=0 \%$ & $3=0 \%$ \\
\hline Murcia & 1 & $35=4 \%$ & $15=2 \%$ & $0=0 \%$ & $41=5 \%$ & $51=3 \%$ \\
\hline Navarra & 1 & $18=2 \%$ & $14=2 \%$ & $0=0 \%$ & $27=3 \%$ & $213=18 \%$ \\
\hline País Vasco & 1 & $34=3 \%$ & $81=13 \%$ & $0=0 \%$ & $52=6 \%$ & $21=1 \%$ \\
\hline Rioja & 1 & $6=1 \%$ & $12=2 \%$ & $0=0 \%$ & $11=1 \%$ & $67=4 \%$ \\
\hline Valencia & 1 & $55=6 \%$ & $28=5 \%$ & $1=11 \%$ & $137=15 \%$ & $162=9 \%$ \\
\hline Suma N+Aut. & 20 & 991 & 614 & 9 & 893 & 1779 \\
\hline
\end{tabular}

Los descriptores más utilizados por este orden son: tradición (1779), patrimonio (991), manifestaciones (893), identidad (614), e inmaterial (9) que es con una amplia diferencia el término menos utilizado. Con el descriptor patrimonio destaca ampliamente Andalucía $\left(\mathbf{n}_{\mathbf{i}}\right.$ $20 \%$ ), seguida de Asturias ( $n_{i} 14 \%$ ), Canarias y Extremadura $\left(n_{i} 8 \%\right.$ ). Con el descriptor identidad sigue destacando ampliamente Andalucía $\left(n_{i} 27 \%\right.$ ) y también País Vasco $\left(n_{i} 13 \%\right)$; en el otro extremo encontramos las comunidades de Madrid y Cataluña ( $\left.n_{i} 1 \%\right)$. En lo relativo al descriptor inmaterial, solo encontramos su presencia en Andalucía $\left(n_{i} 6 \%\right)$ y en las comunidades de Aragón, Asturias y Valencia ( $\left.n_{i} 1 \%\right)$. Por el contrario, el término manifestaciones tiene una amplia presencia en la legislación educativa, sobre todo en Andalucía y Valencia ( $n_{i} 19 \%$ y $15 \%$ respectivamente). El análisis de contenido nos muestra cómo el descriptor manifestaciones es equiparable al concepto de patrimonio inmaterial. Finalmente, con el descriptor tradición, son Asturias ( $\left.n_{i} 19 \%\right)$ y Navarra $\left(n_{i} 18 \%\right)$ las comunidades más lo emplean.

A continuación se muestran las barras que comparan las frecuencias con las que cada término contribuye al total en el ámbito nacional y por autonomías (Figura 2).

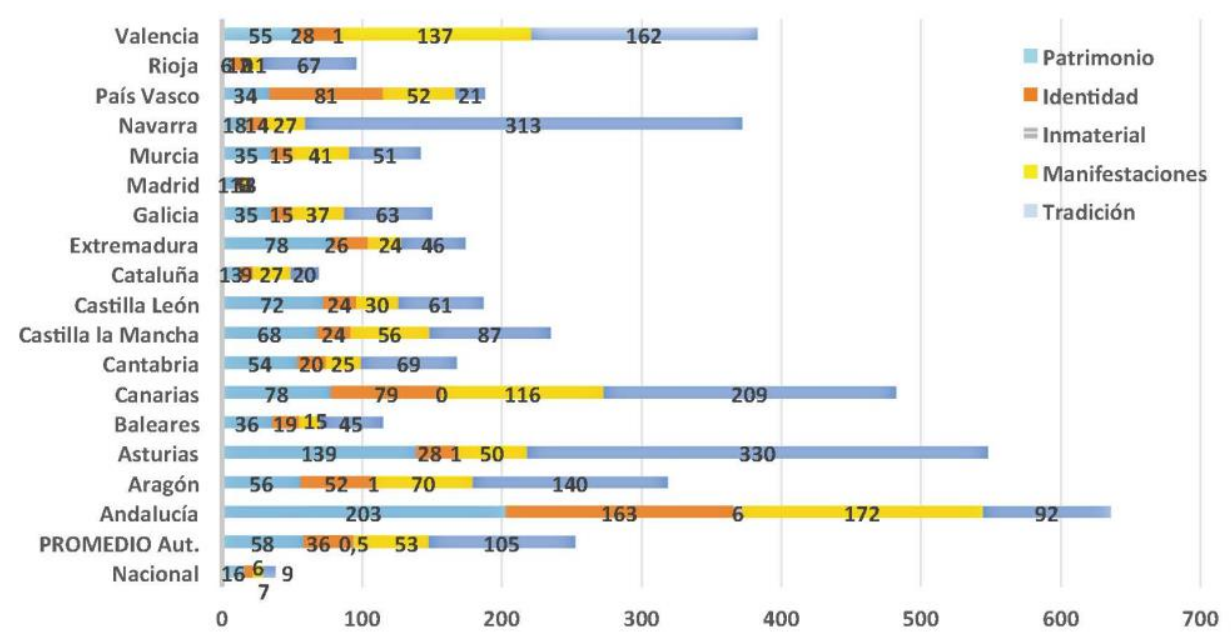

Figura 2. Frecuencias de los términos nacionales, autonómicos y promedios de las autonomías en Educación Primaria. 
Las Comunidades Autónomas de Andalucía, Asturias y Canarias muestran un mayor tratamiento e interés hacia el patrimonio, rebasan ampliamente el promedio autonómico. En al caso contrario se encuentran Madrid, Cataluña y La Rioja, en las cuales las entradas de los descriptores buscados son muy reducidas, siendo casi nulas en el caso de Madrid.

Análisis de contenido y estadístico descriptivo de los planes de estudio del Grado de Maestro en Educación Primaria.

Los planes de estudio analizados pertenecen a la muestra de $(\mathrm{N}=100)$ centros adscritos a la conferencia de decanos de educación. La muestra se distribuye en un total de $59 \%$ de universidades y centros públicos, $24 \%$ privados y $17 \%$ adscritos. Para comenzar con el análisis de los programas de aquellas asignaturas tanto genéricas, como específicas que se encargan de los contenidos patrimoniales, realizamos un primer análisis que nos permite conocer la frecuencia de las asignaturas (Obligatoria/Básica u Optativa) que abordan el patrimonio en el total de la muestra.

\section{aSIGNATURA Obligatoria/Básica m ASIGNATURA Optativa}

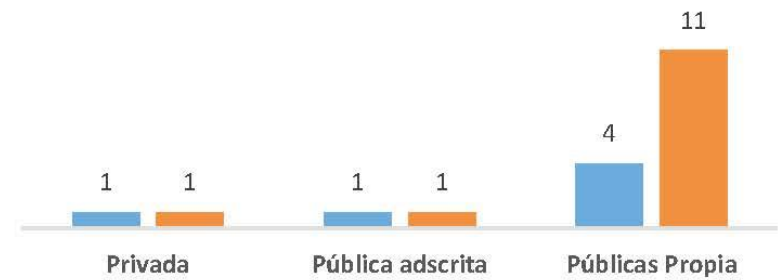

Figura 3. Frecuencia de las asignaturas sobre patrimonio de la muestra $(N=100)$.

La figura 3 detalla las frecuencias absolutas $\left(\mathbf{f}_{\mathbf{i}}\right)$ de los tipos de asignaturas que abordan los contenidos patrimoniales. Si atendemos a las frecuencias relativas $\left(\mathbf{n}_{\mathbf{i}}\right)$, podemos observar que el $6.78 \%$ de las Universidades públicas propias imparten asignaturas obligatorias/básicas sobre patrimonio, y el $18.64 \%$ imparten asignaturas optativas. Con un porcentaje mucho menor $(5,88 \%)$ se encuentran las Universidades públicas adscritas que imparten asignaturas obligatorias/básicas y optativas sobre patrimonio, y solo el $4.17 \%$ de las Universidades privadas imparten asignaturas obligatorias/básicas y optativas sobre patrimonio.

Si nos adentramos en el análisis de contenido, el sustantivo Patrimonio está presente en los 19 casos e Identidad en 15 , con unos porcentajes del $100 \%$ y el $78.5 \%$ respectivamente. La naturaleza tangible o intangible del concepto de patrimonio, aparece en un total de 18 casos, arrojando un porcentaje del $94.7 \%$ (Tabla II). La lectura y análisis del contenido de las guías docentes nos muestra una consideración del concepto holístico de patrimonio (Cuenca, 2002). En muchas asignaturas no se realiza una división en cuanto a su naturaleza material e inmaterial, sino que ambas dimensiones se engloban dentro del término patrimonio cultural (Lähdesmäki, 2016). 
Tabla 2.

Frecuencias y porcentajes de los términos en los casos.

\begin{tabular}{|c|c|c|c|c|}
\hline \multicolumn{5}{|c|}{ Términos } \\
\hline & & Frecuencia & Porcentaje & Porcentaje válido \\
\hline \multirow[t]{4}{*}{ Válidos } & Patrimonio & 19 & 100.0 & 100.0 \\
\hline & Identidad & 15 & 78.9 & 78.9 \\
\hline & Material/Tangible & 18 & 94.7 & 94.7 \\
\hline & Inmaterial & 18 & 94.7 & 94.7 \\
\hline
\end{tabular}

Los contenidos de las asignaturas obligatorias/básicas, abordan todas las tipologías patrimoniales en un $58.33 \%$, no alcanzándose en su totalidad en el restante $41.67 \%$. Dentro de las asignaturas optativas, se aborda toda la tipología patrimonial en un $56.59 \%$ y no se hace en el 43.41\%; podemos observar la distribución del número de casos según el gráfico 4.

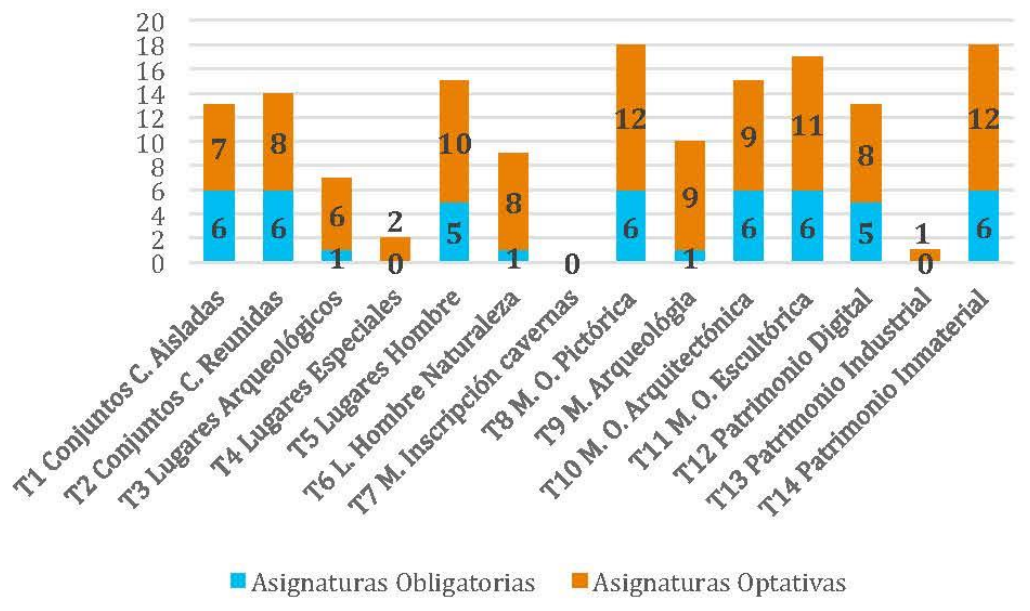

Gráfico 4. Contingencias Tipos de Patrimonio*Asignaturas Obligatorias/Básicas y Optativas

Las tipologías que menos se abordan en ambos casos son -T4 Lugares Espaciales-, -T7 Monumentos Inscripción Cavernas-y T13 Patrimonio Industrial.

Con la intención de profundizar más en el tratamiento didáctica y en el modo en el que los planes de estudios abordan el patrimonio, realizamos un análisis de contingencias entre las asignaturas obligatorias/básicas y optativas y la secuencia de los procesos de patrimonialización (Fontal, 2003), presentes posteriormente en el Plan Nacional de Educación y Patrimonio (Domingo, Fontal y Ballesteros, 2013). El gráfico que recoge la información derivada del análisis, muestra cómo de los 19 planes de estudios que abordan el patrimonio en sus contenidos, 6 son relativos a asignaturas obligatorias/básicas y 13 son asignaturas optativas. 


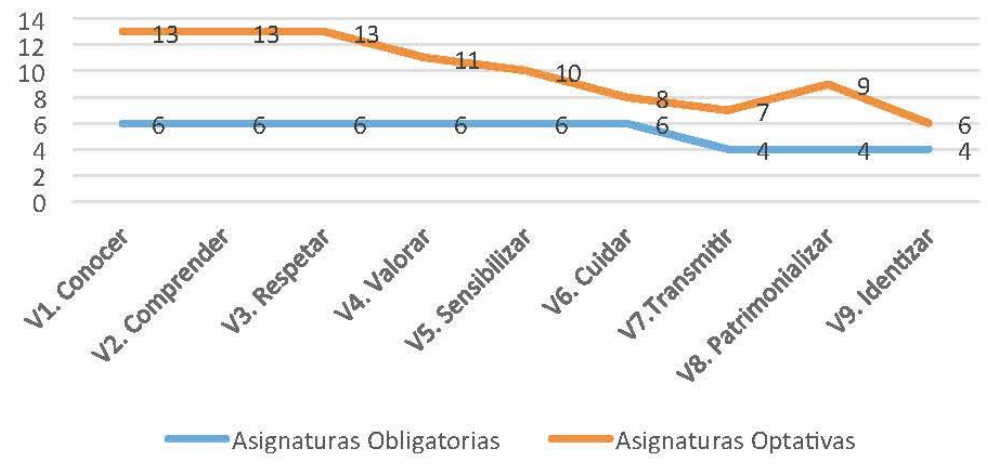

Figura 5. Contingencias entre tipo de asignatura* Cadena de patrimonialización

De las 6 Universidades con asignaturas obligatorias/básicas, un total de 4 se ocupan de la secuencia de patrimonialización completa (66.67\%). De las 13 Universidades con asignaturas optativas, un total de 6 cumplen la cadena completa (46.15\%). Si observamos el gráfico 5 , todas ellas plantean el bien cultural, conocer sus características y contexto socio-histórico, trabajan en los alumnos la comprensión y el respeto. La primera ruptura significativa en la secuencia se produce en torno la valorización, sensibilización y cuidado, donde encontramos una falta de interés en despertar al alumnado una sensibilidad especial en el cuidado y la puesta en valor de ese patrimonio. Si este hecho no se produce, difícilmente los programas se ocuparán de la trasmisión, que alcanza valores muy escasos (4\% y 6,8\%). La falta de eslabones clave en torno a la sensibilización y puesta en valor hace que no sea posible completar la cadena de patrimonialización. Por lo tanto, muchos estudiantes conocerán los bienes culturales y sus características pero no lograrán que ese bien cultural se convierta en su propio patrimonio, ni mucho menos lograrán identizarse con él (GómezRedondo, 2012).

Inicialmente, planteábamos la falta de sincronización existente entre la normativa educativa vigente en Educación Primaria y los planes de estudios de los futuros maestros (Barredo et al., 2013). En este sentido, realizamos un análisis de los Planes de estudio de las asignaturas tanto obligatorias/básicas como optativas que abordan el patrimonio, buscando en ellas relaciones con las competencias básicas que establece el Real Decreto 126/2014, de 28 de febrero, por el que se establece el currículo básico de la Educación Primaria. Con la intención de descubrir si existe o no relación entre los contenidos que abordan las asignaturas y las competencias básicas, consideramos que, sí entendemos que se produce dicha relación, el docente que cursa las asignaturas obligatorias/básicas u optativas sobre patrimonio recibe la formación necesaria que le capacita para impartir los contenidos relativos al patrimonio (Martín-Domínguez y Lavega, 2013) y, más importante aún, trabajar en sus alumnos la adquisición de las competencias básicas que debe poseer todo alumnos de educación primaria (At. 2.2, RD 126/2014). 


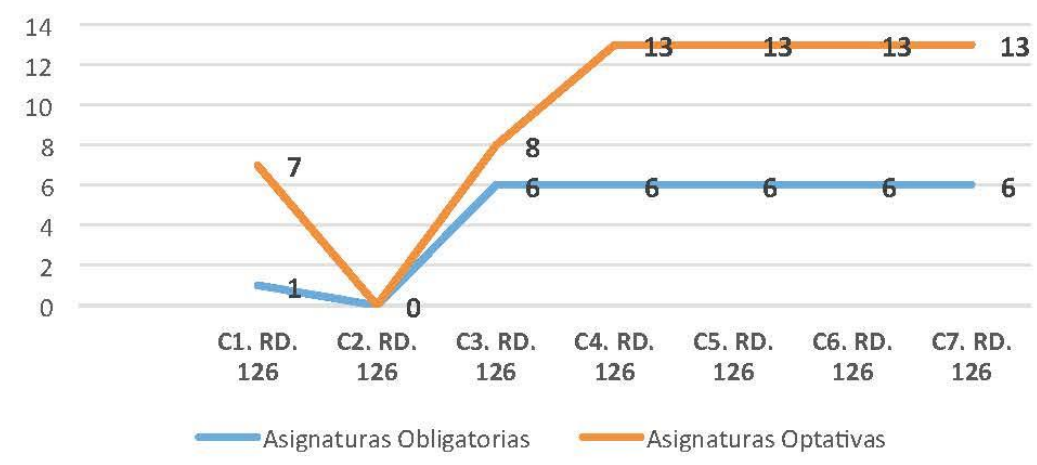

Gráfico 6. Contingencias entre tipo de asignatura* Competencias básicas EP

El análisis de la correlación, permite ver una amplia relación entre los contenidos de las asignaturas sobre patrimonio y todas las competencias básicas, salvo en la competencia C2 (Competencia matemática y competencias básicas en ciencia y tecnología). Así, el docente se capacita para trabajar el $73.8 \%$ de las competencias del currículo básico que establece el Real Decreto. De igual modo, y por medio de las optativas -si llegan a ser cursadas-, el docente se capacitaría un $73.6 \%$.

Análisis comparativo entre los análisis de la normativa y los planes de estudio.

Con la intención de hacer una comparativa entre la $1^{\circ}$ y la $2^{\circ}$ fase, realizamos un estudio correlacional en un único momento temporal por comunidades, relacionando el porcentaje total de descriptores localizados en la normativa y el número de asignaturas obligatorias/básicas y optativas correspondientes a los planes de estudio (Gráfico 7).

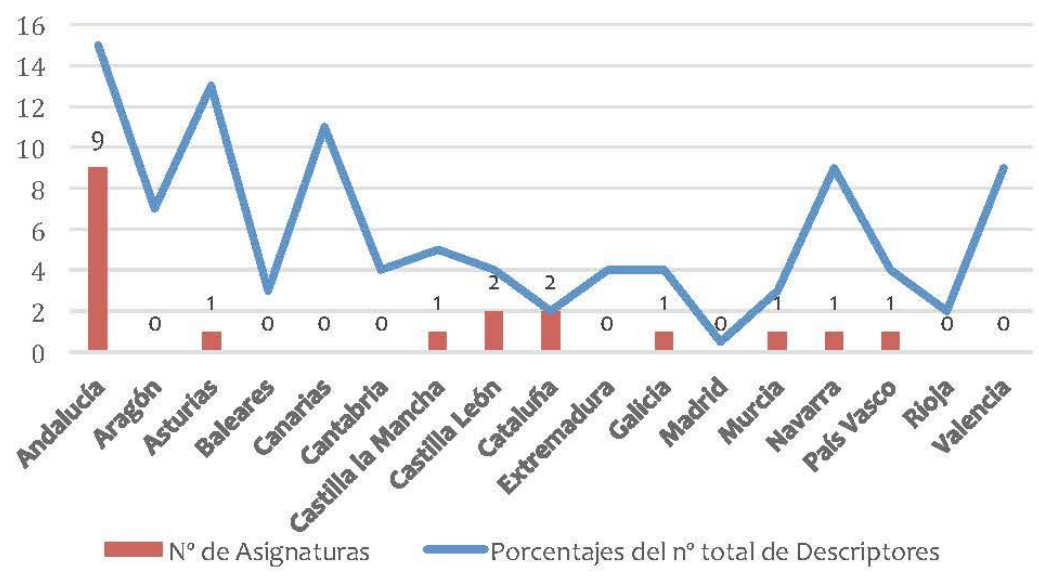

Gráfico 7. Correlación por comunidades entre el $N^{\circ}$ de descriptores* $N^{\circ}$ de asignaturas 
El análisis permite destacar la comunidad de Andalucía por su mayor contenido y la existencia de una mayor correlación. Por el contrario, Madrid es la comunidad que presenta menores índices de presencia del patrimonio, tanto en la legislación educativa vigente de Educación Primaria, como en las asignaturas de los planes de estudios en los grados de formación de maestros. Castilla y León o Cataluña se sitúan como valores medios y bastante parejos tanto en la legislación como en las asignaturas. El resto de las comunidades no muestran ninguna relación patente, pues los resultados son dispersos.

\section{Estudio de casos}

De entre todos los casos analizados, destacamos una selección de tres, de acuerdo con los siguientes criterios: Caso 1: muestra excepcionalidad en el enfoque, metodología y desarrollo de propuestas didácticas relacionadas con la difusión y protección del patrimonio histórico y cultural; Caso 2: presenta una amplia correspondencia con los contenidos curriculares; Caso 3: se relaciona con objetivos del Plan Nacional de Educación y Patrimonio que y con otros agentes educativos o culturales.

\section{Universidad de Granada}

La Universidad de Granada en todos sus centros (4 analizados), y dentro del plan de estudios de Grado Maestro Educación Primaria, imparte en su primer curso la asignatura El Patrimonio Histórico y Cultural y su Didáctica, con carácter obligatorio. Esta asignatura busca que los futuros docentes alcancen los siguientes objetivos: identificar los valores y bienes culturales como signo de identidad de un pueblo; entender las tradiciones, bienes materiales e inmateriales como representación de una cultura; despertar el interés, animar a contemplar y disfrutar del patrimonio histórico y cultural; incrementar a los titulados para poder guiar la observación de las distintas manifestaciones culturales y la comprensión espacial; capacitarles para elaborar propuestas didácticas relacionadas con la difusión y protección del patrimonio histórico y cultural, así como la planificación de actividades culturales y educativas.

Todos estos contenidos se pueden trabajar desde diferentes enfoques. Cabe destacar, dentro de las enseñanzas vinculadas a lo patrimonial, la metodología didáctica para el análisis de la arquitectura (Pérez, 2013), las creaciones escultóricas y las manifestaciones pictóricas. La utilización de los museos como recurso didáctico para la enseñanza aprendizaje del patrimonio en Educación Primaria y el empleo de las TIC en el proceso (Gómez-Redondo, Fontal e lbáñez-Etxeberria, 2016; Larouche, 2016; Rivero y Flores-Hole, 2014), todo ello asociado a una actividad práctica.

\section{Facultad de Educación de Albacete}

En la Facultad de Educación de Albacete (Universidad de Castilla La Mancha), los estudiantes de Grado de Maestro en Educación Primaria cuentan en su plan de estudios con la Mención en Historia, Cultura y Patrimonio. La mención se justifica como una preparación para los futuros profesionales que desarrollen de manera completa la visión cultural y humanística, a través, de "promover el conocimiento histórico y el respeto a las diferencias culturales al tiempo que contribuye a ampliar su visión crítica, el gusto artístico así como el conocimiento de la identidad cultural de la comunidad". De este modo, van a conocer las posibilidades que el Patrimonio Cultural les ofrece, también con referencia a su comunidad, 
"y así ofertarles una serie de recursos y aplicaciones didácticas que les sean de utilidad en su futura práctica docente".

De entre los resultados de aprendizaje esperados destacamos el objetivo de "conocer, comprender, apreciar y valorar diferentes manifestaciones culturales y artísticas, utilizarlas como fuente de enriquecimiento y disfrute y considerarlas como parte del patrimonio de los pueblos"; apreciar el hecho histórico-artístico y el hecho cultural en general, dotará a los futuros docentes de aquellas actitudes y habilidades necesarias que les permitan acceder y comprender las distintas manifestaciones, valorarlas y disfrutarlas, para poder trabajarlas en el aula (Fontal, 2013).

Por otra parte, y de igual modo, la Mención de Historia y patrimonio con la vista puesta en la aplicación docente, intenta valorar la extensión formativa de la Geografía como una visión integral del Paisaje, considerando de acuerdo con la definición del Convenio Europeo del Paisaje como "cualquier parte del territorio tal y como la percibe la población, cuyo carácter sea el resultado de la acción y la interacción de factores naturales y/o humanos" (Cap. I, Art 1a). En la elaboración de los contenidos de esta Mención, y de acuerdo a la guía docente del Centro, se ha tenido en cuenta el Decreto 54/2014, por el que se establece el currículo de Educación Primaria en la Comunidad de Castilla La Mancha, al menos, sorprende que el resto de centros de esta Comunidad no haga la misma interpretación, si bien entendemos que ni la mención ni las asignaturas impartidas tienen carácter obligatorio, al menos los alumnos cuentan con esta opción.

\section{Universidad de Almería}

La Facultad de Ciencias de la Educación, Enfermería y Fisioterapia de Almería, oferta a sus estudiantes de Grado de Maestro en Educación Primaria la asignatura optativa Gestión del Patrimonio Cultural basada en cuatro bloques temáticos: 1) Patrimonio cultural. La antropología social. Métodos y técnicas del trabajo de campo, 2) El patrimonio como riqueza. Bienes patrimoniales: los rituales, las fiestas, las romerías etc. El ecomuseo. Valor del patrimonio inmaterial, 3) La arquitectura vernácula como arte popular. Variedades y aplicaciones. Almería ej. La cultura material y simbólica del agua y 4) El PC articulador del desarrollo rural. Itinerarios históricos-artísticos-culturales. Proyecto para visitas turísticas.

Los objetivos específicos de este aprendizaje son: 1. Transmitir una actitud investigadora, comprensión y análisis reflexivo y creativo en situaciones prácticas. La gestión patrimonial como marco de oportunidades y nuevos retos. 2. Afrontar la carrera como gestor del PC. 3 . Modelos de planificación, esquemas de gestión, técnicas de interpretación y viabilidad en los proyectos culturales. 4. Criterios para la elaboración de proyectos de gestión patrimonial de una ciudad o comarca. Sin duda, en estos objetivos vemos una clara correspondencia con la intención recogida en el Plan Nacional de Educación y Patrimonio de favorecer la investigación en materia de educación patrimonial y potenciar la comunicación entre gestores culturales y educadores, así como impulsar la capacitación de ambos colectivos en la transmisión de los valores patrimoniales (Domingo et al., 2013).

\section{Conclusiones}

En las normas analizadas, los descriptores buscados aparecen vinculados entre sí en muchas ocasiones, siendo los más frecuentes el binomio patrimonio e identidad, que trabajada el desarrollo de una conciencia cultural y social que comience en el ámbito local hasta el 
nacional e internacional (Fontal y Martínez, 2016). En cuanto al análisis del contenido de la normativa, debemos destacar la Orden de 17 de marzo de 2015, por la que se desarrolla el currículo de la Educación Primaria en Andalucía, que presentan una legislación concienciada con el patrimonio cultural y, dentro de éste, una sensibilidad especial hacia las tradiciones y manifestaciones.

En lo relativo a la naturaleza del patrimonio se observa una tendencia a la inclusión de ambas dimensiones en el mismo concepto, tanto en la legislación educativa vigente como en los planes de estudio. En este sentido, varios estudios y autores rechazan la dicotomía categórica entre ambas dimensiones, y argumentan que están estrechamente vinculadas y entrelazadas en un sentido epistemológico debido a su naturaleza, aunque presenten una divergencia semántica según la normativa internacional (Munjeri, 2004; Smith y Akagawa, 2009; Lähdesmäki, 2016). Por otra parte, del análisis de contenido de la normativa, impelimos que ésta no utiliza la dicotomía conceptual patrimonio tangible-intangible que responde a distinciones institucionales y organizativas (Kuutma, 2012), sino que entiende y posiciona el patrimonio inmaterial dentro del concepto de patrimonio cultural (Smith y Akagawa, 2009).

Por otra parte, salvando grandes ausencias en ciertas comunidades, en la normativa educativa se detecta un interés general hacia el patrimonio como elemento capaz de vehicular la comprensión de las identidades, el conocimiento de técnicas y recursos, y como fomentador de actitudes. También, se identifica una redacción que parte desde lo más cercano para poder comprender otras realidades más lejanas, desde el patrimonio local, hasta alcanzar el universal o colectivo, siempre con una visión enfocada a la cadena ya comentada que pretende conocer para valorar, valorar para respetar y respetar para conservar (Fontal, 2003), partiendo de lo más cercano para comprender lo ajeno (Rivero, 2008).

Con respecto al análisis de las asignaturas de los planes de estudios que abordan el patrimonio en la formación de los maestros de primaria, observamos una escasa presencia respecto al total de universidades analizadas, siendo mayor la presencia, aunque todavía deficiente, en las universidades públicas. Estas asignaturas, se enmarcan generalmente dentro de las opciones disponibles en la elección de asignaturas optativas, lo que supone que aquellos alumnos que no las eligen, no tienen contacto con los contenidos patrimoniales y su didáctica. El análisis de contenido de las asignaturas analizadas, tanto obligatorias como optativas, muestra como sus contenidos siguen la secuencia de patrimonialización (Fontal, 2003), aunque se producen rupturas en torno a la valorización y sensibilización. Aspecto que debe ser reforzado para lograr una puesta en valor que permita la identización (Gómez-Redondo, 2012). También debemos destacar positivamente el alto grado de correlación existente entre los contenidos de las asignaturas y las competencias básicas del currículo, que capacitarán profesionalmente a los docentes que las cursen para poder trasladar los contenidos al aula. Por lo tanto, entendemos que el principal problema radica en la escasez de la oferta de asignaturas en torno al patrimonio, aunque no debemos olvidar que los futuros maestros, se forman en las universidades, con diferentes necesidades sociales y profesionales de las que han de vivir en el futuro, y por lo tanto, con legislaciones que están por venir (Barredo et al., 2013).

En general, las investigaciones previas sobre los programas de formación del profesorado, inciden en la necesidad de vincular estos programas a la finalidad de la enseñanza en sociedades democráticas en el contexto de la globalización (Avery, 2010), lo que en el campo de la Educación Patrimonial se vincula al concepto holístico de patrimonio (Cuenca, 2002) y a su relación con la creación de identidades, que el presente estudio confirma como una cuestión pendiente (Gómez-Redondo, 2012), aunque con diferencias por comunidades 
autónomas. Debemos destacar, al igual que se demostraba en estudios anteriores (Fontal y Martínez, 2016; Martínez 2016; Rivero, 2008), que Andalucía es la comunidad que ofrece un tratamiento más completo respecto al patrimonio cultural dentro de todos los ámbitos educativos analizados, tanto en la educación obligatoria como en la superior.

Por lo general, salvo en los casos excepcionales analizados, del estudio realizado, se puede inferir el mantenimiento de una gran distancia entre la amplia presencia del patrimonio en el currículo escolar de la Educación Primaria y la escasa presencia de contenidos relacionados en los grados de maestro. Esta disfunción, puede deberse al "desfase" existente entre el currículum vigente en el momento de diseñar los planes de estudios de los futuros maestros, lo cual puede resultar un punto de reflexión significativo para la revisión de la formación del profesorado en España en este ámbito. En este sentido, debemos recordar que el patrimonio es una herramienta básica para la adquisición de las competencias por parte del alumnado. Sin embargo, en los casos en los que sí figuran los contenidos patrimoniales en la formación de maestros, tanto en asignaturas obligatorias como optativas, el docente se capacita para trabajar la mayor parte de las competencias del currículo básico que establece el Real Decreto 126/2004. Todo ello, redunda en la necesidad de incorporar los contenidos patrimoniales a la formación inicial de maestros (Koster, Brekelman, Korthagen y Wubeels, 2005; Pesquero et al., 2008), tomando los casos analizados como referentes para orientar esa formación hacia el máximo cumplimiento de los contenidos curriculares y, por tanto, para garantizar que el futuro maestro será capaz de impartirlos a sus alumnos de primaria, garantizando de este modo la rentabilidad social, cultural e identitaria del patrimonio (Domingo et al., 2013).

\section{Bibliografía}

Avery, P.G. (2010). Investigación sobre la enseñanza de las Ciencias Sociales y la educación del profesorado. En R. A. Ávila, P. Rivero y P. L. Domínguez, Metodología de investigación en Didáctica de las Ciencias Sociales (pp. 337-355). Zaragoza: Institución Fernando el Católico - Asociación Universitaria de profesorado de Didáctica de las Ciencias Sociales.

Barredo, B., Colen, M.T., y Arino, A. (2013). What teachers does our society need? Functions that current legislation attributes to the primary teacher and competencies that take place in their initial training. En Chova, L., Martínez, A., y Torres (Eds.), $6^{\circ}$ Conferencia Internacional sobre Educación, Investigación e Innovación (ICERI) (pp.174182). España, Sevilla: IATEC.

Cuenca, J. M. (2002). El patrimonio en la didáctica de las ciencias sociales: análisis de concepciones, dificultades y obstáculos para su integración en la enseñanza obligatoria. (Tesis Doctoral). UHu, Huelva.

Convenio Europeo del Paisaje. (2000). Consejo de Europa. (Florencia 20.X.2000)

CDE (2017). Estatutos de la conferencia de decanos de centros universitarios con títulos de magisterio y educación. http://www.conferenciadecanoseducacion.es/

De Juanas, A., Fernández, P., Martín, R., González, M., Pesquero, E., y Sánchez, E. (2009). Comparative study of the evaluation of professional competencies by experienced and trainee Spanish primary teachers. European Journal of Teacher Education, 32(4), 437-454. DOI. 10.1080/02619760903005823 
Domingo, M., Fontal, O., y Ballesteros, P. (Coords.). (2013). Plan Nacional de Educación y Patrimonio. Madrid: Ministerio de Educación, Cultura y Deporte, Secretaría de Estado de Cultura.

Fontal, O. (2003). La Educación Patrimonial. Teoría y práctica en el aula, el museo e internet. Gijón: Trea.

Fontal, O. (2011). El patrimonio en el marco curricular español. Revista de Patrimonio Cultural de España, 5, 21-44.

Fontal, O. (2013). El patrimonio en la escuela. Más allá del patrimonio como contenido curricular. En O. Fontal (coord.), La educación patrimonial. Del patrimonio a las personas (pp. 23-44). Gijón: Trea.

Fontal, O. (2016). El patrimonio a través de la educación artística en la etapa de primaria. Arte, Individuo y Sociedad, 28(1), 105-120.

Fontal, O., e Ibáñez-Etxeberria, A. (2017). La investigación en Educación Patrimonial. Evolución y estador actual a través del análisis de indicadores de alto impacto. Revista de Educación, 375(1), 84-214.

Fontal, O., y Martínez, M. (2016). Análisis del tratamiento del Patrimonio Cultural en la legislación educativa vigente, tanto nacional como autonómica, dentro de la educación obligatoria. Madrid: Instituto del Patrimonio Cultural de España /MECD.

Gómez-Redondo, C. (2012). Identización: la construcción discursiva del individuo. Arte, Individuo y Sociedad, 24(1), 21-37.

Gómez-Redondo, C., Fontal, O., e Ibáñez-Etxeberria, Á. (2016). Procesos de patrimonialización e identización patrimonial con uso de TIC en torno al arte contemporáneo. Artnodes, 17.

Koster, B., Brekelmans, M., Korthagen, F., y Wubbels, T. (2005). Quality requirements for teacher educators. Teaching and Teacher Education, 21(2), 157-76.

Kuutma, K. (2012). Between Arbitration and Engineering: Concepts and Contingencies in the Shaping of Heritage Regimes. En R. F. Bendix, A. Eggert, y A. Peselmann (Eds.), Heritage Regimes and the State (pp. 21-36). Göttingen: Universitätsverlag Göttingen.

Lähdesmäki, T. (2016). Politics of tangibility, intangibility, and place in the making of a European cultural heritage in EU heritage policy. International Journal of Heritage Studies, 22(10), 766-780, DOI: 10.1080/13527258.2016.1212386

Larouche, M. C. (2016). Using museum resources and mobile technologies to develop teens'historical thinking formative evaluation of an innovative educational set-up. In V. Gosselin and P. Livinsgtone (Eds.), Museum and the past. Contructing historical conciousness, (pp. 122-141). Vancouver-Toronto: UBC Press.

Ley $14 / 1970$, de 4 de agosto, General de Educación y Financiamiento de la Reforma Educativa, con la modificación establecida por Ley 30/1976, de 2 de agosto. (B.O.E. de 6 de agosto de 1970, correcciones de errores en B.O.E. de 7 de agosto de 1970 y de 10 de mayo de 1974, y modificación en B.O.E. de 3 de agosto de 1976).

LOE (2006): Ley Orgánica 2/2006, de 3 de mayo, de Educación (BOE número 106 de 4/5/2006, páginas 17158 a 17207)

LOGSE (1990): Ley Orgánica 1/1990, de 3 de octubre de 1990, de Ordenación General del Sistema Educativo (BOE número 238 de 4/10/1990, páginas 28927 a 28942). 
López-Noguero, F. (2002). El análisis de contenido como método de investigación. XXI Revista de Educación, 4(1), 167-179.

Martín-Domínguez, J., y Lavega, P. (2013). Enseñar competencias en el Espacio Europeo de Educación Superior. Revista Electrónica Interuniversitaria de Formación del Profesorado, 16(1), 1-4. DOI: http://dx.doi.org/10.6018/reifop.16.1.179391

Martínez, M. (2016). Análisis comparativo de la imagen del patrimonio en la legislación nacional y autonómica, dentro de la educación obligatoria. En S. Molina, A. Escribano y J. Díaz (Eds.), Patrimonio, identidad y ciudadanía en la enseñanza de las ciencias sociales (pp. 186-199). Murcia: Universidad de Murcia.

Munjeri, D. (2004). Tangible and Intangible Heritage: From Difference to Convergence. Museum International, 56(1-2), 12-20.

Pérez, J. (2013). Arquitectura y Patrimonio: nuevos paradigmas conceptuales y docentes. Revista Electrónica Interuniversitaria de Formación del Profesorado, 16(2), 163-174. DOI: http://dx.doi.org/10.6018/reifop.16.2.180781

Pérez, R. (2006). Evaluación de programas educativos. Madrid: La Muralla.

Perrenoud, P. (2010). La formación del profesorado: Un compromiso entre visiones inconciliables de la coherencia. Revista interuniversitaria de Formación del Profesorado, 68(24), 103-122.

Real Decreto 1006/1991, de 14 de junio, por el que se establecen las enseñanzas mínimas correspondientes a la Educación Primaria (BOE número 152 de 26/6/1991, páginas 21191 a 21193).

Real Decreto 1513/2006, de 7 de diciembre, por el que se establecen las enseñanzas mínimas de la Educación primaria. (BOE número 293 de 8/12/2006, pp. 43053-43102)

Rivero, P. (2008). Propuesta para una integración del patrimonio arqueológico en el Nuevo currículo de Educación primaria. En R.M. Ávila, A. Cruz y M.C. Díez (Eds.) Didáctica de las Ciencias Sociales, currículo escolar y formación del profesorado. La didáctica de las Ciencias Sociales en los nuevos planes de estudio (pp.391-400). Jaén: Universidad de Jaén / Asociación universitaria de profesorado de Didáctica de las Ciencias Sociales.

Rivero, P., y Flores-Hole, H. C. (2014). Social Science teachers' perspective, purposes and benefits of the cybermuseum VIRGO 1.1. as a cognitive tool for learning History, GSTF. Journal on Education (Jed), 2(1), 26-30. DOI: 10.5176/2345-7163_2_1.39.

Smith, L., y N. Akagawa. (2009). Introduction. In L. Smith and N. Akagawa (Eds.), Intangible Heritage (pp. 1-10). London: Routledge.

Pesquero, E., Sánchez, E., González, M., Martín del Pozo, R., Guardia, S., Cervelló, J., Fernández, P., Martínez, M., y Varela., P. (2008). Las competencias profesionales de los Maestros de Primaria. Revista Española de Pedagogía, 241, 447-66. 


\subsubsection{An Analysis of Educational Designs in Intangible Cultural Heritage Programmes: the Case of Spain}

Fontal , O., y Martínez, M. (2018). An Analysis of Educational Designs in Intangible Cultural Heritage Programmes: the Case of Spain. International Journal of Intangible Heritage, 13 , 192-204. http://www.ijih.org/volumeMgr.ijih?cmd=volumeDtlView\&volNo=13\&lang=ENG\&dV olId=712\&manuType $=$

Fecha de publicación: 31 de mayo de 2018

La Revista: Enfoque y alcance.

El International Journal of Intangible Heritage es, la primera revista académica internacional de su tipo. Se publicó por primera vez en 2006 en respuesta a los crecientes intereses académicos y profesionales en el patrimonio intangible, en particular después de la ratificación generalizada por parte de los Estados de la Convención del Patrimonio Intangible de la UNESCO de 2003 para la salvaguardia de Herencia cultural intangible. El IJIH es una publicación académica y profesional en inglés dedicada a la promoción de la comprensión de todos los aspectos del patrimonio inmaterial y la comunicación de investigaciones y ejemplos de buenas prácticas profesionales.

\begin{tabular}{ll}
\hline Título: & INTERNATIONAL JOURNAL OF INTANGIBLE HERITAGE \\
\hline ISSN: & $1975-3586$ \\
\hline País: & Korea, Republic of \\
\hline URL: & http://www.ijih.org/mainMgr.ijih?cmd=mainPageView \\
\hline C. académico: & CIENCIAS SOCIALES Y HUMANIDADES EN GENERAL; \\
& HUMANIDADES EN GENERAL; MUSEOLOGÍA. \\
\hline Indizada en: & Scopus, Arts and Humanities Citation Index, International \\
& Bibliography of Social Sciences, CAB Abstracts, Index Islamicus, \\
& MLA - Modern Language Association Database \\
\hline Evaluada en: & CARHUS Plus+ 2018 \\
\hline Métricas en: & SJR (2018) 0.17; SCImago Journal \& Country Rank, Q2. \\
& Scopus Journalmetrics \\
\hline ICDS: & ISSN: 1975-4019,1975-4019,1975-3586 \\
& Ídices de citas (Arts and Humanities Citation Index, Scopus) = +3.5 \\
& Está al tiempo en WoS (AHCI, SCIE o SSCI) y en Scopus (Arts and \\
& Humanities Citation Index, Scopus) = +1 \\
& Está en dos o más bases datos de indización y resumen o en DOAJ \\
\hline
\end{tabular}


(International Bibliography of Social Sciences, CAB Abstracts, Index Islamicus, MLA - Modern

Language Association Database $)=3+2=5$

Antigüedad = 13 años (fecha inicio: 2006)

Pervivencia: $\log 10(13)=+1.1$ 


\section{An Analysis of Educational Designs in Intangible Cultural Heritage Programmes: the Case of Spain}

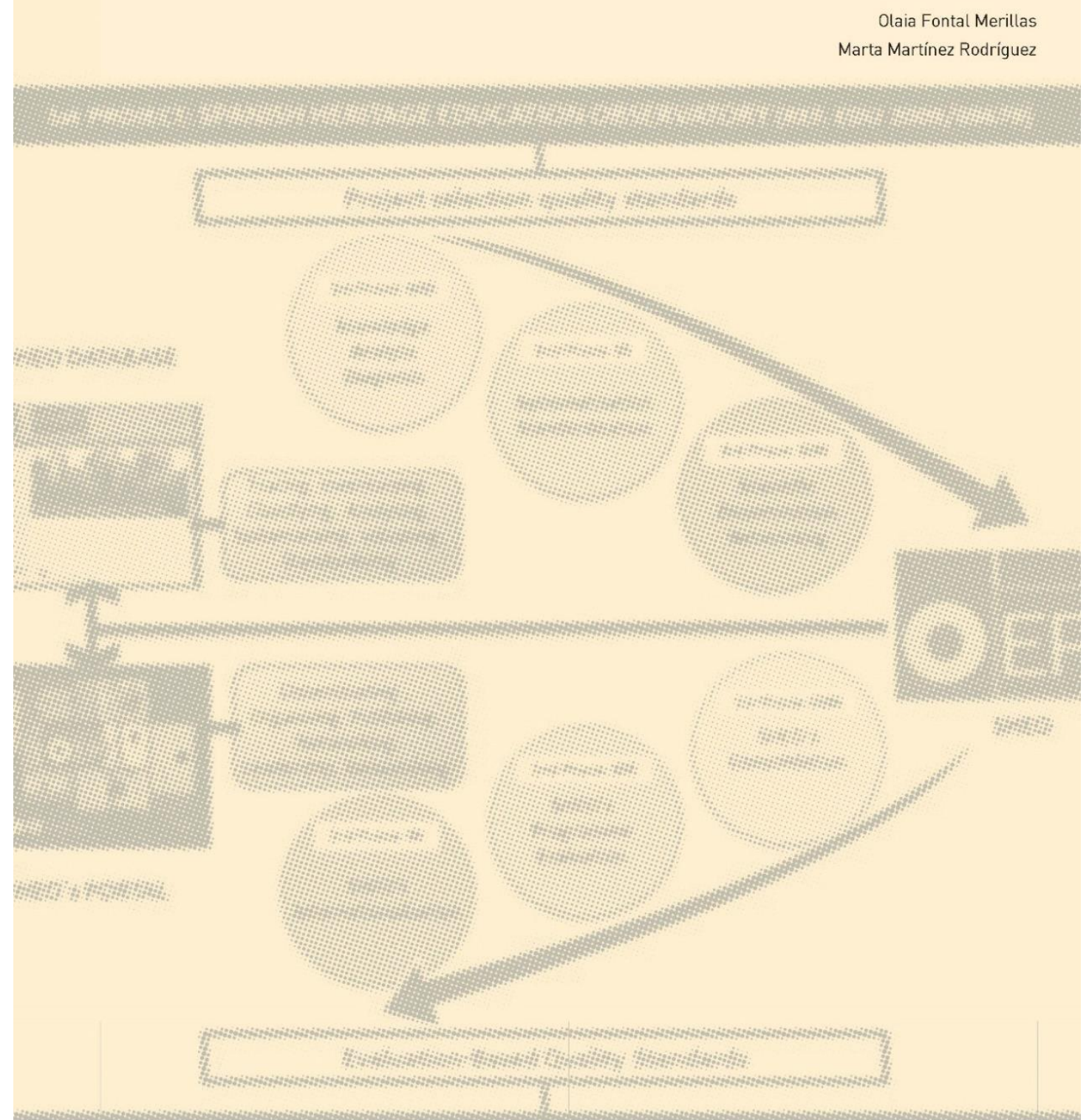




\section{An Analysis of Educational Designs in Intangible Cultural Heritage Programmes: the Case of Spain}

Olaia Fontal Merillas

Professor of Visual Arts Education, University of Valladolid. Spain

\section{Marta Martínez Rodríguez}

Ph. D candidate, University of Valladolid, Spain

\section{ABSTRACT}

The goal of this paper is to analyse the approaches and categories that underpin the educational programmes related to intangible heritage in Spain, inventoried by the Spanish Heritage Education Observatory [SHEO). We need to define the question and provide guidelines concerning the main issues to be borne in mind in designing programmes for such a sensitive area as intangible heritage, the ultimate aim being to contribute towards the improvement of future designs. The study shows that the educational programmes under scrutiny belong to a broad range of typologies within intangible heritage and have several shortcomings in their educational design. This is indeed a source of concern in view of the important role played by Heritage Education in raising the awareness of people and guaranteeing unifying processes to ensure that cultural expressions become part of the community's shared heritage.

\section{Keywords}

heritage education, Spanish Heritage Education Observatory (SHEO), evaluation of educational programmes, 'heritagisation; Spain

\section{Introduction}

The heritage/education dyad began to operate on an institutional level in 1972 following UNESCO's Convention Concerning the Protection of the World Cultural and Natural Heritage, which explicitly mentioned the need to make known the importance of heritage and strengthen appreciation and respect for it by means of educational programmes (UNESCO, 1972, Arts. 27 and 28). Since then, cultural heritage has undergone a number of changes involving its conception and development. Within the several spheres responsible for its protection, the seed was planted for an understanding of heritage as connected to the anthropological concept of culture. This resulted in a new mentality fed by several theoretical perspectives which see culture itself as the expression of a people's identity originating as a result of adaptation to the environment (Carrera: 2009, p. 195). In this way, the concept of cultural heritage that had prevailed in past centuries lone which largely focused on the great 
monuments of the westl gradually evolved as a new way of thinking that fuelled interest in intangible cultural assets This process was shaped by charters, recommendations and resolutions adopted by international bodies like UNESCO or ICOMOS IAhmad: 2006]. This new concept, however, was not merely the outcome of introducing the category of intangible heritage, but must rather be seen as a more complex process encouraged by society's rethinking of the general concept of heritage (Bortolotto 2007: 2015). This series of developments culminated in 2003 with the adoption of the Convention for the Safeguarding of the Intangible Cultural Heritage, which was an important step towards the formulation of new policies that earned international recognition for this heritage typology and sanctioned the need for education and awareness-raising aimed at achieving the hoped-for appreciation and respect for intangible heritage (UNESCO: 2003, Articles: 14 and 15)

\section{Background and problem statement}

The scientific field that studies the relationship between heritage and education is constantly evolving as a result of the proliferation of research. Over the last few decades a large number of studies have produced theoretical constructs and a frame of reference which have no doubt succeeded in bridging the initial gap. In the case of Spain, we may refer to contributions by authors like Cuenca [2003], Fontal [2003] or Calaf [2009]. From a more international perspective, the topic has been discussed by scholars like Lobovikov-Katz [2009] or Texeira [2006]. Besides this ample theoretical canon, there has also been an increase in the amount of research on heritage and education, including that conducted in the formal sphere which addresses the teaching of heritage-related contents in the classroom /Cuenca and López: 2014; Estepa, Ávila, and Ferreras: 2008; Fontal et al.: 2017; de Troyer et al.: 2005, Vlachaki: 2007l. As regards informal education, mention must be made of work conducted in museum settings (Borges and Braz: 2008; Logan and Sutter: 2012: Macdonald 2011; Musinguzi and Kibirige: 2009). Both groups of authors deal with educational programmes implemented in museums, as well as with the importance of adapting to the new social realities of the 21st century. The use of technological resources in the implementation of research has been the main focus of international publications by numerous authors like Ibáñez et al. (2012), Lobovikov-Katz et al. (2014) and Ott and Pozzi (2011). A more relational approach involving the connections between museum, community, lifelong learning and identity is illustrated by the work of Davis, [2007) and Folk, Dierking and Adams [2006]. In order to gain a deeper insight into the research outcomes reached in the field of heritage-related education both at home and abroad, we recommend the study by Martin and Cuenca [2015]. Other contributions display a more specific approach and a stronger focus on the didactics of heritage (Calbó, Juanola and Vallés: 2011; Calaf: 2009). We can even find studies which position heritage education as a key discipline in the context of cultural heritage management (Martín and Cuenca: 2011; Fontal and Juanola: 2015) by underscoring its potential for supporting processes like value-enhancement, awareness-raising or community ownership of cultural heritage. Regarding the connection between heritage education and people with disabilities or special educational needs, mention must be made of Fontal and Marín [2016] and Marín et al. [2017], where educational programmes are evaluated which are adapted to several target groups with the purpose of developing a model for inclusion.

All the above-mentioned studies are rooted in the need to position heritage education as a central discipline in the safeguarding and management of cultural heritage both tangible and intangible. Heritage education is thus understood as a guarantee that has the potential to raise the awareness of the community and to activate new links between culture and society while ensuring the transformation of cultural assets into heritage assets

In the area of heritage education, major projects are being developed in the international. scene which have become reference models in our field of study. A brief comparative overview now follows of the most relevant projects implemented either individually or in collaboration between several countries or universities from across the world. Let us in the first place highlight the project World Heritage in Young Hands, since it takes place within such a major international institution as UNESCO. The purpose of this project is to encourage young people to involve themselves in the protection of our common cultural and natural heritage by using education as a major tool. Again with an international scope, the - Treasures project, implemented as part of the European Union's 7th Framework Programme, is being developed in universities around the world. The project has generated an open platform that provides access to intangible cultural heritage resources with the aim of producing an ICT-based framework for the transmission 
of $\mathrm{ICH}$ and its educational treatment. Multiple publications have resulted from this project, including the study by Ott, Dagnino and Pozzi (2014) on the design of innovative educational interventions in the area of $\mathrm{ICH}$

There are likewise co-operative networks for cultural heritage education like the one developed in Finland, the main goals of which are to strengthen the connection between the Finnish population and their own cultural heritage and to reinforce the latter's role in education. The Oak of Finland is remarkable for involving co-operation across national, regional and local levels where schools, museums, NGOs and educational administrations work together in order to further heritage education. Within the European sphere, mention must be made of the HEREDUC Project, since it is the first co-operative project involving several countries in Europe. With participation by Germany, Belgium, France, the Netherlands and Italy, its main aim is to develop guides in order to help teachers integrate heritage education in their classes, including the possibility of implementing models of transferable action

Outside Europe, Brazil is host to the project Mais Educacão, which conducts an educational inventory of cultural heritage to be used by schools and institutions that work on heritage-related education in that country. With a different approach, yet similar tools, Korea's ICHPEDIA project aims to produce an inventory that in turn generates two databases operating as a mutually complementary platform. The first one has been designed so as to gather multimedia data, while the second one is meant to be particularly user-friendly. By creating this inventory, networks and active co-operative relationships are generated between the administrations and the citizenry ICheol: 2014l. Both projects share similar traits with our own Spanish Heritage Education Observatory [SHEO] in terms of the tools used in compiling the inventory and the database.

This overview of international research work and benchmark projects, now lets us focus on the observation and analysis of heritage education in Spain. The subject has been addressed not only by a number of scholars, but also by numerous legislative and regulatory frameworks like the Organic Law for Quality Enhancement in Education [2013], the Spanish Historic Heritage Act 11985], the National. Plan for the Safeguarding of Intangible Cultural Heritage [2011], and the National Plan for Heritage and
Education (Domingo, Fontal and Ballesteros 2013). Given the need to closely observe educational actions implemented in the sphere of cultural heritage, an R\&D\&l project named the Spanish Heritage Education Observatory (EDU2009-09679) was started in 2010. Initially meant to span a 3-year period (between January 2010 and December 2012), the project was then extended over a second phase between January 2013 and December 2015 [EDU2012-37212) and is currently in a third phase [EDU2015-65716-C2-2-R]. Its goals were set up within the framework of national and international regulations concerning heritage and education, and for over five years now it has been dedicated to tracing, inventorying and analysing heritage education programmes

The present piece of research has been conducted under the auspices of SHEO. The research problem arose from early analyses [Fontal and Martínez: 2017] claiming that intangible heritage is not prioritised content in educational programmes lonly 14\% from among 18 heritage typologies specifically include this categoryl, even though there are very interesting proposals in this regard which possess a high educational value. Moreover, among proposals implemented in non-formal settings there is a large variability land a fair amount of dispersal tool, which points to the need to order and classify them appropriately.

The situation described above, on the other hand, takes place in a country that can boast no fewer than 44 properties included in the World Heritage List as well as 11 elements that enjoy the status of intangible heritage inscribed on UNESCO's Representative List of the Intangible Cultural Heritage of Humanity Spain thus ranks as the second country in the world by the number of items inscribed on UNESCO's World Heritage List and the third country in Europe by the number of assets qualifying as intangible heritage. Additionally, and according to Spain's Cultural Heritage Institute [IPCE], the country's autonomous regions have thus far ensured protection for 60 cultural manifestations by declaring them 'Assets of Cultural Interest'

All of this justifies the need to thoroughly scrutinise educational actions put into practice in Spain over the last few decades regarding intangible cultural heritage. Such is the inspiration for our research, the goal of which is to appraise and shed light on the available education opportunities in the field of intangible cultural heritage in Spain. In order to achieve this end, the present study 


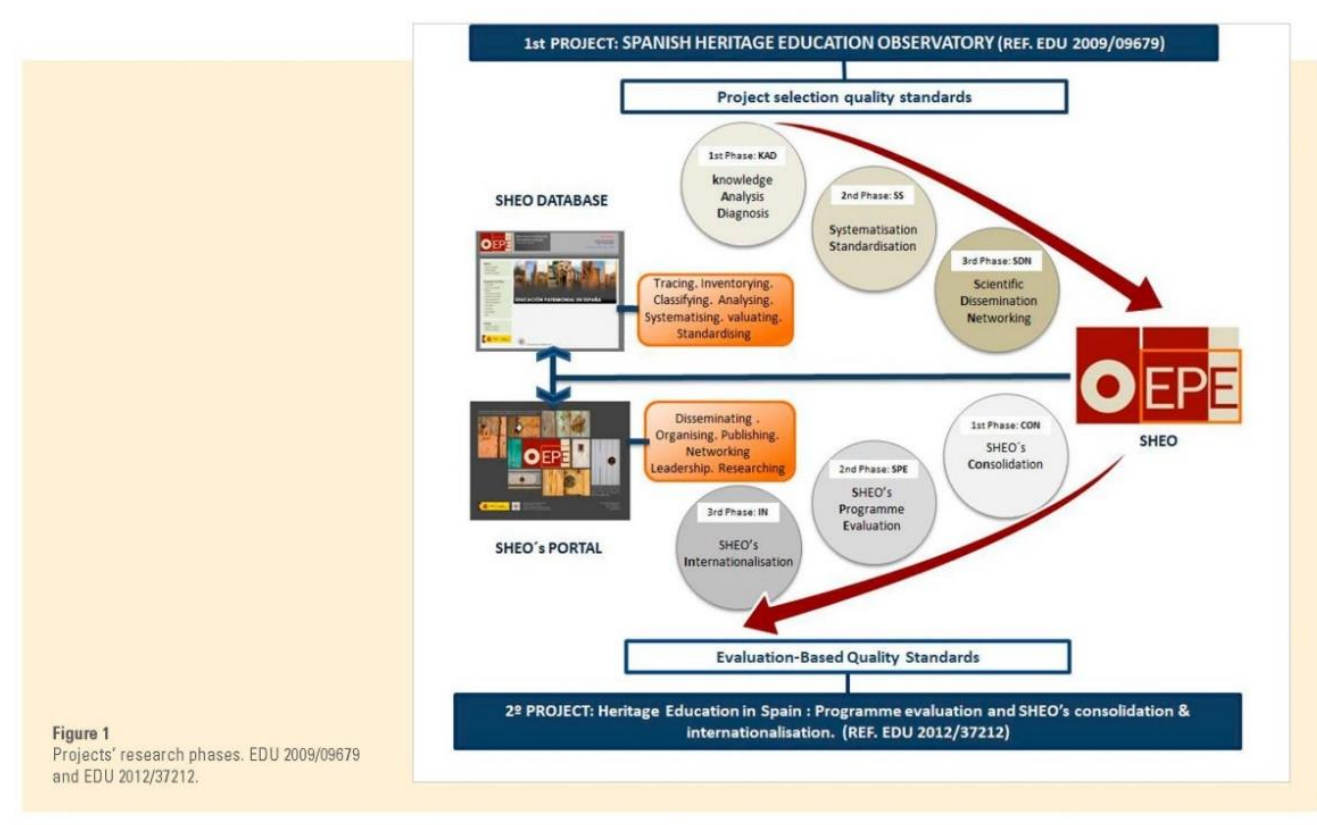

collects the results of analyses conducted on approaches and categories informing educational programmes related to intangible heritage, in order to define the state of the question and provide guidelines concerning the main issues to be borne in mind in designing programmes for such a sensitive area as intangible heritage, the ultimate aim being to contribute towards the improvement of programme design in the future. As far as our line of research lintangible cultural heritage education] is concerned, a number of published studies have explored connections with higher education (Jinlong: 2009], language acquisition and development [Asiáin and Aznárez: 2012l or emerging resources in educationoriented museum studies (Yanes: 2007)

\section{SHEO's analytical method}

Besides diagnosing and formulating the state of the question, SHEO has defined a method (Fontal: 2016) in order to inventory, analyse and evaluate educational programmes. Disseminating the results of this method is indeed one of the Observatory's goals IFontal and GómezRedondo: 2015; Fontal and Ibáñez: 2015; Marín, et al 2017; Fontal and Ibáñez: 2017]. To date, SHEO has digitally inventoried 1,686 programmes and proposals in the field of heritage education, both national and international Regarding the Observatory's research structure - one supported by two successive and interrelated projects research can be distinguished. [Figure 1]

The implementation of these phases has generated a large database (the SHEO Databasel that lists events, programmes, projects, plans, teaching materials, networks, conferences, courses, competitions, etc. that have been produced in Spain over the last decade. Together with that database, the SHEO Website provides a tool for the dissemination of heritage education initiatives and of the Observatory's own work.

\section{Sequential procedure for programme evaluation}

SHEO's method starts by searching and tracing programmes by using pre-established search indexes. Later on, findings are inventoried after applying a number of inclusion/exclusion criteria. The data is used to carry out a descriptive-statistical analysis of programmes so as to discern their heritage and educational typologies. It 


\section{Sequential procedure for evaluating programmes}

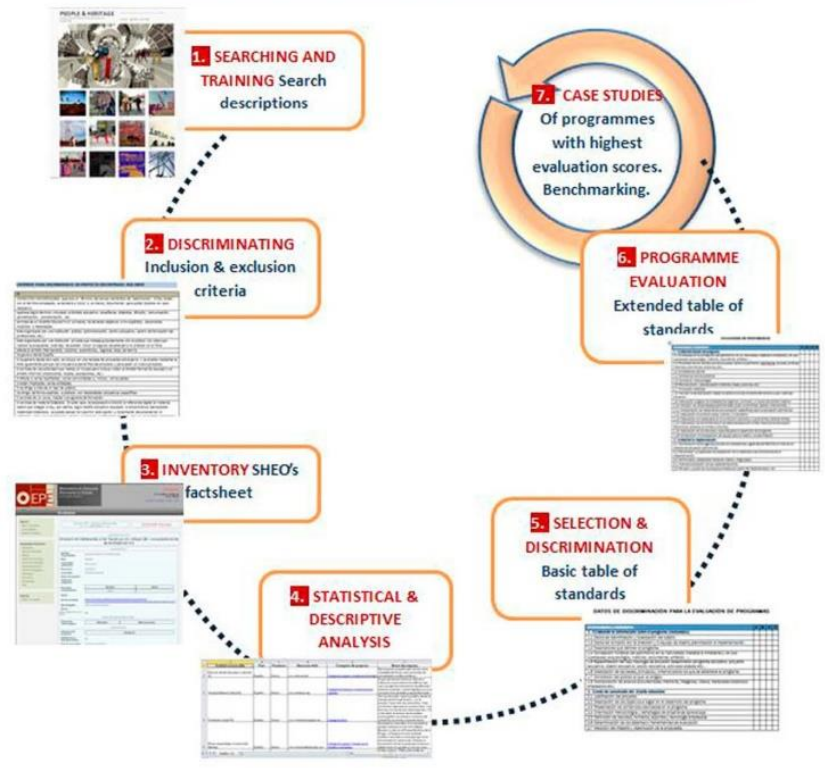

is at this point that programme evaluation proper begins. The latter involves resorting to a system of sequential filters defined by SHEO's research team as well as by international experts. During the first screening, such programmes are selected as meet the basic quality standards regarding quality of information and specificity of educational design. These programmes are then subjected to a second screening where they are evaluated according to extended quality standards related to the quality of their design, implementation and results (Stake: 2006). The programmes that rank highest in this last phase are next selected for the purpose of conducting single or multiple case studies. (Figure 2)

\section{Sample and sub-sample selection criteria}

From SHEO's digital database we have drawn a sample for the purposes of our research according to the following selection criteria: the sampled programmes should belong to the category Intangible Heritage and should have been implemented in Spain. For the analysis of educational programmes, a sub-sample was drawn according to the following selection criterion: the subsampled programmes should belong to the project type Educational Programme. A record form designed by SHEO and based on a series of descriptors (Figure 2. Phase 3) provides the data-collection tool. The form allows us to conduct searches for relevant data, specific typologies of educational actions, educational stages involved, teachinglearning strategies, possible adaptations and intangible heritage types used by the programmes under scrutiny. Data will be exported from SHEO into the data-analysis tools that enable us to obtain the sought-for frequencies (Figure 3. Phase 4)

\section{Sample description and analysis}

The selection of initiatives and programmes revolving around intangible heritage creates a sample of 209 actions classified into several project typologies. What follows is an analysis of the distribution of these actions across the several typologies, the aim being to determine the rate 


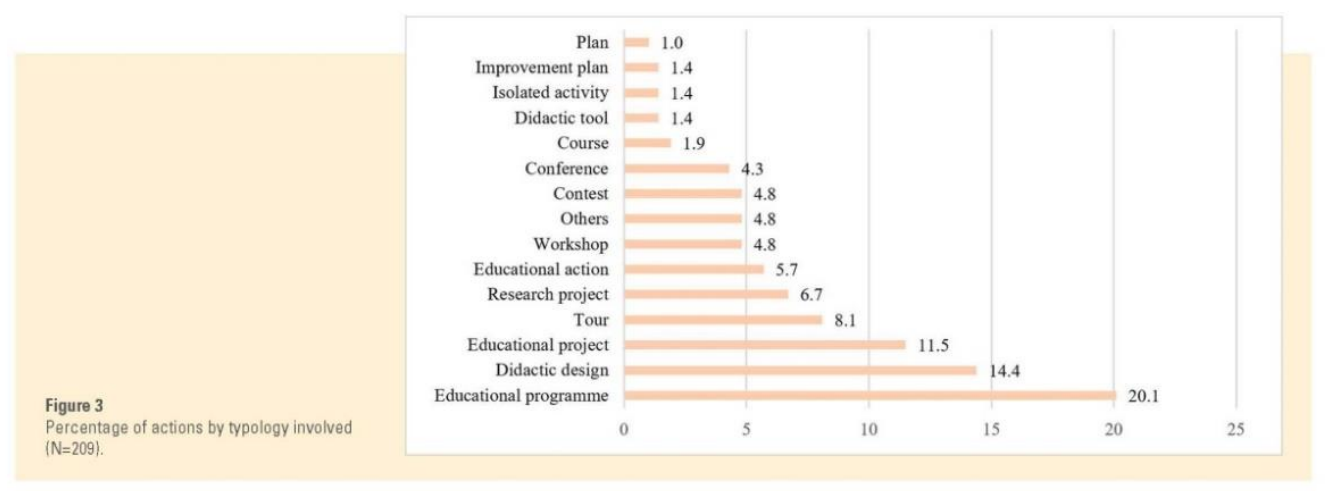

of occurrence of such actions with regard to the type of project involved

As can be seen in Figure 3, there is an extremely low number of plans $[1.0 \%$ or improvement programmes $[1.4 \%]$ that start from situations usually diagnosed as shortfalls. We likewise observe that isolated experiences or activities that have no continuity and are generally designed for the celebration of a specific event are poorly represented $(1.4 \%)$. Training actions like courses and workshops represent $4.8 \%$, while research projects only account for $6.7 \%$ of the total sample - a percentage that may not seem particularly low by comparison with other typologies, but it is if we consider the need for innovation in this area. Widely represented $(14.4 \%)$ are didactic designs: these are characterised by the fact that they organise educational actions and teaching-learning processes. Finally, educational programmes prove to have a higher incident rate $(20.1 \%)$ in our sample, accounting for a total of 42 such actions

\section{Results}

Educational programmes are documents that detail and organise an educational process by systematically collecting a set of activities aimed at achieving well-defined purposes. They involve forecasting and planning ahead for continuity, and they are generally framed within the educational sphere. Our goal, therefore, was to find out the extent to which those 42 educational programmes fulfil those requirements. This we did by analysing the Intangible Cultural Heritage typology used, the targeted educationa stages, the teaching-learning strategies involved, the potential for adaptation and the evaluation tools

\section{Intangible Cultural Heritage used in the programmes}

The concept of cultural heritage has evolved and expanded over the last century. Indeed, it has moved from a perspective where the monumental, the artistic and the ancient were the main values deserving protection to another, focused on lifestyles, social practices, knowledge, techniques and beliefs or belief systems shared by the several individuals and groups (National Plan for the Safeguarding of Intangible Cultural Heritage: 2011]. Within the current decade, the use of adjectives like intangible or immaterial has become widespread in order to vindicate recognition of this dual reality and attach the importance they deserve to the so-called intangible assets. This is also reflected within the field of heritage education by the emergence over the last ten years of many different educational programmes relating to intangible cultural heritage.

The latter, in turn, can be divided into several typologies depending on the nature of its manifestations. There are five domains where $\mathrm{ICH}$ manifests itself according to the Convention for the Safeguarding of the Intangible Cultural Heritage:

al oral traditions and expressions, including language as a vehicle of the intangible cultural heritage;

b) performing arts

c) social practices, rituals and festive events;

d) knowledge and practices concerning nature and the universe;

e) traditional craftsmanship (UNESCO: 2003] 


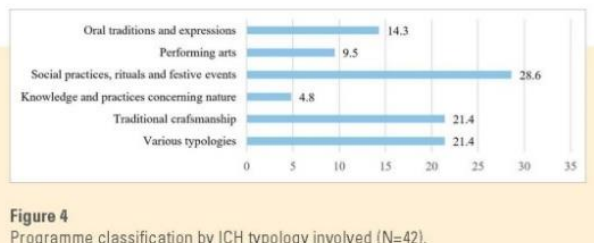

Figure 4
Programme classification by ICH typology involved ( $N=42$.

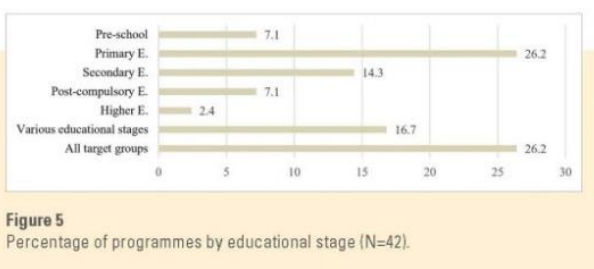

Students targeted by these programmes are variously distributed across the several educational stages (Figure 5).

The educational stage indicating the highest concentration of programmes is Primary Education (26.2\%), together with the category 'Various educational stages', where programmes do not address a specific educational stage but a broader range of students. The least represented stage is Higher Education (2.4\%).

\section{Programmes with/without adaptation}

Within the several educational stages, we found programmes targeted at people with disabilities or with special educational needs (SEN) like the feature Visits adapted for all' within the programme Accesible Madrid. We also included programmes which, while not specifically addressing such students, do indeed contemplate their participation in their didactic designs. Even so, their representation is quite low.

Diversity is present in all spheres of contemporary society, since every individual displays differences with regard to others and these must be acknowledged. According to Fontal and Marín (2016), it is critical to bring

\section{The school environment and educational stage}

Before starting the analysis of didactic designs, we think it appropriate to highlight the environment where these programmes are implemented so as to better understand their real operation. Most programmes analysed $(64.3 \%)$ are conducted in formal settings. They can be categorised as belonging to two modalities: on the one hand those implemented on the initiative of schools and within their premises; and on the other, those lwhich constitute the larger partl where schools engage in a collaboration with institutions in their environment like museums, local councils and associations.

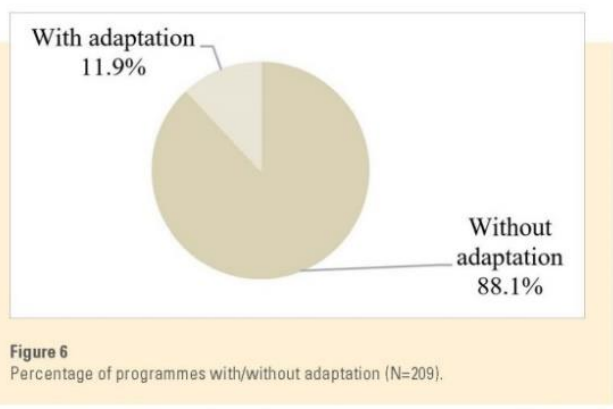


a paradigm shift towards the culture of diversity: one that breaks away from uniformity-based education and focuses instead on the potential for the development of all human beings

Heritage education affords a perfect tool, making it possible to work on diversity within the framework provided by the concept of heritage, the aim being to achieve a normalisation-based heritage education

\section{Typologies of teaching-learning and their representative programmes}

When analysing the kinds of teaching-learning strategies proposed in theprogrammes, we haveclassified the latter into four non-mutually exclusive categories Narration, Workshop, Didactic Resource and Others which are in turn subdivided into several subcategories [Table 1]. The most widely recorded strategy in working on intangible cultural heritage is the use of narratives Within them, traditional guided tours constitute the most widespread modality, possibly because they can be adapted to audiences with different ages and needs This is the strategy used by the Autonomous Region of the Canary Islands in designing their programme on the trail of my village: adopting the day labourers' craft, where many visits are scheduled with the purpose of discovering the ethnographic heritage of the Canary Islands.

Also worth highlighting are didactic guided tours like those organised in the programme Heritage Schoot developed by the Autonomous Region of Castile and Leon We generally observe that lectures tend to be part of specific designs targeted at an older audience, like for example the proposal named Learning through art. Ceuta and Mythology, which features talks for secondary education and vocational training students

Table 1.

Programme categories depending on teaching-learning strategy $(\mathrm{N}=42)$.

\begin{tabular}{ll}
\hline NARRATION & $\frac{19}{9}$ \\
\hline Guided tour & $\frac{9}{6}$ \\
\hline Didactic guided tour & $\frac{4}{12}$ \\
\hline Lecture & 2 \\
\hline PORKSHOP
\end{tabular}

\begin{tabular}{lll}
\hline Performing arts & 4 \\
\hline Experiential & 3 \\
\hline Creation of didactic materials & 3 \\
\hline DIDACTIC RESOURCE & 9 \\
\hline Didactic unit & 5 \\
\hline Pedagogical concept & 2 \\
\hline ICTs & 1 \\
\hline Exhibition & 2 \\
\hline OTHERS
\end{tabular}

In the case of workshops, we find proposals in the area of the performing arts, Like a programme implemented by primary and secondary schools in Girona named Sardana at schoot, or Let's Opera! in Navarre. Also plastic arts workshops, like a proposal developed by a secondary education school in the Basque Country called Building a sailboat made of skins or experiential workshops, such as those scheduled every year as part of the activities organised by the Legado Andalusi foundation. Worth mentioning as well is Lugo's Museum Network, which provides a wide range of networks for all educational stages. The creation of educational materials by the students themselves is the approach chosen by the Manuel Peleteiro school in its programme Project 800 The anniversary of Santiago de Compostela's cathedra

The main educational resources used are the so-called didactic units, notably those developed by UNESCO's Associated Schools Network with an interdisciplinary approach and a special focus on the manifestations of intangible cultural heritage in Asturias. As far as the use of ICTs is concerned, their presence is scarce according to our observations. There are a few programmes that occasionally employ the resources provided by ICTs, but the only one that uses them consistently as its main educational resource by means of interactive guides and CDs is the programme called Awareness-raising and the Spanish League of Education and Popular Culture Exhibitions are likewise seldom used as strategies. The only example that we have traced is the programme Heritage and Memory, which consists of touring exhibitions visiting five museums in Asturias. Under the category 'Others' we find initiatives that use heritage for the purposes of occupational training and employment like the programme Heritage for development developed by the autonomous region of Madrid. 


\section{Goals and evaluation}

Regarding programme goals, we found that many programmes would require a detailed study of the curriculum and the basic skills involved in the educational stage they target in order to achieve a more balanced design. We have detected that appreciation for the wealth and diversity of natural, social and cul tural heritage, as well as the development of individual and social responsibility in the preservation of intangible cultural heritage, are most often the declared goals, followed, albeit to a lesser extent, by others concerning the avallability of spaces for experience-transmission and inter-generational exchange, heritage-driven motivation for students with disabilities or SENS, or issues related to values involved in living together, such as team work or the enhancement of inter-cultural awareness, where we believe heritage has a lot to offer

Regarding the analysis of evaluation systems and tools used by the several programmes, only $14.3 \%$ of them plan to use them in advance, in contrast to the remaining $85.7 \%$ that do not. This is surprising if we consider how important evaluation is in order to learn about the students' learning achievements IStake: 1967), the project's success and any aspects that may need improving. Evaluation systems and tools range between the simplest types, like observationbased general evaluation, to the most complex approaches like ongoing evaluation of the methods used and the project as a whole, including survey-based and continuous and formative evaluation, the purpose of which is to generate feedback. There are even programmes that engage in a detailed evaluation methodology: procedural evaluation by means of checklists, summative evaluation using worksheets, evaluation of the teaching process through teacher feedback, anecdotal records and student interviews. No programme evaluates outcome continuity, since the programmes under scrutiny do not contemplate any timeline extension beyond their termination date.

\section{Conclusions}

Our paper set out to analyse the approaches and categories involved in educational programmes on intangible heritage inventoried by the Spanish Heritage Education Observatory. Our research has proven that there are shortcomings in several aspects of educational designs. One of the main deficiencies that we have spotted is the small degree of adaptation of programmes to the needs and interests of a range of target groups. This is a surprising flaw if we bear in mind that diversity is present in all spheres of contemporary life. This view has also been expressed in several studies like Marín et al. (2017) or Fontal and Marin (2016), who argue that within the sphere of heritage education, diversity must be seen as a two-sided asset insofar as it relates, in the first place to heritage diversity and, secondly, to diversity among the recipients of educational actions: the potential owners of heritage expressions

To this we should add the shortfall in evaluation planning, since only $14.3 \%$ of scrutinised programmes seem to contemplate the latter's need as defended in published studies by Stake $[1967 ; 2006)$. The use of ICTs is likewise hardly present despite the benefits they afford as shown in research work on heritage education and these technologies (lbáñez et al: 2012; Ott and Pozzi: 2011; Ott, Dagnino and Pozzl: 2014). Moreover, and regarding programme goals, we have found a disconnect with the school curriculum. The link between both things, however, is key in furnishing heritage-related programmes with ties to content, values and skills that must be developed throughout successive educational stages, as advocated by other studies in this area IFontal: 2008; Lobovikov-Katz et al.: 2014l.

On the other hand and despite the limitations that we have discovered, we have also detected good examples of highly original practice and programmes in the area of intangible heritage. A high proportion of these take place in the formal sphere and in collaboration with other institutions in their neighbouring environment - an interesting issue insofar as this entails the participation of all educational agents. Following (Fontal and GómezRedondo: 2015) the involvement of educational agents immersed in heritagisation processes facilitates the construction of identity, thus enhancing the programme's quality Another aspect worth mentioning is the wealth of intangible heritage assets explored by these programmes. Regardless of the heritage type involved in each case, programmes must be designed by paying close attention to all aspects required by a sound didactic layout. This is critical in achieving their main ultimate goal: making heritage known and strengthening respect and appreciation for it [UNESCO: 1972, Arts. 27 and 28]. Programmes, therefore, must have a proper educational design that makes it possible to develop the didactic chain discussed by Fontal [2003] - knowing in order to understand, understanding in order to respect, and 
respecting in order to value. In this sense we provide a few guidel ines pointing to a number of aspects to be borne in mind in programme preparation in order to improve the quality of future designs

- Developing a programme suited to the context and to the initial needs.

- Setting feasible targetsaccording tothebeneficiaries age and the current regulations for each educational stage if the programme in question takes place in a formal setting.

- Notwithstanding the educational environment [formal, non-formal or informal] where the programme takes place, it is enriching to seek the participation of other groups and institutions with the aim of gathering additional support and engaging the participation of the whole school community.

- Teaching-learning resources must be suited to the methodology that the programme intends to implement. Furthermore, they must be carefully selected on the basis of the group's characteristics the institution's educational programme and the material or human resources available.

- Training of staff responsible for implementing the programme, both in formal and informal settings

- Developing programme adaptations and bearing in mind the special needs of the target community or group

- Detailed development of a methodology for programme implementation.

- Periodic scheduling of the programme

- Programme evaluation oriented towards content adequacy and compliance with current legislation Evaluation of programme implementation Feedback-oriented continuous and formative evaluation. Evaluation of programme results regarding the acquisition of knowledge and values contemplated in the programme's goals.

- Reflecting on the negative aspects during evaluation and searching for strategies to improve deficit areas so as to ensure the continuity of the programme.
The above discussion makes clear the need to consider all aspects involved in producing fine educational designs that underpin programmes concerned with intangible heritage. It is worth mentioning that we have been able to detect a wide range of typologies in our examination of such programmes, which reflects the wealth of intangible heritage itself. This is why it is so important to encourage a feeling of belonging among young people that should ultimately become a sense of responsibility towards the preservation of this particularly vulnerable heritage type. It is in this context that heritage education can play a key role in attempting to convey and create relationships that teach people to appreciate cultural wealth as a sign of identity [Fontal and Gómez-Redondo: 2015], thus becoming a fundamental tool in the management of intangible cultural heritage. We need to develop programmes capable of bringing about the transformation of cultural assets into heritage assets, since heritage education provides a key guarantee in such unifying processes to ensure that a cultural asset becomes community-owned heritage [Lobovikov-Katz: 2009]. 폼 


\section{Acknowledgement}

This work was supported by the Ministry of Economy and Competitiveness under Grant [EDU 2009/09679], Grant [EDU2012-37212] and under Grant [EDU2015-65716-C2-2-R]

\section{REFERENCES}

- Ahmad, Yahaya, 2006. 'The Scope and Definitions of Heritage: From Tangible to Intangible' in International Journal of Heritage Studies 12 [3]: pp. 292-300.

- Asiáin, Alfredo, and Aznárez, Mónica, 2012. 'Patrimonio cultural inmaterial y adquisición/desarrollo del lenguaje: Tradición discursiva y psicodinámica oral' in Huarte De San Juan 12: pp. 45-64.

- Bortolotto, Chiara, 2007. 'From Objects to Processes: Unesco's 'Intangible Cultural Heritage' in Journal of Museum Ethnography 19: pp. 21-33.

- - - 2015. 'UNESCO, Cultural Heritage, and Outstanding Universal Value: Value-Based Analyses of the World Heritage and Intangible Cultural Heritage Conventions' in International Journal of Heritage Studies 21(5): pp. 528-30.

- Borges, Luis Carlos, and Braz, Marilia, 2008 'Cosmology an Intangible Heritage Exhibition and Educational Programme at the Museum of Astronomy, Fio de Janeiro' in International Journal of Intangible Heritage 3: pp. 56-70

- Calaf, Roser, 2009. Didáctica del patrimanio epistemología, metodología y estudio de casos. Gi jón: Trea.

- Calbó, Muntsa, Roser, Juanola, and Vallés, Joan, 2011. Visionesinterdisciplinaresen educación del patrimonio Girona: Documenta Universitaria

- Carrera, Gemma, 2009 . 'Iniciativas para la salvaguardia del patrimonio inmaterial en el contexto de la convención Unesco, 2003: Una propuesta desde Andalucía' in Revista Patrimonio Cultural De España 0: pp. 179-195

- Cheos, Soon, 2014. 'ICHPEDIA, a case study in community engagement in the safeguarding of ICH online' in International Journal of Intangible Heritage 9: pp. 69-82.

- Cuenca, José María, 2003. Análisis de concepciones sobre la enseñanza del patrimonio en la educación obligatoria' in Enseñanza de las Ciencias Sociales: Revista de Investigación 2 pp. 37-46.

- Cuenca, José María, and López, Inmaculada, 2014 . Teaching Heritage in Social Science, Geography and History Textbooks in Compulsory Secondary Education' in Culture and Education 26(1): pp. 1-43

- Davis, Peter, 2007. Place Exploration: Museums, Identity, Community' in Museums and their Cammunities edited by Watson, Sheila. New York, Routledge: pp. 53-75

- De Troyer, Veerler, Vermeersch, Jens, Van Genechten, Hildegarde, Kosten, Klaus, Mols, Pieter, Van Leeuwen, Jacqueline, Vitré, Nicole, Pizzicanela, Fabio and Destro, Antonietta, 2005. Heritage in the Classroom. A Practical Manual for Teachers. Translated by Julian Morgan. Brussels: Hereduc

- Domingo, María, Fontal, Olaia, and Ballesteros, Paloma, 2013. Plan Nacional de Educación y Patrimonio Madrid: Ministerio de Educación, Cultura y Deporte, Secretaría de Estado de Cultura

- España. Ley 13/1985, de 25 de junio, del Patrimonio Histórico Español. BOE, 29 de Junio de 1985, núm. 155 o. $20432-20352$

- España. Ley Orgánica 8/2013, de 9 de diciembre, para la mejora de la calidad educativa. BOE, 10 de diciembre de 2013, núm. 295, p. $97858-97921$.

- Estepa, Jesús, Ávila, Rosa María, and Ferreras, Mario, 2008. 'Primary and Secondary Teachers' Conceptions about Heritage and Heritage Education: A Comparative Analysis' in Teaching and Teacher Education 24: pp. 2095-2107. Doi 10 1016/j. tate 2008.02 .017 
- Falk, John H., Dierking, Lynn D., and Adams, Marianna, 2006. 'Living in a Learning Society Museums and Free-choice Learning' in A Companion to Museum Studies, edited by Macdonald, Sharon. New York: Wiley-Blackwell: pp. 323-335

- Fontal, Olaia, 2003. La educación patrimonial. Teoría y práctica en el aula, el museo e internet. Gijón: Trea

. - - 2017. 'The Spanish Heritage Education Observatory' in Culture and Education 27(4). pp. 1-13. Doi 10. 1080/1 1356405.2015 1110374

- Fontal, Olaia, and Gómez-Redondo, Carmen, 2015. 'A Quarterly Revew of Education. Heritage Education and Heritagization Processes: SHEO Methodology for Educational Programs Evaluation' in interchange 46(1): pp. 1-26. Doi: 10.1007/s10780-015-9269-z

- Fontal, Olaia, and Ibánèz, Alex, 2015. 'Estrategias e instrumentos para la educación patrimonial en España' in Educatio SigloxXI 33(1): pp. 15-32.

- - - 2017. 'Research on Heritage Education. Evolution and Current State Through analysis of High Impact Indicators' in Revista de Educación, 375: pp. 184-214.

- Fontal, Olaia, Ibáñez, Alex, Martínez, Marta, and Rivero, Pilar, 2017. 'El patrimonio como contenido en la etapa de Primaria: del currículum a la formación de maestros' in Revista Electrónica Interuniversitaria de Formación del Profesorado 20(2): pp. 79-94. DOl: http.//dx.doi.org/10.6018/reifop. 20.1.286321.

- Fontal, Olaia, and Marín, Sofía, 2016. 'Heritage Education in Museums: An inclusion-focused Model' in The International Journal of the Inclusive Museum 9(4): pp: 47-64.

- Fontal, Olaia, and Martínez, Marta, 2017. 'Evaluación de programas educativos sobre Patrimonio Cultural Inmaterial' in Revista de Estudios Pedagógicos [en prensa].

- Fontal, Olaia and Roser, Juanola, 2015. 'La educación patrimonial: Una disciplina útil y rentable en el ámbi to de la gestión del patrimonio cultural' in Cadmo. International Journal of Educational Research 23(1): pp. 9-25.

- Ibáñez, Alex, Asensio, Mikel, Vicent, Naiara and Cuenca, José María, 2012. 'Mobile Devices: a Tool for Tourism and Learning at Archaeological Sites' in International Journal of Web Based Communities 8[1] pp. 67-72.

- IPCE, 2011. Plan Nacional de Salvaguarda del Patrimonio Cultural Inmaterial. Madrid: IPCE.

- Jin-long, Xu, 2009. 'Thinking about Strengthening Undergraduates' Intangible Heritage Education' in Journal of Gannan Normal University 1 pp. 30-54.

- Lobovikov-Katz, Anna, 2009. 'Heritage Education for Heritage Conservation' in A Teaching Approach Strain 45(1): pp. 480-484

- Lobovikov-Katz, Anna, Moropoulou, Antonia, Konstanti, Agoritsa, Ortiz, Pilar, Van Grieken, Rene, Worth, JoAnn, Cassar, Susannah, De Angelis, Roberta, Biscontin, Guido, and Izzo, Francesca Caterina, 2014. 'Tangible Versus Intangible in e-learning on Cultural Heritage: From Online Learning to On-site Study of Historic Sites' in Digital Hentage. Progress in Cultural Hentage: Documentation, Freservation, and Protection. Switzerland: Springer International Publishing: pp. 819-828.

- Logan, Rosemary, and Sutter, Glenn, 2012. Sustainability and Museum Education: What Future are we Educating for?' in The International Journal of the Inclusive Museum 4(3): pp. 11-26.

- Macdonald, Sharon, 2011. A companion to museum studies. New York: John Wiley \& Sons.

- Marín, Sofía, García, Silvia, Vicent, Naiara, Gillate, Iratxe, and Gómez-Redondo, Carmen, 2017. 'Inclusive Heritage education in SHEO: a prospective study' in Revista de Educación 375: pp.110-130. DOI: 10.4438/1988-592X-RE-2016-375-337

- Martín, Myriam, and Cuenca, José María, 2011. 'La enseñanza y el aprendizaje del patrimonio en los museos. La perspectiva de los gestores' in Revista de Psicodidáctica 16(1): pp. 99-122.

.--_2015. 'Heritage Communication and Education' in Educatio Siglo XXI 33(1): pp. 33-54

- Musinguzi, Dan, and Kibirige, Israel, 2009 . 'The role of culture and heritage education at Bakoni Malapa Open Air Museum: demonstrations of cultural practices and craftwork techniques in international Journal of Intangible Heritage 4: pp. 152-158. 
Educational Design Programmes in Spain

- Ott, Michela, Dagnino, Francesca, and Pozzi, Francesca, 2014. 'Intangible cultural heritage: Towards collaborative planning of educational interventions' in Computers in Human Behaviour, 51: pp. 1314-1319

- Ott, Michela, and Pozzi, Francesca, 2011 'Towards a New Era for Cultural Heritage Education: Discussing the Role of ICT' in Computers in Human Behavior 27 (4) : pp. 1365-1371.

-Stake, Robert, 1967. 'The Countenance of Educational Evaluation' in The Teachers College Record 68(7): pp $523-540$

- Stake, Robert, 2006 Evaluación comprensiva y evaluación basada en estándares. Vol. 10. Barcelona: Graó.

- Teixeira, Simonne, 2006. 'Educación patrimonial alfabetización cultural para la ciudadanía' in Estudios Pedagógicos 32(2): pp. 133-145

- UNESCO, 1972. Convention Concerning the Protection of the World Cultural and Natural Heritage, Paris

- UNESCO, 2003. Convention for the Safeguarding of the Intangible Cuitural Heritage. $32^{\text {nd }}$ Session of the General Conference, Paris, 29 September-17 October

- Vachaki, María, 2007. 'Crossing Cultures through the Intangible Heritage: an Educational Frogramme about Migration in Greece' in International Joumal of Intangible Heritage 3: pp. 94-102

- Yanes, Cristina, 2007. 'El patrimonio educativo intangible: Un recurso emergente en la museología educativa in Cadernos de Históna da Educaçao 2: pp. 71-85 


\subsubsection{Evaluación de programas educativos sobre Patrimonio Cultural Inmaterial}

Fontal, O., y Martínez, M. (2017). Evaluación de programas educativos sobre

Patrimonio Cultural Inmaterial. Estudios Pedagógicos, 43(4), 69-89. http://dx.doi.org/10.4067/S0718-07052017000400004.

Fecha de publicación: junio de 2018

La Revista: Enfoque y alcance

Estudios Pedagógicos se publica desde 1976 por el Instituto de Ciencias de la Educación de la Facultad de Filosofía y Humanidades de la Universidad Austral de Chile. Es una revista inter transdisciplinaria en Ciencias de la Educación, que acoge artículos de investigación y revisión en las áreas de epistemología, gestión educacional, políticas educativas, didácticas generales y específicas, psicología y sociología de la educación.

\begin{tabular}{|c|c|}
\hline Título: & ESTUDIOS PEDAGÓGICOS \\
\hline ISSN: & 0718-0705 \\
\hline País: & Chile \\
\hline URL: & http://revistas.uach.cl/index.php/estped/ \\
\hline C. académico: & EDUCACIÓN EN GENERAL \\
\hline Indizada en: & $\begin{array}{l}\text { Scopus; Periodicals Index Online ; EBSCO Education Source, MLA } \\
\text { - Modern Language Association Database, DIALNET; } \\
\text { SciMago Journal Rank: Education. Q1 3. H 11, SJR: } 0.338 . \\
\text { Scientific Electronic Library Online - Scielo; Revistas electrónicas } \\
\text { UACh; Redalyc; Periodicals Index Online. } \\
\text { MLA - Modern Language Association Database. } \\
\text { International bibliography of periodical literature: IBZ. } \\
\text { International bibliography of book reviews: IBR. } \\
\text { Google Scholar 2017. Índice H5: 13, mediana m5: } 21 \\
\text { Educator's Reference Complete; EBSCO Education Source,: } \\
\text { EBSCO; DOAJ; DIALNET; CLASE; Academic One File }\end{array}$ \\
\hline Evaluada en: & LATINDEX. Catálogo v1.0 (2002 - 2017) \\
\hline Métricas en: & Scopus Journalmetrics \\
\hline ICDS: & $\begin{array}{l}\text { SSN: 0718-0705,0718-0705,0716-050X } \\
\text { Está en índices de citas (Scopus) }=+3.5 \\
\text { Está en dos o más bases datos de indización y resumen o en DOAJ } \\
\text { (Periodicals Index Online, EBSCO Education Source, MLA - } \\
\text { Modern Language Association Database) }=3+2=5\end{array}$ \\
\hline
\end{tabular}


Antigüedad $=43$ años (fecha inicio: 1976 )

Pervivencia: $\log 10(30)=+1.5$

ICDS $=10.0$ 
Estudios Pedagógicos XLIII, № 4: 69-89, 2017

INVESTIGACIONES

\title{
Evaluación de programas educativos sobre Patrimonio Cultural Inmaterial*
}

\author{
Evaluation of educational programmes on Intangible Cultural Heritage
}

\author{
Olaia Fontal, ${ }^{a}$ Marta Martínez ${ }^{a b}$
}

${ }^{a}$ Departamento de didáctica de la expresión musical, plástica y corporal, Universidad de Valladolid

Telf.: (34) 983084063. Correo electrónico: olaia.fontal@uva.es

'Telf.: (34) 983423745. Correo electrónico: marta.martinez.rodriguez@uva.es

\section{RESUMEN}

El artículo ofrece un análisis relacional de los enfoques y categorías de programas educativos generados en torno al patrimonio inmaterial, derivado de un estudio financiado por el Ministerio de Economía y Competitividad y los Fondos Feder (UE) en el marco del proyecto de investigación EDU2015-65716-C2-2-R, y se enmarca en las acciones del Plan Nacional de Educación y Patrimonio. Este análisis se desarrolla dentro de un proceso evaluativo con una muestra de 202 programas educativos, que tiene como finalidad detectar el estado de la cuestión, así como sus fortalezas y debilidades. El estudio muestra cómo los programas analizados abordan todos los ámbitos educativos, y presentan una amplia gama de tipologías. También se observan tendencias relacionales entre el tipo de público y tipo de programa. Por otro lado, se denotan deficiencias en torno al alto porcentaje de programas detectados sin diseño educativo. Este aspecto nos plantea la necesidad de generar nuevas prospectivas para la educación patrimonial, que garanticen su función activadora de los procesos de identización y de la sociedad hacia su patrimonio.

Palabras clave: educación patrimonial, patrimonio cultural inmaterial, evaluación de programa, UNESCO, Instituto del patrimonio cultural de España.

\section{ABSTRACT}

The paper provides a relational analy sis of approaches and categories in educational programs related to intangible heritage, in the framework of a study funded by Economy and Competitivity Ministry in Spain and Feder funds (UE) based on the Research EDU2015-65716-C2-2-R and is part of a set of actions promoted by the National Plan for Heritage and Education. Our analysis is conducted within an evaluation process applied on a sample of 202 educational programmes in order to diagnose the state of the question and detect their strengths and weaknesses. The study shows that the educational programmes under scrutiny deal with all educational settings and belong to a broad range of typologies. Additionally, relational tendencies are established between the programmes' target audience and their typology. On the other hand, shortfalls are detected involving a high percentage of programmes that have no educational design. On the whole, there emerges the need to generate new perspectives for heritage education that ensure its activating function of the processes of identity and society towards its heritage.

Keywords: heritage education, intangible cultural heritage, programme evaluation, UNESCO, Spain's Institute for Cultural Heritage.

* Este trabajo ha sido financiado por el Ministerio de Economía y Competitividad y con Fondos Feder (UE) en el marco del proyecto de investigación EDU2015-65716-C2-2-R. 
Estudios Pedagógicos XLIII, $N^{\circ}$ 4: 69-89, 2017

EVALUACIÓN DE PROGRAMAS EDUCATIVOS SOBRE PATRIMONIO CULTURAL INMATERIAL

\section{INTRODUCCIÓN}

El patrimonio inmaterial, aunque ya entendido como un concepto asentado y reconocido institucionalmente a nivel internacional por diversos organismos como la UNESCO o el Consejo de Europa, puede ser aún considerado un patrimonio emergente, si tenemos en cuenta el dinamismo intrínseco inserto en la conceptualización del término patrimonio cultural. Nos estamos refiriendo a la múltiple y variable dimensión de valores atribuidos por las diferentes sociedades hacia los bienes culturales a lo largo de la historia (Teixeira, 2006). Entendemos así que esta conceptualización seguirá avanzando en un sentido rizomático, crecerá y evolucionará indefinidamente, generando nuevos elementos y valores, los cuales no seguirán una subordinación jerárquica, sino que "cualquier elemento podrá incidir en cualquier otro" (Deleuze \& Guattari, 1972, p. 13). Si echamos la vista atrás, podemos observar, desde una posición privilegiada, el camino recorrido por el concepto del patrimonio cultural, que confirma de algún modo la continua evolución del término. Este camino está marcado por la incorporación del concepto antropológico de cultura a la gestión del patrimonio, que fluye en paralelo al auge de los movimientos sociales en pro del reconocimiento de su especificidad cultural (Carrera, 2005). Estos dos aspectos son determinantes en el origen de nuevos valores identitarios atribuibles a otro tipo de bienes culturales centrados en las expresiones y manifestaciones de una comunidad, originadas como resultado de la adaptación e interacción con el entorno. Así surge la incorporación de la dimensión intangible, que permite conocer la significación social de los bienes, "promover los vínculos entre ellos y dentro de ellos y comprender la vigencia y transformaciones de este 'todo' vivo que es el Patrimonio Cultural" (González, 2015, p. 6). Por ello, la definición de patrimonio cultural es "siempre abierta, negociable, dialógica, transformadora y reflexiva" (Santamarina, 2005, p. 48), en la que participan distintos operadores sociales.

Nos preguntamos entonces si la razón nos permite establecer alguna norma fija o tipo de regla, quizás a través de la comparación de tendencias o la relación de ideas, que nos permita vislumbrar el camino futuro sobre aquello que será o deberá ser considerado patrimonio. $\mathrm{Si}$ apelamos a un pensamiento filosófico, podremos proponer basar el fundamento en las ciencias prácticas, en la experiencia (Hume, 1757). Huimos entonces de atribuir los valores a una condición intrínseca y objetiva del bien cultural, y ubicamos los valores fuera de este, otorgados por el hombre. Son estos valores atribuidos, derivados de la experiencia y las relaciones, los que finalmente convierten a los bienes culturales en patrimonio. En la medida en la cual asumimos que este es el único encargado de otorgar valores a dichos bienes, entendemos la multiplicidad de dimensiones y la posibilidad de miradas hacia el patrimonio, donde la educación es una mirada fundamental, ya que hablar de relaciones, experiencias y procesos es hablar de educación. Por lo tanto, "comprender el patrimonio en estos términos permite situar la acción educativa como algo no solo necesario sino absolutamente imprescindible, desde el momento en que la educación patrimonial opera con este tipo de procesos" (Fontal \& Valles, 2013, p. 151).

\section{ANTECEDENTES Y PROBLEMA DE ESTUDIO: EL BINOMIO PATRIMONIO Y EDUCACIÓN}

El volumen científico desarrollado en torno a la educación patrimonial ha aumentado de manera exponencial en la última década y continua en crecimiento si aludimos a la 
Estudios Pedagógicos XLIII, N 4: 69-89, 2017 EVALUACIÓN DE PROGRAMAS EDUCATIVOS SOBRE PATRIMONIO CULTURAL INMATERIAL

proliferación de investigaciones realizadas en este campo. Muchas de estas investigaciones se desarrollan dentro del ámbito formal de la educación y abordan diferentes perspectivas, como el análisis de la enseñanza del patrimonio en las ciencias sociales y el uso del patrimonio en los libros de texto (Cuenca \& López, 2014), o las concepciones de los profesores sobre patrimonio y educación patrimonial (Estepa, Ávila \& Ferreras, 2008; Jiménez, Cuenca \& Ferreras, 2010). También encontramos el desarrollo de manuales para ayudar a los profesores a integrar la educación patrimonial en las clases (De Troyer et al., 2005). Esta última investigación tuvo lugar dentro del Proyecto HEREDUC, desarrollado de manera cooperativa por Alemania, Bélgica, Francia, Holanda e Italia. Incluso, hallamos investigaciones que presentan la interpretación de los resultados de los programas sobre educación patrimonial implementados en la República Checa, bajo el título de programa NAKI (National and Cultural Identity) (Dušan, 2015). Dentro del ámbito formal también encontramos estudios que realizan un análisis de la normativa educativa con la intención de conocer el uso, el tratamiento y el enfoque que recibe en ellas el patrimonio (Cuenca, Estepa \& Martín, 2011; Fontal \& Martínez, 2016; Pinto \& Molina, 2015). Sus resultados muestran que el patrimonio es un contenido presente desarrollado de forma trasversal y siempre desde un sentido simbólico-identitario. Otras investigaciones proponen un análisis relacional entre el currículo de educación primaria y los planes de estudios de los futuros docentes (Fontal et al., 2017). También encontramos investigaciones que determinan hasta qué punto las diferentes áreas del currículo conciencian y fomentan el respeto hacia el patrimonio (Barghi et al., 2016) e investigaciones que analizan el grado de conciencia patrimonial y compromiso de los alumnos (Azmana et al., 2010; Curtis \& Seymour, 2004). Más estrechamente relacionadas con el patrimonio cultural inmaterial, encontramos estudios centrados en la educación universitaria (Jin-long, 2009), el punto de vista de los estudiantes de educación primaria y social (Yalcinkaya, 2015), y la adquisición y desarrollo del lenguaje (Asiáin \& Aznárez, 2012).

Las investigaciones desarrolladas en el ámbito informal se encuentran, en su mayor parte, vinculadas al entorno museal (Garner, Kaplan \& Pugh, 2016; Nardi, 2008; Rosmary \& Sutter, 2012) y abordan la educación como mediación cultural en los museos. Con un enfoque más relacional entre museo, comunidad, aprendizaje continuo e identidad, encontramos las investigaciones de Falk, Dierking y Adams (2011), y utilizando el patrimonio inmaterial como recurso emergente en la museología educativa a Yanes (2007). Entre la relación sobre museos, educación patrimonial y diversidad de colectivos hacemos referencia a Fontal y Marín (2016), que entienden la educación patrimonial desde una perspectiva inclusiva y realizan una evaluación de programas educativos adaptados a diversos públicos con la finalidad de desarrollar un modelo de inclusión universal. La utilización de recursos tecnológicos está cada vez más presente en los museos, en la educación y en la sociedad en general, provocando un aumento de investigaciones sobre educación patrimonial y nuevas tecnologías. Estas investigaciones abordan la educación patrimonial desde el m-learning (Angelopoulou et al., 2012; Ibáñez et al., 2012), el e-learning (Lobovikov-Katz et al., 2014), la aplicación didáctica de modelos digitales (Forte, 2007; Vicent, Rivero \& Feliu, 2015), y el concepto de edutainment y serious games (Haddad, 2016). Relacionadas de manera más específica con el patrimonio inmaterial, destacan las investigaciones realizadas dentro del proyecto i-Treasures, que se integra en el $7^{\circ}$ Programa Marco de la Unión Europea. Este proyecto ha generado una plataforma que contiene recursos educativos innovadores sobre patrimonio cultural inmaterial (Ott 
Estudios Pedagógicos XLIII, $\mathrm{N}^{\circ}$ 4: 69-89, 2017

EVALUACIÓN DE PROGRAMAS EDUCATIVOS SOBRE PATRIMONIO CULTURAL INMATERIAL

\& Pozzi, 2011; Ott, Dagnino \& Pozzi, 2015). Esta relación entre las TIC y el Patrimonio Cultural Inmaterial es la base del proyecto ICHPEDIA desarrollado en Corea, cuyo principal objetivo es elaborar un inventario nacional que sea utilizado para la difusión y sensibilización de esta tipología patrimonial (Soon, 2014). Finalmente, hacemos alusión a un proyecto desarrollado en Turquía dentro del ámbito formal, que plantea un programa educativo sobre patrimonio intangible utilizando la aplicación tecnológica educativa "WebQuest" (Kasapoglu, 2016).

Las investigaciones referidas están sustentadas sobre bases teóricas que han desarrollado un marco de referencia para una disciplina relativamente reciente, y que hasta hace varias décadas no disponía de bagaje teórico. A este respecto destacamos el estudio realizado por Fontal e Ibáñez (2017) que ofrece un análisis de la evolución de la investigación en educación patrimonial a través de indicadores de alto impacto y publicaciones de artículos en las bases de datos de referencia internacionales WOS y Scopus. Dentro de este marco de referencia destacan autores como Cuenca (2003), quien aborda la educación patrimonial desde la didáctica de las ciencias sociales y Fontal (2003) desde una perspectiva más identitaria. Copeland (2006) y Texeira (2006) plantean la educación patrimonial desde el gran potencial didáctico que presenta para trabajar la ciudadanía, la identidad y la democracia. Lobovikov-Katz (2009) entiende la educación patrimonial como una disciplina capaz de generar y garantizar procesos como la sensibilización o socialización del patrimonio cultural. En torno a la educación patrimonial y su didáctica, destacamos a Calaf (2009), por sentar las bases epistemológicas y Fontal (2008) que entiende la dimensión humana como un elemento imprescindible en la didáctica del patrimonio. Toda la literatura y las investigaciones desarrolladas están acrisoladas por el objetivo de situar la educación patrimonial como una disciplina esencial en la salvaguarda y gestión del patrimonio cultural, tanto tangible como intangible. Esto se debe a que entendemos la educación patrimonial como el motor que acciona la cadena de sensibilización, "conocer para comprender, comprender para respetar y respetar para valorar" (Fontal, 2003, p. 209). La educación patrimonial garantiza la atribución de valores a los bienes culturales por parte de la sociedad, pasando estos a formar parte de su patrimonio, que querrá cuidar, disfrutar y trasmitir. Muchos estudios defienden la posición de la educación patrimonial como disciplina fundamental para la gestión y conservación del patrimonio cultural (Fontal \& Juanola, 2015) e incluso para el beneficio social de la población (Buckley \& Graves, 2016), ya que entienden que la misma es capaz de garantizar procesos necesarios para trasformar los bienes culturales en patrimonio para la sociedad.

Este tema preocupa dentro de nuestro ámbito nacional a múltiples marcos normativos e institucionales. En el año 2006, España ratifica la Convención para la Salvaguarda del Patrimonio Inmaterial, que establece cinco ámbitos o contextos en los que se manifiesta: "las tradiciones y expresiones orales; las artes del espectáculo; los usos sociales; rituales y actos festivos; los conocimientos y usos relacionados con la naturaleza y el universo; y las técnicas artesanales tradicionales" (UNESCO, 2003, p. 2). Desde entonces se comienza a trabajar con la finalidad de cumplir los objetivos planteados en la convención. Este proceso culmina en 2011, con la entrada en vigor del Plan Nacional para la Salvaguarda del Patrimonio Cultural Inmaterial. Pero la preocupación en torno a esta materia continúa, y se desarrolla la Ley 10/2015, para la Salvaguardia del Patrimonio Cultural Inmaterial. Ambas normativas nacionales perfilan los ámbitos o contextos en los que se manifiesta el Patrimonio Cultural Inmaterial (González \& Querol, 2014). 
Estudios Pedagógicos XLIII, $\mathrm{N}^{\circ}$ 4: 69-89, 2017 EVALUACIÓN DE PROGRAMAS EDUCATIVOS SOBRE PATRIMONIO CULTURAL INMATERIAL

Dentro de estas normativas se presentan medidas educativas que instan a las administraciones educativas a velar por la inclusión del conocimiento y respeto al patrimonio inmaterial en los contenidos educativos. Estas nuevas medidas nos recuerdan la importancia de la educación para la gestión y conservación del patrimonio, ya planteada en 2013 en el Plan Nacional de Educación y Patrimonio (en adelante PNEyP) (Domingo, Fontal \& Ballesteros, 2013). Dentro de las acciones del PNEyP, financiado por el Instituto del Patrimonio Cultural de España (IPCE), se desarrolla el presente estudio requerido para la consecución de sus objetivos en el marco del proyecto de investigación EDU201565716-C2-2R $\mathrm{R}^{1}$

Este estudio está estrechamente vinculado con los objetivos del PNEyP, ya que busca cumplir y garantizar la investigación continua y el seguimiento de las acciones y líneas proyectuales desarrolladas en materia de educación patrimonial (Domingo et al., 2013). La investigación responde a una evaluación secuenciada de una selección de programas educativos sobre patrimonio cultural intangible, que surge ante la necesidad de investigación en torno al mismo debido al reconocimiento legislativo más reciente en comparación con otras tipologías patrimoniales, y cuyas acciones educativas necesitan -muchas de ellas de gran valor pedagógico-ser categorizadas y analizadas. La finalidad del mismo es conocer el estado de la cuestión, así como las fortalezas y debilidades de los programas educativos, que ayuden a establecer criterios y parámetros para el diseño de materiales educativos estructurados que permitan adaptarse a múltiples contextos y colectivos, superando el modelo lineal y cerrado. Esta evaluación secuenciada de programas consta de varias fases. En el presente artículo se presentan los resultados de la primera fase de evaluación relativa al análisis estadístico-descriptivo y correlacional de los programas, que pretende conocer sus enfoques y categorías. Este aspecto nos permitirá vislumbrar el estado de la cuestión en un campo escasamente analizado, y ayudará a definir los estándares de calidad relacionados con el diseño, la implementación y los resultados (Stake, 2006).

\section{EL MÉTODO OEPE}

El estudio que presentamos forma parte de una investigación más amplia dentro del Observatorio de Educación Patrimonial en España. El observatorio ha definido un método (Fontal, 2016) para inventariar, analizar y evaluar programas educativos, y tiene entre sus objetivos dar a conocer sus resultados, que ayudan a diagnosticar el estado de la educación patrimonial, tanto en España como en el ámbito internacional (Fontal \& Gómez-Redondo, 2016; Fontal \& Marín, 2016; Marín et al., 2017). Desde el Observatorio, en el momento actual, hay inventariados en la base de datos digital para investigadores $n=1682$ programas de educación patrimonial desarrollados en el ámbito de la educación formal, no formal e informal, tanto nacionales como internacionales.

Título: "Evaluación de los aprendizajes en programas de educación patrimonial centrados en los procesos de sensibilización, valorización y socialización del patrimonio cultural". Fecha de concesión: 1-1-2016 a 31-12-2018. IP: Olaia Fontal Merillas. Dentro del Programa Estatal de Investigación, Desarrollo e Innovación Orientada a los Retos de la Sociedad, Convocatoria 2015, Modalidad 1: «Proyectos de I+D+I». Entidades financiadoras: MINECO + FONDOS FEDER. 
Estudios Pedagógicos XLIII, $N^{\circ}$ 4: 69-89, 2017

EVALUACIÓN DE PROGRAMAS EDUCATIVOS SOBRE PATRIMONIO CULTURAL INMATERIAL

\subsection{CRITERIOS PARA LA SELECCIÓN DE LA MUESTRA}

La muestra de nuestra investigación se corresponde con un muestreo intencional que ha sido entresacado de la base de datos digital del OEPE, realizando una selección de nuestros descriptores de interés: pertenencia a la categoría de Patrimonio Inmaterial y país de localización: España. Estos programas han sido localizados empleando términos y descriptores del campo semántico relativos al PCI, y utilizando buscadores oficiales del Ministerio de Educación Cultura y Deporte, así como buscadores genéricos. Los programas resultantes son sometidos a una serie de criterios de inclusión y exclusión (Tabla I).

Tabla 1. Criterios de inclusión y exclusión de los programas educativos para el inventario

\begin{tabular}{|c|c|}
\hline Criterios de Inclusión & Criterios de Exclusión \\
\hline $\begin{array}{l}\text { Contener el término patrimonio cultural } \\
\text { inmaterial o los ámbitos del PCI que establece la } \\
\text { Convención UNESCO } 2003 \text {. }\end{array}$ & Web o portal que únicamente informa. \\
\hline Contener algún término afín al ámbito educativo. & Se trata únicamente de material divulgativo. \\
\hline $\begin{array}{l}\text { Actividad que realiza un museo dentro del ámbito } \\
\text { formal o el ámbito informal. }\end{array}$ & $\begin{array}{l}\text { Webs de museos. Si sus propuestas no son } \\
\text { referidas al patrimonio. }\end{array}$ \\
\hline $\begin{array}{l}\text { Organizado por una institución pública, privada o } \\
\text { que implique varias entidades. }\end{array}$ & \\
\hline $\begin{array}{l}\text { Generado en España, ámbito nacional, autonómico, } \\
\text { regional o local. }\end{array}$ & \\
\hline Diseño educativo con objetivos. & \\
\hline Se dirige a más de un público. & \\
\hline $\begin{array}{l}\text { Se dirige, de forma explícita, a públicos con } \\
\text { necesidades educativas específicas. }\end{array}$ & \\
\hline Se trata de un curso o programa de formación. & \\
\hline $\begin{array}{l}\text { Formato web con interacción de aprendizaje o } \\
\text { propuestas al usuario. }\end{array}$ & \\
\hline
\end{tabular}

Fuente: elaboración propia.

Así, de los 223 programas localizados, y después de someter los mismos a los criterios de inclusión y exclusión, obtenemos una muestra de 202 programas que procedemos a inventariar y que constituyen la muestra final a analizar.

\subsection{INSTRUMENTOS DE INVENTARIOY ANÁLISIS}

El método cuenta con una ficha de inventario basada en descriptores para facilitar el registro de los programas y su gestión. Este instrumento de registro esta refrendado por su contenido, pues dispone de todos aquellos campos necesarios para plasmar todas las categorías propias 
Estudios Pedagógicos XLIII, N 4: 69-89, 2017 EVALUACIÓN DE PROGRAMAS EDUCATIVOS SOBRE PATRIMONIO CULTURAL INMATERIAL

de un programa educativo. Los datos recogidos en las fichas de inventario son exportamos a una hoja Excel, y posteriormente al programa de análisis estadístico SPSS (Versión 21.0), que nos permite obtener las frecuencias buscadas, así como valores porcentuales.

\subsubsection{La ficha de inventario}

La ficha para el inventario de programas está organizada y sistematizada en 42 campos, y abarca los elementos más significativos del diseño educativo de cada programa. La organización consta de cuatro grandes apartados:

- Localización e identificación: En este primer apartado se clasifica e identifica el proyecto, se le asigna un nombre o título específico que posteriormente permita su búsqueda a través del programa diseñado; lugar donde se realiza el programa, ciudad y comunidad; datos de los responsables del proyecto y a qué institución u organización pertenecen. Se describen los datos de contacto con los organizadores y responsables, así como la página web en el caso de tenerla.

- Descripción del programa: En la descripción del programa se desarrollan los aspectos básicos: tipología de patrimonio, tipología de proyecto, adaptación a discapacitados y tipo, breve descripción, duración, lugar, profesionales encargados, disposición de documentos físicos y repercusiones sociales y mediáticas de la programación.

- Diseño educativo: En este apartado se describen los diferentes contenidos sobre la estructura didáctica del proyecto. Se introducen los datos relativos a las características educativas del programa: justificación del proyecto, objetivos, contenidos principales, orientación metodológica, estrategias de enseñanza aprendizaje, recursos empleados, datos sobre el educador que implementa el programa, sistemas y las herramientas de evaluación, así como la temporalización del mismo y la repercusión social y mediática que ha podido tener con posterioridad.

- Dosier documental: Recopilación de todos los documentos que aporta el programa, memoria, imágenes, videos, materiales didácticos, materiales de evaluación y cualquier otro documento disponible.

\subsection{PROCEDIMIENTO}

Este proceso secuencial, desde la búsqueda hasta la evaluación, se divide en cuatro partes diferenciadas:

- Búsqueda y localización de programas conforme a una serie de indicadores de búsqueda (Tabla 1).

- Discriminación. De la relación de 223 programas localizados, tras la aplicación de los criterios de inclusión y de exclusión, se obtiene una muestra 202 programas.

- Inventario. Se utiliza la ficha digital de recogida de datos, completando todos los campos y descriptores. Los programas son inventariados en base a su tipología de programa, en función de la mayor consistencia y conceptualización de su diseño educativo (Tabla 2), y se clasifican en base a 16 tipologías en función de su naturaleza educativa: programa educativo, proyecto educativo, diseño educativo, 
Estudios Pedagógicos XLIII, $\mathrm{N}^{\circ}$ 4: 69-89, 2017

EVALUACIÓN DE PROGRAMAS EDUCATIVOS SOBRE PATRIMONIO CULTURAL INMATERIAL

plan educativo, acción educativa, proyecto de mejora, actividad aislada, taller, recurso didáctico, herramienta didáctica, ruta o itinerario didáctico, curso, jornada, congreso, seminario y concurso.

- Análisis. Los datos inventariados son exportados al programa de análisis estadístico, donde realizamos, en primer lugar, un análisis estadístico-descriptivo y, posteriormente, un análisis correlacional.

Análisis estadístico-descriptivo. Se analizan los programas atendiendo a:

a. Tipo de programa en función de las 16 acciones educativas.

b. Ámbito donde se desarrolla, educación formal, no formal e informal.

c. Tipo de público al que se dirige, alumnado o público en general.

d. Adaptación a personas con diversidad funcional.

e. Diseño educativo.

Análisis correlacional. Se analiza la relación entre las siguientes variables:

a. Tipo de proyecto * Tipo de público.

b. Ámbito del programa * diseño educativo.

\section{RESULTADOS}

Los programas educativos como conjunto de procesos, proyectos, intervenciones, planificaciones, acciones, actividades y estudios de carácter didáctico, dirigidos hacia la consecución de unos objetivos previamente fijados, constituyen la muestra de los 202 programas sobre PCI. Son la base a través de la cual vamos a analizar sus enfoques y categorías.

\subsection{TIPOLOGÍA DE PROGRAMA EDUCATIVO}

Tras declarar el PNSPCI (2011) como valores a proteger las formas de vida, las prácticas sociales, los conocimientos, las técnicas y las mentalidades de los diversos individuos y grupos, la generalización de los términos "intangible" o "inmaterial" durante los últimos años da sus frutos a la vista del reconocimiento de la doble realidad, o como las corrientes teóricas apuntan, ampliando los horizontes de la conceptualización del término patrimonio cultural (Fontal, 2016). Este desarrollo se manifiesta también en el ámbito de la educación patrimonial, con la aparición en la última década de múltiples y diversos programas educativos sobre patrimonio cultural inmaterial, existiendo representación en todas las tipologías de programas. Si los objetivos de los distintos programas se establecen en función de su tipología -ya que estas presentan diferentes niveles de conceptualización-, cabe preguntarse cuáles son las tipologías más utilizadas actualmente (Tabla 2). 
Estudios Pedagógicos XLIII, N 4: 69-89, 2017 EVALUACIÓN DE PROGRAMAS EDUCATIVOS SOBRE PATRIMONIO CULTURAL INMATERIAL

Tabla 2. Frecuencias y porcentajes de los tipos de los programas educativos

\begin{tabular}{|c|c|c|c|c|c|}
\hline \multicolumn{2}{|r|}{ Tipo de Proyecto } & & & Porcentaje & Porcentaje \\
\hline \multirow{17}{*}{ Válidos } & Programa educativo & 41 & 20,3 & 20,3 & 20,3 \\
\hline & Proyecto educativo & 27 & 13,4 & 13,4 & 33,7 \\
\hline & Diseño didáctico & 30 & 14,9 & 14,9 & 48,5 \\
\hline & Recurso didáctico & 15 & 7,4 & 7,4 & 55,9 \\
\hline & Herramientas didácticas & 3 & 1,5 & 1,5 & 57,4 \\
\hline & Acción educativa & 17 & 8,4 & 8,4 & 65,8 \\
\hline & Actividad aislada & 7 & 3,5 & 3,5 & 69,3 \\
\hline & Taller & 20 & 9,9 & 9,9 & 79,2 \\
\hline & Proyecto de mejora & 4 & 2,0 & 2,0 & 81,2 \\
\hline & Concurso & 10 & 5,0 & 5,0 & 86,1 \\
\hline & Itinerario didáctico & 16 & 7,9 & 7,9 & 94,1 \\
\hline & Plan educativo & 2 & 1,0 & 1,0 & 95,0 \\
\hline & Congreso & 1 &, 5 &, 5 & 95,5 \\
\hline & Jornadas & 3 & 1,5 & 1,5 & 97,0 \\
\hline & Seminario & 2 & 1,0 & 1,0 & 98,0 \\
\hline & Curso & 4 & 2,0 & 2,0 & 100,0 \\
\hline & Total & 202 & 100,0 & 100,0 & \\
\hline
\end{tabular}

Fuente: elaboración propia

El porcentaje más alto $(20,3 \%)$ corresponde a los programas educativos, seguido por los diseños didácticos $(14,9 \%)$ y los proyectos educativos $(13,4 \%)$. En los porcentajes más bajos se encuentran las tipologías de congresos $(0,5 \%)$, seminarios y planes educativos (1\%) (Gráfico 1). 
Estudios Pedagógicos XLIII, N 4: 69-89, 2017

EVALUACIÓN DE PROGRAMAS EDUCATTVOS SOBRE PATRIMONIO CULTURAL INMATERIAL

Gráfico 1. Porcentajes de las tipologías de los programas educativos

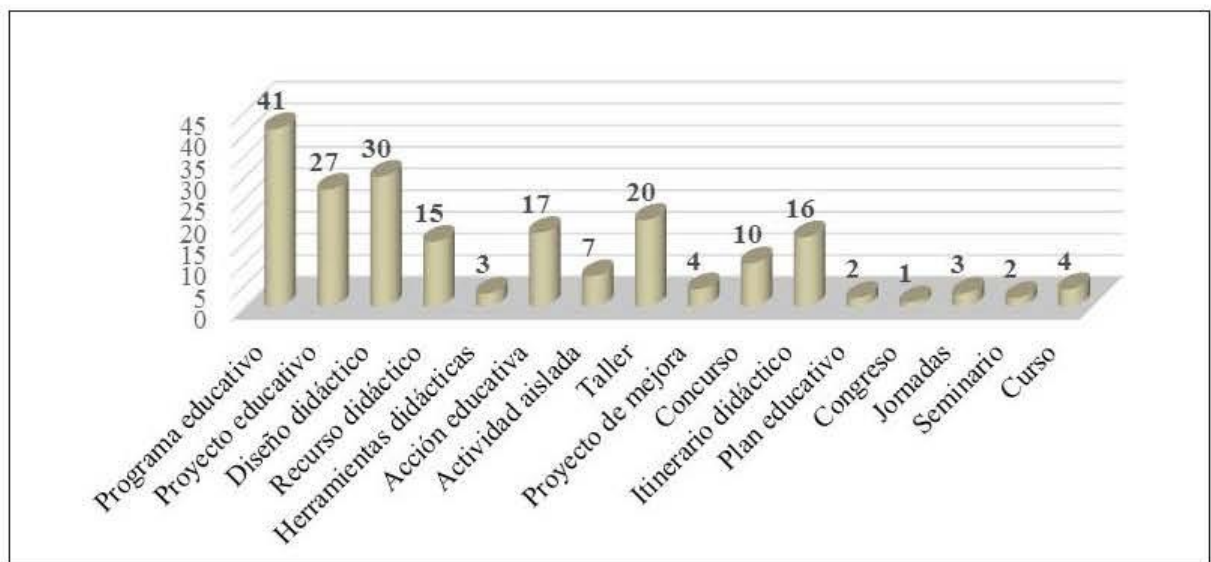

Fuente: elaboración propia

\section{2. ÁMBITO EDUCATIVO}

Con el fin de acercarnos al ámbito donde se desarrolla la actuación, diferenciamos los siguientes marcos de la actuación (Cuadrado, 2008):

- Educación formal: aprendizajes regulados por instituciones con competencia educativa.

- Educación no formal: acciones educativas no reguladas por normas, sino por el ejercicio de instituciones culturales.

- Educación informal: acciones educativas no pautadas, realizadas por individuos o colectivos.

En la Tabla 3 mostramos los resultados obtenidos en relación con el ámbito educativo dentro del cual se desarrollan los programas.

Tabla 3. Frecuencias y porcentajes de los ámbitos de los programas educativos

\begin{tabular}{|l|l|c|c|c|c|}
\hline \multicolumn{2}{|c|}{ Ámbito de los Programas } & Frecuencia & Porcentaje & $\begin{array}{c}\text { Porcentaje } \\
\text { válido }\end{array}$ & $\begin{array}{c}\text { Porcentaje } \\
\text { acumulado }\end{array}$ \\
\cline { 3 - 6 } & Educación formal & 28 & 13,9 & 13,9 & 13,9 \\
\cline { 2 - 6 } & Educación no formal & 152 & 75,2 & 75,2 & 89,1 \\
\cline { 2 - 6 } & Educación informal & 22 & 10,9 & 10,9 & 100,0 \\
\cline { 2 - 6 } & Total & 202 & 100,0 & 100,0 & \\
\hline
\end{tabular}

Fuente: elaboración propia. 
Estudios Pedagógicos XLIII, N 4: 69-89,2017 EVALUACIÓN DE PROGRAMAS EDUCATIVOS SOBRE PATRIMONIO CULTURAL INMATERIAL

El ámbito en el cual se desarrollan con más frecuencia los programas educativos sobre el PCI es en la educación no formal, con una amplia diferencia sobre la educación formal y la educación informal. Así tenemos la educación no formal, con 152 programas $(75,2 \%)$; la educación formal, con 28 programas ( $13,9 \%$ ) y la educación informal con 22 programas, que supone solamente un $10,9 \%$ (Gráfico 2).

Grafico 2. Porcentajes de las tipologías de los programas educativos

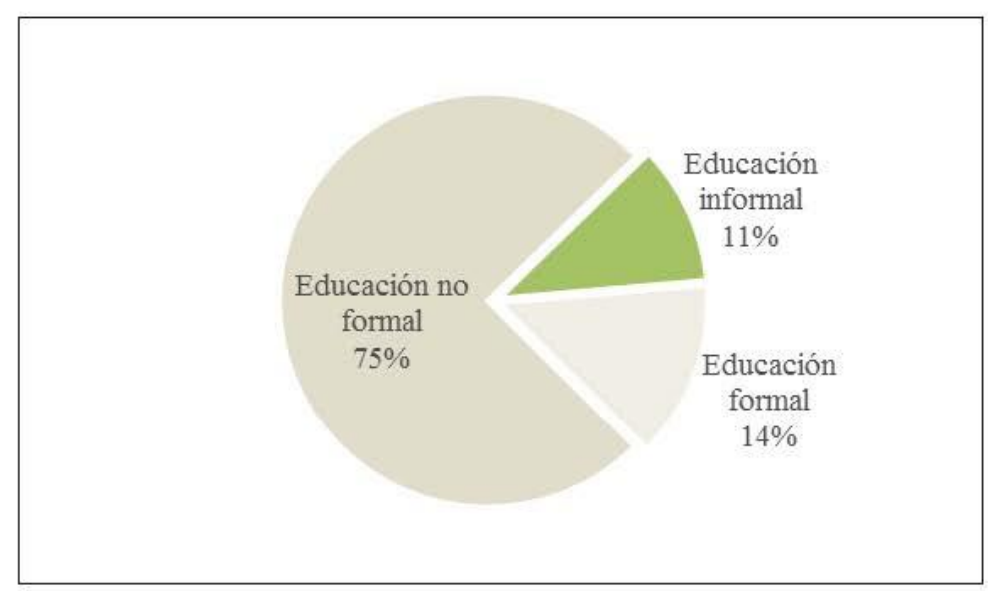

Fuente: elaboración propia.

\subsection{DESTINATARIOS}

Atendiendo a cuál es el público mayoritario al que se dirigen los programas, analizamos los programas teniendo en cuenta dos tipos de público: Alumnado y Público general.

Tabla 4. Frecuencias y porcentajes de tipo de público de los programas educativos

\begin{tabular}{|c|l|c|c|c|c|}
\hline \multicolumn{2}{|c|}{ Tipo de público } & \multicolumn{2}{|c|}{} \\
\cline { 3 - 6 } & Frecuencia & Porcentaje & $\begin{array}{c}\text { Porcentaje } \\
\text { válido }\end{array}$ & $\begin{array}{c}\text { Porcentaje } \\
\text { acumulado }\end{array}$ \\
\hline \multirow{3}{*}{ Válidos } & Alumnado & 97 & 48,0 & 48,0 & 48,0 \\
\cline { 2 - 6 } & Público general & 105 & 52,0 & 52,0 & 100,0 \\
\cline { 2 - 6 } & Total & 202 & 100,0 & 100,0 & \\
\hline
\end{tabular}

Fuente: elaboración propia. 
Estudios Pedagógicos XLIII, N 4: 69-89, 2017

EVALUACIÓN DE PROGRAMAS EDUCATIVOS SOBRE PATRIMONIO CULTURAL INMATERIAL

Con el código Público general, encontramos más de la mitad de los programas educativos, un $52 \%$, al no especificar el tipo de público al que se dirige se podría inferir que se refiere a programas que abarcan a la mayoría de los destinatarios posibles, puesto que muestra una generalización. El $48 \%$ restante está dirigido hacia el Alumnado. Dentro del alumnado, la etapa educativa con mayor número corresponde a la educación primaria (Gráfico 3).

Gráfico 3. Porcentajes de tipos de público de los programas educativos

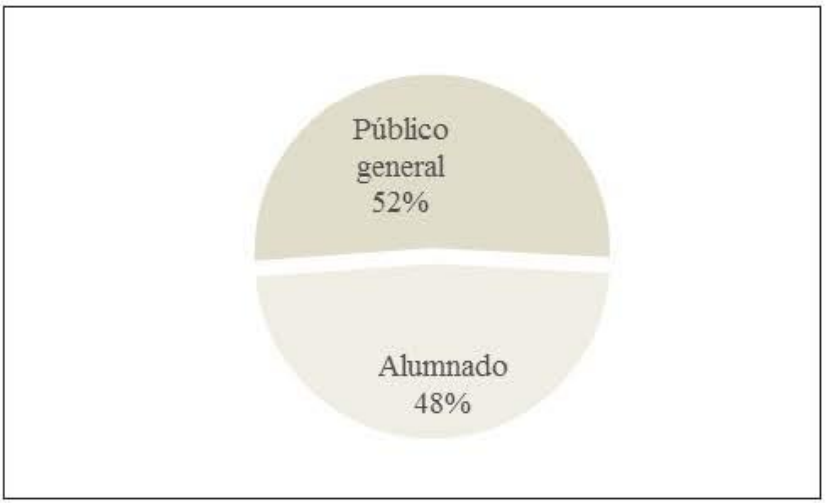

Fuente: elaboración propia.

\subsection{ADAPTACIÓN A PERSONAS CON DIVERSIDAD FUNCIONAL}

En cuanto a los programas dirigidos a personas con diversidad funcional o necesidades educativas especiales, consideramos que el propio concepto de patrimonio sitúa a este como herramienta fundamental para trabajar la diversidad. De acuerdo con Fontal y Marín (2016) es necesario un cambio de paradigma hacia la cultura de la inclusión que entienda la diversidad como una realidad presente en todas las esferas de la sociedad. Por ello, en la Tabla 5 analizamos la frecuencia de programas que presentan adaptación a personas con diversidad funcional. Es decir, Adaptado a personas con diversidad funcional, No adaptado.

Tabla 5 . Frecuencias y porcentajes de programas adaptados a personas con diversidad funcional

\begin{tabular}{|l|l|c|c|c|c|}
\cline { 2 - 5 } \multicolumn{2}{c|}{} & Frecuencia & Porcentaje & $\begin{array}{c}\text { Porcentaje } \\
\text { válido }\end{array}$ & $\begin{array}{c}\text { Porcentaje } \\
\text { acumulado }\end{array}$ \\
\hline Válidos & $\begin{array}{l}\text { Adaptado a personas con } \\
\text { diversidad funcional }\end{array}$ & 9 & 4,5 & 4,5 & 4,5 \\
\cline { 2 - 6 } & No habilitado & 193 & 95,5 & 95,5 & 100,0 \\
\cline { 2 - 6 } & Total & 202 & 100,0 & 100,0 & \\
\hline
\end{tabular}

Fuente : elaboración propia 
Estudios Pedagógicos XLIII, N 4: 69-89,2017 EVALUACIÓN DE PROGRAMAS EDUCATIVOS SOBRE PATRIMONIO CULTURAL INMATERIAL

De los 202 programas educativos inventariados solamente 9 están adaptados a personas con diversidad funcional, lo que supone el $(4,5 \%)$ sobre el total. Debemos destacar que, de los 9 programas adaptados a discapacitados, solamente uno de ellos cuenta con recursos humanos (Gráfico 4).

Gráfico 4. Porcentajes adaptación a discapacitados de los programas educativos

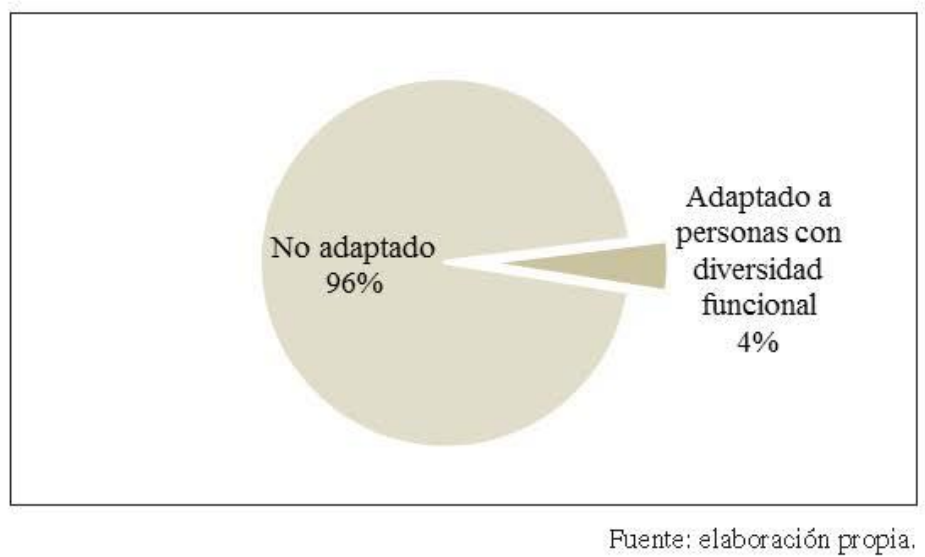

\subsection{DISEÑO EDUCATIVO}

Para el análisis descriptivo de este apartado relativo a las características del diseño educativo, y con el fin de valorar la estructura didáctica de los programas, hemos clasificado los programas en dos grupos: "con diseño educativo" y "sin diseño educativo" (Tabla 6). Incluimos dentro de los programas con diseño educativo aquellos que plantean y desarrollan los siguientes parámetros:

- Justificación de los planteamientos (si la hay).

- Los objetivos didácticos, atendiendo a la terminología verbal tal como conocer, sensibilizar, valorar comprender y reflexionar.

- Los contenidos patrimoniales.

- La orientación metodológica, activa, participativa, lúdica, práctica, etc.

- Las estrategias de enseñanza aprendizaje.

- Adaptación.

- Temporalización del programa.

- Evaluación del programa y de los resultados del programa con respecto a la adquisición de conocimientos y valores planteados en los objetivos. 
Estudios Pedagógicos XLIII, Nº 4:69-89, 2017

EVALUACIÓN DE PROGRAMAS EDUCATIVOS SOBRE PATRIMONIO CULTURAL INMATERIAL

Tabla 6 . Frecuencias y porcentajes del diseño educativo de los programas educativos

\begin{tabular}{|c|c|c|c|c|c|}
\hline & seño educativo & & & Porcentaje & Porcentaje \\
\hline & Diseño educativo & 117 & 57,9 & 57,9 & 57,9 \\
\hline Válidos & Sin diseño educativo & 85 & 42,1 & 42,1 & 100,0 \\
\hline & Total & 202 & 100,0 & 100,0 & \\
\hline
\end{tabular}

Fuente: elaboración propia.

En lo relativo a los planteamientos metodológicos en los que se fundamentan los programas educativos, únicamente el $57,9 \%$ de los programas presentan diseño didáctico motivo de estudio. Frente al $42,1 \%$ restante que no define un diseño didáctico (Gráfico 5 ), es decir, que no desarrollan las partes necesarias que conforman un diseño educativo completo, o solo se abordan alguna de sus partes, de manera muy superficial.

Grafico 5. Porcentajes de diseño educativo de los programas educativos

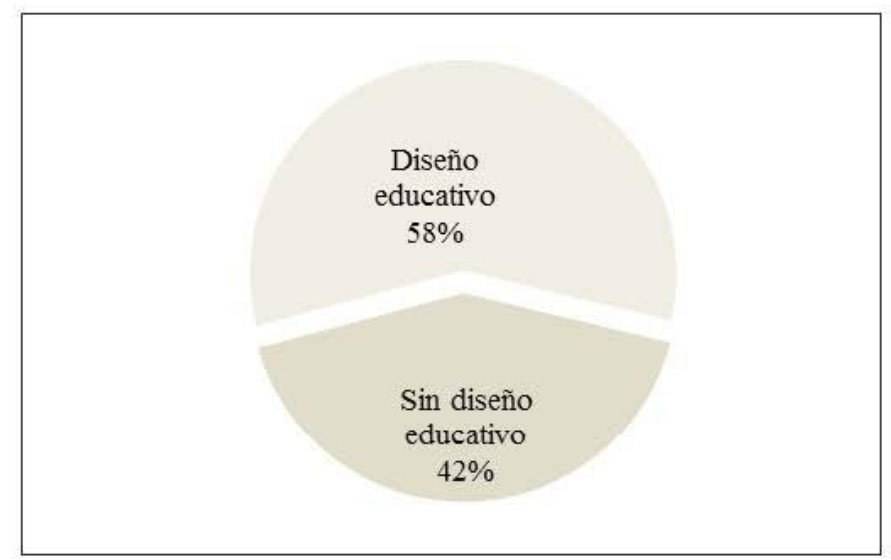

Fuente: elaboración propia.

\subsection{CONTINGENCIAS ENTRE LAS VARIABLES}

A continuación, empleamos la tabla de contingencias para explorar y analizar la relación entre las siguientes variables:

- $\quad$ Tipo de Proyecto * Destinatarios.

- Ámbito educativo* Diseño Educativo. 
Estudios Pedagógicos XLIII, N 4: 69-89, 2017 EVALUACIÓN DE PROGRAMAS EDUCATIVOS SOBRE PATRIMONIO CULTURAL INMATERIAL

En primer lugar, relacionamos la categoría tipo de programa con el tipo de público (Tabla 7),

Tabla 7. Tabla de contingencia Tipo de Proyecto * Tipo de Público

\begin{tabular}{|c|c|c|c|c|}
\hline \multirow{2}{*}{\multicolumn{2}{|c|}{ Recuento }} & \multicolumn{2}{|c|}{ Tipo de público } & \multirow{3}{*}{$\begin{array}{c}\text { Total } \\
41\end{array}$} \\
\hline & & \multirow{2}{*}{$\frac{\text { Alumnado }}{25}$} & \multirow{2}{*}{$\frac{\text { Público general }}{16}$} & \\
\hline \multirow{16}{*}{ Tipo de Proyecto } & Programa educativo & & & \\
\hline & Proyecto educativo & 10 & 17 & 27 \\
\hline & Diseño didáctico & 28 & 2 & 30 \\
\hline & Recurso didáctico & 6 & 9 & 15 \\
\hline & Herramientas didácticas & 0 & 3 & 3 \\
\hline & Acción educativa & 8 & 9 & 17 \\
\hline & Actividad aislada & 0 & 7 & 7 \\
\hline & Taller & 12 & 8 & 20 \\
\hline & Proyecto de mejora & 0 & 4 & 4 \\
\hline & Concurso & 5 & 5 & 10 \\
\hline & Itinerario didáctico & 2 & 14 & 16 \\
\hline & Plan educativo & 0 & 2 & 2 \\
\hline & Congreso & 0 & 1 & 1 \\
\hline & Jornadas & 0 & 3 & 3 \\
\hline & Seminario & 0 & 2 & 2 \\
\hline & Curso & 1 & 3 & 4 \\
\hline \multicolumn{2}{|l|}{ Total } & 97 & 105 & 202 \\
\hline
\end{tabular}

Fuente: elaboración propia.

En la Tabla 7 podemos apreciar las tipologías de programas cuyos diseños educativos presentan mayor consistencia y conceptualización. Es decir, aquellas tipologías de programas que presentan un diseño educativo planificado y completo se dirigen en mayor medida al alumnado, entre ellos los programas educativos y los diseños didácticos. Por otra parte, los programas de menor conceptualización, o cuya definición no contempla diseño educativo, se desarrollan entre el público general, como son itinerarios didácticos, talleres y jornadas. Debemos destacar la falta de desarrollo de ciertos programas para el alumnado, si bien, dentro de los programas dirigidos al público en general, también podemos encontrar al alumnado. De igual modo, en la representación gráfica (Gráfico 6) podemos observar que ambas líneas de tendencia se muestran ascendentes hacia los programas cuyos diseños educativos son más consistentes; sin embargo, la del alumnado lo hace en mayor medida. 
Estudios Pedagógicos XLIII, N 4: 69-89, 2017

EVALUACIÓN DE PROGRAMAS EDUCATIVOS SOBRE PATRIMONIO CULTURAL INMATERIAL

Gráfico 6. Contingencia Tipo de Proyecto * Tipo de Público

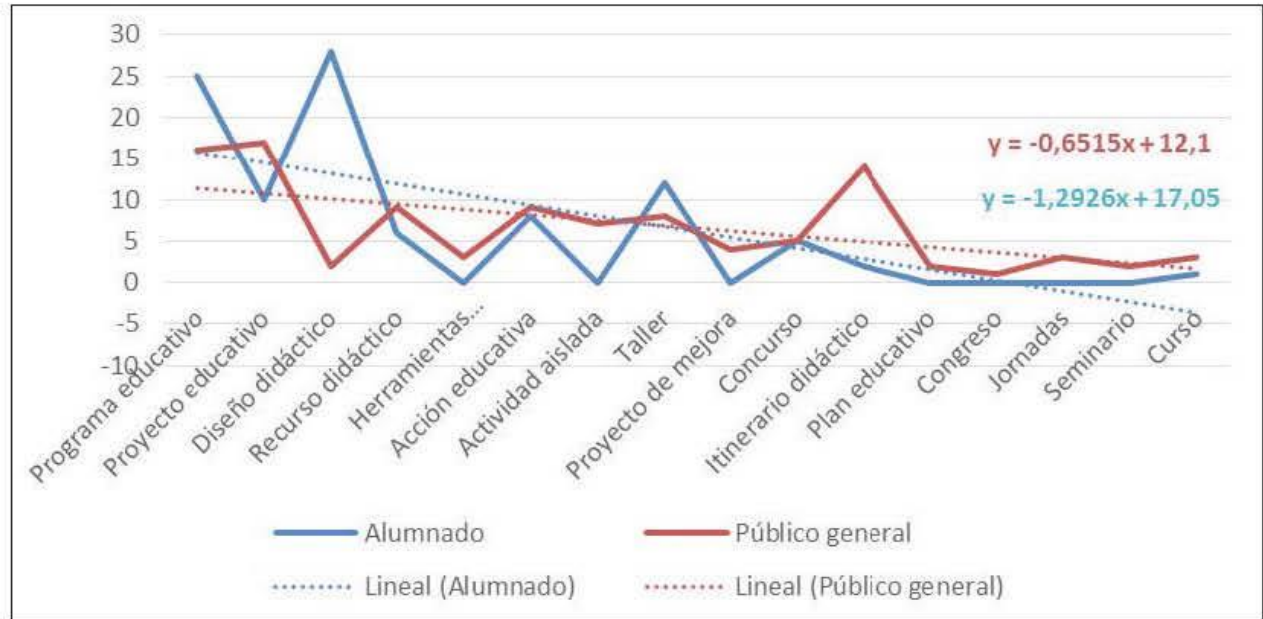

Fuente: elaboración propia

Mostramos a continuación la relación entre el ámbito educativo, donde son implementados los programas y el diseño educativo (Tabla 8).

Tabla 8. Tabla de contingencia Ámbito de los Programas * Diseño Educativo

\begin{tabular}{|l|l|c|c|c|}
\hline \multirow{2}{*}{ Recuento } & \multicolumn{2}{|c|}{ Diseño educativo } & \multirow{2}{*}{ Total } \\
\cline { 3 - 5 } & \multirow{4}{*}{ Ámbito educativo } & $\begin{array}{c}\text { Diseño } \\
\text { educativo }\end{array}$ & $\begin{array}{c}\text { Sin diseño } \\
\text { educativo }\end{array}$ & \\
\hline & Educación formal & 19 & 1 & 20 \\
\cline { 2 - 5 } & Educación no formal & 92 & 65 & 157 \\
\cline { 2 - 5 } & Educación informal & 6 & 19 & 25 \\
\hline \multirow{2}{*}{ Total } & 117 & 85 & 202 \\
\hline
\end{tabular}

Fuente: elaboración propia.

En la educación formal, casi la totalidad de los programas presentan diseño educativo. En la educación no formal, existe cierta proporción entre programas con diseño educativo y sin diseño educativo. La educación informal presenta menos programas con diseño educativo. Gráficamente, podemos observar cómo la línea de tendencia diseño educativo, es ascendente hacia la educación formal. En el caso contrario, la línea de tendencia sin diseño educativo es ascendente hacia la educación informal (Gráfico 7). 
Estudios Pedagógicos XLIII, N 4: 69-89, 2017 EVALUACIÓN DE PROGRAMAS EDUCATIVOS SOBRE PATRIMONIO CULTURAL INMATERIAL

Gráfico 7. Contingencia Ámbito educativo de los Programas * Diseño Educativo

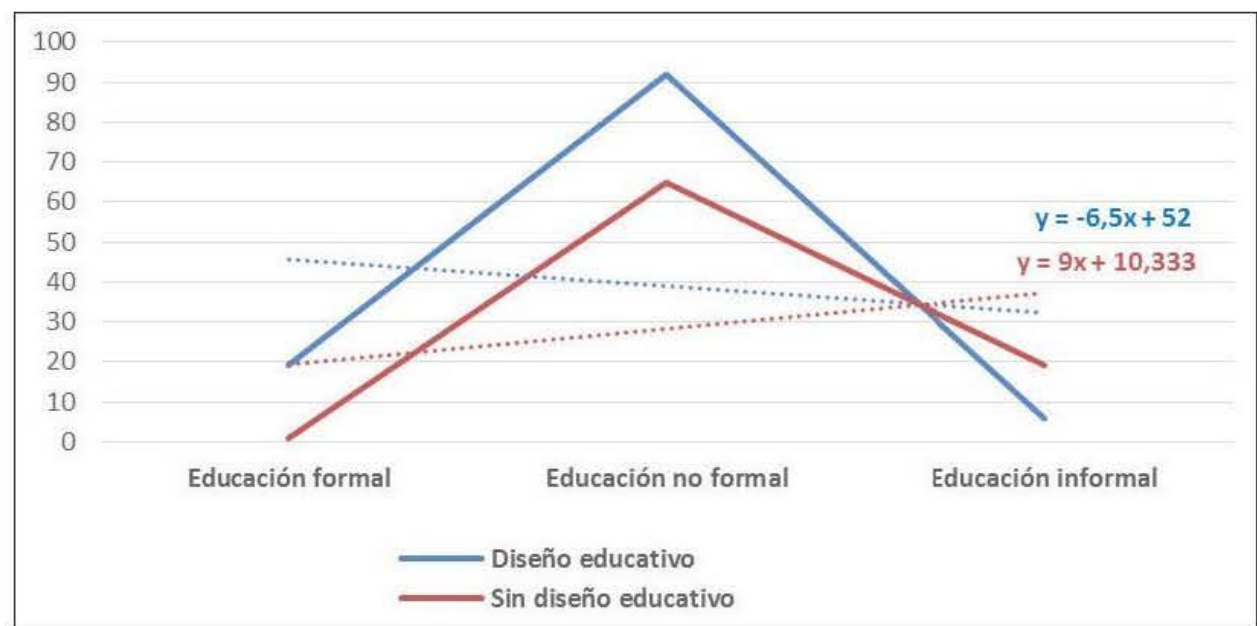

Fuente: elaboración propia.

\section{CONCLUSIONES Y DISCUSIÓN: AUSENCIAS Y PROSPECCIÓN EN LA EDUCACIÓN PATRIMONIAL}

El dinamismo intrínseco en el concepto de patrimonio cultural influye en la evolución del término y deriva en nuevos bienes patrimoniales, como son los bienes inmateriales. Este aspecto también provoca una evolución en el ámbito de la educación patrimonial, con la aparición de programas educativos sobre patrimonio cultural inmaterial que deben ser analizados y evaluados. En este sentido, este artículo ofrece un análisis relacional de los enfoques y categorías de los programas educativos desarrollados en tomo al patrimonio inmaterial, que se desarrolla dentro de un proceso evaluativo secuenciado de los mismos, a su vez enmarcado dentro del Observatorio de Educación Patrimonial en España (Fontal, 2016). La investigación ha mostrado que la gran deficiencia detectada es el gran porcentaje de programas analizados que no presentan un diseño educativo estructurado o completo. Es decir, que no desarrollan las partes necesarias que conforman un buen diseño didáctico -fundamentación y adecuación al contex to, objetivos, contenidos, metodología, actividades de enseñanza-aprendizaje, temporalización, adaptación y evaluación-, o son abordadas de manera superficial y muestran limitaciones. Estos resultados coinciden con la investigación llevada a cabo por Marín et al. (2016), donde se presentan limitaciones en el diseño educativo de los programas de educación patrimonial que abordan la inclusión.

Elaborar diseños didácticos sólidos y donde exista concordancia y coherencia entre los contenidos y objetivos planteados en los programas y los contenidos curriculares, es fundamental para dotar a los programas sobre patrimonio de conexiones con los valores, competencias básicas y contenidos que se deben desarrollar en cada etapa como reivindican otros estudios que trabajan en esta área (Cuenca, et al., 2011; Dušan, 2015; Pinto \& Molina, 2015). También debemos destacar de manera negativa la ausencia de programas adaptados a diversos colectivos. Aspecto preocupante si consideramos la diversidad como 
Estudios Pedagógicos XLIII, N 4: 69-89, 2017

EVALUACIÓN DE PROGRAMAS EDUCATIVOS SOBRE PATRIMONIO CULTURAL INMATERIAL

una realidad presente en todas las esferas de la sociedad. Esta postura es compartida en el estudio realizado por Fontal y Martín (2016) que defiende la diversidad presente en el patrimonio y la diversidad de las personas destinatarias de los programas educativos. El uso de las TIC también es escaso en los programas sobre patrimonio inmaterial, a pesar de las ventajas que presenta su utilización, como nos muestran muchas de las investigaciones ya referidas a este respecto (Ibáñez et al., 2012; Ott et al., 2015; Ott \& Pozzi, 2011).

Por otro lado, detectamos ejemplos de buenas prácticas y programas dentro del patrimonio inmaterial que presentan una gran originalidad. Otro aspecto que destacar es la riqueza dentro de la tipología de programa educativo, existiendo representación en todas ellas y mostrando que el patrimonio inmaterial se está trabajando educativamente desde diferentes enfoques. Observamos también bastante representación de programas desarrollados en el ámbito informal y, en menor medida, en el ámbito formal. Además, muchos de ellos se desarrollan en el ámbito formal y en colaboración con otras instituciones de su entorno, aspecto enriquecedor ya que hacen partícipe a todos los agentes educativos, asumiendo lo establecido por el PNEyP como criterio metodológico esencial (Domingo et al., 2013). La participación de los agentes educativos inmersos en el proceso de patrimonialización facilita el proceso de construcción de la identidad, mejorando así la calidad del programa (Fontal \& Gómez-Redondo, 2016). También es fundamental que la legislación educativa aborde de manera sistematizada en todos los niveles la inclusión de contenidos relacionados con el Patrimonio Cultural, su preservación, valoración y disfrute (Fontal \& Martínez, 2016; Fontal et al., 2017), sin olvidar la necesidad de avanzar hacia la coordinación interadministrativa planteada en el PNEyP, que sea capaz de integrar los ámbitos educativos formal, no formal e informal de la educación patrimonial (Cuadrado, 2008).

En cuanto al grado de relación entre categorías que presentan los análisis de contingencias, podemos observar que los programas cuyos diseños educativos son más consistentes presentan un mayor grado de relación con el tipo de público - alumnado-. Por otro lado, aquellos programas con diseño educativo se desarrollan mayoritariamente según las líneas de tendencia en el ámbito de la educación formal, frente a la educación no formal o informal. Estas relaciones pueden deberse a que solamente lo vinculado con el ámbito más formal o escolar se considera que requiere un diseño educativo fundamentado. Esta concepción debe replantearse, ya que toda acción educativa-independientemente del ámbito educativo y del público al cual se dirija - debe estar correctamente planificada y estructurada.

Los programas educativos deben ser diseñados atendiendo en detalle a todos los aspectos que un diseño didáctico -que verdaderamente se haya realizado desde presupuestos propiamente educativos- requiere. Este aspecto es imprescindible para lograr la principal finalidad de los mismos, que es concienciar y estimular el respeto y aprecio al patrimonio (UNESCO 1972, Art. 27 y 28), y activar la cadena de sensibilización (Fontal, 2003) que garantice que el bien cultural, en este caso inmaterial, se convierta en patrimonio para la sociedad, en un referente identitario (Dušan, 2015). Las ausencias y limitaciones detectadas en este análisis deben transformarse en estándares alcanzables, que contengan los diseños de futuros materiales educativos orientados a la transmisión de conceptos y valores patrimoniales sobre el patrimonio inmaterial. Es fundamental que, desde las administraciones, se garantice el desarrollo y consolidación de proyectos de investigación orientados a la consecución de la investigación continua y el seguimiento de acciones desarrolladas en torno a la educación patrimonial (Domingo et al., 2013). Dentro de estos, incluimos el fomento de inventarios y centros de documentación acordes con 
Estudios Pedagógicos XLIII, N 4: 69-89, 2017 EVALUACIÓN DE PROGRAMAS EDUCATIVOS SOBRE PATRIMONIO CULTURAL INMATERIAL

las necesidades de conservación, preservación y difusión orientados a la educación como factor fundamental en la gestión de estos bienes inmateriales. En efecto, la educación patrimonial nos permitirá establecer vínculos identitarios y, desde la experiencia, atribuir significados y valores a los bienes inmateriales transformándolos en patrimonio, para poderlo así conservar y trasmitir (Lobovikov-Katz, 2009).

\section{REFERENCIAS BIBLIOGRÁFICAS}

Angelopoulou, A., Economou, D., Bouki, V., Psarrou, A., Jin, L., Printchar, C., \& Kolyda, F. (2012). Mobile Augmented Reality for Cultural Heritage. Mobile Wireless Middleware, Operating Systems, and Applictions. Springer, 15-22.

Asiáin, A., \& Aznárez, M. (2012). Patrimonio cultural inmaterial y adquisición/desarrollo del lenguaje: Tradición discursiva y psicodinámica oral. Huarte De San Juan, 12, 45-64.

Azmana, N., Halimb, S. A., Liuc, O. P., Saidinb, S., \& Komoo, I. (2010). Public education in heritage conservation for geopark community. Procedia Social and Behavioral Sciences, 7, 504-511.

Barghi, R., Zakaria, Z., Hamzah, A., \& Hashim, N.H. (2017). Heritage education in the Primary School Standard Curriculum of Malaysia. Teaching and Teacher Education, 61, 124-131.

Buckey, J. M., \& Graves D. (2016). Tangible Benefits from Intangible Resources: Using Social and Cultural History to Plan Neighborhood Futures. Journal of The American Planning Association, $82(2), 152-166$.

Calaf, R. (2009). Didáctica del patrimonio: epistemología, metodología y estudio de casos. Gijón: Trea.

Carrera, G. (2005). La evolución del patrimonio (inter) cultural: políticas culturales para la diversidad. Colección Cuadernos IAPH, 17, 15-29.

Copeland, T. (2006). European democratic citizenship, heritage education and identity. Strasbourg. France: Council of Europe.

Cuadrado, T. (2008). La enseñanza que no se ve: educación informal en el siglo XXI(Vol. 7). Madrid: Narcea Ediciones.

Cuenca, J. M. (2003). Análisis de concepciones sobre la enseñanza del patrimonio en la educación obligatoria. Revista de Investigación, 2, 37-46.

Cuenca, J. M., Estepa, J., \& Martín, M.J. (2011), El patrimonio cultural en la educación reglada. Revista de Patrimonio Cultural de España, 4, 45-58.

Cuenca, J. M., \& López. I. (2014). Teaching Heritage in Social Science, Geography and History Textbooks in Compulsory Secondary Education. Culture and Education, 26(1), 1-43.

Curtis, R., \& Seymour, C. (2004). Louisiana heritage education program and heritage in the classroom: Children's attitudes toward cultural heritage. Journal of Social Studies Research, 28(2), 20-24.

Deleuze, G., \& Guattari, F. (1972). Lanti-oedipe: capitalisme et schizophrénie. Paris: Editorial De Minuit.

De Troyer, V., Vermeersch, J., VanGenechten, H., Kösten, K., Mols, P., Van Leeuwen, J., . . Vitré, N. (2005). Heritage in the Classroom. A Practical Manual for Teachers (Translated by Julian Morgan). Brussel: Hereduc.

Domingo, M., Fontal, O., \& Ballesteros, P. (2013). Plan Nacional de Educación y Patrimonio. Madrid: MECD, Secretaría de Estado de Cultura.

Dušan, K. (2015). Analysis of National and Cultural Identity Educational Programmes with Examples of Good Practice. Czech-Polish historical and pedagogical journal, 7(2), 72-90.

Estepa, J., Ávila, R. M., \& Ferreras, M. (2008). Primary and Secondary Teachers'Conceptions about Heritage and Heritage Education: A Comparative Analysis. Teaching and Teacher Education, 24, 2095-2107. doi:10.1016/j.tate.2008.02.017 
Estudios Pedagógicos XLIII, $\mathrm{N}^{\circ}$ 4: 69-89, 2017

EVALUACIÓN DE PROGRAMAS EDUCATIVOS SOBRE PATRIMONIO CULTURAL INMATERIAL

Falk, H., Dierking, D., \& Adams, M. (2006). Living in a Learning Society: Museums and Free-choice Learning. In S. Macdonald (Ed.), A Companion to Museum Studies (pp. 323-335). Nueva York: Wiley-Blackwell.

Fontal, O. (2016). The Spanish Heritage Education Observatory. Culture and Education, 28(1), 261266.

Fontal, O. (2008). La importancia de la dimensión humana en la didáctica del patrimonio. En S. Mateos (Coord.), La comunicación global del Patrimonio cultural (pp. 79-110). Gijón: Trea.

Fontal, O. (2003). La educación patrimonial. Teoría y práctica en el aula, el museo e internet. Gijón: Trea.

Fontal, O., \& Gómez-Redondo C. (2016). A Quarterly Review of Education. Heritage Education and Heritagization Processes: SHEO Metodology for Educational Programs Evaluation. Interchange, 46(1), 1-26. doi:10.1007/s10780-015-9269-z

Fontal, O., \& Ibáñez, A. (2017). Research on Heritage Education. Evolution and Current State Through analysis of High Impact Indicators. Revista de Educación, 375, 184-214.

Fontal, O., Ibáñez, A., Martínez, M., \& Rivero, P. (2017). El patrimonio como contenido en la etapa de Primaria: del currículum a la formación de maestros. Revista Electrónica Interuniversitaria de Formación del Profesorado, 20(2), 79-94. doi:10.6018/reifop.20.1.286321

Fontal, O., \& Juanola, R. (2015). Heritage Education: a useful and profitable discipline within the cultural heritage management. Revista Cadmo. Giornale Italiano di Pedagogia sperimentale. An International Journal of Educational Research, 23(1), 7-25. doi:10.3280/CAD2015-001002

Fontal, O., \& Marín, S. (2016). Heritage Education in Museums: an Inclusion-Focused Model, International Journal of the Inclusive Museum, 9(4), 47-64.

Fontal, O., \& Martínez, M. (2016). Análisis del tratamiento del Patrimonio Cultural en la legislación educativa vigente, tanto nacional como autonómica, dentro de la educación obligatoria. Madrid: IPCE.

Fontal, O., \& Vallés, J. (2013). Mucho más que... ampliando horizontes para la educación patrimonial. En R. Huerta \& R. de la Calle (Coords.), Patrimonios migrantes (pp. 149-158). Valencia: Servei de publicacions.

Forte, M. (2007). Ecological Cybernetics, Virtual Reality and Virtual Heritage. In F. Cameron \& S. Kenderdine (Eds.), Theorizing digital cultural heritage. A critical discourse (pp. 389-408). Massachussetts: MIT Press.

González, S. (2015). La salvaguarda del patrimonio inmaterial en España (Doctoral Dissertation). Universidad Complutense de Madrid, Madrid.

González, S., \& Querol, M. A. (2014). El patrimonio inmaterial. Madrid: Catarata.

Garner, J., Kaplan, A., \& Pugh, K. (2016). Museums as Contexts for Transformative Experiences and Identity Development. Journal of museum education, 41(4), 341-352.

Haddad, N. (2015). Multimedia and cultural heritage: A discussion for the community involved in children's edutainment and serious games in the 21 st century. Virtual Archaeology Review, 7(14), 61-73.

Hume, D. (1757). La norma del gusto. Valencia: Teoriema, 1980.

Ibáñez, A., Asensio, M., Vicent, N., \& Cuenca, J. M. (2012). Mobile Devices: a Tool for Tourism and Learning at Archaeological Sites. International Journal of Web Based Communities, 8(1), 67-72.

IPCE. (2013). Plan Nacional de Educación y Patrimonio. Madrid: IPCE.

IPCE (2011). Plan Nacional de Salvaguarda del Patrimonio Cultural Inmaterial. Madrid: IPCE.

Jiménez, R.; Cuenca, J. M., \& Ferreras, M. (2010). Heritage education: Exploring the conceptions of teachers and administrators from the perspective of experimental and social science teaching. Teaching and teacher education, 26(6), 1319-1331.

Jin-long, X. (2009). Thinking about Strengthening Undergraduates' Intangible Heritage Education. Journal of Gannan Normal University, 1, 30-54.

Kasapoglu, P. (2016). Applying the Intangible Cultural Heritage Into the Formal Education: A 
Estudios Pedagógicos XLIII, N 4: 69-89, 2017 EVALUACIÓN DE PROGRAMAS EDUCATIVOS SOBRE PATRIMONIO CULTURAL INMATERIAL

WebQuest Example. MILLI FOLKLOR, 111, 149-170.

Lobovikov-Katz, A. (2009). Heritage Education for Heritage Conservation. A Teaching Approach, Strain, 45(1), 480-484.

Lobovikov-Katz, A., Moropoulou, A., Konstanti, A., Ortiz Calderón, P., Van Grieken, R., Worth, S., . . Cassar, J. (2014). Tangible Versus Intangible in e-learning on Cultural Heritage: From Online Learning to On-site Study of Historic Sites. In Digital Heritage. Progress in Cultural Heritage: Documentation, Preservation, and Protection (pp. 819-828). Switzerland: Springer International Publishing.

Marín, S., García, S., Vicent, N., Gillate, I., \& Gómez-Redondo C. (2017). Inclusive Heritage education in SHEO: a prospective study. Revista de Educación, 375, 110-130. doi:10.4438/1988592X-RE-2016-375-337

Nardi, E. (2008). Education and cultural mediation in museums. Cadmo, 16(2), 1-6.

Ott, M., \& Pozzi, F. (2011). Towards a New Era for Cultural Heritage Education: Discussing the Role of ICT. Computers in Human Behavior, 27(4), 1365-1371.

Ott, M., Dagnino F. M., \& Pozzi, F. (2015). Intangible Cultural Heritage: Towards Collaborative Planning of Educaional Interventions. Computers in Human Behaviour, 51, 1314-1319.

Pinto, H., \& Molina, S. (2015). Heritage Education in the curricula of Social Sciences in Spain and Portugal. Educatio SXXI, 33(1), 103-128.

Rosemary, L., \& Sutter, G. (2012). Sustainability and Museum Education: What Future are we educating for? The International Journal of the inclusive museum, 4(3), 11-26.

Santamarina, C. (2005). Consumo y ocio de los Inmigrantes Latinoamericanos en España: un acercamiento desde la perspectiva cualitativa (Vol. 4). Murcia: Ministerio Trabajo y Asuntos Sociales, Subdirección General de Información Administrativa y Publicaciones.

Soon, C. (2014). ICHPEDIA, a case study in community engagement in the safeguarding of ICH online. International Journal of Intangible Heritage, 9, 69-82.

Stake, E. (2006). Evaluación comprensiva y evaluación basada en estándares (Vol. 10). Barcelona: Graó.

Teixeira, S. (2006). Educación patrimonial: alfabetización cultural para la ciudadanía. Estudios Pedagógicos, 32(2), 133-145.

UNESCO. (1972). Convention Concerning the Protextion of the World Cultural and Natural Heritage. Paris: Author.

UNESCO. (2003). Convention for the Safeguarding of the Intangible Cultural Heritage. 32nd Session of the General Conference, Paris, 29 September-17 October, 2003.

Vicent, N., Rivero, P., \& Feliu, M. (2015). Arqueología y tecnologías digitales en Educación Patrimonial. Educatio Siglo XXI, 33(1), 83-102.

Yanes, C. (2007). El patrimonio educativo intangible: Un recurso emergente en la museología educativa. Cadernos de História da Educaçao, 2, 71-85. 


\section{CAPITULO V}

\section{Conclusiones}

St. Louis Blues (Bessie Smith y Luis Armstrong, 1925)

[

1. Bessie Smith - St. Louis Blues.mp3

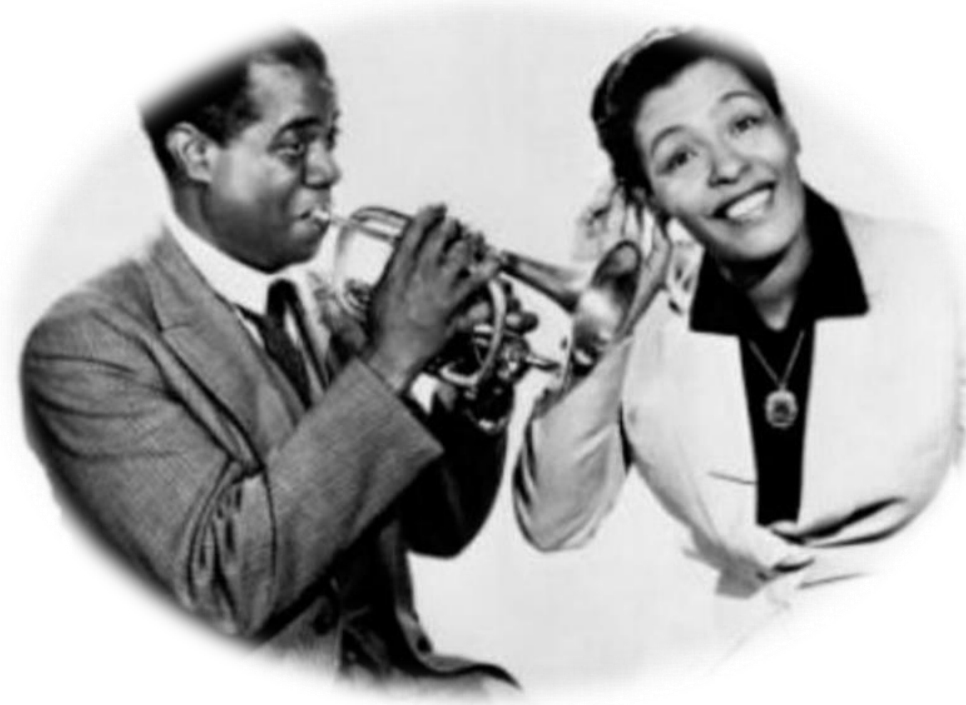





\section{Conclusiones y discusión}

En este capítulo se recogen una serie de conclusiones obtenidas durante el proceso de elaboración de los artículos seleccionados, así como otras más generales obtenidas durante la elaboración de esta tesis doctoral, que tratan de reponder a la dimensiones del estudio (cuestiones, objetivos e hipótesis) que nos planteamos en el capítulo I. Este apartado se articula en torno a dos grandes secciones. La primera aborda las sinergias que la política internacionales han ido creando entre la educación y el patrimonio para enfrentar los desafíos de la sociedad del S. XXI. En la segunda sección se presentan las aportaciones más relevantes, que giran en torno a la presencia y el enfoque del patrimonio en el currículo y en la formación de los futuros maestro; así como, los enfoques y categorías de los programas educativos sobre PCI. Este apartado concluye con un decálogo de estándares o aspectos a tener en cuenta en la elaboración de programas, con la finalidad de mejorar la calidad de futuros diseños. Finalmente se plantean las líneas de futuras de investigación y las principales limitaciones.

\subsection{La educación y el patrimonio para enfrentar los desafíos del S.XXI.}

En el primer apartado de este capitulo recogemos los principales aspectos relativos a la conexión existente entre la educación, el patrimonio y la identidad y como las políticas internacionalesjustifica la necesidad de trabajar educativamente el patrimonio dentro de la educación formal y no formal.

La educación ocupa un lugar muy importante dentro de los objetivos de la Agenda 2030 de Desarrollo Sostenible de las Naciones Unidas (Asamblea General Naciones Unidas, 2015). La esencia de estas aspiraciones y metas en el campo de la educación se resume en el cuarto Objetivo de Desarrollo Sostenible, que pretende garantizar una educación inclusiva y equitativa de alta calidad y promover oportunidades de aprendizaje permanente para todos, aunque la comunidad internacional reconoció que la educación es fundamental para el éxito de los 17 objetivos escogidos. Por ello, en el Foro Mundial de la Educación en 2015 se aprobó la Declaración de Incheon (UNESCO, 2015a), que confió a la UNESCO la dirección y coordinación del Marco de Acción Educación 2030, que considera a la educación como un mecanismo para responder a los desafíos que enfrenta la humanidad en la actualidad (UNESCO, 2016). Además, la educación también ocupa una posición de importancia fundamental en el informe sobre el desarrollo del 
Banco Mundial 2018, que concluye que la educación se percibe como un aspecto esencial, necesario y fundamental del desarrollo, y para enfrentarse a los desafíos del siglo XXI (Marope, Griffin y Gallagher, 2017; Wahlström, 2016).

Sin educación no hay herencia, porque la conciencia de identidad no puede existir y, por lo tanto, no se crean vínculos entre los bienes culturales y las personas, los grupos y las sociedades (Fontal, 2013; Mun, 2018). La educación es la actividad que garantiza que el patrimonio sea conocido, comprendido, valorado y disfrutado. Nos damos cuenta de ello, lo disfrutamos a través del aprendizaje y lo transmitimos. Si no estamos educados, dentro de un marco formal, no formal o informal, sobre estos temas, el patrimonio no significará nada para nosotros, ya que no nos sentimos parte de ello. Como resultado de esto, la educación es para el patrimonio mucho más que necesaria, es absolutamente esencial (Casanova et al., 2018; Garner, Kaplan, y Pugh, 2016; Islamoglu, 2018). La educación patrimonial es el aval que despierta sensibilidades y activa la creación de nexos entre la cultural y la sociedad, garantizando la metamorfosis del bien cultural hacia el bien patrimonial. Debemos destacar que nunca hablamos de un proceso transmitivo, sino de un proceso vinculante, relacional y experiencial entre el bien cultural y los persona.

La concepción de la educación patrimonial ha ido evolucionando desde que apareció reflejada en la normativa internacional de la UNESO, el Consejo de Europa y la Unión Europea, donde se comenzaba a plantear la importancia y necesidad de introducir la educación dentro de las políticas culturales sobre gestión de los bienes patrimoniales. Esta evolución también se ve reflejada en el discurso teórico, que inicialmente planteaba una división dentro de la educación patrimonial: educación sobre el patrimonio, que únicamente presentaba una función transmisora de contenidos patrimoniales; y educación a través del patrimonio, donde el patrimonio se utilizaba como un recurso interdisciplinario para la enseñanza de las áreas curriculares (Copeland, 1991).

Pero la forma de entender la educación patrimonial cambia cuando Fontal (2003), planea la educación patrimonial como un proceso vinculante, relacional y experiencial entre el bien cultural y la persona. La persona, a través del proceso de patrimonialización, es la única capaz de atribuir valor a los bienes culturales para convertirlos en patrimonio, el cual querrá cuidar, disfrutar y trasmitir (Fontal y Gómez-Redondo, 2016). Por lo tanto, el autosignificado otorgado a los bienes culturales evoluciona en función de las 
experiencias educativas (Copeland, 2006). Esta perspectiva deriva en un nuevo enfoque de carácter globalizador, integrador y simbiótico; educación desde y hacia el patrimonio, que coloca el acento en el proceso relacional y en el acto de patrimonialización. Así, la educación patrimonial adquiere un carácter doblemente relacional, donde "el patrimonio es el contenido de ese aprendizaje y las formas de relación se refieren a la identidad, la propiedad, el cuidado, disfrute, transmisión, etc.” (Domingo et al., 2013, p. 10).

En este sentido, en el marco del European Year of Cultural Heritage (2018) se defiende que, "Cultural Heritage becomes instrumental for the development of the learning process, as well as an occasion for students to engage with it to enhance their perception of the diversity and richness embodied in heritage" (European Parliament, 2017). También es ampliamente defendido el potencial didáctico que la educación patrimonial presenta para trabajar la ciudadanía (Muñoz, Sánchez-Agustí, y Wilhelm, 2012; Muñoz y Torres, 2014), la identidad (Tilley, 2006) y la democracia (Copeland, 2006; Cuenca et al., 2017; Martínez-Rodríguez, Muñoz, y Sánchez-Agustí, 2019; Rodríguez y Valdivia, 2016); así como, garantizar procesos de sensibilización y socialización en torno al patrimonio cultural (Lobovikov-Katz, 2009). Todo ello justifica la necesidad de trabajar educativamente el patrimonio dentro de la educación formal y no formal, para que las nuevas generaciones comprendan su herencia cultural y desarrollen un sentido de propiedad que las empodere en su gestión.

\subsection{Aportaciones más relevantes}

\subsubsection{La educación patrimonial en el currículo y en la formación de maestros}

El currículo siempre ha sido objeto de tensiones políticas como articulador del orden social presente y futuro, pues los planes educativos establecen qué aprenden los individuos, cómo y cuándo, fijando el porvenir de una sociedad (Dello-lacovo, 2009; Mcculloch, 2005). El mayor desafío de un nuevo modelo curricular que quiere cumplir los retos futuros según Marope et al. (2017), es producir aprendices que puedan cambiar el contexto para mejor. En este sentido el currículo y el modo de enseñar el patrimonio en el sistema educativo es un factor clave para su preservación sostenible, porque solo se protege y se conserva lo que se conoce y se valora. Esta postura es defendida desde hace décadas a nivel internacional en convenciones de la UNESCO (1972, 2005, 2014), y también por el Consejo de Europa donde destaca la Recommendation No R (98) 5 of the 
Committee of Ministers to Member States Concerning Heritage Education (Committee of Ministers, 1998), que defiende que la educación patrimonial garantiza los procesos de empoderamiento social, que nos permiten ser competentes en la salvaguarda de nuestro pasado común.

En el territorio español las administraciones encargadas de la gestión de los bienes patrimoniales han desarrollado marcos legales para salvaguardar la amplia riqueza patrimonial del país, donde la educación patrimonial se ha convertido en una de las líneas de actuación cada vez más reconocida. En el 2013 se instaura el Plan Nacional de Educación y Patrimonio, como instrumento de coordinación de acciones entre los ámbitos estatal, autonómico y local, que conecta la educación formal, no formal e informal y defiende la necesidad de analizar el tratamiento que el currículo hace del patrimonio, así como velar por una mayor presencia. Con la intención de dar respuesta a esta última cuestión se ha desarrollado el primer artículo de esta tesis doctoral (Fontal et al., 2017) que concluye, que el currículo de Educación Primaria (RD 126, 2014) aborda el patrimonio de una manera holística en todas sus dimensiones -natural, material e inmaterial- y de un modo integral (Desantes, 2013).

Hay una amplia alusión a los ámbitos del patrimonio cultural inmaterial. Estos datos coinciden con la investigación realizada por Barghi et al. (2017), cuyos resultados revelan un foco en el patrimonio cultural inmaterial en algunas asignaturas, como historia, idioma Bahasa Malaysia, arte y educación musical dentro del currículo de educación primaria en Malaysia. A pesar de la amplia presencia que revelan los datos, la terminología patrimonio cultural inmaterial no se utiliza de manera específica en la legislación educativa española, sino que el término patrimonio cultural engloba ambas concepciones, material e inmaterial. Por ello, en multitud de ocasiones no se especifica ni se utiliza el término inmaterial en su particularidad. El mundo académico ha debatido y teorizado sobre la dicotomía tangible e intangible generada dentro del concepto patrimonio cultural (Pocock et al., 2015) y rechaza la división categórica entre ambas dimensiones. Muchos autores argumentan que estas están estrechamente vinculadas y entrelazadas en un sentido epistemológico debido a su naturaleza, aunque presenten una divergencia semántica según la normativa internacional (Lähdesmäki, 2016). Por lo tanto, resulta imposible separar lo material de lo inmaterial en un contexto cultural, y por ello también el contexto educativo aborda ambas dimensiones de una manera conjunta. 
Analizar el enfoque metodológico del proceso de enseñanza-aprendizaje que presenta la legislación nos ha permitido conocer el grado de sensibilización hacia el patrimonio que se busca alcanzar. Dentro de la educación patrimonial entendemos por sensibilizar, un proceso, en el cual el alumno parte de conocer la existencia del bien cultural y de sus conocimientos previos, y comienza a trabajar en la comprensión lógica del elemento patrimonial hasta determinar una respuesta actitudinal y valorativa. La valoración fruto de la comprensión le hace pasar de la idea, a la acción de conservar y legar. A través de este proceso, se activan en el alumno actitudes de cuidado, disfrute y transmisión.

Prácticamente en la totalidad de los textos de la normativa vigente encontramos completa la secuencia procedimental de sensibilización, conocer-comprender-respetarvalorar, para cuidar-disfrutar-transmitir. Aunque el enfoque se centra mayoritariamente en una aproximación actitudinal, de acuerdo con autores como Fontal y Gómez-Redondo (2016), debe ser superado hacia un enfoque que coloque el acento en la dimensión relacional, vinculante y experiencial entre el bien cultural y el alumno. Con la finalidad de construir autosignificados, a través de procesos de patrimonialización que genere vínculos y sentimientos del alumnado con, desde y hacia el patrimonio (Copeland, 2006). También de acuerdo con otras investigaciones observamos que en la legislación educativa existe un predominio de visiones estéticas y temporales, con estrategias metodológicas de carácter tradicional y finalidades académicas y conservacionistas (Cuenca et al., 2017). Este enfoque debe evolucionar hacia un modelo de carácter globalizador y simbiótico, que desarrolle procesos relacionales entre el bien cultural y el alumno para construir autosignificados (Copeland, 2006). La frecuencia con la que encontramos la secuencia de sensibilización está en relación directa con la presencia del patrimonio como contenido curricular, y esta varía en función de la oferta educativa de cada comunidad en el bloque de asignaturas de libre configuración.

La amplia presencia del término identidad no nos sorprende debido al potencial didáctico que la educación patrimonial tiene para trabajarla. Los datos obtenidos coinciden con la opinión de autores que defienden la estrecha relación existente entre patrimonio e identidad (Copeland, 2006; Teixeira, 2006) e investigaciones que concluyen que el patrimonio es un contenido curricular desarrollado siempre desde un sentido simbólico-identitario (Pinto y Molina-Puche, 2015). En lo relativo al término 
manifestaciones, que hace referencia a la dimensión más intangible del patrimonio, sigue destacando Andalucía y también Valencia

Esta conclusión presenta muchos matices debido a la descentralización a la que se ve sometido en la década de los noventa el sistema educativo español. Esta descentralización curricular, que surge de la distribución competencial, provoca que sean las administraciones educativas de cada comunidad, las que fijan el mayor o menor grado de sensibilización hacia el patrimonio cultural, y así lo reflejan en la organización de las áreas en las que tienen competencias. Es en este espacio donde muchas muestran un mayor interés y aprovechan para introducir asignaturas de libre configuración que abordan contenidos sobre la lengua propia de la comunidad, su cultura y patrimonio. En este sentido, destacan las comunidades de Andalucía y Canarias que intentan sensibilizar a sus alumnos desde la más temprana edad, sobre las manifestaciones culturales propias como primer paso para comprender otras culturas y favorecer la inclusión y el orden social (Buckley y Graves, 2016; Fontal y Marin, 2016). De igual modo, Asturias y Navarra destacan por el trato privilegiado a sus tradiciones y manifestaciones más intangibles. Estas cuatro comunidades son las que arrojan mejores resultados en los análisis, y también son las únicas que ofertan una asignatura de libre configuración sobre la cultura de su comunidad al menos en algún curso de la etapa.

Las Comunidades destacadas no se corresponden con las comunidades que cuentan con lenguas cooficiales -Galicia, Cataluña, Valencia, País Vasco, Islas Baleares y Navarra-. Esto supone un interesante punto de reflexión, ya que inicialmente se esperaba que las comunidades con lenguas cooficiales arrojaran una mayor presencia del patrimonio local, las manifestaciones, tradiciones y el sentimiento identitario que la comunidad quiere transmitir. En esta misma línea Fuhai (2017), argumenta las limitaciones del currículo para transmitir el patrimonio étnico a través de la educación escolar, y defienden la necesidad de integrar el conocimiento local, en un formato apropiado dentro del plan de estudios de la escuela como clave para el éxito.

En cambio, otras comunidades emplean las asignaturas de libre configuración como mecanismo de refuerzo poniendo el énfasis en la atención individualizada y prevención de dificultades de aprendizaje. Consideramos que uno de los principales motivos de las comunidades donde prima el refuerzo de troncales, responde más a la obtención de un resultado temprano positivo en las evaluaciones externas -una al finalizar el tercer curso 
por parte de la comunidad y la otra al final de etapa de carácter estatal-, que a un aprendizaje constructivista y continuo por parte del alumno. Parece que existen competencias que tienen que ser adquiridas de una forma más primordial, es decir, no se interpreta el concepto de conocimiento en términos de competencia, sino que se apuesta por un conocimiento más tradicional dentro de las asignaturas (Wahlström, 2016; Wexler, 2014). Este hecho puede condicionar al docente y al alumno, que se centren en enseñar y aprender únicamente lo que se evalúa, y provocar que el sistema de enseñanza-aprendizaje, que realmente tenga lugar en las aulas, se aleje de la metodología normalizada en los textos analizados.

Cada comunidad tiene distinta lectura del currículo básico del RD, y por ello, existen grandes diferencias en el tratamiento del patrimonio cultural como contenido curricular según la comunidad autónoma analizada, a pesar de estar todas ellas reguladas en base a la Ley Orgánica 8/2013, de 9 de diciembre, para la mejora de la calidad educativa. Estas diferencias no deben pasarse por alto, ya que de acuerdo con Scalise (2015), la educación es una variable fundamental en la dinámica de la formación de la identidad cultural y patrimonial, además de ser un factor imprescindible para la gestión sostenible del patrimonio (UNESCO, 2014). Así, un concepto central como es el patrimonio cultural y natural en los textos de la Unión Europea se recontextualiza en nuestro currículo nacional (Nordin y Sundberg, 2016). Por ello, es imprescindible la revisión continuada para la mejora de los planes curriculares, que genera el debate de incluir la dimensión del patrimonio cultural en la educación como una asignatura en sí misma (Barghi et al., 2017; Hang et al., 2017; Hunter, 1988) o visto como una fuente fértil para el estudio en otras materias (Fuhai, 2017). A study requested by the CULT CommitteeEducation in Cultural Heritage, concluye que "el 88\% de los participantes consideran que el patrimonio debería integrarse de ambos modos" (Gesche-Koning, 2018, p. 31). Esta distinción es importante porque la segunda opción puede implementarse en las escuelas de manera más fácil que la primera, que necesita encontrar una sincronización estructural. Pero para asegurarse de que el patrimonio se convierte en un recurso trasversal en otras materias - segunda opción-, y es visto por los docentes como algo natural, deben haberse familiarizado con los asuntos patrimoniales durante su formación. Y aquí nuevamente, se debe encontrar tiempo para integrar la educación patrimonial en los planes de estudios. 
Otra de las principales conclusiones del primer artículo (Fontal et al., 2017) fue la amplia diferencia encontrada entre la presencia del patrimonio en el currículo y la escasa presencia de contenidos relacionados en los grados de maestro. Con respecto al análisis de las asignaturas de los planes de estudios que abordan el patrimonio en la formación de los maestros de primaria, observamos una escasa presencia respecto al total de universidades analizadas, siendo mayor la presencia, aunque todavía deficiente, en las universidades públicas. Estas asignaturas, se enmarcan generalmente dentro de las opciones disponibles en la elección de asignaturas optativas, lo que supone que aquellos alumnos que no las eligen, no tienen contacto con los contenidos patrimoniales y su didáctica. El análisis de contenido muestra como sus contenidos siguen la secuencia de patrimonialización (Fontal, 2003), aunque se producen rupturas en torno a la valorización y sensibilización. Por lo tanto, entendemos que el principal problema radica en la escasez de la oferta de asignaturas en torno al patrimonio. Solo las comunidades de Andalucía, Asturias y Valencia ofertan una asignatura de la cultura de su comunidad al menos en algún curso de la etapa, independientemente de las comunidades de Aragón, Navarra, País Vasco, Galicia y Valencia y Cataluña que ofertan una asignatura específica de su lengua cooficial y su literatura, como podemos ver en la tabla 5. Al mismo tiempo, no debemos olvidar que los futuros maestros, que se forman en las universidades, con diferentes necesidades sociales y profesionales de las que han de vivir en el futuro, y por lo tanto, con legislaciones que están por venir (Barredo et al., 2013).

Consideramos que esta disfunción, puede deberse al "desfase" existente entre el currículum vigente en el momento de diseñar los planes de estudios de los futuros maestros, y apelamos a la revisión y la necesidad de incorporar los contenidos patrimoniales en los programas universitarios (Koster et al., 2005; Zhang y Zhao, 2014). La formación se debe orientar hacia el cumplimiento de los contenidos patrimoniales y debe garantizar que el futuro maestro sea capaz de trasladarlos al aula. Los maestros deben desarrollar un modelo de enseñanza y aprendizaje que incorpore las dimensiones relacional y emocional del patrimonio (Domínguez y López-Facal, 2017; Domínguez et al., 2019), para construir valores identitarios, fomentando el respecto intercultural y el desarrollo de una juventud socioculturalmente comprometida con el patrimonio. Empoderar y dotar de competencias en la revisión y reelaboración del currículo a los docentes, también es un aspecto que debe ser reivindicado, ante el abandono de su 
autonomía y libertad intelectual para diseñar el currículo, pruebas y evaluaciones, que quedan en manos de "expertos” y compañías de prueba como Pearson (Wexler, 2014).

En cualquier caso, toda reforma curricular siempre debe responder a un análisis educativo (Gimeno, 2005) y a las necesidades sociales, que según las políticas internacionales buscan forjar personas competentes en la responsabilidad personal y colectiva respecto al patrimonio cultural, su uso sostenible y la consciencia del valor del patrimonio cultural para la sociedad (Council of Europe, 2005). Para llevar a cabo la contextualización de un modelo curricular, coincidimos con Gesche-Koning, que "it is highly recommended having cultural heritage at the very core of education and not as a stopgap and seeing education more deeply rooted in cultural heritage through adequate and efficient mutual long-term partnership policies" (2018, p. 3). Todo ello, con la finalidad de garantizar que las nuevas generaciones conozcan, y por tanto comprendan y valoren su legado cultural, del mismo modo que experimenten un proceso de reafirmación de valores identitarios frente a los modelos culturales cada vez más homogeneizados derivados de la globalización.

\subsubsection{Enfoques y categorías de los programas educativos sobre PCI}

Tras el análisis de los programas educativos hemos observado que el patrimonio cultural inmaterial, presenta una amplia gama de tipologías y es inmensamente rico. Por ello, es ampliamente necesario, desarrollar en los más jóvenes un sentimiento de pertenencia, que desemboque en la responsabilidad hacia su conservación, en esta tipología patrimonial especialmente frágil. Una de las principales conclusiones a las que llegamos tras la investigación, y a la vez una gran deficiencia detectada, es el gran porcentaje de programas analizados que no presentan un diseño educativo estructurado o completo. Es decir, que no desarrollan las partes necesarias que conforman un buen diseño didáctico fundamentación y adecuación al contexto, objetivos, contenidos, metodología, actividades de enseñanza-aprendizaje, temporalización, adaptación y evaluación-, o son abordadas de manera superficial y muestran limitaciones. Estos resultados coinciden con la investigación llevada a cabo por Marín et al. (2016), donde se presentan limitaciones en el diseño educativo de los programa de educación patrimonial que abordan la inclusión. 
Por lo tanto, uno de los objetivos de futuro fundamentales será elaborar diseños didácticos sólidos y donde exista concordancia y coherencia entre los contenidos y objetivos planteados en los programas y los contenidos curriculares. Es fundamental dotar a los programas sobre patrimonio de conexiones con los valores, competencias básicas y contenidos que se deben desarrollar en cada etapa, como reivindican otros estudios que trabajan en esta área (Dussan, 2015; Pinto y Molina-Puche, 2015; Pinto y Zarbato, 2017). También debemos destacar de manera negativa la ausencia de programas adaptados a colectivos diversos. Este aspecto es preocupante si consideramos la diversidad como una realidad presente en todas las esferas de la sociedad. Esta postura es compartida en el estudio realizado por Fontal y Martín (2016) que defiende la diversidad como una característica humana y patrimonial que requiere una educación patrimonial pluridimensional, diversa, inclusiva e igualitaria. Autores como Buckley y Graves (2016) también defienden el patrimonio como una gran herramienta para fomentar el respeto y el aprecio a la diversidad, que ayude al alumnado a adquirir un enfoque intercultural que fomente una sociedad más justa e inclusiva (Pinto, 2017).

Por ello consideramos fundamental tener en cuenta la diversidad patrimonial. Se debe eliminar la concepción restringida de patrimonio, que sólo beneficia a grupos culturales específicos y adoptar un concepto amplio de cultura y patrimonio, que beneficie a todo el alumnado. Así pues, la comprensión del patrimonio cultural inmaterial de diferentes comunidades, nos permite conocer y aceptar activamente la diferencia, al mismo tiempo que contribuye al diálogo entre culturas y promueve el respeto hacia otros modos de vida. En este sentido el PCI es una gran herramienta para fomentar e inculcar el respeto a la diversidad y también ser un lugar de encuentro entre alumnos de diferentes etnias, lenguas y culturas. Los alumnos deben respetar, reconocer y estimar esta diversidad para fomentar una sociedad más justa, inclusiva y solidaria, como indica la Convención sobre la Protección y la Promoción de la Diversidad de las Expresiones Culturales (UNESCO, 2005), la Declaratión on Cultural Diversity (Committee of Ministers, 2000) o la Recommendation 1884 Cultural education: The promotion of cultural knowledge, creativity and intercultural understanding through education (Parliamentary Assembly, 2009).

El uso de las TIC también es escaso en los programas sobre patrimonio inmaterial a pesar de las ventajas que presenta su utilización como nos muestras muchas de las 
investigaciones ya referidas a este respecto (Cozzani et al., 2017; Dagnino et al., 2015; Kasapoglu, 2016; Ott y Pozzi, 2011; Ott et al., 2015; Soon, 2014). Aunque los datos del estudio bibliométrico presentes en el punto 2.5.2 de este documento, nos indican un claro aumento en el desarrollo de investigaciones que aúnan el binomio patrimonio cultural inmaterial y TIC.

Por otro lado, detectamos ejemplos de buenas prácticas y programas dentro del patrimonio inmaterial, que presentan una gran originalidad. Otro aspecto a destacar es la riqueza dentro de la tipología de programa educativo, existiendo representación en todas ellas, y mostrando que el patrimonio inmaterial se está trabajando educativamente desde diferentes enfoques. Observamos también bastante representación de programas desarrollados en el ámbito informa y en menor medida en el ámbito formal. Además, muchos de ellos se desarrollan en el ámbito formal y en colaboración con otras instituciones de su entorno, aspecto enriquecedor ya que hacen partícipe a todos los agentes educativos. La participación de los agentes educativos inmersos en el proceso de patrimonialización facilita el proceso de construcción de la identidad, mejorando así la calidad del programa (Fontal y Gómez-Redondo, 2016).

En el segundo artículo de esta tesis (Fontal y Martínez, 2016a) se elabora un decálogo de estándares o aspectos a tener en cuenta en la elaboración de programas, con la finalidad de mejorar la calidad de futuros diseños.

- Desarrollo de un programa adecuado al contexto y a las necesidades iniciales.

- Establecer objetivos factibles, adecuados a la edad y a la normativa vigente de cada etapa educativa, si el programa se desarrolla en el ámbito formal.

- Independientemente del ámbito (formal, no formal o informal) donde se desarrolle el programa, es enriquecedor buscar participación de otros colectivos e instituciones, con la finalidad de encontrar apoyos y para hacer partícipe a toda la comunidad educativa.

- Los recursos de enseñanza-aprendizaje, deben ser acordes a la metodología que pretende desarrollar el programa, así como cuidadosamente seleccionados, respecto a las características del grupo, a la tipología de PCI y a los recursos materiales o humanos con los que se cuenta. 
- Instrucción de las personas encargadas de llevar a cabo el programa, tanto en el ámbito formal como el informal.

- Desarrollar adaptaciones del programa y tener en cuenta las necesidades educativas especiales de la sociedad o colectivo al que se destina.

- Desarrollo detallado de una metodología de implementación del programa.

- Planificación temporal y periódica del programa.

- Evaluación del programa atendiendo a la adecuación de los contenidos y la legislación vigente. Evaluación de la implementación del programa. Evaluación continua y formativa que produzca retroalimente. Evaluación de los resultados del programa, con respecto a la adquisición de conocimientos y valores planteados en los objetivos.

- Reflexión acerca de los aspectos negativos en la evaluación y búsqueda de estrategias de mejora a los aspectos que lo necesiten con la finalidad de garantizar la continuidad del programa.

Se hace palpable tras lo expuesto la necesidad de seguir investigando en este campo, para desarrollar un modelo con pautas detalladas e indicadores de calidad válidos y fiables sobre los cuales elaborar y evaluar los programas sobre educación patrimonial.

En cuanto al grado de relación entre categorías que presentan los análisis de contingencias, podemos observar que los programas cuyos diseños educativos son más consistentes, presentan un mayor grado de relación con el tipo de público -alumnado-. Por otro lado, aquellos programas con diseño educativo, se desarrollan mayoritariamente según las líneas de tendencia en el ámbito de la educación formal frente a la educación no formal o informal. Estas relaciones pueden deberse a que solo lo vinculado con el ámbito más formal o escolar, se considera requiere un diseño educativo fundamentado. Esta concepción que debe replantearse, ya que toda acción educativa independientemente del ámbito educativo y del público al cual se dirija, debe estar correctamente planificada y estructurada.

Los programas educativos, deben ser diseñados atendiendo en detalle a todos los aspectos que un buen diseño didáctico requiere. Aspecto imprescindible para lograr la principal finalidad de los mismos que es concienciar y estimular el respeto y aprecio al patrimonio (UNESCO, 1972, art. 27 y 28) y activar la cadena de sensibilización (Fontal, 
2003) que garantizar que el bien cultural, en este caso inmaterial, se convierta en patrimonio para la sociedad. Las ausencias y limitaciones detectadas en los análisis (Fontal y Martínez, 2017, 2018), deben convertirse en estándares alcanzables que deberán abordar los diseños de futuros materiales educativos, orientados a la transmisión de conceptos y valores patrimoniales sobre el patrimonio inmaterial. Es fundamental que desde las administraciones se garantice el desarrollo y consolidación de proyectos de investigación orientados a la consecución de la investigación continua y el seguimiento de acciones desarrolladas en torno a educación patrimonial (Domingo et al., 2013, p. 7). Dentro de los cuales, incluimos el fomento de inventarios y centros de documentación acordes con las necesidades de conservación, preservación y difusión, orientados a la educación como factor fundamental, en la gestión de estos bienes inmateriales. Y es que la educación patrimonial, nos permitirá establecer relaciones y desde la experiencia atribuir significados y valores a los bienes inmateriales transformándolos en patrimonio, el cual querremos conservar y trasmitir (Lobovikov-Katz, 2009).

\subsection{Líneas futuras}

Una de las líneas futuras de investigación será el desarrollo de análisis curriculares que superen el contexto nacional, con la finalidad de poder aportar resultados correlacionales entre diferentes países que interesen a la comunidad internacional de la disciplina, así como a las políticas de gestión educativa y patrimonial. Al mismo tiempo estamos interesados en analizar las tensiones entre las tendencias a un currículo homogeneizador y el reconocimiento de la diversidad cultural, la selección el enfoque de enseñanza o los contenidos patrimoniales y quien puede o debe decidir sobre ello. Al mismo tiempo los datos obtenidos en el análisis de los planes de estudios de los futuros maestros de educación primaria sobra formación inicial que reciben, debe ser comparada con la situación de otros países de la UE. Este hecho es fundamental, si aludimos a la homogenización derivada la Declaración de Bolonia ${ }^{51}$ (European Ministers of Education, 1998), que establece un sistema de créditos ECTS y del Suplemento al

\footnotetext{
${ }^{51}$ La Declaración de Bolonia sienta las bases para la construcción de un "Espacio Europeo de Educación Superior", organizado conforme a ciertos principios (calidad, movilidad, diversidad, competitividad) y orientado hacia la consecución entre otros de dos objetivos estratégicos: el incremento del empleo en la Unión Europea y la conversión del sistema Europeo de Formación Superior en un polo de atracción para estudiantes y profesores de otras partes del mundo.
} 
Título (Real decreto 1044/2003), con la finalidad de dotar de las mismas competencias profesionales a todos los estudiantes universitarias dentro del marco de europeo.

Otra de las líneas futuras será la continuidad en la evaluación de programas educativos sobre PCI con muestras más representativas, utilizando la escala Q-Edutage (Fontal et al., 2019), así como el diseño de instrumentos de evaluación específicos en torno al PCI, que nos permitan revisar las prácticas a través de estudios de caso y tratar de mejorarlas como acción continuada. Sin olvidar el horizonte investigador que es la evaluación de aprendizajes que se alcanzan con la implementación de los programas educativos.

Además de todo ello, la educación patrimonial garantiza procesos de empoderamiento social que nos permiten preservar de manera competente un pasado común y nuestro propio patrimonio cultural como ciudadanos europeos. Por esa razón, consideramos que es importante establecer instrumentos de coordinación derivados de la investigación en educación patrimonial que actualmente se encuentra dispersa en diferentes países y diferentes disciplinas. Por otra parte, otra de las líneas de interés será contribuir a desarrollar canales de comunicación y redes entre todos los actores clave involucrados en la gestión del patrimonio, con la finalidad de promover el compromiso social, ya que es la sociedad la que constituye el principal receptor y legatario del patrimonio.

\subsection{Limitaciones de la investigación}

Una de las principales limitaciones del estudio, ha sido la ausencia de un diseño educativo completo en algunos los programas sobre PCI analizados, que presentaban una estructura didáctica superficial que no se describía, ni detallaba, en profundidad. Este aspecto ha dificultado la labor de análisis y evaluación. Otro de los aspectos que limitan la investigación gira en torno a las muestras de los programas analizados, ya que esta no es representativa de un modo equitativo a nivel internacional. Se trata de una muestra aleatoria en base a la búsqueda y localización de los programas por parte de los diferentes investigadores. Por otro lado, destacamos la dificultad encontrada en torno al análisis estadístico-descriptivo, correlacional y de contenido realizado sobre la legislación y los planes de estudios, debido a su gran volumen documental. 


\section{Conclusions and discussion}

This chapter contains a list of conclusions obtained during the process of preparing the selected articles, as well as other more general conclusions obtained during the elaboration of this $\mathrm{PhD}$ thesis, which try to respond to the dimensions of the study (issues, objectives and hypotheses) that we set out in chapter I. This section is structured around two large sections. The first deals with the synergies that international politics have created between education and heritage to face the challenges of 21 st century society. The second section presents the most relevant contributions, which revolve around the presence and focus of heritage in the curriculum and in the training of future teachers; as well as, the approaches and categories of educational programs on PCI. This section concludes with a few guidelines pointing to a number of aspects to be borne in mind in programme preparation in order to improve the quality of future designs. Finally, the future research lines and the main limitations are considered.

\subsection{Education and heritage: Facing the challenges of the 21st century}

In the first section of this chapter we gather the main aspects related to the relationship between education, heritage and identity, and how international policies justify the need work heritage education within formal and non-formal education.

Education holds a very important position within the UN's 2030 Agenda for Sustainable Development (United Nations General Assembly, 2015). The quintessence of the agenda's aspirations and goals is summed up in the fourth Sustainable Development Goal, which attempts to ensure inclusive and equitable quality education and promote lifelong learning opportunities for all, since the international community agreed that education is critical in order to accomplish the 17 SDGs. This is why the 2015 World Education Forum adopted the Incheon Declaration (UNESCO, 2015a), which entrusted UNESCO with the management and coordination of the Education 2030 Framework for Action. The latter recognises that education constitutes a key mechanism in meeting the current global challenges for humanity (UNESCO, 2016). Moreover, education also features prominently in the 2018 World Development Report issued by the World Bank, which concludes that education is perceived as a key aspect of development: one which is critically necessary in facing up to the challenges of the 21st century (Marope, Griffin \& Gallagher, 2017; Wahlström, 2016). 
Without education, there is no legacy, since the very existence of an identity awareness is made impossible and, therefore, no bonds can be created between cultural assets, on the one hand, and people, groups and communities on the other (Fontal, 2013; Mun, 2018). Education is the activity that ensures that heritage may be known, understood, valued and enjoyed. We become aware of its existence, we enjoy it through learning and we transmit it to other people. Unless we have been educated with regard to heritage-in formal, non-formal or informal settings-, heritage itself will mean nothing to us, since we will not feel that it belongs to us. Accordingly, heritage education is much more than simply necessary: it is absolutely essential (Garner, Kaplan \& Pugh, 2016; Islamoglu, 2018). Heritage education is the guarantee that makes it possible for our awareness to be raised and for ties to be created between culture and society, thus securing the transformation of cultural properties into heritage assets. Let us highlight that this is in no way a purely transmission-geared process, but rather a binding, relational and experiential one that takes place between the cultural property and the people.

The concept of heritage education has evolved since it first appeared in international documents published by UNESCO, the Council of Europe and the European Union when the need to incorporate education into the cultural policies on the management of cultural properties began to be discussed. This evolution was also mirrored by the theoretical discourse, which initially argued for a division within heritage education itself between education about heritage, exclusively focused on the transmission of heritage-related contents, and education through heritage, where the latter was used as an interdisciplinary resource for teaching in the several curricular areas (Copeland, 1991).

However, the understanding of heritage education changed when Fontal (2003) described it as a binding, relational and experiential process that takes place between the cultural property and the individual. The latter alone, by means of a heritagisation process, is capable of assigning value to cultural properties and transforming them into heritage worth caring for, enjoying and transmitting (Fontal \& Gómez-Redondo, 2016). Therefore, the self-meaning assigned to cultural properties develops on the basis of educational experiences (Copeland, 2006). Such an outlook leads to a new approach globalising, comprehensive and symbiotic: education in and for heritage that emphasises the relational process and the act of heritagisation. In this way, heritage education achieves a strongly relational character, since "heritage becomes the content of learning 
and the ways of relating to it have to do with identity, ownership, care, enjoyment, transmission, etc.” (Domingo et al., 2013, p. 10) [Our translation].

It is worth remembering in this sense that, within the framework of the European Year of Cultural Heritage (2018), it was claimed that "Cultural Heritage becomes instrumental for the development of the learning process, as well as an occasion for students to engage with it to enhance their perception of the diversity and richness embodied in heritage" (European Parliament, 2017). Also the didactic potential of heritage education in working on citizenship (Muñoz, Sánchez-Agustí, \& Wilhelm, 2012; Muñoz \& Torres, 2014), identity (Tilley, 2006) and democracy issues has been widely recognised (Copeland, 2006; Cuenca et al., 2017; Martínez-Rodríguez, Muñoz, \& Sánchez-Agustí, 2019; Rodríguez \& Valdivia, 2016); and so is the need to secure processes of sensitisation and socialisation around cultural heritage (Lobovikov-Katz, 2009). All of which justifies the need to work on heritage in both formal and non-formal settings so that the new generations understand their own cultural legacy and develop a sense of ownership that empowers their performance.

\subsection{Most relevant contributions}

\subsubsection{Heritage education in the curriculum and in teacher education}

The curriculum has always been exposed to political tensions insofar as it articulates de present and future social order, since educational plans determine how, when and what individuals should learn, and shape the future of society (Dello-lacovo, 2009). The biggest demand on the new curricular model aimed at meeting the future challenges, according to Marope et al. (2017), is producing learners capable of changing their context for the better. In this sense, both the curriculum itself and the ways heritage contents are taught constitute key factors to the sustainable conservation of heritage itself, since only what is known and valued can be protected and preserved. In the international scene, this is the position that the UNESCO conventions (1972, 2005, 2014) as well as the Council of Europe have been advocating for several decades: a position illustrated, for example, in the latter organisation's Recommendation No R (98) 5 of the Committee of Ministers to Member States Concerning Heritage Education (Committee of Ministers, 1998), which argues that heritage education ensures social empowerment processes that enable us to become more competent in the safeguarding of our common past. 
In Spain's territory, the administrations entrusted with managing heritage properties have developed legal frameworks in order to safeguard the country's great heritage wealth where heritage education has become increasingly recognized as an important line of action. In 2013 the National Education and Heritage Plan was enacted as an instrument for the coordination of actions across the state, regional and local levels: one which links formal, non-formal and informal educational settings and emphasises the need to analyse the curriculum coverage of heritage itself and ensure the latter's expansion. In order to address this issue we have conducted the present research, whose main conclusion is that the Primary Education Curriculum (RD 126, 2014) approaches heritage in a holistic and integral way by encompassing all its dimensions: natural, tangible and intangible (Desantes, 2013).

Intangible cultural heritage receives an ample coverage. The data are consistent with the research findings by Barghi et al. (2017), which demonstrate a strong focus on this heritage typology in a number of subjects like History, Bahasa Malaysia, Art, and Music Education in Malaysia's Primary Education curriculum. Despite such a broad coverage, the term "intangible cultural heritage" is not specifically used in Spain's educational legislation. Instead the general label "cultural heritage" encompasses both categories, tangible and intangible. This explains why it is so very common for the term "intangible" to be omitted. Indeed, the academia has extensively debated (and theorised about) the dichotomy tangible/intangible in the context of cultural heritage (Pocock, Collett, \& Baulch, 2015) and rejects a categorical split between both dimensions. Many authors argue that both are closely intertwined from the epistemological point of view as a result of their nature, even though the semantic divergence between the two is acknowledged in European policy (Lähdesmäki, 2016). We may conclude in this regard that in the cultural context it is impossible to separate the tangible from the intangible, which in turn explains why in educational settings both dimensions are likewise approached jointly.

The analysis of the methodological approach implemented in the teaching-learning process envisaged in the current legislation has enabled us to ascertain the targeted degree of heritage sensitization or awareness-raising. In the context of heritage education, the latter involves a process where the student starts by learning about the existence of a cultural property and by tapping his prior knowledge in search for a logical understanding of the heritage element. This search in turn leads to an attitudinal 
and evaluative response. The appreciation that follows such an understanding drives the student to move from idea to action-conservation and transmission. The process activates in the learner attitudes of care, enjoyment and willingness to pass on what is seen as a legacy.

Practically the whole set of current legal texts include the full procedural sequence of sensitisation: Knowing-Understanding- Respecting-Valuing in order to Take Care ofEnjoy-Transmit. Even so, the approach taken mainly focuses on an attitudinal stance that, according to authors like Fontal and Gómez-Redondo (2016) must be superseded towards an approach that puts the accent on the relational, binding and experiential dimension between the cultural asset and the student. In order to build self-meaning, through the heritagisation processes capable of generating heritage-related bonds and feelings among students (Copeland, 2006). Again in tune with other published research, we observe that in Spain's education legislation there is a predominance of aesthetic and temporal views involving traditional methodologies and academic as well as conservation-oriented purposes (Cuenca et al., 2017). Such an approach must evolve towards a globalising and symbiotic approach that fosters relational processes between the cultural property and the student in order to construct self-meanings (Copeland, 2006). The rate of occurrence of the sensitisation sequence is directly related to the presence of heritage as curricular content, which in turn varies according to each region's supply of subject courses offered under its jurisdiction

The ample presence of the term "identity" is not surprising, given the large potential of heritage education in working with this concept. The data obtained match the views of authors who foreground the close connection between heritage and identity (Copeland, 2006; Teixeira, 2006) and the conclusions of research work underscoring the fact that heritage is a curricular content invariably developed from a symbolic and identity-driven perspective (Pinto \& Molina-Puche, 2015). As regards the term "manifestations", which refers to the most intangible dimension of heritage, the figures are again highest for Andalusia, and also for Valencia

The above conclusion, however, lends itself to many shades and nuances due to the decentralisation of Spain's educational system as of the 1990s. As a result of devolution policies, curricular decentralisation means that the education administration in each autonomous community establishes the degree of awareness of cultural heritage that 
should inform the curriculum as reflected in the areas under their jurisdiction. It is in this respect that many regions exhibit a greater interest and take the opportunity to introduce autonomously determined subjects that address specific contents regarding the community's language, culture and heritage. In this sense, regions like Andalusia and the Canary Islands are remarkable in that they try to raise the awareness of their students from a very early age over the community's peculiar cultural manifestations as a first step in understanding other cultures and promoting inclusion and the social order (Buckley \& Graves, 2016; Fontal \& Marin, 2016). Similarly, Asturias and Navarre are outstandingly committed to putting the focus on their most intangible traditions and cultural manifestations. Indeed, all four autonomous communities display better results in the analyses conducted in the course of this research and turn out to be the only ones that provide a freely determined subject on the region's culture in one or another grade within their Primary Education course of study.

The Communities that come uppermost in terms of rate of occurrence are not the ones that have co-official languages -Catalonia, Valencia, the Basque Country and Navarre. This is an observation worth pondering, since initially the latter set of communities may be expected to have exhibited a larger prominence of their autochthonous heritage, manifestations, traditions and sense of identity as elements to be transmitted through education. In this context, Fuhai (2017) discusses the curriculum's shortcomings in passing on ethnic heritage by means of school education and argues for fittingly integrating local knowledge into the school's programme of studies as a key to success.

By contrast, other communities resort to these "free configuration" subjects as reinforcement teaching by emphasising customised attention and the prevention of learning difficulties. In our view, one of the main motivations behind this core-subjects reinforcement strategy has more to do with obtaining early positive results in external evaluations (one is performed by the regional administration upon third grade conclusion and the other is a state level assessment at the end of the whole educational phase) than with a focus on the students' constructive and continuous learning. It would appear that the acquisition of some competences received a special priority -i.e., knowledge is not understood in terms of competence but rather in the conventional sense and in the framework of individual courses (Wahlström, 2016). This may condition both teachers and students, who will thus focus on respectively teaching and learning that which is going to be evaluated, so that ultimately the teaching-learning system as implemented in 
the classroom departs from what has really become mainstream methodology in the texts under examination.

Every community has its own distinct interpretation of the basic curriculum defined in the $\mathrm{RD}$, so that there exist broad differences in the curricular coverage of cultural heritage depending on the autonomous region under consideration, despite the fact that the regional education administrations must all comply with Organic Law 8/2013 of 9 December for the enhancement of the quality of education. Such differences, however, should not be oversighted since, according to Scalise (2015), education is a fundamental variable in the dynamics of cultural and heritage identity construction, apart from being a key factor in sustainable heritage management (UNESCO, 2014). In this way, a core notion like cultural and natural heritage in European Union texts becomes recontextualised in our national curriculum (Nordin \& Sundberg, 2016). This is why it is critical to undertake a continuous revision in order to improve curricular plans leading to the discussion as to whether cultural heritage should be included in the educational design as a subject in its own right (Barghi et al., 2017; Hang et al., 2017; Hunter, 1988) or as a fertile source for the study of other subjects (Fuhai, 2017). A study requested by the European Parliament's CULT Committee on Education in Cultural Heritage concluded that $88 \%$ of people responding the survey "answered 'yes' to the two questions", i.e. claimed that heritage should be integrated into the curriculum in both fashions (Gesche-Koning, 2018, p. 31). The distinction is meaningful, since the second choice is easier to implement in schools than the first one, "which needs finding structural timing". Yet in order to make sure that heritage becomes a transversal resource across other subjects - the second choice - and is seen by teachers as something natural, the latter should have become familiar with heritage issues in the course of their training. And this once again requires time in order to integrate heritage education into the curricula.

Another of the main conclusions of the first article (Fontal et al., 2017) was the wide gap between the presence of heritage-related contents in the curriculum and the scanty representation of such contents in the teaching degrees. Regarding the analysis of subjects addressing heritage contents in the course of study of prospective Primary Education teachers, we observe a scanty coverage in relation to the total number of universities under examination. While still insufficient, such coverage is larger in the case of public universities. Heritage-related subjects are generally provided as elective 
courses, which means that those students who do not enrol in them will not be exposed to heritage contents and their didactic treatment. The analysis of contents shows that the latter are arranged according to the heritagisation sequence (Fontal, 2003), although there are a number of discontinuities regarding the links "valuing" and "sentitisation". We believe, therefore, that the main problem lies in the limited range of heritage-related courses that are provided. Only the autonomous region of Andalusia, Asturias and Valencia offer a subject of their culture, without taking into account the autonomous regions of Aragón, Navarra, País Vasco, Galicia and Valencia and Catalonia that offer a specific subject of their cooficial language and its literature, as we can see in table 5. At the same time, we should not forget, however, that prospective teachers who are being trained at universities experience different social and professional needs from those they will encounter in the future, and that new legislation is still pending in this area (Barredo et al., 2013).

We believe that such a dysfunction may be due to a time "mismatch" between the current situation and the curriculum that was in force when the study programmes for the future teachers were designed. Consequently, some scholars argue for a review of such programmes in order to include heritage-related contents in university education (Koster et al., 2005; Zhang y Zhao, 2014). Training must be targeted at ensuring that heritage contents are duly imparted by prospective teachers in their future classroom. In other words, teachers must implement a teaching-learning model that engages the relational and emotional dimensions of heritage (Domínguez \& López-Facal, 2017; Domínguez et al., 2019) with a view to building identity-driven values, promoting intercultural respect and educating young people who are socially and culturally committed to heritage. Empowering teachers and providing them with the skills and the responsibility to revise and reshape the curriculum is another claim that must be made in view of the fact that "their autonomy and intellectual freedom to craft curriculum, tests, and assessments are relinquished and put in the hands of 'experts' and testing companies such as Pearson" (Wexler, 2014, p. 172).

$\mathrm{Be}$ it as it may, every curricular reform should always result from an analysis of the educational and social demands (Gimeno, 2005) and from the need to train people in personal and collective responsibility with regard to cultural heritage, its sustainable use and the awareness of its value for society (Council of Europe, 2005). In order to properly contextualize a curricular model, we agree with Gesche-Koning that "it is 
highly recommended having cultural heritage at the very core of education and not as a stopgap and seeing education more deeply rooted in cultural heritage through adequate and efficient mutual long-term partnership policies" (2018, p. 3). The ultimate goal is to ensure that the new generations know, and therefore understand and value their cultural legacy while they experience a process of reaffirmation of identity values in the face of the ever more homogeneous cultural models that result from globalisation.

\subsubsection{Approaches and categories in educational programmes related to ICH}

Following our analysis of educational programmes, we may conclude that intangible cultural heritage displays a wide range of typologies and is indeed very rich. For this reason, it is certainly necessary to instil in young people a sense of belonging that leads to the assumption of responsibility with regard to the conservation of this particularly fragile heritage type. One of the main conclusions of our research, as well as an important shortcoming detected by our study, is the high percentage of scrutinised programmes that do not have a properly structured and complete educational design. In other words, such programmes do not develop the parts that are needed for a sound didactic design - theoretical grounding and context-adequacy, goals, contents, methodology, timeline, adaptation and evaluation-; or if they do, these components are only addressed superficially or exhibit limitations. These results match the research findings by Marín et al. (2016), where such shortcomings of educational designs in inclusion-driven heritage education programmes are highlighted.

One of the key goals for the future, therefore, will be to produce sound didactic designs where there is agreement and consistency between the programme's aims and contents, on the one hand, and the curricular contents themselves on the other. It is critical to endow heritage-related programmes with links to the values, core skills and contents to be developed in each phase, as otherwise claimed by several scholars working in this field (Dussan, 2015; Pinto \& Molina-Puche, 2015; Pinto \& Zarbato, 2017). A negative feature that is also worth mentioning is the absence of programmes adapted to several target groups. This should be a matter of concern insofar as diversity is present in all spheres of society: a claim made in the study by Fontal and Martín (2016), who argue that since diversity characterizes both human beings and heritage itself, heritage education should be multidimensional, diverse, inclusive and equitable. Authors like Buckley and Graves (2016) also entertain the view that heritage can be a powerful tool 
in promoting respect for and appreciation of diversity, as well as in helping students acquire an intercultural perspective that espouses a fairer, more inclusive society.

This is why we believe it essential to bear in mind heritage diversity. We should get rid of a narrow understanding of heritage which only specific cultural groups benefit from and instead adopt a broader conception of culture and heritage that serves the interests of all students. Understanding the intangible cultural heritage of diverse communities enables us to understand and accept difference while at the same time fostering intercultural dialogue and promoting respect for other ways of life. In this sense, ICH constitutes a formidable tool in order to encourage and instil in learners respect for diversity as well as a meeting point for students with several ethnic, linguistic and cultural backgrounds. Students must respect, recognise and appreciate such diversity so as to promote a fairer, more inclusive and caring society, as demanded by the Convention for the Protection and Promotion of the Diversity of Cultural Expressions (UNESCO, 2005), the Declaration on Cultural Diversity (Committee of Ministers, 2000) or the Recommendation 1884-Cultural education: The promotion of cultural knowledge, creativity and intercultural understanding through education (Parliamentary Assembly, 2009).

The use of ICTs is likewise scarce in programmes dealing with intangible heritage despite the many benefits that may be derived from embracing these tools, as proven by abundant research work on this topic cited in this dissertation (Cozzani et al., 2017; Dagnino et al., 2015; Kasapoglu, 2016; Ott \& Pozzi, 2011; Ott et al., 2015; Soon, 2014). Indeed, the results of our bibliometric study in section 2.5.2 suggest an unequivocally growing trend in the development of research work on the coupling of ICTs and intangible cultural heritage.

On the other hand, we detect examples of good practices and programmes regarding ICH - some of them remarkably original. Another aspect worth highlighting is the wealth of educational programme types. In fact, all existing typologies are represented in our sample, which goes to show that intangible heritage is being dealt with in education according to several approaches. Also observable is a fair representation of programmes implemented in informal educational settings and, to a lesser extent, in non formal ones. Many of them, on the other hand, take place in formal environments and in collaboration with local institutions: an enriching development insofar as it engages the participation 
of all players in education. Indeed, the contribution of such actors as are immersed in the heritagisation process facilitates the construction of identity and therefore enhances the quality of programmes (Fontal \& Gómez-Redondo, 2016).

In the second article of this thesis (Fontal and Martínez, 2016a) we provide a few guidelines pointing to a number of aspects to be borne in mind in programme preparation in order to improve the quality of future designs.

- Developing a programme suited to the context and to the initial needs.

- Setting feasible targets according to the beneficiaries' age and the current regulations for each educational stage if the programme in question takes place in a formal setting.

- Notwithstanding the educational environment (formal, non-formal or informal) where the programme takes place, it is enriching to seek the participation of other groups and institutions with the aim of gathering additional support and engaging the participation of the whole school community.

- Teaching-learning resources must be suited to the methodology that the programme intends to implement. Furthermore, they must be carefully selected on the basis of the group's characteristics, the institution's educational programme and the material or human resources available.

- Training of staff responsible for implementing the programme, both in formal and informal settings.

- Developing programme adaptations and bearing in mind the special needs of the target community or group.

- Detailed development of a methodology for programme implementation.

- Periodic scheduling of the programme.

- Programme evaluation oriented towards content adequacy and compliance with current legislation. Evaluation of programme implementation.

- Feedback-oriented continuous and formative evaluation. Evaluation of programme results regarding the acquisition of knowledge and values contemplated in the programme's goals.

- Reflecting on the negative aspects during evaluation and searching for strategies to improve deficit areas so as to ensure the continuity of the programme. 
The above discussion makes clear the need to consider all aspects involved in producing fine educational designs that underpin programmes concerned with intangible heritage.

As regards the degree of correlation shown by our contingency analyses, we can observe that programmes whose educational designs are more consistent exhibit a higher degree of correlation with the type of target users (students). On the other hand, those programmes that have an educational design are mostly implemented according to the trend lines observable in the sphere of formal education by contrast with non formal or informal educational settings. These correlations may be attributed to the understanding that only those actions that are tied to the more formal school settings require a solid educational design. Such a conception, however, must be challenged, since any educational action, regardless of its setting and target audience, should be correctly planned and structured.

Educational programmes must be designed by paying close attention to all aspects involved in a fine didactic design. This is critical if they are to achieve their main goal, which is to raise awareness about the importance of heritage and promote respect for and appreciation of the latter (UNESCO, 1972, arts. 27 and 28): in other words, to activate the sensitisation chain (Fontal, 2003) whereby a cultural property, intangible in this case, becomes society's heritage. Gaps and shortcomings detected in published analyses (Fontal \& Martínez, 2018a; 2018b) must be converted into achievable standards with which to address the design of future educational materials aimed at the transmission of concepts and values related to intangible heritage. Administrations should critically ensure the development and consolidation of research projects endeavouring to achieve continuous findings and providing follow-up for actions in the field of heritage education (Domingo et al., 2013, p. 7). Such projects include an emphasis on inventories and documentation centres that meet the needs of heritage conservation, preservation and dissemination and support education as a key factor in the proper management of intangible assets. Heritage education, then, will enable us to build relationships in an experiential way and assign meanings and values to intangible assets which will thus become heritage: a legacy that we will wish to preserve and pass on to others (Lobovikov-Katz, 2009). 


\subsection{Future lines of research}

One of the future avenues of research in this field will be the development of curricular analyses that extend beyond the national context so as to obtain correlational results across several countries which may be interesting for the international community of scholars in this discipline and for policy-makers in the area of heritage education. Another line of research involves the analysis of such tensions as exist between the tendency towards a standardised curriculum and the recognition of cultural diversity; or the focus on the choice of teaching approaches and heritage-related contents and who should or could make those decisions. Additionally, the data obtained from the analysis of the courses of study leading to a Teaching degree in Primary Education, especially as regards the initial training received by future teachers in this educational level, should be compared with the situation in other EU countries. This is a fundamental issue in the wake of the standardisation resulting from the Bologna Declaration ${ }^{52}$ (European Ministers of Education, 1998), which set up the system of academic credit known as ECTS and the Diploma Supplement (Real decreto 1044/2003) with the aim of equipping all university students in the European Higher Education Area with the same professional competencies.

Yet another future line of inquiry will be the continuation of educational programme evaluation in the field of ICH by employing more representative samples and using instruments like the Q-Edutage scale (Fontal et al., 2019), as well as the design of specific evaluation tools around ICH that make it possible to revise educational practices by means of case studies and improve on them through continuous actions. Finally, we should not forget the research potential of evaluating learning outcomes resulting from the implementation of educational programmes.

In addition to all this, heritage education secures such processes of social empowerment as enable us to competently preserve a commonly shared past and our own cultural heritage as European citizens. For that reason, we believe that is important to set up coordination instruments to bring together research on heritage education which is

\footnotetext{
52 The Bologna Declaration laid down the foundations of the European Higher Education Area, organised according to a number of principles (quality, mobility, diversity, competitiveness) and aimed at achieving, among others, two strategic goals: increasing employability in the European Union and transforming the European Higher Education system into a pole of attraction for students and teachers from other parts of the world.
} 
currently dispersed throughout different countries and different disciplines, and develop communication channels and networks between all key stakeholders involved in heritage management and promoting the engagement of society, since it is the society that constitutes the main recipient and legatee of heritage itself.

\subsection{Limitations of research}

One of the main limitations of the present study has been the absence of a complete educational design in some of the ICH programmes under examination, since they exhibit a superficial didactic structure that is neither described nor detailed. This has hampered our analysis and evaluation work. Another aspect that constrained our research is related to the sample of programmes that were analysed, which was not evenly representative at an international level. Indeed it is a random sample resulting from programme search and location by several researchers. On the other hand, mention must be made of the fact that difficulties were encountered while performing our descriptive statistical, correlational and content-based analysis of legislation and curricula, due to the considerable volume of documents involved. 


\section{CAPITULO VI Bibliografía}

Blowin' in The wind (Bob Dylan, 1963)

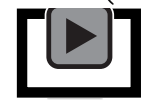

Bob Dylan-Blowin' in the wind-lyrics.mp3

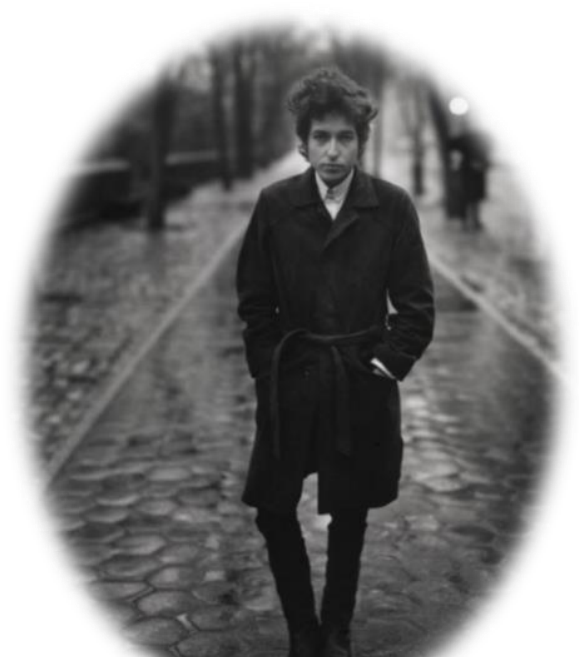

Bob Dylan, singer. (Richard Avedon, 1965) MOMA) 



\section{Bibliografía}

Aerila, J. A., Rönkkö, M. L., y Grönman, S. (2016). Field Trip to a Historic House Museum with Preschoolers: Stories and Crafts as Tools for Cultural Heritage Education. Visitor Studies, 19(2), 144-155. doi:10.1080/10645578.2016.1220187

Agulló, M. C. (2010). La voz y la palabra de los tesoros vivos: fuentes orales y recuperación del patrimonio histórico-educativo inmaterial. Educatio Siglo XXI, $28(2), 157-178$.

Ahmad, Y. (2006). The Scope and Definitions of Heritage: From Tangible to Intangible. International Journal of Heritage Studies, 12(3), 292-300.

Ahmet, A. (2018). Intangible Cultural Heritage and Education: Critical Examination of the Education in Periodic Reports. Milli Folklor, 120, 59-72.

Aikawa, N. (2004). Visión histórica de la Preparación de la Convención Internacional de la UNESCO para la Salvaguardia del Patrimonio Cultural Inmaterial. Museum International, 221, 140-153.

Akmehmet, K. T. (2017). Analysing of elementary and middle school visual arts lesson curriculum in terms of relation between art history instruction and museum education. Milli Egitim, 1(214), 181-207.

Alaminos, A., y Castejón, J. L. (2006). Elaboración, análisis e interpretación de encuestas, cuestionarios y escalas de opinión. Serie: Docencia UniversitariaEspacio Europeo de Educación Superior. Instituto de Ciencias de la Educación (ICE). Vicerrectorado de Calidad y Armonización Europea. Universidad de Alicante. Alcoy: Marfil.

Alkateb, M. (2013). Non-traditional education using cultural heritage: A case study from Syria. International Journal of Education through Art, 9(2), 189-204. https://doi.org/10.1386/eta.9.2.189_1

Álvarez, M. D., Bellido, M. C., y Atencia, P. (2019). Teaching though ICT in Obligatory Secundary Education. Analysis of online teaching toos. Red-Revista de Educación a Distancia, 59(5), 1-19. doi: https://doi.org/10.6018/red/59/05 
Álvarez, P., Martínez, N., y García, R. (2017). Cultural heritage in students memories upon completing High School in Spain: education and heritage identity. Tempo e argumento, 9(22), 198-235.

Alves, L. A., y Pinto, H. (2019). Educación histórica con el patrimonio: desafiando la formación de profesorado. Revista Electrónica Interuniversitaria de Formación del Profesorado, 22(1), 71-81. doi: http://dx.doi.org/10.6018/reifop.22.1.356381

Angelopoulou, A., Economou, D., Bouki, V., Psarrou, A., Jin, L., Printchar, C., y Kolyda, F. (2012). Mobile Augmented Reality for Cultural Heritage. En N. Venkatasubramanian, V. Getov y S. Steglichm(Eds.), Mobile Wireless Middleware, Operating Systems, and Applications (pp. 15-22). Heidelberg, Berlin: Springer.

Apaydin, V. (2016). Effective or not? Success or Failure? Assessing Heritage and Archaeological Education Programmes - The Case of Çatalhöyük. International Journal of Heritage Studies 22(10), 828-43. doi: https://doi.org/10.1080/13527258.2016.1218912

Apaydin, V. (2018). The entanglement of the heritage paradigm: values, meanings and uses. International Journal of Heritage Studies, 24(5): 491-507. doi: https://doi.org/10.1080/13527258.2017.1390488

Apostolopoulou, A. P., Carvoeiras, L. M., y Klonari, A. (2014). Cultural heritage and education. Integrating tour maps in a bilateral Project. European Journal of Geography, 5(4), 67-77.

Arante, A. (2019). Safeguarding, a key dispositive of the ICH convention. Vibrante, virtual Brazilian anthropology, 16. doi: http://dx.doi.org/10.1590/1809$\underline{43412019 v 16 a 201}$

Arciniegas, A. T. (2016). El documental interactivo como un instrumento educativo. propuesta teórico práctica para la difusión digital del patrimonio cultural colombiano (Tesis doctoral). Universitat politécnica de Valencia, Valencia.

Arias-Ferrer, L., y Egea, A. (2017). Thinking Like an Archaeologist: Raising Awareness of Cultural Heritage Through the Use of Archaeology and Artefacts in Education. 
Public Archaeology, 16(2), 90-109. doi: https://doi.org/10.1080/14655187.2017.1479558

Arizpe, L. (2004). Intangible cultural heritage, diversity and coherence. Museum International, 56(2), 130-136.

Arraiz, A., y Sabirón, F. (2012). Orientación para el aprendizaje a lo largo de la vida: modelos y tendencias. Zaragoza: prensas de la Universidad de Zaragoza.

Asamblea General Naciones Unidas. (2015). Transformar nuestro mundo: la Agenda 2030 para el Desarrollo Sostenible.

Avci, M., y Memişoğlu, H. (2016). Views of social studies teachers about the cultural heritage education. Elementary Education Online, 15(1), 104-124.

Azman, N., Halim, S. A., Liu, O. P., Saidin, S., y Komoo, I. (2010). Public education in heritage conservation for geopark community. Procedia-Social and Behavioral Sciences, 7, 504-511. doi: https://doi.org/10.1016/j.sbspro.2010.10.068

Ballar, J., y Tresseras, J. (2001). Gestión del patrimonio cultural. Barcelona: Ariel

Bangdiwala, K. (1987). Using SAS software graphical procedures for the observeragreement chart. Proceedings of the SAS User's Group International Conference, 12, 1083-1088.

Barañano, A., García, J. S, Cátedra, M., y Devillard, M. J. (coords.). (2007). Diccionario de relaciones interculturales: diversidad y globalización. Madrid: Editorial Complutense.

Barghi, R., Zakaria, Z., Hamzah, A., y Hashim, N. (2017). Heritage education in the Primary School Standard Curriculum of Malaysia. Teacher and teaching education, 61, 124-131. doi: https://doi.org/10.1016/j.tate.2016.10.012.

Barriga, E. (2017). Las rutas literarias en el marco de la educación literaria y sus valores patrimoniales, ambientales y turísticos (Tesis doctoral). Universidad de Extremadura, Extremadura.

Barthes, A., y Blanc-Maximin, S. (2017). What are the developments in the French Schools for heritage education? Revue des Sciences de l Education, 43(1), 85-115. doi: https://doi.org/10.7202/1042075 
Bauman, Z. (2000). Liquid Modernity. Cambridge, UK: Polity Press.

Bendix, R. (2009). Heritage between Economy and Politics: An Assessment from the Perspective of Cultural Anthropology. En L. Smith y N. Akagawa (Eds.), Intangible Heritage (pp. 253-269). London: Routledge.

Bhatawadekar, S., y Yedurkar, C. (2016). Role of Heritage Education in Cultural Heritage Conservation. En A. Macchia, F. Prestileo, S. Cagno y F. Khalilli (Eds.), Professionals 'Experiences in Cultural Heritage Conservation in America, Europe, and Asia (pp. 9-13). United Kingdom: Cambridge Scholars Publishing.

Bolívar, C. R. (2013). Instrumentos y técnicas de investigación educativa: un enfoque cuantitativo y cualitativo para la recolección y análisis de datos ( $3^{\mathrm{a} E d}$.). Houston, Texas: Danaga.

Bortolotto, C. (2010). Globalising intangible cultural heritage? Between internacional arenas and local appropriations. En S. Labadi y C. Long (Eds.), Heritage and Globalisation (pp. 6-17). London: Taylor \& Francis, 6-17.

Bortolotto, C. (2014). La problemática del patrimonio cultural inmaterial. Culturas. Revista de Gestión Cultural, 1(1), 1-22.

Bortolotto, C. (2015). UNESCO, Cultural Heritage, and Outstanding Universal Value: Value-Based Analyses of the World Heritage and Intangible Cultural Heritage Conventions. International Journal of Heritage Studies, 21(5), 528-30. doi: https://doi.org/10.1080/13527258.2015.1024462

Bosić, N., y Mihić, I. G. (2017). Cultural and arts education - project benčić youth council. Ge-Conservacion, 1(11), 224-229.

Bourdie, P. (1997). Capital Cultural, Escuela y Espacio Social. Madrid: Siglo XXI Editores.

Branchesi, L. (Ed.). (2007). Heritage Education for Europe. Outcome and perspective. Roma: Armando Editore.

Brugman, F. (2005). La Convención para la Salvaguarda del Patrimonio Cultural Inmaterial. PH Cuadernos, 17, 54-29. 
Buckley, J. M., y Graves, D. (2016). Tangible Benefits from Intangible Resources: Using Social and Cultural History to Plan Neighborhood Futures. Journal of The American Planning Association, 82(2), 152-166. doi: https://doi.org/10.1080/01944363.2016.1141663

Cabero, J., y Llorente, M. C. (2013), La aplicación del juicio de experto como técnica de evaluación de las tecnologías de la información (TIC). Eduweb. Revista de Tecnología de Información y Comunicación en Educación, 7(2) 11-22. Recuperado de http://tecnologiaedu.us.es/tecnoedu/images/stories/jca107.pdf

Cai, L., Thissen, D., y du Toit, S. (2015). IRTPRO for Windows [Computer software]. Lincolnwood, IL: Scientific Software International.

Calaf, R., Gillate, I., y Gutierrez, S. (2015). Assessing the Educational Programs in art Museums linked to the ECPEME Project. Educatio siglo XXI, 33(1), 129-150. doi: http://dx.doi.org/10.6018/j/222531

Calaf, R., San Fabián, J. L., y Gutiérrez, S. (2017). Evaluación de programas educativos en museos: Una nueva perspectiva. Bordon, 69(1), 45-65. doi: https://doi.org/10.13042/Bordon.2016.42686

Calaf, R., y Gutiérrez, S. (2017). The Thyssen-Bornemisza Museum; evaluating it's educative programs to teach art. Arte, Individuo y Sociedad. 29(1), 39-56.

Capel, H. (2014). El patrimonio: la construcción del pasado y del futuro. Barcelona: Ediciones del Serbal.

Carrera, G. (2005). Patrimonio inmaterial y gestión de la diversidad. PH Cuader-nos. Sevilla: Instituto Andaluz del Patrimonio Artístico.

Carrera, G. (2009). Iniciativas para la salvaguardia del patrimonio inmaterial en el contexto de la convención Unesco, 2003: Una propuesta desde Andalucía. Revista Patrimonio Cultural De España, 0, 179-195.

Carrera, G. (2015). La Ley 10/2015 para la Salvaguarda del PCI (2013-2014): ¿patrimonio inmaterial o nacionalismo de Estado? Revista ph, 88. doi: https://doi.org/10.33349/2015.0.3674 
Casanova, A., Arias, L., y Egea, A. (2018). Project based learning as an opportunity to introduce history and heritage at early years-foundation stage. Contextos Educativos-Revista de Educación, 22, 79-95. Doi:

Casimiro, A. (2008). Articulations in curriculum policies. Perfiles educativos, 120(3), 63-78.

Castro, B., y López-Facal, R. (2019). Portomarin: the wounded memory of being uprooted. Revista Electrónica Interuniversitaria de Formación del Profesorado, 22(2), 95-110. doi: 10.1590/0104-4060.64402

Castro, M. P., y Avila, C. M. (2015). La salvaguardia del patrimonio Inmaterial: Una aproximación a la reciente ley 10/2015. RIIPAC, 5(6), 89-124.

Cavalcanti, L. M. (2016). The heritage education and the incentive practices to local cultures. SIMBIOTICA, 3(1), 76-99.

Cepeda, J., y Fontal, O. (2019). Diseño de una encuesta para identificar las formas de relación identitaria en Castilla y León. Revista Electrónica Interuniversitaria de Formación del Profesorado, 22(1), 29-40. doi: http://dx.doi.org/10.6018/reifop.22.1.356031

Cerri, A. (2007). The political dimension of the Council of Europe Heritage Education programme. En L. Branchesi (Ed.), Heritage Education for Europe. Outcome and perspective. (pp. 19-29). Roma: Armando Editore.

Chaves, M., Montenegro, M., y Zambrano, M. (2010). Mercado, consumo y patrimonialización cultural. Revista Colombiana de Antropología, 46(1), 7-26.

Chen, F. (2017). Research on Deficiency of Intangible Cultural Heritage Education in Colleges and Its Countermeasures. International Conference on Culture, Education and Financial Development of Modern Society (ICCESE), Moscow 103, 207-209.

Colom, A. J. (1998). Educación ambiental y la conservación del patrimonio. En A. J. Colom; J. Sarramona y G. Vázques. Educación no formal. Barcelona: Ariel.

Coma, L. (2011). Actividades educativas y didáctica del patrimonio en las ciudades españolas. Análisis, estado de la cuestión y valoración para una propuesta de modernización (Tesis doctoral). Universidad de Barcelona, Barcelona. 
Committee of Ministers. (1985). Resolution (85) 6 on European Cultural Identity (Adopted by the Committee of Ministers on 25 April 1985 at its 76th Session).

Committee of Ministers. (1998). Recommendation No $R$ (98) 5 of the Committee of Ministers to Member States Concerning Heritage. (Adopted by the Committee of Ministers on 17 March 1998 at the 623rd meeting of the Ministers' Deputies).

Committee of Ministers. (2000). Declaration on Cultural Diversity. (Adopted by the Committee of Ministers on 7 December 2000 at the 733rd meeting of the Ministers' Deputies)

Committee of Ministers. (2017). Recommendation of the Committee of Ministers to member States on the European Cultural Heritage Strategy for the 21st century. (Adopted by the Committee of Ministers on 22 February 2017 at the 1278th meeting of the Ministers' Deputies). CM/Rec (2017)

Cook, T. D., y Reichardt, C. S. (2005). Métodos cualitativos y cuantitativos en investigación evaluativa. Madrid: Morata.

Copeland, T. (1991). A teacher's guide to maths and the historic environment. London, England: English Heritage.

Copeland, T. (2006). European democratic citizenship, heritage education and identity. Strasbourg, France: Council of Europe.

Copeland, T. (2007). Heritage Education and citizenship in the Council of Europe. In L. Branchesi (Ed.), Heritage Education for Europe. Outcome and perspective. (pp. 65-86). Roma: Armando Editore.

Corral, C. (2009). Validez y confiabilidad de los instrumentos de investigación para la recolección de datos. Revista Ciencias de la Educación, 19(33), 228-247.

Council of Europe. (1954). European Cultural Convention. Paris, 19.XII.1954: European Treaty Series - No. 18.

Council of Europe. (1975). The Declaration of Amsterdam. Congress on the European Architectural Heritage.

Council of Europe. (1993). Handbook on European heritage classes. Strasbourg: Council of Europe Press. 
Council of Europe. (2005). Council of Europe Framework Convention on the Value of Cultural Heritage for Society. (Faro, 27.X.2005), Series -No.199.

Council of Europe. (2018). Faro Convention. Convention Action Plan Handbook 20182019. Recuperado de https://rm.coe.int/faro-convention-action-plan-handbook$\underline{2018-2019 / 168079029 c}$

Cozzani, G., Pozzi, F., Dagnino, F.M., Katos, A.V., y Katsouli, E. F. (2017). Innovative technologies for intangible cultural heritage education and preservation: the case of i-Treasures. Personal and Ubiquitous Computing, 21(2), 253-265. doi: https://doi.org/10.1007/s00779-016-0991-z

Craith, M. N., y Kockel, U. (2016). (Re-)Building Heritage: Integrating Tangible and Intangible. En W. Logan, M. N. Craith \& U. Kockel (Eds.), A Companion to Heritage Studies (pp. 426-442). Londres: Wiley-Blackwell.

Creswell, J. W. (2008). Educational research: Planning, conducting, and evaluating quantitative and qualitative research. Upper Saddle River, NJ: Pearson Publishing.

Cuenca, J. M. (2002). El patrimonio en la didáctica de las ciencias sociales: análisis de concepciones, dificultades y obstáculos para su integración en la enseñanza obligatoria (Tesis doctoral). Universidad de Huelva, Huelva.

Cuenca, J. M., Estepa, J., y Martín-Cáceres, M. (2017). Heritage, education, identity and citizenship. teachers and textbooks in compulsory education. Revista de Educación, 375, 136-159. doi: https://doi.org/10.4438/1988-592X-RE-2016-375$\underline{338}$

Cuenca, J. M., Martín-Cáceres, M., y Schugurensky, D. (2017). Citizenship education and identity in U.S. museums: An analysis from a heritage education perspective. Estudios pedagógicos, 43(4), 29-48.

Cuenca, J. M., Molina-Puche, S., y Martín-Cáceres, M. (2018). Identity, citizenship and heritage. Comparative analysis of education treatment in museums in the United States of America and Spain. ARBOR-Ciencia pensamiento y cultural, 194(788). doi: https://doi.org/10.3989/arbor.2018.788n2007 
Cuenca, J. M., y López. I. (2014). Teaching Heritage in Social Science, Geography and History Textbooks in Compulsory Secondary Education. Culture and Education, 26(1), 1-43. doi: https://doi.org/10.1080/11356405.2014.908663

Curtis, R., y Seymour, C. (2004). Louisiana heritage education program and heritage in the classroom: Children's attitudes toward cultural heritage. Journal of Social Studies Research, 28(2), 20-24.

Dado, M., y Bodemer, D. (2017). A review of methodological applications of social network analysis in computer-supported collaborative learning. Educational Research Review, 22, 159-180.

Dagnino, F. M., Hadjileontiadis, L.J., Ott, M., y Pozzi, F. (2015). An integrated platform supporting intangible cultural heritage learning and transmission: Definition of requirements and evaluation criteria. Journal of Computing and Information Technology, 22(4), 277-292.

Daltro, O. J. (2014). A experiencia da potencialidade didáctica pedagógica da arte capoeira como veiculo da educaçao nao formal nos niveis de educaçao pública e privada nas escolas da cidade de salvador da bahía - Brasil (Tesis doctoral). Universidad de Salamanca, Salamanca.

De Castro, P. (2016). Cartografía autoetnográfica de una genealogía de programas de Educación Patrimonial desde la perspectiva del aprendizaje basado en proyectos y la investigación-acción (Tesis doctoral). Universidad de Valladolid y Universidad del País Vasco, Valladolid.

Dello-lacovo, B. (2009). Curriculum reform and "Quality Education" in China: An overview. International Journal of Educational Development, 29(3), 241-249. doi: https://doi.org/10.1016/j.ijedudev.2008.02.008

Desantes, M. (2013). Hacia una visión holística del Patrimonio Cultural. RIIPAC, 3, 122.

De Troyer, V. (Coord.). (2005). Heritage in the classroom. A practical manual for teachers. Brussel, Belgic: Hereduc. 
Dias, R. M., y Cletes, M. A. (2016). Heritage, cultural diversity and education school: Education in programa mais educacao on heritage. Revista Ibero-Ameriaca de Estudos en Educacao, 11(1), 23-35.

Díaz-Emparanza, M., Peruarena, J., y Jiménez, R. (2017). Actividades de intervención educativa y de difusión del patrimonio organístico en entornos formales y no formales. Estudios pedagógicos, 43(4), 277-292.

Domingo, M., Fontal, O., y Ballesteros, P. (Coords.). (2013). Plan Nacional de Educación y Patrimonio. Madrid: Ministerio de Educación, Cultura y Deporte, Secretaría de Estado de Cultura.

Domingo, M., y Timón, M. P. (Coords.). (2011). Plan Nacional para la Salvaguarda del Patrimonio Cultural Inmaterial. Madrid: Ministerio de Educación Cultural y Deporte. Dirección General de Bellas Artes y Bienes Culturales y Archivos y Bibliotecas.

Domínguez, A., Costa-Casais, M., y López-Facal. (2019). Apropiación patrimonial de los depósitos cuaternarios del litoral gallego por estudiantes de Magisterio. Reifop, 22(1), 57-70. doi: https://doi.org/10.6018/reifop.22.1.357591

Domínguez, A., y López-Facal, R. (2017). Conflictive heritage, civic competence and profesional training in primary education. Revista de Educación, 375, 86-109. doi: 10.4438/1988-592X-RE-2016-375-336

Dusan, K. (2015). Analysis of National and Cultural Identity Educational Programmes with Examples of Good Practice. Czech-Polish historical and pedagogical journal, 7(2), 72-90.

Elena, M. (2018). Heritage education and teacher education from the Transcomplejidad. Telos-Revista interdisciplinaria en Ciencias Sociales, 20(3), 431-449.

Emiliani, M. D. (2007). Cultural Heritage Education in Italy and other European Countries. En L. Branchesi (Ed.), Heritage Education for Europe. Outcome and perspective. (pp. 15-19). Roma: Armando Editore.

Estepa, J., Ávila, R. M., y Ferreras, M. (2008). Primary and Secondary Teachers'Conceptions about Heritage and Heritage Education: A Comparative 
Analysis. Teaching and Teacher Education, 24, 2095-2107. doi: https://doi.org/10.1016/j.tate.2008.02.017

European Comission. (2014). Communication from the Commission to the European Parliament, the European Council, the Council, the European Economic and Social Committee and the Committee of the Regions. "Toward an integrated approach to cultural heritage for Europe", COM (2014) 477 final.

European Comission. (2017). Mapping of Cultural Heritage actions in European Union policies, programmes and activities. Complement the European Commission Communication. "Towards an integrated approach to cultural heritage for Europe", COM/2014/0477 final.

European Ministers of Education. (1998). Declaración de Bolonia.

European Parlament. (2017). Decision (EU) 2017/864 of the European Parliament and of the Council of 17 May 2017 on a European Year of Cultural Heritage (2018) OJ L 131, 20.5.2017, pp. 1-9.

Ferreras. M. (2015). El patrimonio como contenido de enseñanza análisis de concepciones y de recursos didácticos (Tesis doctoral). Universidad de Huelva, Huelva.

Ferreras, M., y Jiménez, R. (2013). How is heritage conceptualized in primary school textbooks? Revista de Educación, 361, 591-618. doi: https://doi.org/10.4438/1988592X-RE-2013-361-234

Foley, K. (2014). No More Masterpieces: Tangible Impacts and Intangible Cultural Heritage in Bordered Worlds. Asian Theatre Journal, 31(2), 369-398.

Fontal, O. (2003). La Educación Patrimonial. Teoría y práctica en el aula, el museo e internet. Gijón: Trea.

Fontal, O. (2011). El patrimonio en el marco curricular español. Revista de Patrimonio Cultural de España, 5, 21-44.

Fontal, O. (2013). La educación patrimonial. Del patrimonio a las personas. Gijón: Trea. 
Fontal, O. (2016a). El patrimonio a través de la educación artística en la etapa de primaria. Arte, Individuo y Sociedad, 28(1), 105-120.

Fontal, O. (2016b). The Spanish Heritage Education Observatory. Culture and Education, 28(1), 254-266. doi: https://doi.org/10.1080/11356405.2015.1110374

Fontal, O., García-Ceballos, S., Arias, B., y Arias, V. (2019). Assessing the quality of heritage education programs: Construction and calibration of the Q-Edutage scale. Revista de Psicodidactica, 24(1), 31-38. doi: https://doi.org/10.1016/j.psicoe.2018.11.001

Fontal, O., García-Ceballos, S., Aso, B., y Martínez, M. (2017). Patrimonios, objetos e historias de vida. Análisis de propuestas educativas desde el OEPE. MIDAS, 8,117.

Fontal, O., García-Ceballos, S., e Ibáñez-Etxeberria, A. (2015). Educación y patrimonio, visiones caleidoscópicas. Gijón: Trea.

Fontal, O., y Gómez-Redondo, C. (2016). Heritage Education and Heritagization Processes: SHEO Methodology for Educational Programs Evaluation. Interchange, 47(1), 65-90. doi: 10.1007/s10780-015-9269-z.

Fontal, O., e Ibáñez-Etxeberria, A (2017). La investigación en Educación Patrimonial. Evolución y estado actual a través del análisis de indicadores de alto impacto. Revista de Educación, 375(1), 84-214.

Fontal, O., Ibáñez-Etxeberria, A., Martínez, M., y Rivero, P. (2017). El patrimonio como contenido en la etapa de Primaria: del currículum a la formación de maestros. Revista Electrónica Interuniversitaria de Formación del Profesorado, 20(2), 7995. doi: http://dx.doi.org/10.6018/reifop.20.1.286321

Fontal, O., y Juanola, R. (2015). La Educación Patrimonial: Una disciplina útil y rentable en el ámbito de la gestión del patrimonio cultural. Cadmo. International Journal of Educational Research, 23(1), 254-266. doi: 10.3280/CAD2015-001002

Fontal, O., y Marín, S. (2016). Heritage Education in Museums: an inclusion-focused model. The International Journal of the Inclusive Museum, 9(4), 47-64. 
Fontal, O., y Marín. S. (2018). Nudos Patrimoniales. Análisis de los vínculos de las personas con el patrimonio personal. Arte, individuo y sociedad, 30(3), 483-500. doi: http://dx.doi.org/10.5209/ARIS.57754

Fontal, O., Marín, S. García-Ceballos, S, Martínez, M., De Castro, P., y Cepeda, J (2018). El plan de educación y patrimonio de la iniciativa Duero Douro, patrimonio para el desarrollo. Duero Douro patrimonio para el desarrollo Clúster AEICE: Valladolid.

Fontal, O., Marín S., y Pérez, S. (2013). Informe sobre el grado de cumplimiento de lo establecido por la legislación mediante la revisión de programas y acciones llevadas a cabo en los centros formativos, además de los materiales y recursos didácticos utilizados. Madrid: Instituto del Patrimonio Cultural de España.

Fontal, O., y Martínez M. (2017). Evaluación de programas educativos sobre Patrimonio Cultural Inmaterial. Estudios Pedagógicos, 43(4), 69-89. doi: http://dx.doi.org/10.4067/S0718-07052017000400004

Fontal, O., y Martínez, M. (2016a). Análisis del tratamiento del Patrimonio Cultural en la legislación educativa vigente, tanto nacional como autonómica, dentro de la educación obligatoria. Madrid: Instituto del Patrimonio Cultural de España.

Fontal, O., y Martínez, M. (2016b). La Educación Patrimonial como praxis pedagógica para la enseñanza de la arqueología. En D. Vaquerizo, A. B. Ruiz y M. Delgado. (Eds.), Rescate, Tomo I (pp. 141-153). Córdoba: UCOPress.

Fontal, O., y Martínez, M. (2018). Analysis of educational designs in intangible cultural heritage programmes: the case of Spain. Internacional Journal of Intangible Heritage, 13, 189-202.

Fontal, O., y Martínez, M. (2019). The Heritage and Education Research Network: Place value on Cultural Heritage in Europe. En E. Delgado y J. M. Cuenca. (Eds.), Handbook of Research on Citizenship and Heritage Education. IGI Global Publisher. Manuscrito presentado para su publicación.

Frías del Val, A. S. (2007). El currículo escolar y la descentralización educativa en España. Revista de Educación, 343, 199-221. 
Fuhai, A. (2017). The Basis for Integrating Local Knowledge into the School Curriculum for Tibetans in Southern Gansu. Chinese Education \& Society, 50(1), 12-17. doi: https://doi.org/10.1080/10611932.2016.1262182

García, N. (1999). Los usos sociales del Patrimonio Cultural. En E. Aguilar (Coord.), Patrimonio Etnológico. Nuevas perspectivas de estudio (pp. 16-33). Sevilla, Instituto Andaluz de Patrimonio Histórico.

García-Ceballos, S. (2018). Evaluación de programas en educación patrimonial: Indicadores de calidad a través del método SAEPEP-OEPE y su instrumento basado en estándares EBEB-OEPE. (Tesis doctoral). Universidad de Valladolid, Valladolid.

García-Ceballos, S., do Amaral, L., y Olivar, J. (2017). La Educación Patrimonial en el contexto no formal de São Paulo (Brasil). Plataforma Paranapiacaba: memoria y experimentación. Estudios Pedagógicos, 43(4), 91-113. Consultado de http://revistas.uach.cl/index.php/estped/article/view/1792

Garner, J., Kaplan, A., y Pugh, K. (2016). Museums as Contexts for Transformative Experiences and Identity Development. Journal of museum education, 41(4), 341352.

Gelabert, M. À. E. (2006). Liderar escuelas interculturales e inclusivas: equipos directivos y profesorado ante la diversidad cultural y la inmigración (Vol. 222). Barcelona: Graó.

Gesche-Koning, N. (2018). Research for CULT Committee - Education in Cultural Heritage, European Parliament, Policy Department for Structural and Cohesion Policies, Brussels. Recuperado de http://www.europarl.europa.eu/RegData/etudes/STUD/2018/617486/IPOL_STU(2 018)617486_EN.pdf

Gillate, I. (2014). Programas de Educación Patrimonial en contextos informales: análisis y valoración de su influencia en el alumnado de eso de la zona mineroindustrial de Bizkaia (Tesis doctoral). Universidad de País Vasco, Donosti. 
Gimeno, J. (2005) ¿Qué se puede ganar descentralizando la educación?: ¿Es posible diferenciarse sin desigualdad? En J. Gairín. (coord.), La descentralización educativa: ¿Una solución o un problema? (pp. 85-134). Madrid: Ed. Praxis.

Gómez, C. J., y Miralles, P. (2015). ¿Pensar históricamente o memorizar el pasado? La evaluación de los contenidos históricos en la educación obligatoria en España. Revista de Estudios Sociales, 52, 52-68.

Gómez, C. J., Ortuño, J., y Molina-Puche, S. (2014). Aprender a pensar históricamente. Retos para la historia en el siglo XXI. Revista Tempo e Argumento, 6(11).

Gómez-Redondo, C. (2012). Identización: la construcción discursiva del individuo. Arte,

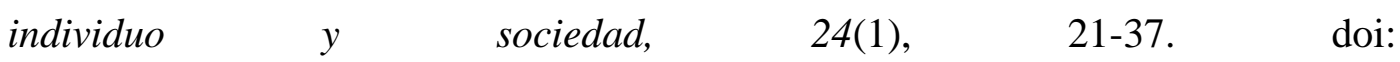
http://dx.doi.org/10.5209/rev_ARIS.2012.v24.n1.38041

Gómez-Redondo, C. (2013). Procesos de patrimonialización en el arte contemporáneo: diseño de un artefacto educativo para la identización (Tesis doctoral). Universidad de Valladolid, Valladolid.

Gómez-Redondo, C., Calaf, R., y Fontal, O. (2016). "Roser Calaf's collection” of textual educational resources for museums and heritage places: analysis and evaluation from the point of view for heritage education. Revista de Humanidades, 28, 87113.

González-Sanz, M, Feliu, M., y Cardona, G. (2017). Visual Thinking Strategies from the perspectives of museum educators: a SWOT analysis of the method's practical implementation. Revista de Educación, 375, 160-183. doi: 10.4438/1988-592XRE-2016-375-339

Gracía, Z. (2009) ¿Cómo acercar los bienes patrimoniales a los ciudadanos? Educación Patrimonial, un campo emergente en la gestión del patrimonio cultural inmaterial. Pasos. Revista de Turismo y Patrimonio Cultural, 7(2), 271-180.

Gueler-Biyikli, S., y Aslam, C. (2013). A review of Cultural Heritage Education in Turkish Scholls (1962-2011). Public Archaeology, 12(4), 255-270.

Haddad, N. (2016). Multimedia and cultural heritage: A discussion for the community involved in children's edutainment and serious games in the 21 st century. Virtual Archaeology Review, 7(14), 61-73. doi: https://doi.org/10.4995/var.2016.4191 
Hằng, N. V. T., Meijer, M. R., Bulte, A. M., y Pilot, A. (2017). Designing a primary science curriculum in a globalizing world: How do social constructivism and Vietnamese culture meet? Cultural Studies of Science Education, 12(3), 739-760. doi: https://doi.org/10.1007/s11422-015-9696-2

Heinich, N. (2009). La Fabrique du patrimoine. De la cathédale á la petite cuillere. París: Éditions de la Maison des sciences de l’homme.

Hernández, A. M., y Guillen, R. (2017). Heritage education in school textbooks of Primary Education: a journey from LOGSE to LOMCE. Didáctica de las ciencias experimentales y sociales, 32, 25-49.

Huerta, R. (2015). Desarrollo de ciudadanía desde la educación artística y patrimonial: Identidades urbanas en Iberoamérica. Aisthesis, 58, 197-220.

Huerta, R., y Hernández, A. (2015). Educación artística y gestión de museos: intereses y expectativas del alumnado a partir de encuestas manuscritas. Cadmo. International Journal of Educational Research, 23(2), 47-54.

Hunter, K. (1988). Heritage Education in the social studies. Bloomington, IN: Information Analysis.

Ibáñez-Etxeberria, A. (2006). Educación y patrimonio: el caso de los campos de trabajo en la comunidad autónoma del País Vasco (Tesis doctoral). Universidad del País Vasco, Donosti.

Ibáñez-Etxeberria, A., Asensio, M., Vicent, N., y Cuenca, J. M. (2012). Mobile Devices: a Tool for Tourism and Learning at Archaeological Sites. International Journal of Web Based Communities, 8(1), 67-72.

Ibáñez-Etxeberria, A., Fontal, O., y Rivero, P. (2018). Educación patrimonial y TIC en España: Marco normativo, variable estructurales y programas referentes. Arbor, 194(788), 2-17. doi: https://doi.org/10.3989/arbor.2018.788n2008

Ibáñez-Etxeberria, A, Kortabitarte, A, De Castro, P., y Gillate, I. (2019). Competencia digital mediante apps de temática patrimonial en el marco DigComp. Revista Electrónica Interuniversitaria de Formación del Profesorado, 22(1), 13-27. doi: http://dx.doi.org/10.6018/reifop.22.1.356231 
Ibáñez-Etxeberria, A., Vicent, N., Asensio, M., Cuenca, J.M., y Fontal, O. (2014). Document Learning in archaeological sites with mobile devices. Munibe Antropologia-Arkeologia, 65, 313-321.

Iglesias, J. (1991). Sociología del folclore. Gazeta de Antropología, 8(4), 1-3.

Islamoglu, Ö. (2018). The importance of Cultural Heritage Education in Early Ages. International Journal of Educational Sciences, 22(1-3), 19-25

Jaafar, M., Noor, S. M., y Rasoolimanesh, S. M. (2015). Perception of young local residents toward sustainable conservation programmes: A case study of the Lenggong World Cultural Heritage Site. Tourism Management, 48, 154-163.

Jagielska-Burdul, A., y Piotr, S. (2019). Council of Europe Culture Heritage and Education Policy: Preserving Identity and Searching for a Common Core? Revista Electrónica Interuniversitaria de formación del profesorado, 22(1), 1-12. doi: https://doi.org/10.6018/reifop.22.1.354641

Jiménez, R.; Cuenca, J. M., y Ferreras, M. (2010). Heritage education: Exploring the conceptions of teachers and administrators from the perspective of experimental and social science teaching. Teaching and teacher education, 26(6), 1319-1331. doi: https://doi.org/10.1016/j.tate.2010.01.005.

Jiménez, N., Maz, A., y Bracho, R. (2013). Bibliometric analysis of the mathematics education journals in the SSCI. International Journal of Research in Social Sciences, 2(3), 26-32.

Jin-long, X. (2009). Thinking about Strengthening Undergraduates' Intangible Heritage Education. Journal of Gannan Normal University, 1, 30-54.

Jurion de Waha, F. (2007). Heritage Education and social integration. 10 years of actions since the Brussels Seminar. En L. Branchesi (Ed.), Heritage Education for Europe. Outcome and perspective (pp. 85-102). Roma: Armando Editore.

Kasapoglu, P. (2016). Applying the Intangible Cultural Heritage Into the Formal Education: A WebQuest Example. Milli Folklor, 111, 149-170.

Kirshenblatt-Gimblett, B. (2004). El patrimonio inmaterial como producción metacultural. Museum Internacional, 221, 52-67. 
Klein, S., Grever, M., y van Boxtel, C. (2011). 'See, think, feel, ask, talk, listen, and wonder'. distance and proximity in history teaching and heritage education in the netherlands. Tijdschrift $\quad$ Voor $\quad$ Geschiedenis, 124(3), 381-395. http://hdl.handle.net/1765/92507

Konstantinov, O., Kovatcheva, E., y Palikova, N. (2018). Gamification in cultural and historical heritage education. En L. Gómez, A. López (Eds.), 12th International Technology, Education and Development Conference (INTED) (pp.8443-8451). Valencia: IATED Academy

Koster, B., Brekelmans, M., Korthagen, F., y Wubbels, T. (2005). Quality requirements for teacher educators. Teaching and Teacher Education, 21(2), 157-76. doi: https://doi.org/10.1016/j.tate.2004.12.004

Koutrelakos, J. (2013). Identidad étnica: similitudes y diferencias en grupos blancos basados en prácticas culturales. Informes psicológicos, 112(3), 745-762.

Kronegger, L., Mali, F., Ferligoj, A., y Doreian, P. (2012). Collaboration structures in Slovenian scientific communities. Scientometrics, 90(2), 631-647. doi:10.1007/s11192-011-0493-8

Kurin, R. (2007). Safeguarding Intangible Cultural Heritage. Key factors in implementing the 2003 Convention. International Journal of Intangible Heritage, 2, 10-20.

Lacarrieu, M. (2008) ¿Es necesario gestionar el patrimonio inmaterial? Notas y reflexioens para repensar las estrategias políticas y de gestión. Boletín gestión Cultural, 17, 2-26.

Lähdesmäki, T. (2016). Politics of tangibility, intangibility, and place in the making of a European cultural heritage in EU heritage policy. International Journal of Heritage $\quad$ Studies, $22(10), \quad 766-780 . \quad$ doi: https://doi.org/10.1080/13527258.2016.1212386

Lema, A. (2008). La gestión del patrimonio inmaterial en sociedades complejas en el siglo XXI. Propuestas para implementar políticas de actuación en la Región de Murcia, España. En AA.VV. (2008). El patrimonio cultural inmaterial. Definición y sistemas de catalogación. Actas del seminario 
internacional, Murcia, 15 y 16 de febrero de 2007 (pp.71-84). Murcia: Comunidad Autónoma de la Región de Murcia.

Leone Sciabolazza, V., Vacca, R., Kennelly Okraku, T., y McCarty, C. (2017). Detecting and analyzing research communities in longitudinal scientific networks. PLoS ONE, 12(8), 1-23. doi:10.1371/journal.pone.0182516.

Ley 14/1970, de 4 de agosto, General de Educación y Financiamiento de la Reforma Educativa. Boletín Oficial del Estado, núm. 187, de 6 de agosto de 1970, (pp. 12525 a 12546). https://www.boe.es/boe/dias/1970/08/06/pdfs/A12525-12546.pdf

Ley 16/1985, de 25 de junio, del Patrimonio Histórico Español. Boletín Oficial del Estado, núm. 155, de 29 de Junio de 1985, (pp. 1-32). https://www.boe.es/eli/es/1/1985/06/25/16/com

Ley Orgánica 1/1990, de 3 de octubre, de Ordenación General del Sistema Educativo. (LOGSE). Boletín Oficial del Estado, núm. 238, de 4 de octubre de 1990, (pp. 28927 a 28942). https://www.boe.es/boe/dias/1990/10/04/pdfs/A28927-28942.pdf

Ley Orgánica 10/2002, de 23 de diciembre, de Calidad de la Educación (LOCE). Boletín Oficial del Estado, núm. 307, de 24 de diciembre de 2002, (pp. 45188 a 45220). https://www.boe.es/boe/dias/2002/12/24/pdfs/A45188-45220.pdf

Ley Orgánica 2/2006, de 3 de mayo, de Educación (LOE). Boletín Oficial del Estado, núm. 106, de 04/05/2006, (pp. 1 a 110). https://www.boe.es/buscar/pdf/2006/BOEA-2006-7899-consolidado.pdf

Ley Orgánica 8/2013, de 9 de diciembre, para la mejora de la calidad educativa (LOMCE). Boletín Oficial del Estado, núm. 295, de 10/12/2013, (pp. 1 a 64). https://www.boe.es/boe/dias/2013/12/10/pdfs/BOE-A-2013-12886.pdf

Ley 10/2015, de 26 de mayo, para la salvaguarda del Patrimonio Cultural Inmaterial. Boletín Oficial del Estado, núm. 126, de 27 de mayo de 2015, (pp. 1-18). https://www.boe.es/eli/es/1/2015/05/26/10/con

Lobovikov-Katz, A. (2009). Heritage Education for Heritage Conservation. A Teaching Approach, Strain, 45(1), 480-484. doi: https://doi.org/10.1111/j.1475$\underline{1305.2008 .00569 . x}$ 
Lobovikov-Katz, A. (2019). Methodology for Spatial-Visual Literacy (MSVL) in Heritage Education: Application to Teacher Training and Interdisciplinary Perspectives. Revista Electrónica Interuniversitaria de Formación del Profesorado, 22(1), 41-55. doi: http://dx.doi.org/10.6018/reifop.22.1.358671

Lobovikov-Katz, A., Moropoulou, A., Konstanti, A., Ortiz Calderón, P., Van Grieken, R., Worth, S., Cassar, J., De Angelis, R., Biscontin, G., y Caterina Izzo, F. (2014). Tangible Versus Intangible in e-learning on Cultural Heritage: From Online Learning to On-site Study of Historic Sites. En M. Ioannides et al. (Eds.), Digital Heritage. Progress in Cultural Heritage: Documentation, Preservation, and Protection (pp. 819-828). Switzerland: Springer International Publishing.

López, I. (2014). La educación patrimonial. Análisis del tratamiento didáctico del patrimonio en los libros de texto de ciencias sociales de la enseñanza secundaria (Tesis doctoral). Universidad de Huelva, Huelva.

Lopez-Facal, R. (2015). La LOMCE y la enseñanza de las ciencias sociales. La LOMCE y la enseñanza de las ciencias sociales. Iber: Didáctica de las ciencias sociales, geografía e historia, 79, 5-7. ISSN 1133-9810.

Lowenthal, D. (1985). The past is a foreign country. Cambridge: Cambridge University Press.

Lucas, L., y Delgado, E. J. (2018). Education for a committed citizenship in the teaching of Social Sciences: What do the students think in relation to their learning with an innovative teacher? Didáctica de las ciencias experimentales y sociales, 35, 3-16.

Luna, U., Vivent, N., Reyes, W., y Quiñones, S. (2019). Patrimonio, curriculum y formación del profesorado de Educación Primaria en México. Revista Interuniversitaria de Formación del Profesorado, 22(1). doi: https://doi.org/10.6018/reifop.22.1.358761

Maffesoli, M. (2017). From postmedievality to postmodernity. Revista de Educación, 376, 245-258. doi: 10.4438/1988-592X-RE-2016-375-342

Maldonado, M. S. (2016). Educación Patrimonial y redes sociales. Análisis y evaluación de acciones en los medios de comunicación social para la definición de una cartografía educativa (Tesis doctoral). Universidad de Valladolid, Valladolid. 
Mali, F., Kronegger, L., y Ferligoj A. (2010). Co-authorship trends and collaboration patterns in the Slovenian sociological community. Corvinus Journal of Sociology and Social Policy (CJSSP), 1(2), 29-50.

Malpas, J. (2008). New Media, Cultural Heritage and the Sense of Place: Mapping the Conceptual Ground. International Journal of Heritage Studies, 14(3), 197-209.

Marín, S. (2014). Educación Patrimonial y diversidad: evaluación de programas y definición de un modelo basado en los procesos de patrimonialización (Tesis doctoral). Universidad de Valladolid, Valladolid.

Marín, S., García, S., Vicent, N., Gillate, I., y Gómez-Redondo C. (2017). Inclusive Heritage education in SHEO: a prospective study. Revista de Educación, 375, 110130. https://doi.org/10.4438/1988-592X-RE-2016-375-337

Marope, M., Griffin, P., y Gallagher, C. (2017). Document: Exec summary, reconceptualizing and Repositioning Curriculum in the 21 st Century. Paris: OIEUNESCO. http://www.ibe.unesco.org/es/news/document-reconceptualizing-andrepositioning-curriculum-21st-century

Martí, J. (2000). El folklorismo: Uso y abuso de la tradición. Barcelona: Ronsel.

Martín-Cáceres, M. (2012). La educación y la comunicación patrimonial. Una mirada desde el museo de Huelva (Tesis doctoral).Universidad de Huelva, Huelva.

Martín-Cáceres, M., y Cuenca, J. M. (2011). La enseñanza y el aprendizaje del patrimonio en los museos: la perspectiva de los gestores. Revista de Psicodidáctica, 16(1), 99-122.

Martín-Cáceres, M., y Cuenca, J. M. (2015). Heritage comunication and education. Educatio siglo XXI, 33(1), 33-54. doi: http://dx.doi.org/10.6018/j/222491

Martín-Cáceres, M., y Cuenca, J. M. (2016). Communicating heritage in museums: outlook, strategies and challenges through a SWOT analysis. Museum Management and Curatorship, 31(3), 1-18. doi: https://doi.org/10.1080/09647775.2016.1173576

Martínez, M. (2016). Análisis comparativo de la imagen del patrimonio en la legislación nacional y autonómica, dentro de la educación obligatoria. En S. Molina, A. 
Escribano y J. Díaz (Eds.), Patrimonio identidad y ciudadanía en la enseñanza de las ciencias sociales (pp.187-201). Murcia: Editum.

Martínez-Rodríguez, R., Muñoz, C., y Sánchez-Agustí, M. (2019). Teacher knowledge and beliefs and their relationship with the purpose of teaching recent history. The transition to democracy in Spain as a controversial case. Revista de Educación, 383, 11-35. doi: 10.4438/1988-592X-RE-2019-383-399

Martínez, T., López, V, Asensio, M, y Santacana, J. (2018). Entertainment or Learning? Mobile technologies evaluation for heritage education. Ensayos. Revista de la Facultad de Educación de Albacete, 33(1), 39-52.

McAnany, P. A., y Parks, S. (2012). Casualties of heritage distancing children, ch'orti' indigeneity, and the copan archaeoscape. Current Anthropology, 53(1), 80-107. doi: https://doi.org/10.1086/663687

Mcculloch, G. (2005). Curriculum reform, educational change, and school improvement. In D. Hopkins (Ed.), the practice and theory of school improvement: International handbook of educational change (pp. 169-181). Netherlands: Springer, Dordrecht.

Méndez, R. (2016). Educación Patrimonial, museos y ferrocarril: un estudio de caso sobre el museo del ferrocarril de Madrid (Tesis doctoral). Universidad Autónoma de Madrid, Madrid.

Merrian, A. (1964). The Anthropology of Music. Evanston: Northwestern University Press.

Meseguer, A., Arias, L., y Egea, A. (2017). Archaeological heritage in Secondary Education textbooks. Didáctica de las ciencias experimentales y sociales, 33, 6582.

Miralles, P., Gómez, C. J. y Rodríguez, R. (2017). Patrimonio, competencias históricas y métodos activos de aprendizaje. Un análisis de las opiniones de los docentes en formación en España e Inglaterra. Estudios Pedagógicos, XLIII(4), 161-184).

Molina, M. P. (2018). The patrimonial education in the didactics of the social science in primary. Contextos educativos-revista de educación, 22, 199-213. 
Morata, M., Catalano, C. E., Bellotti, F., Fiucci, G., Houry, M., y Petridis, P. (2014). Earning cultural heritage by serious games, 15(3), 318-325. doi: 10.1016/j.culher.2013.04.004

Morón, M. C. (2016). El paisaje en la enseñanza secundaria obligatoria: análisis de libros de textos y del currículum oficial, el abordaje patrimonial (Tesis doctoral). Universidad de Huelva, Huelva.

Mun, J. (2018). Developments of Cultural Heritage Education and the Raising of Local Cultural Heritage Education. Annual Review in Cultural Heritage. 154-169.

Munjeri, D. (2004). Tangible and Intangible Heritage: From Difference to Convergence. Museum International, 56 (1-2), 12-20.

Muñoz, C., Sánchez-Agustí, M., y Wilhelm, R. (2012). The student and citizen education in the School: A study from history classes. Revista Escuela de Historia, $11(2)$.

Muñoz, C., Torres, B. (2014). La formación ciudadana en la escuela: Problemas y desafíos. Revista Electrónica Educare, 18(2), 233-245. doi: http://dx.doi.org/10.15359/ree.18-2.1

Ning, L. (2018). Research on the Role of College Art Education in of intangible Cultural Heritage. Educational Sciences-Throry \& practice, 18(5), 1591-1597. doi: 10.12738/estp.2018.5.057

Nitko, A. J. (2001). Educational assessment of students. Upper Saddle River, NJ: Merrill.

Nocus, I., Guimard, P., Vernaudon, J., Paia, M., Cosnefroy, O., y Florin, A. (2012). Effectiveness of a heritage educational program for the acquisition of oral and written french and tahitian in french polynesia. Teaching and Teacher Education, 28(1), 21-31. doi: https://doi.org/10.1016/j.tate.2011.07.001

Nordin, A, y Sundberg, D (2016). Travelling concepts in national curriculum policymaking: The example of competencies. European Educational Research Journal. 15(3). 314-328. doi: https://doi.org/10.1177/1474904116641697

Ochoa, A. M. (2003). Entre los deseos y los derechos. Un ensayo crítico sobre políticas culturales. ICANH, Bogotá. 
Ortiz, $M^{a}$ A. (2012). Identidad y diferencia del folklore en la Península Ibérica. Recuperación del patrimonio folklórico tradicional. DEDiCA. Revista de educação e humanidades, 3, 63-102.

Ott, M., Dagnino, F. M., y Pozzi, F. (2015). Intangible Cultural Heritage: Towards Collaborative Planning of Educational Interventions. Computers in the Human Behaviour, 51, 1314-1319. doi: http://dx.doi.org/10.1016/i.chb.2014.11.039

Ott, M., y Pozzi, F. (2011). Towards a New Era for Cultural Heritage Education: Discussing the Role of ICT. Computers in Human Behavior, 27, 1365-1371. doi: http://dx.doi.org/10.1016/j.chb.2010.07.031

Pablos, L. (2018). Evaluación de programas de educación patrimonial para personas con trastorno del espectro autista (TEA) en museos (Tesis doctoral). Universidad de Valladolid, Valladolid.

Pablos, L., y Fontal., O. (2018). Programas inclusivos para personas con trastorno del espectro autista (TEA) en museos: Ejemplos de buenas prácticas. Revista Iberoamericana de educación, 76(1), 23-38.

Parliamentary Assembly. (2009). Recommendation 1884 Cultural education: The promotion of cultural knowledge, creativity and intercultural understanding through education.

Perales, R. M. (2016). Flamenco, educación y política: Analítica de su inclusión en el aula de primaria (Tesis doctoral). Universidad de Jaén, Jaén.

Pereira, Z. (2011). Los diseños de método mixto en la investigación en educación: Una experiencia concreta. Revista electrónica educare, 15(1), 15-29.

Pérez, R. (2006). Evaluación de programas educativos. Madrid: La Muralla.

Pérez-López, S. (2014). Educación artística y patrimonial para la percepción, comprensión y reflexión del colectivo sordo en el ámbito museal. Estudio de casos evaluativo (Tesis doctoral). Universidad de Valladolid, Valladolid.

Pinto, H. (2017). A interculturalidade em Educação Patrimonial: desafios e contributos para o ensino de História. Educar em Revista, 63, 205-220. doi: http://dx.doi.org/10.1590/0104-4060.48650 
Pinto, H., y Molina-Puche, S. (2015). La educación patrimonial en los currículos de ciencias sociales en España y Portugal. Educatio Siglo XXI, 33(1), 103-128. doi: https://doi.org/10.6018/j/222521

Pinto, H., y Zarbato, J. (2017). Construyendo un aprendizaje significativo a través del patrimonio local: prácticas de Educación patrimonial en Portugal y Brasil. Estudios Pedagógicos, 43(4), 203-227. doi: http://dx.doi.org/10.4067/S0718$\underline{07052017000400011}$

Piñón, M. (2014). Diseño y evaluación de material didáctico del día de los muertos de México (Tesis doctoral). Universidad de Málaga, Málaga.

Poce, A., Agrusti, F., y Re, M. R. (2017). Mooc design and heritage education. developing soft and work-based skills in higher education students. Journal of ELearning and Knowledge Society, 13(3), 97-107. doi: https://doi.org/10.20368/1971-8829/1385

Poce, A., Agrusti, F., y Re, M. R. (2018). Heritage Education and initial teacher training: An international Experience. Journal of E-learning and knowledge society, 14(2), 127-143.

Pocock, C., Collett, D., y Baulch, L. (2015). Assessing Stories before Sites: Identifying the Tangible from the Intangible. International Journal of Heritage Studies, 21(10), 962-982. doi: https://doi.org/10.20368/1971-8829/1385

Popkewitz, T. (1988). Los paradigmas en la ciencia de la educación: sus significados y la finalidad de la teoría. Paradigma e ideología en investigación educativa. (pp. 61-88). Madrid: Mondadori.

Potočnik, R. (2017). Effective approaches to heritage education: Raising awareness through fine art practice. International Journal of Education Through Art, 13(3), 285-294. doi: https://doi.org/10.1386/eta.13.3.285_1

Prieto, G., y Delgado. A. R. (2010). Fiabilidad y validez. Papeles del Psicólogo, 31(1), $67-74$.

Prutsch, M. J. (2017). Investigación para la Comisión CULT - Identidad europea, Parlamento Europeo, Departamento Temático de Políticas Estructurales y de Cohesión. Bruselas. 
Puelles, M. (1992). Oscilaciones de la política educativa en los últimos 50 años: reflexiones sobre la orientación política de la educación. Revista Española de Pedagogía, 50(192), 311-320.

Puelles, M. (2016). Reflexiones sobre cuarenta años de educación en España o la irresistible seducción de las leyes. Historia y Memoria de la Educación, 3, 15-44.

Punja, S. (2010). Teaching comparative religions in india through heritage. Material Religion, 6(2), 156-165. doi: https://doi.org/10.2752/175183410X12731403772832

Real Decreto 111/1986, de 10 de enero, de desarrollo parcial de la Ley 16/1985, de 25 de junio, del Patrimonio Histórico Español (BOE núm. 24 de 28 de enero de 1986, pp. 3815 a 3831). Recuperado de https://www.boe.es/eli/es/rd/1986/01/10/111

Real Decreto 1044/2003, de 1 de agosto, por el que se establece el procedimiento para la expedición por las universidades del Suplemento Europeo al Título, (BOE núm. 218, de 11 septiembre 2003, pp. 33848- 33853). Recuperado de http://www.eees.es/pdf/RD_Suplemento_Europeo_Titulo.pdf

Real Decreto (1105/2014, de 26 de diciembre), por el que se establece el currículo básico de la Educación Secundaria Obligatoria y del Bachillerato. Recuperado de https://www.boe.es/boe/dias/2015/01/03/pdfs/BOE-A-2015-37.pdf

Real Decreto (126/2014, de 28 de febrero), por el que se establece el currículo básico de la Educación Primaria. Boletín Oficial del Estado, 52, de 1 de marzo de 2014. https://www.boe.es/buscar/pdf/2014/BOE-A-2014-2222-consolidado.pdf

Real Decreto 284/2017, de 24 de marzo, por el que se desarrolla la estructura orgánica básica del Ministerio de Educación, Cultura y Deporte, (BOE núm. 72 de 25 de marzo de 2017, pp. 21316 - 21338, pp. 21316 a 21338). Recuperado de https://www.boe.es/eli/es/rd/2017/03/24/284

Real Decreto 817/2018, de 6 de julio, por el que se desarrolla la estructura orgánica básica del Ministerio de Cultura y Deporte y se modifica el Real Decreto 595/2018, de 22 de junio, por el que se establece la estructura orgánica básica de los departamentos ministeriales, (BOE núm. 164, de 7 de julio de 2018, pp. 68304 a 68315). Recuperado de https://www.boe.es/eli/es/rd/2018/07/06/817 
Recommendation 2006/962/EC, of 18 December, on key competences for lifelong learning. Official Journal of the European Union, L 394 of 30 Decembre 2006. http://data.europa.eu/eli/reco/2006/962/oj

Rivero, P., Fontal, O., García-Ceballos, S. y Martínez, M. (2018a). Heritage Education in The Archaeological Sites. An Identity Approach in The Museum of Calatayud. Curator: The Museum Journal, 61(2), 315-326. doi: https://doi.org/10.1111/cura.12258

Rivero, P., Fontal, O., Martínez, M., y García-Ceballos, S. (2018b). La educación patrimonial y el patrimonio arqueológico para la enseñanza de la Historia: el caso de Bílbilis. Ensayos. Revista de la Facultad de Educación de Albacete, 33(1), 23 37. http://www.revista.uclm.es/index.php/ensayos

Rodríguez, E., y Valdivia, I. (2016). The Heritage Education. Considerations about its Contribution to the Process of Education. Amazonia Investiga, 5(9), 82-90.

Samejima, F. (1997). Graded response model. En W. J. van der Linden y R. K. Hambleton (Eds.), Handbook of modern item response theory (pp. 85-100). New York, NY: Springer-Verlag.

Sánchez-Ferri, A. (2016). Memoria, identidad y comunidad: evaluación de programas de Educación Patrimonial en la comunidad de Madrid (Tesis doctoral). Universidad de Valladolid, Valladolid.

Santacana, J., y Martínez, T. (2018). The cultural heritage and the emotional system: and approach from teaching. Arbor-Ciencia pensamiento y cultura, 194(788). Doi: 10.3989/arbor.2018.788n2006

Santamarina, B. (2013) Los mapas geopolíticos de la Unesco: entre la distinción y la diferencia están las asimetrías. El éxito (exótico) del patrimonio inmaterial, en Revista de Antropología Social, 22, 263-286.

Santos, J. A. (2002). Algunas observaciones sobre la actual legislación española de patrimonio arqueológico. Iberia: Revista de la Antigüedad, 5, 7-20.

Santoyo, A. (2010). Del folclor y el patrimonio cultural inmaterial en Colombia. Reflexiones críticas sobre dos conceptos antagónicos. Patrimonio y Cultura en Latinoamerica. En J. Hernández, M., Rotman., A. González (Eds.) Patrimonio y 
cultural en Ámerica Latina. Nuevas vinculaciones con el Estado, el mercado y el turismo y sus perspectivas actuales (109-135). México: Acento Editores.

Scalise, G. (2015). The Narrative Construction of European Identity. Meanings of Europe "from below. European Societies, 17(4), 593-614. doi: https://doi.org/10.1080/14616696.2015.1072227

Scharnhorst, A., Börner, K., y Van den Besselaar, P. (2012). Models of science dynamics. encounters between complexity theory and information sciences. New York: Springer.

Shashayeva, G., Zhappasov, Z., y Tasilova, N. (2016). Teaching the cultural heritage of Kazakh people in higher education by means of extracurricular activities in museums. International Journal of Critical Cultural Studies, 14(2), 11-22.

Sibony, D. (1998). Le patrimoine. Un lieu d'être autrement. En Le Goff, J. (ed.).

Simons, H. (2011). El estudio de caso: Teoría y práctica. Madrid: Ed. Morata.

Smith, L. (2006). Uses of Heritage. Londres: Routledge.

Smith, L., y N. Akagawa. 2009. Introduction: In Intangible Heritage. Intangible Heritage, 1-9.

Stake, E. (2006). Evaluación comprensiva y evaluación basada en estándares, vol., 10. Barcelona: Graó.

Stake, R. E. (2010). Investigación con estudios de casos. $5^{\circ}$ ed. Madrid: Morata.

Stake, R. E., y Munson, A. (2008). Qualitative assessment of arts education. Arts \& Education Policy Review, 109(6), 13-22. doi: https://doi.org/10.3200/AEPR.109.6.13-22

Suárez, M. A., Calaf, R., y Fernández, M. C. (2017). The communication of heritage: Assesment of the Comunnicative Process in Museums of Asturias. FonsecaJournal of Communication, 14, 131-146.

Teixeira, S. (2006). Educación patrimonial: alfabetización cultural para la ciudadanía. Estudios Pedagógicos, 32(2), 133-145. http://dx.doi.org/10.4067/S0718$\underline{07052006000200008}$ 
Tilley, C. (2006). Introduction: Identity, place, landscape and heritage. Journal of Material Culture, 11(1-2), 7-32. doi: https://doi.org/10.1177/1359183506062990

Tortosa, T., y Mora, G. (1996). La actuación de la Real Academia de la Historia sobre el Patrimonio Arqueológico: ruinas y antigüedades. Archivo Español de Arqueología, 69, 191- 217.

Trivino, L., y Rico, L. (2016). Proposals based on service-learning methodology to arouse interest in heritage education in teacher training. IJERI-International Journal of Educational Research and Innovation, 5, 1-13.

UNESCO. (1931). Carta de Atenas para la restauración de monumentos históricos. Adoptada en la Primera Conferencia Internacional de Arquitectos y Técnicos de Monumentos Históricos. Atenas: UNESCO.

UNESCO. (1945). Constitución de la Organización de las Naciones Unidas para la Educación, la Ciencia y la Cultura. Paris: UNESCO.

UNESCO. (1972a). Convención sobre la Protección del Patrimonio Mundial Cultural y Natural. Paris: UNESCO.

UNESCO. (1972b). Recomendación sobre la Protección, en el Ámbito Nacional, del Patrimonio Cultural y Natural.

UNESCO (1976). Recomendación relativa a la Salvaguardia de los Conjuntos Históricos o Tradicionales y su Función en la Vida Contemporánea.

UNESCO. (1978). Recomendación sobre la Protección de los Bienes Culturales Muebles.

UNESCO. (1982). Conferencia Mundial sobre las Políticas Culturales. Paris: UNESCO.

UNESCO. (1989). Recomendación sobre la Salvaguardia de la Cultura Tradicional y Popular. Paris: UNESCO.

UNESCO. (1993). Directrices para la creación de sistemas nacionales de "Tesoros Humanos Vivos".

UNESCO. (1997). Consulta internacional de Expertos sobre la preservación de Espacios Culturales Populares. 
UNESCO. (1998). Recomendación sobre la Salvaguardia de la Cultura Tradicional y Popular.

UNESCO. (2001a). Declaración Universal de la UNESCO sobre la Diversidad Cultural Adoptada por la $31^{a}$ reunión de la Conferencia General de la UNESCO. Paris: UNESCO.

UNESCO. (2001b). Reunión de expertos sobre "Patrimonio cultural inmaterial: definiciones de trabajo. Turín: UNESCO.

UNESCO. (2002). Declaración de Estambul. III ${ }^{a}$ Mesa Redonda de Ministros de Cultura "El patrimonio Cultural Inmaterial, espejo de la Diversidad Cultural". Paris: UNESCO.

UNESCO. (2003). Convención para la Salvaguarda del Patrimonio Cultural Inmaterial. Paris: UNESCO.

UNESCO. (2005). Convención sobre la Protección y la Promoción de la Diversidad de las Expresiones Culturales. Paris: UNESCO.

UNESCO. (2014). Declaración de Florencia. La cultura y las industrias culturales: Cultura, creatividad y desarrollo sostenible. Investigación, innovación, oportunidades. CLT/CRE/DCE/2014/1

UNESCO. (2015a). Declaración de Incheon: Educación 2030: Hacia una Educación Inclusiva y Equitativa de Calidad y un Aprendizaje a lo Largo de la Vida para Todos. World Education Forum, Incheon, Korea R. ED/WEF2015/MD/3

UNESCO (2015b). Recomendación relativa a la protección y promoción de los museos y colecciones, su diversidad y su función en la sociedad.

UNESCO. (2016). Declaración de Incheon y Marco de Acción para la realización del Objetivo de Desarrollo Sostenible 4: Garantizar una educación inclusiva y equitativa de calidad y promover oportunidades. ED-2016/WS/28

Uribe, A. B., Covarrubias, K. Y., y Uribe, J. I. (2009). La metodología mixta en un estudio sobre los ex braceros colimenses: una experiencia interdisciplinaria para comprender una realidad compleja. Estudios sobre las Culturas Contemporaneas. $X V, 30,123-154$. 
Van Eck, N. J., y Watlman, L. (2010). Software survey: VOSviewer, a computer program for bibliomatric mapping. Scientometrics, 84(2), 523-538.

Van Eck, N.J., y Waltman, L. (2014). Visualizing bibliometric networks. En Y. Ding, R. Roussearu, y D. Wolfram (Eds.), Measuring scholarly impact: Methods and practice (pp. 285-320). Springer.

Vecco, M. (2010). A Definition of Cultural Heritage: From the Tangible to the Intangible. Journal of Cultural Heritage, 11(3), 321-324.

Vicent, N. (2013). Evaluación de un programa de Educación Patrimonial basado en tecnología móvil (Tesis doctoral). Universidad Autónoma de Madrid, Madrid.

Vicent, N., e Ibáñez-Etxeberria, A. (2012). El uso de las nuevas tecnologías y el patrimonio en el ámbito escolar. Aula de innovación educativa, 208, 22-27.

Vicent, N., Ibáñez-Etcheberria, A., y Asensio, M (2015). Evaluation of heritage education technology-based programs. Virtual Archaeology Review, 6(13), 20-27.

Vicent, N., Rivero, P., y Feliu-Torruella, M. (2015). Archeology and digital technologies in Heritage Education. Educatio siglo XXI. 33(1), 83-102.

Villaseñor, I., y Zolla, E. (2012). Del patrimonio cultural inmaterial o la patrimonialización de la cultura. Cultura y representaciones sociales, 6(12), 75101.

Wahlström, N. (2016). A third wave of European education policy: Transnational and national conceptions of knowledge in Swedish curricula. European Educational $\begin{array}{llll}\text { Research } \quad \text { Journal, } & \text { 298-313. }\end{array}$ https://doi.org/10.1080/00393541.2014.11518926

Wexler, A. (2014). The Common Core "State" Standards: The Arts and Education Reform. Studies in Art Education, 55(2), 172-176. https://doi.org/10.1080/00393541.2014.11518926

Williams, R. (1972). The Country and the City. Chatto and Windus. Londres.

World Bank. 2018. The World Bank Annual Report 2018 (English). Washington, D.C.: World Bank Group. http://documents.worldbank.org/curated/en/630671538158537244/The-WorldBank-Annual-Report-2018 
Xie, Q., y He, M. (2017). Cultural Heritage Education in the Curriculum of Nine-Year Compulsory Education of China: Sustainability of Ethnic Languages. Norhtesast Asia International Symposium on Linguistics, Literature and Teaching. Lvlian University: China

Yáñez, A., y Lavín, A. C. (1999). La legislación española en materia de Arqueología hasta 1912: análisis y evolución en su contexto. Patrimonio cultural y derecho, 3, $123-146$.

Zhang, Y., y Zhao, H. (2014). Exploration on Ways of Protecting Intangible Cultural Heritage from the Perspective of Higher Education. Asia-Pacific Management and Engineering Conference, 515-522. Shanghai. 